\title{
Europeanization through Framing? : an Inquiry into the Influence of the open method of coordination on childcare policy in the Netherlands
}

Citation for published version (APA):

Radulova, E. (2011). Europeanization through Framing? : an Inquiry into the Influence of the open method of coordination on childcare policy in the Netherlands. [Doctoral Thesis, Maastricht University]. Maastricht University. https://doi.org/10.26481/dis.20111007er

Document status and date:

Published: 01/01/2011

DOI:

10.26481/dis.20111007er

Document Version:

Publisher's PDF, also known as Version of record

\section{Please check the document version of this publication:}

- A submitted manuscript is the version of the article upon submission and before peer-review. There can be important differences between the submitted version and the official published version of record.

People interested in the research are advised to contact the author for the final version of the publication, or visit the DOI to the publisher's website.

- The final author version and the galley proof are versions of the publication after peer review.

- The final published version features the final layout of the paper including the volume, issue and page numbers.

Link to publication

\footnotetext{
General rights rights.

- You may freely distribute the URL identifying the publication in the public portal. please follow below link for the End User Agreement:

www.umlib.nl/taverne-license

Take down policy

If you believe that this document breaches copyright please contact us at:

repository@maastrichtuniversity.nl

providing details and we will investigate your claim.
}

Copyright and moral rights for the publications made accessible in the public portal are retained by the authors and/or other copyright owners and it is a condition of accessing publications that users recognise and abide by the legal requirements associated with these

- Users may download and print one copy of any publication from the public portal for the purpose of private study or research.

- You may not further distribute the material or use it for any profit-making activity or commercial gain

If the publication is distributed under the terms of Article $25 \mathrm{fa}$ of the Dutch Copyright Act, indicated by the "Taverne" license above, 


\section{Europeanization through Framing?}

An inquiry into the influence of the Open Method of Coordination on childcare policy in the Netherlands

\section{PROEFSCHRIFT}

ter verkrijging van de graad van doctor aan de Universiteit Maastricht,

op gezag van de Rector Magnificus, Prof. mr. G.P.M.F. Mols

volgens het besluit van het College van Decanen,

in het openbaar te verdedigen

op vrijdag 7 oktober 2011 om 12.00 uur

door

Elissaveta Radulova 


\section{Promotor:}

Prof. dr. C. Blom

\section{Beoordelingscommissie:}

Prof. dr. S. Vanhoonacker (voorzitter)

Prof. dr. Th. Christiansen

Dr. W. Lowe (Manheim University)

Dr. E. Versluis

Prof. dr. B. Waaldijk (Universiteit Utrecht) 
To Georgi, Ivan and Julian

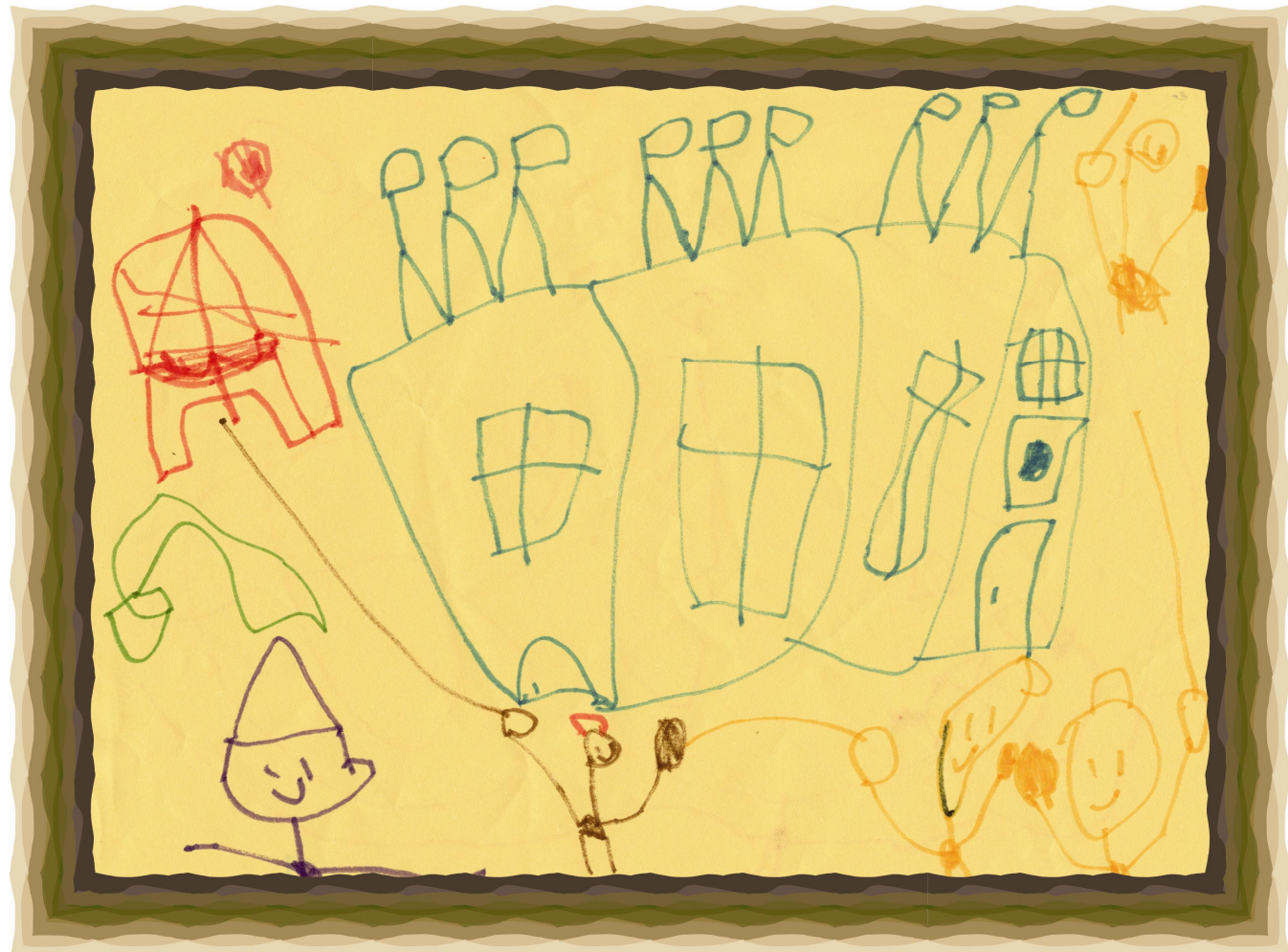


(C) Copyright Elissaveta Radulova Maastricht, the Netherlands 2011

(C) Drawings Ivan Radulov

ISBN 978-90-9026-312-0 


\section{TABLE OF CONTENTS}

ACKNOWLEDGEMENTS 9

LIST OF ABBREVIATIONS

LIST OF FIGURES

LIST OF TABLES 14

INTRODUCTION 16

Research objectives and relevance of the study 21

Outline of the thesis $\quad 24$

THEORETICAL AND METHODOLOGICAL FRAMEWORK OF THE $\begin{array}{lr}\text { STUDY } & 26\end{array}$

1.1. State of the art in theorizing the domestic impact of European integration 26

1.2. Theorising OMC's influence 30

1.3. Discursive institutionalism 33

1.4. An analytical strategy for the study of Europeanization 37 
THE OPEN METHOD OF COORDINATION AS A NEW MODE OF EU GOVERNANCE

2.1. The origins of the employment policy coordination 56

2.2. Institutional choice and the emergance of the OMC 59

2.3. The various $\mathrm{OMC}$ processes and their features 64

2.4. The OMC in employment policy: process and actors 70

2.5. The OMC: a platform for policy learning? 77

\section{CHILDCARE PROVISION AS A PUBLIC POLICY CONCERN AND}

CHILDCARE RELATED POLICY FRAMES IN THE MEMBER STATES

AND AT THE EU LEVEL

3.1. Childcare: an issue of private or of public policy? 80

3.2. The welfare state as provider of childcare and welfare regime types 82

3.3. Feminist critique on the mainstream welfare regime classifications 85

3.4. Childcare as a public policy solution and childcare related policy frames $\quad 88$

\section{CONSTRUCTING CHILDCARE POLICY IN EUROPEAN}

GOVERNANCE: THE CAREER OF A POLICY SOLUTION AT THE EU

LEVEL

4.1. Historical overview of EU Policy developments in the field of gender equality and reconciliation of work and family life

4.2. Dynamics of childcare policy framing at the EU level 104

4.3. Conclusions: what vision of childcare does the EU propagate?

CASE STUDY: THE INFLUENCE OF THE EUROPEAN EMPLOYMENT STRATEGY ON THE DUTCH CHILDCARE POLICY-MAKING 
5.1. The attitude toward parenting and childcare in the Netherlands: a cultural chronicle

5.2. Public policy developments

5.3. Policy outputs after the introduction of the EES

5.4. Policy outcomes

5.5. Polcy discourses

5.6. Conclusion: convergence to the EU policy prescriptions?

6.1. The Dutch childcare policy process

6.3. Analysis of the evolution in the actors' positions and of the coalition building dynamics

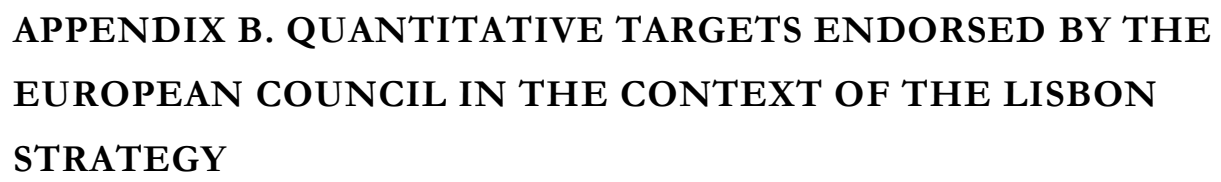


APPENDIX C. CONDUCTED INTERVIEWS

APPENDIX D. TREATY PROVISIONS WITH REGARD TO

EMPLOYMENT POLICY COORDINATION(THE EUROPEAN

EMPLOYMENT STRATEGY)

233

SAMENVATTING

236

CURRICULUM VITAE

239 


\section{ACKNOWLEDGEMENTS}

A $\mathrm{PhD}$ project is the journey of an academic wannabe in the jungle of a research project designed from scratch (most of the time), revised one thousand times (at least), and accomplished with the help of many people. It is to these wonderful people I met along the way that the first pages of the book are dedicated.

First of all, I am grateful to my supervisor. Thank you, Tannelie, for "constructing" a constructivist from someone raised and shaped by rational-choice theories. Thank you for leading me through the frustrations of setting-up and accomplishing a social sciences project and for constantly reminding me of the beauty and the privilege of this enterprise.

Dear Sophie, from the first day we met - some 9 years ago - until the present day you always supported and encouraged me. I admire deeply your ability to relate to everyone on so many different levels - professional as well as personal. Thank you for the unconditional availability, for the care, for the warm encouragement, and for the example you set for all of us.

My colleague Esther was the first one to introduce me to the Europeanization literature. Throughout this research we always had great discussions and she provided me with invaluable tips and guidelines about the completion of the project. Her professional qualities are wonderfully coupled with a unique bubbling personality. Her warm attitude and 'infectious' laughter have the capacity to transform even the gloomiest day. Thank you for always being there for me!

Christine Neuhold is also someone who supported me since the very beginning. We accomplished successfully several projects together and I am extremely happy and grateful for all your help, and for being able again to work closely with you!

The Bulgarian 'enclave' at the Faculty - Aneta, Michaela, Peter and Gergana thank you for being such great colleagues and compatriots! I am very proud and grateful to Aneta and Michaela for accepting to become my paranymphs. No doubt that with you beside me I will feel strong and determined - thank you for that!

My fellow $\mathrm{PhD}$ and post-doc students have been a great source of ideas, inspiration and experiences. Thank you: Cornelia, Patrick, Hylke, Saskia, Julia, Sandra, Sophie Bouwens, Andreas, Dirk, Chris, Pat, Vivian, Josine.

Roommates are a special category that deserves highlighting. They are the ones who most immediately co-experience (willingly or not) the joyous and frustrating 
moments of drafting a PhD thesis. Through the years I shared a room with a great bunch of people and I am thankful to all of them: Linda, Jon, Vivian and Meike (for short). Then Madalina and Christine Arnold, and most recently Will and Arjan.

There are other colleagues in the department and at the Faculty who were not directly following my progress, but who were important for shaping me as a researcher. I thank them on occasion but here I want to stress the significance of the (informal) exchange of ideas. I am therefore grateful to Maarten, Thomas Christiansen, Thomas Conzelmann, Paul, Heidi, Karolina, Giselle, Karin, Meike, Natalia, Jaap, Nico, Bernard, and many others.

The administrative staff of the faculty has always been very helpful, and hereby I would like to acknowledge in particular our wonderful secretaries Joke, Sabine and Jacqueline. They always assure the smooth and swift arrangement of all paperwork or any other issues that might arise. Thank you for always being there for us!

Albeit from a distance, my family has been of great help. I firstly, want to thank my parents Julian and Tsvetelina for their love and support in everything I decided to embark on. My grandmother Elissaveta always took care of me, and I am very happy that through me she got her dream for education fulfilled. These people, and my two late grandmothers - Tsviata and Donna - not only raised me, they were the ones who introduced me to care work and to the gender issues long before I got to know the academic literature on the subject. Thank you from the bottom of my heart!

Two other great women help me enormously at present with the raising of my own children - my aunt Rossitza and my mother in law Eleonora. Thank you so much for the unconditional and devoted care, for the advices, for the shining personal examples that you are, for the time and the sincere love you devote to our family! If it was not for you - this book would not have been a reality.

I found a second family in the family of my husband Georgi. Thank you, Nora, Ivan and Ani (and Viki, Ivan and Kalin) for your warm welcome and for the wonderful time we are having every time we are together.

In Eindhoven, Georgi and I found many new friends, and most importantly Snejka and Mitko. Two amazing persons with big hearts, who have always helped and supported us. Thank you for everything you have done, are doing, and without doubt will keep on doing in the future for our family!

Finally, I want to thank the love of my life, my husband Georgi, for the inspiration and ambition he radiates every day. The family that we've created and our two sons Ivan and Julian are the greatest and most precious achievements of my life. To you, my dearest, I dedicate this book. 


\section{LIST OF ABBREVIATIONS}

$\begin{array}{ll}\text { BEPGs } & \begin{array}{l}\text { Broad Economic Policy Guidelines } \\ \text { BOINK }\end{array} \\ \text { Belangenvereniging van ouders in de kinderopvang en } \\ \text { peuterspeelzalen } \\ \text { Centrale Bureau voor de Statistiek } \\ \text { CDA } & \text { Christen Democratisch Appèl } \\ \text { CEC } & \text { Commission of the European Communities } \\ \text { CLA } & \text { Collective Labour Agreement } \\ \text { CNV } & \text { Christelijk Nationaal Vakverbond } \\ \text { COREPER } & \text { Comité de Representantes Permanentes } \\ \text { CREST } & \text { Scientific and Technical Committee of the EU } \\ \text { CU } & \text { Christen Unie } \\ \text { DG } & \text { Directorate General } \\ \text { DI } & \text { Discursive Institutionalism } \\ \text { EC } & \text { European Community } \\ \text { EES } & \text { European Employment Strategy } \\ \text { EGGE } & \text { European Commission's Expert Group on Gender and } \\ \text { EMCO } & \text { Employment Issues } \\ \text { EMU } & \text { Employment Committee } \\ \text { EPC } & \text { Economic and Monetary Union } \\ \text { ERDF } & \text { Economic Policy Committee } \\ \text { ESF } & \text { European Research and Development Fund } \\ \text { EU } & \text { European Social Fund } \\ \text { FNV } & \text { European Union } \\ \text { GL } & \text { Federatie Nederlandse Vakbeweging } \\ \text { GDP } & \text { GroenLinks } \\ & \end{array}$


IGC Intergovernmental Conference

IGGJ Integrated Guidelines for Growth and Jobs

IMF International Monetary Fund

IO International Organization

JER Joint Employment Report

LPF Lijst Pim Fortuyn

NAP National Action Plans

NGO

Non-Governmental Organization

NPR

National Progress Reports

NRP

National Reform Programmes

OECD

Organisation for Economic Co-operation and Development

OMC

Open Method of Coordination

PFA

Policy Frame Analysis

PvdA

Partij van de Arbeid

QMV

Qualified Majority Voting

R\&D Research and Development

RCI

Rational Choice Institutionalism

SCI

Sociological Institutionalism

SER

Sociaal-Economische Raad

SME

Small and Medium Sized Enterprises

$\mathrm{SP}$

Socialistiche Partij

SPC

Social Protection Committee

SvdA

Stichting van de Arbeid

TEC

Treaty establishing the European Community

TEU

Treaty establishing the European Union

TFEU

Treaty on the Functioning of the European Union

VNO/NCW Verbond van Nederlandse Ondernemingen/Nederlands Christelijk Werkgeversverbond

VVD

Volkspartij voor Vrijheid en Democratie 


\section{LIST OF FIGURES}

An analytical strategy for the study of the EU influence on domestic policy processes 37

Europeanization model flow based on discursive institutionalist premises 39

Policy frames and their four dimensions

Datasets for the policy frame analyses 46

Operationalisation for public policy analysis $\quad 50$

Methods for data analysis applied in the study

Agenda-setting and policy formulation in the European Employment Strategy 71

Implementation in the European Employment Strategy

Policy Review in the European Employment Strategy

Frequency distribution by policy frame 113

Relative proportions of policy frames F1 and F2 in secondary EU legislation 114

Three periods in the 'career' of the childcare solution 115

Growth in the number of childcare places in the Netherlands (1989-2008) 145

The Dutch childcare coverage rate 1989-2008 (in \%) 146

Relative proportions of policy frames F1 and F2 in Dutch coalition agreements 151

Relative proportions of childcare-related policy frames in party manifestos of D66 173

Relative proportions of childcare-related policy frames in party manifestos of GroenLinks 176

Relative proportions of childcare-related policy frames in party manifestos of PvdA 179

Relative proportions of childcare-related policy frames in party manifestos of VVD 182

Relative proportions of childcare-related policy frames in party manifestos of SP 183

Relative proportions of childcare-related policy frames in party manifestos of CD $A$ 


\section{LIST OF TABLES}

Defining properties of three OMC processes

Properties of $O M C$

Types of OMC processes

Policy frames related to childcare provision

Steps in the dataset formation

Frequency distribution of the childcare related policy frames in the Presidency Conclusions from 1997 to 2008

Frequency distribution of the childcare related policy frames in the dataset

Main policy actions in the evolution of the Dutch childcare policy in the period 1998 - 2008

140

Number of childcare places and childcare facilities coverage rate in the Netherlands (1989 - 2008)

Coverage rate in the Netherlands according to the hours spent in the daycare facility per week (0-3 years old, in \%) 146

Coverage rate in Denmark according to the hours spent in the daycare facility per week (0-3 years old, in \%) 147

Childcare-related policy frames in Dutch coalition agreements (1963-2006) 149

Childcare-related policy frames in party manifestos of D66 (1963-2006) 174

Childcare-related policy frames in party manifestos of GroenLinks (1963-2006) 175

Childcare-related policy frames in party manifestos of PvdA (1963-2006) 178

Childcare-related policy frames in party manifestos of VVD (1963-2006) 181

Childcare-related policy frames in party manifestos of SP (1963-2006) 184

Childcare-related policy frames in party manifestos of CDA (1963-2006) 186

Dynamics of the actors' standpoints on childcare according to the policy frame analysis of the party manifestos 197 


\section{INTRODUCTION}

Contemporary global governance witnesses the proliferation of international organizations (IOs) and their prominent input in the processes of national, regional and global policy-making. While the emergence and the processes of decision-making in IOs are relatively well researched and theorized, the influence of IOs' decisions on the national level of policy-making is a more recent subject of academic interest. There are various methodological difficulties related to the study of the domestic policy impact of international agreements. The most important limitation stems from the fact that the potential influence is mediated by domestic institutional and policy constellations i.e. the processes that have to be examined and theorized are very complex, involve various levels of governance and respectively many actors. Furthermore, the examination of practical implementation i.e. the impact beyond legal compliance (transposition) of the international agreement demands unravelling country-specific and path dependent policy processes. Consequently, there is a limited number of empirical academic studies on the subject (for an overview see Joachim et al., 2008: 13; and Treib, 2008: 14). Nevertheless, the question of whether the initial goals of the international agreement have been realized remains pertinent. This study aims to contribute theoretically and methodologically to the growing academic literature on the domestic influence of policy-making at the international level by examining a case of practical implementation of a soft-law agreement in the Netherlands.

In the context of the IO's proliferation on the global scene the European Union $(\mathrm{EU})$ is a case that stands out. Starting as a project of sectoral regional integration in the 1950s and only with 6 members from Western Europe, in less than 60 years this IO has grown remarkably, both in terms of member states and in terms of fields of cooperation, to the extent that academic analysts refer to it as a "supranational polity" (Hix, 1994, 2005; Rittberger and Zangl, 2006). Indeed, currently the European Union encompasses more than half of the countries on the European continent - 27 member states from Northern, Western, Southern and Eastern Europe - and its competences surpass economic integration and stretch to fields such as security and defence, humanitarian aid and crisis management, food safety, migration, environmental policy-making, etc.

The history of European integration is rich and varying (Dinan, 2004, 2010) with the decade of the 1990s being one of the most dynamic periods. Apart from major treaty revisions and significant increases in the competences of the supranational institutions, the European Union member states also endorsed new 
practices of cooperation and modes of EU governance. Next to the intergovernmental method of cooperation, which is typical for the IOs, and to the Community Method specific for the EU (for details see Dehousse, 2011), the EU's toolbox of integration instruments was enlarged with new modes of steering such as co-governance (e.g. the Social Dialogue where the European Social Partners coregulate with the EU institutions) and the open method of coordination (WarleighLack and Drachenberg, 2009). The latter is applied in particularly contentious policy areas such as employment policy, social inclusion, pensions, enterprise policy, education and vocational training, and research and innovation policy. Most of these fields were carefully safeguarded from communitarisation by national governments for years. Yet, somewhat surprisingly, at the end of the 1990s the strategic formulation of such policy fields came to be decided at the EU level. Moreover, they became central elements of the so-called Lisbon Process i.e. the millennium strategy to transform the EU into the most competitive economy in the world, capable of developing and maintaining a high level of social cohesion and environmental sustainability ${ }^{1}$. The Open Method of Coordination was the governance tool chosen to achieve progress toward these ambitious goals.

The Open Method of Coordination (OMC) was officially launched in 2000 at the Lisbon European Council. In its fully-fledged form, the method involves the following processes (as defined by the Presidency Conclusions from the European Council of Lisbon, 2000, Paragraph 38):

- fixing guidelines for the Union combined with specific timetables for achieving the goals which they set in the short, medium and long terms;

- establishing, where appropriate, quantitative and qualitative indicators and benchmarks against the best in the world and tailored to the needs of different member states and sectors as a means of comparing best practice;

- translating these European guidelines into national and regional policies by setting specific targets and adopting measures, taking into account national and regional differences;

- periodic monitoring, evaluation and peer review organised as mutual learning processes.

The OMC has attracted substantial attention in recent academic literature on the EU. One of the most explored themes is the question whether the OMC is a new mode of EU governance (Radaelli 2003; Borras and Jacobson, 2004). As convincingly argued by Schaefer (2006), in terms of institutionalization and procedural set-up, the

${ }^{1}$ See the Presidency Conclusions of the Lisbon European Council, March 2000. 
OMC is a multilateral surveillance procedure similar to the ones applied in IOs such as the IMF and the OECD. Indeed, if conceptualized in this way, the OMC should be regarded as a 'yet another' case of organizing political 'steering' at the transnational and supranational level - by setting objectives and monitoring their implementation. Nevertheless, in the EU such a multilateral surveillance procedure is certainly an addition to the toolbox of European integration instruments. What is more, this surveillance procedure displays characteristics which are rather atypical for EU governance during the mid-1990s: reliance on soft law, deliberative style of decisionmaking and participation, and emphasis on policy learning. Clearly, each of the three features existed in one form or another in EU governance prior to the endorsement of the OMC. However, the bundling of the three in one steering mode is a new development. The following pages review ${ }^{1}$ the political and academic rhetoric which surrounded the introduction of the OMC with the aim to take stock of the novel elements in the design of the method from an EU governance perspective.

\section{Reliance on soft law}

Despite the similarities in terms of organizational set-up and legal packaging that the OMC shares with other instruments of global and EU governance, it is arguably a new mode of supranational steering. The method demonstrates a critical departure from the usual way in which the Union's institutions interact in the policy process. From the very establishment of the European Communities, 'Europe' steers its member states through hard law endorsed via the Community method. This has been the norm in terms of applied instruments. A multilateral surveillance process (such as the OMC) was not needed because a much more stringent procedure was available - the infringement procedure involving the European Court of Justice.

As of the 1990s however EU governance has witnessed a proliferation of policy areas and of different instruments of governance. These instruments - such as co-regulation, self-regulation, benchmarking and target setting - depart substantially from the Community method (Knill and Lenshow, 2003; Trubek and Trubek, 2004). Arguably, they form a new realm of 'soft EU governance' (Heritier, 2002) which includes instruments that have been and are employed by IOs or by the nation-states but which are all allegedly new forms of EU steering. Soft governance is related to the idea that "national policies should gradually become more alike through the voluntary exchange of information among officials on what has worked at the national level in order to achieve shared goals" (Stubb, et al., 2003: 142). The OMC, 
in particular, seeks to establish in contentious policy areas "a feasible balance between the need to respect diversity of member states, and the unity - and meaning - of common action" (Borras and Jacobsson, 2004: 186). As such, the OMC is the materialization of a new governance culture in the EU, which embraces "aspects of 'opt-outs' and 'opt-ins', subsidiarity, flexibility and a post-regulatory approach which allows for variation, generous margins of discretion and a preference for voluntary cooperation instead of detailed, centralized and inflexible rules" (Szyszczak, 2002: 340).

At the procedural level, the Commission and the Council coordinate the various national policies in an iterative process: each year legally non-binding guidelines are endorsed, which set out the strategic framework for the policy actions at the national level. In some fields benchmarks are agreed upon that define the desirable achievements, and each member state is required to report yearly at the EU level about the policy actions adopted (in the form of a national progress report). Aiming at cooperation and exchange of information between the countries, the OMC is expected to create a platform for mutual policy learning that will eventually trigger better policy results for the individual member states.

\section{New participatory structure}

The rhetoric surrounding the OMC's emergence tends to outline participation as a positive and desirable feature. The method is called "open" because "the development of this method in its different stages should be open to the participation of the various actors of civil society" (Council of the European Union, 2000b: 6 Presidency Note No. 9088). Underlining further the importance of broad participation in the process of policy co-ordination at the EU level the former Prime Minister of Luxembourg and former Minister of Labour Jean-Claude Juncker who was very active in the endorsement of the European Employment Strategy states that “...it was very important for us to be associated not only with national governments but also with the social partners as well as the regional and local collectivities" (Juncker, 2002: xi).

Next to a novel participation pattern in EU decision-making, the OMC is supposed to promote a new style of partnership between the EU member states based on experimental learning and deliberative problem-solving. This is reflected in the expectation that it could "help create a culture of strategic management and of learning from experience, involving all relevant partners" (Council of the European Union, 2000b: 7). In particular the method "can foster convergence on common interest and on some agreed common priorities while respecting national and regional differences" (Council of the European Union, 2000b: 6). In other words, the OMC 
aims to establish a common ground among the partners in a novel manner of cooperation.

\section{Emphasis on policy learning}

Learning is perhaps the most original concept employed by the official OMC rhetoric. Arguably the explicit reliance on learning as a mechanism of cooperation reflects a qualitatively new approach to European integration, and indicates an important element in the new governance construction. Instead of leaning on the typical legalistic approach of specifying a desired policy achievement to which all member states must adhere, the OMC purposefully seeks to encourage the interplay between different policy approaches and perceives them as a source of inspiration, rather than as a threat (Jacobsson and Vifell, 2003: 6).

The Portuguese Presidency underlined that the aim of the OMC is "...to organise a learning process at the European level in order to stimulate exchange and the emulation of best practices and in order to help Member States improve their own national policies" (Council of the European Union, 2000b: 6). Frank Vandenbroucke (2001: 2) noted when he was the Minister for Social Affairs and Pensions of the Belgian Federal Government that:

"the open method of co-ordination is both a cognitive and a normative tool. It is a 'cognitive' tool, because it allows us to learn from each other. In my opinion, this learning process is not restricted to the practice of other Member States, but also extends to their underlying views and opinions, an area that is no less important. Open co-ordination is a 'normative' tool because, substantively, we start from the conviction that no European citizen must be left to fend for themselves under difficult circumstances. Thus open co-ordination gradually creates a European social policy paradigm.”

Furthermore, as stated in the White Paper on European Governance (European Commission, 2001: 21, emphasis added): "The open method of coordination ... is a way of encouraging co-operation, the exchange of best practice and agreeing common targets and guidelines for Member States... It relies on regular monitoring of progress to meet those targets, allowing Member States to compare their efforts and learn from the experience of others." The open co-ordination can therefore be regarded as an attempt to experiment with certain types of governance arrangements involving the EU level (Laffan, 2002; Zeitlin, 2005; Rhodes, 2005). 
Open Coordination requires the national governments to focus on a common problem, and to consider their own policy choices in relation to this problem in a comparative perspective and, even more importantly, by exposing their performance to peer review and public scrutiny (Scharpf, 2001: 10). Thus, the OMC is per definition an institutional arrangement that embodies mechanisms for selfactualisation and cross-national policy learning.

According to the website of the European Employment Strategy hosted by the Commission, the learning aspect of the OMC could help a member state to profit "from the experiences of other countries, which may have already found answers to similar challenges in the labour market. Through encouraging mutual learning at all levels within key areas of the EES, knowledge is built about the most effective policies and how these should be implemented." Thus, learning is supposed to take place on all levels of the governance system of the EU.

This section of the introduction revealed the political expectations raised by the introduction of the OMC through review of some of the key official documents and statements that surrounded the launch of the method. Like the politicians, academia was also quite enthusiastic about the introduction of the method. Some authors (Sabel and Zeitlin, 2003; Zeitlin, 2003; Cohen and Sabel, 2003) were quick to herald the arrival of deliberative governance "insofar as it [the $\mathrm{OMC}$ ] pushes the member states to exchange information, compare themselves to one another, and reassess current practices in light of their relative performance" (Zeitlin, 2005b: 22). Moreover, it was expected that the method will strengthen the legitimacy base of EU policy interventions and would improve the democratic quality of the decisionmaking process within the EU (Porte and Nanz, 2004: 267).

\section{RESEARCH OBJECTIVES AND RELEVANCE OF THE STUDY}

It is visible from the above that there are particular elements in the governance mechanisms the OMC introduces that are challenging from an academic perspective. Central to the novel mode of EU governance is that the process of political steering relies on learning and incentives (wrapped up in soft law) rather than on coercion stemming from legal obligation. Furthermore, both the policy formulation and policy implementation remain with the member states, yet the EU level is involved in the process of strategic policy formulation by endorsement of common goals and quantitative targets. Consequently, the national public actions are supposed to conform to a collectively decided framework. Moreover, within the method of open coordination, the EU level is actively involved in monitoring of implementation and the evaluation of performance (bi-/annual reviews, benchmarking and good practice exercises; in some OMC processes also policy recommendations). The coordination 
process is meant to guide and monitor the process of domestic adjustment through constant comparison of performance (quantitative evaluation), and organisation of best practice exercises (qualitative evaluation). Thus, the process is expected to lead incrementally to convergence.

After a more than a decade of implementation, however, a review of some statistical documents suffices to conclude that the policy targets have not yet been achieved. Nevertheless, progress toward the EU targets has been registered in many member states, and academic observers have identified certain influence of the process (for a comprehensive overview see Zeitlin, 2009). Strikingly, there are not many thorough and empirically based studies of the effectiveness of the OMC: "most critical assessments of the OMC are not based on original, first hand research on the method in action" (Zeitlin, 2009: 228). Moreover, the studies often focus on "input indicators rather than output or outcome measures" (de la Porte, 2010: 26). In this way a lot of data is collected about the governmental and other actors' activities and efforts to implement the policy, but not that much about the actual results of these efforts. This empirical deficit of systematic knowledge about the domestic influence of the OMC especially on the outcome side is indicative of the lack of a clear analytical framework about how to study such processes of international soft law steering. This is hardly surprising given that the domestic (or street-level) impact of EU policy-making is acknowledged to be difficult to establish and measure (Versluis, 2007, 2011). Even when it comes to the implementation of hard law, researchers hardly ever examine the process beyond the transposition stage i.e. the follow-up stages of law application and law enforcement are understudied. Outcome studies are in general neglected (Sverdrup, 2007: 205). In the case of a soft law process (such as the $\mathrm{OMC}$ ) it is even harder to identify the observed national policy adjustments, and thus to establish the influence of the international agreement, because the application of the non-binding instruments "does not necessarily include changes in legal frameworks" (Lopez-Santana, 2006: 482).

Given these deficiencies in the existing academic literature, this study sets out to accomplish two research objectives. First, it will elaborate a method for the study of the domestic impact of a new policy mode in the EU - the Open Method of Coordination $(\mathrm{OMC})$. Second, it will test and demonstrate this analytical strategy by applying it to a concrete empirical case. This second stage of the research will gauge the degree to which the OMC affects the policy-making process and the related policy outcomes in a member state by applying the proposed approach.

In practical terms there are two research stages that have to be accomplished an analytical and an empirical one. The analytical stage will be guided by the research question:

(1) What is an appropriate analytical strategy to study the influence of the Open Method of Coordination on the domestic policy-making processes? 
This first stage will theorize the process of open coordination, and will elaborate a methodical set of research steps to study the national policy adjustment induced by the OMC.

The empirical stage will be led by the research question:

(2) How and to what degree does the OMC affect the policy-making process and the related policy outcomes in the member states of the EU?

and involves data collection and analysis of the implementation of the OMC in a concrete case.

This study, therefore, aims to contribute methodologically and in substance to the academic literature on the domestic influence of policy-making at the international level - a field of study that is in its early years. Indeed, from the existing literature on International Relations (IR) and EU studies relatively a lot can be learned about the making of policies at levels of governance beyond the state. Far less priority is accorded to the study of the effects of these policies. Especially in the case of EU implementation there is a "lack of conclusive information" (Versluis et al., 2011: 180) due to the numerous difficulties of methodological character and also due to the time-consuming nature of implementation research. In the EU context there are few studies of practical implementation. Most studies focus on the legal implementation of EU directives, "while comparatively little is known about issues of enforcement and application" (Treib, 2008: 18). Moreover, there are no systematic studies regarding the implementation of other EU policy instruments such as soft law provisions (e.g. the various Council recommendations approved in the OMC framework).

Soft law instruments are increasingly applied in $\mathrm{EU}^{1}$ and global governance. The recourse to such agreements is not only due to the low transaction costs. As argued by Schaefer (2006: 71-72), soft law agreements not only are easier to commit to (i.e. may prevent a deadlock in the negotiations), but may also allow for a greater scope of the international cooperation, and may mitigate the domestic opposition. While the emergence of soft law is relatively well theorised, not much is known about the influence of international soft law agreements at the domestic level. Concretely, in the state of the art EU literature the OMC is considered the third main way in which the EU governs - along with the Community and the Intergovernmental Method (see Wallace, 2010). This increased relevance of the method indicates that research should be invested in the mechanisms and effects of this new mode of EU governance on the domestic level. Even though OMC implementation studies exist, as indicated

${ }^{1}$ For example in the Growth and Jobs Strategy in the 2000s and its continuation - the Europe 2020 Strategy in the 2010s. 
above, they are still rather inconclusive, do not rest on a rigorous methodology (Zeitlin, 2009), and rarely focus on the impact on policy outcomes (de la Porte, 2010: 26). The present study therefore sets out to develop a method for the comprehensive study of the OMC's influence, and to test it in a concrete empirical case.

\section{OUTLINE OF THE THESIS}

This research thesis is structured as follows:

The following Chapter 1 presents the theoretical and methodical framework of the study. Concretely, the specific constructivist analytical lens to EU policy-making is discussed. Furthermore, the theory of discursive institutionalism is outlined as well as its potential application to the study of Europeanization. Moreover, policy frame analysis is presented as a method of data analysis, and the technique of this research method is outlined. Finally, the chapter elaborates the operationalization and the research design of the study, including the choice of the Netherlands and of employment/ childcare policy as the case studies to be accomplished.

Chapter 2 presents the characteristics of the OMC in the policy field of employment policy. This chapter provides inter alia a historical account of the emergence of the OMC method, and discusses the concrete application of this EU 'governance formula' in the field of Employment policy, and outlines the actors taking part in the process at different stages.

Chapter 3 presents the issue of formal childcare as a public policy problem discussing the different ways the issue is constructed and addressed by the various welfare regimes in the EU. The chapter continues by presenting the way public policy discourses link childcare provision to several contemporary public problems, presenting childcare as a solution to six different 'problems'.

Chapter 4 presents the first application in this study of the policy frame analysis as a research method. Concretely, the dynamics in the evolution of the EU policy discourse toward childcare is examined. This allows for the deconstruction of the specific policy frames that the EU has been articulating throughout the period of European integration, and particularly of the policy frame it propagates via the mechanisms of the Open Method of Coordination. On the basis of these findings, the concrete study of the implementation of the childcare guideline as part of the European Employment Strategy will embark.

The chapters 5 and 6 present the Dutch public policy on stimulation of childcare facilities - chapter 5 focuses on structures, while chapter 6 reviews the actors involved. Chapter 5 will trace the evolution of the main structural components of policy-making: cultural norms, institutional and public policy developments, and 
the evolution of the childcare discourse in policy debates. The aim is to establish the extent to which the European Employment Strategy (EES) has had an impact on the Dutch policy-making process i.e. on the dominant discourses, policy instruments, programmes and their effects (the three dependent variables in this analysis). Chapter 6 reviews the procedural aspects of the policy process, and examines the involved agents (the different actors taking part in the policy process e.g. the trade unions, employer's organizations, political parties, etc.). The aim is to unravel the mechanism of influence (if any) that the OMC entails, and to explain the spectacular growth of childcare facilities achieved in the Netherlands.

The Conclusions summarise the findings of the study and its original contributions. 
1. Chapter

\section{THEORETICAL AND \\ METHODOLOGICAL FRAMEWORK OF THE STUDY}

This chapter outlines the theoretical and methodical framework of the study. Given that the goal of this research is to contribute to the study of the domestic impact of an EU mode of governance (the OMC), which is often labelled as the "Europeanization research agenda", first of all, the state of the art in theorizing 'Europeanization' processes will be presented. Concretely, the mechanisms suggested by two competing neo-institutionalist camps based respectively on rationalist and on constructivist premises will be critically discussed. The theory of discursive institutionalism will be suggested as an alternative neo-institutionalist approach. Furthermore, the policy frame analysis will be presented as a method of analysing policy discourses, and the technique of this research method will be outlined. Finally, the choice of data sources and the adopted operationalisation of the dependent variables of the study will be discussed.

\subsection{STATE OF THE ART IN THEORIZING THE DOMESTIC IMPACT OF EUROPEAN INTEGRATION}

This study draws on and aims to contribute to the growing academic literature on Europeanisation. It is important to state that 'Europeanization' is not a theory, but rather a label for a research agenda', an 'orchestration' of existing concepts and

\footnotetext{
1) A research agenda that is generally associated with studies of the domestic impact of the processes of European regional integration.
} 
theories (Radaelli, 2004: 5). Moreover, Europeanization is a concept that refers to a large variety of phenomena - from enlargement of the European Union, through export of European forms of political organisation and governance beyond Europe, to the penetration of European level institutions into national and subnational systems of governance (Olsen, 2003: 334). This extension of the concept demands careful "downsizing" when used in research work. This study is concerned with two sets of phenomena that are commonly subsumed under the term 'Europeanization':

- The emergence and development at the European level of distinct structures of governance, of political, legal, and social institutions, which formalize interactions among the actors, and of policy networks specializing in the creation of authoritative European rules (Risse et al., 2001: 3). For the sake of clarity, this first set of phenomena will be referred to by the notion, of "European-level institutionalisation".

- The changes within domestic institutions of governance and politics that occur as a consequence of the development of European-level institutions, identities, and policies (Olsen, 2003: 343). In this conception, Europeanization is regarded as the changes of the national systems of governance triggered by the participation of the state in the process. Europeanization in this sense represents a consequence of European-level institutionalisation. For the sake of clarity, below this second set of phenomena will be referred to as "Europeanization".

These two notions reflect scholarly interest in two related but analytically different phenomena. The former is associated with understanding the process in which countries pool sovereignty, whereas the latter is concerned with what happens once the EU institutions are in place and produce their effects (Radaelli 2000: 6; Radaelli 2003: 33). Nevertheless, as Graziano and Vink (2007: 9-11) remark, the two processes are undoubtedly related, and a full account of a domestic impact of 'Europe' could only be achieved if both processes are taken into account (see also the end of this chapter).

In Chapter 2 of this thesis the question of the European-level institutionalisation of employment policy will be examined. It will be discussed why the EU member states decided to cooperate in the field of employment and what institutional form was chosen for this cooperation. The bulk of this study however is devoted to the second question - the extent of domestic change that this EU-level cooperation triggered in the Netherlands. Scholarly interest in the process of European-level institutionalization is often referred to as first-wave EU studies. The 'governance turn' in EU studies (Jachtenfuchs 2001) from the end of the 1980s and the beginning of 1990s is considered the second-wave, whereas the "domestic impact question" and the normative analyses of the EU polity and policies belong to the third-wave (Wiener and Diez 2004: 6-10). 
The once central concept in Europeanization literature is the "goodness of fit". It rests upon the idea that the adaptation of the domestic policy-making process to the European-level policy guidelines and objectives depends on the degree to which the latter 'fit' the existing domestic institutions and policy arrangements. There are two intuitively 'correct' suppositions that the fit thesis suggests. Firstly, that in order for Europeanization (or domestic adaptation) to take place there needs to be a certain incompatibility or 'misfit' between the European and the domestic policies, processes and institutions (Boerzel and Risse, 2000: 5). Otherwise there will be no need for adaptation, and Europeanization will not take place. In other words, a certain degree of misfit is considered a necessary condition for Europeanization. Secondly, the fit thesis maintains that the further a country is removed from the outcome required by the EU, the harder and lengthier the adaptation process. Hence, the larger the misfit the less likely it is the Europeanization effect to take place. Studies, however, indicate that neither of the two is supported by empirical evidence. There are examples of Europeanization without (major) adaptational pressure. For example, governments could 'use' the EU even in the absence of pressure (Kallestrup, 2002). Moreover, there are notorious examples of the UK adapting timely and well with the EU norm despite substantial misfit, while Germany's transposition has sometimes been late and inappropriate, despite almost perfect fit (Haverland, 2000; Knill and Lenschow, 1998). Apparently, other factors are of greater importance when accounting for the domestic process of adaptation (Mastenbroek, 2005: 1109-1110; Radaelli, 2004: 7).

The most important conclusion derived from empirical studies, is that fits and misfits are politically constructed. In other words, it is up to political actors at the EU and national levels to determine what a good fit is. This often means that interpretation, inter-subjective understandings and discourse shape the notion of 'goodness of fit' (Schmidt and Radaelli, 2004: 187). Furthermore, as convincingly argued by Kaeding and Mastenbrook (2006) 'goodness of fit' does not bring any added value to the analytical clarity of the Europeanization studies. Eventually, it is other variables - pertaining to the domestic processes of political interaction - that provide a more comprehensive account of the domestic adaptation. Finally, as indicated above, the empirical record of the 'fit thesis' is rather poor - various studies demonstrated that a good fit is neither necessary, nor sufficient condition for smooth compliance (Falkner et al., 2005; Kaeding and Mastenbroek, 2006). For all these reasons the fit thesis could be skipped altogether and the research could directly zoom into the processes of adaptation that unfold at the domestic level (Mair, 2004: 346).

The state of the art Europeanization literature theorizes the processes of adaptation along the lines of neo-institutionalist theories: in particular the Rational Choice Institutionalism (RCI) and the Sociological Institutionalism (SCI). Rationalists emphasize coercion, cost-benefit calculations, and material incentives, whereas 
constructivists focus on socialization, learning, and social norms (Checkel, 2001: 553). For rationalists, member states' compliance with international agreements stems from "coercion (sometimes), instrumental calculation (always), and incentives-usually material, but possibly social as well" (Checkel, 2001: 559). Rational choice institutionalism (RCI) defines (international) institutions rather narrowly, as formal legalistic entities and sets of decision rules that impose obligations upon selfinterested political actors e.g. member states (Rosamond, 2000: 115). The mechanism of compliance acknowledged by this theory is rational calculation of the costs and benefits of adopting the policy model required by the international organization given the specific context of formal domestic institutions. According to this view, EU governance norms provide new opportunities and constraints to the domestic actors, who attempt to grab the new chances (or minimize the harmful effects) but depend in this attempt on the distribution of power within the political system. RCI therefore regards the number of veto points in the domestic system as well as the supporting or impeding function of formal institutions as the most important explanatory variables of national adaptation (Boerzel and Risse, 2003).

Sociological institutionalism (SCI), on the other hand, emphasizes collective learning, socialization, diffusion of norms, internalization, and persuasion as the dynamics producing compliance, with the latter occurring through a redefinition of interests that takes place during the process of interaction itself (Checkel, 2001: 561). While rationalist theories would largely disregard the ability of institutions to shape the actors' preference formation, sociological institutionalism (SCI) emphasises, in a constructivist vein, the hidden, yet powerful capacity of institutions to provide a forum for socialisation and collective development of meanings, identities, and preferences. Crucially, the interaction between agents and structures is a process of mutual constitution (Adler, 1997). Thus, SCI could be an adequate tool to account for "underwater" compliance processes of elite socialisation or cognitive convergence. It suggests that European-level institutionalisation leads to domestic change through a mechanism of norm internalisation and the development of new identities (Boerzel and Risse, 2003: 59). The speed and magnitude of the process of national adaptation is facilitated by norm entrepreneurs and cooperative informal institutions (political culture more generally) (Boerzel and Risse, 2003: 58-59). In this study a version of constructivist neo-institutionalist theorizing is applied, namely discursive institutionalism.

Before reviewing in greater detail the discursive-institutionalist approach to the study of Europeanization, two methodological notes are in order. The first concerns a debate in the Europeanization literature about where the study of the domestic impact of the EU should begin and where it should zoom in. According to Radaelli (2004: 4) there are two approaches: a 'top-down' approach which tracks down changes/ adaptations at the domestic level once the EU has initiated 'pressure' (e.g. 
through the adoption of a legislative act that needs to be implemented in the member states). The second 'bottom-up-down' approach propagates to examine the domestic level before the supposed EU pressure begins, then to track the participation of the country in the EU level negotiations, and as a third step to study the implementation process of the EU act. Instead of starting from the European policies as independent variable and tracking down the consequences for domestic actors, policies, and politics, this research design starts and finishes at the level of domestic political interactions (Radaelli and Pasquier, 2007: 41). In this way the analyst remains alert for the domestic level processes before and after the appearance of the EU act. This continuous observation of the domestic policy field as well as of the capacity a country has to 'upload' its preference to Brussels, allow for a more thorough account of the 'downloading' processes i.e. of the Europeanization effect. In this way the analysis "checks if, when and how the EU provides a change in the national political system" (Radaelli 2004: 4). Moreover, the process-tracing and time-sensitive political analysis that this research design requires is better equipped to control for the rival alternative hypothesis of domestic-driven adaptations (Radaelli and Pasquier, 2007: 41). This 'bottom-up' or actually 'bottom-up-down' approach is considered a more lateral research design, and is therefore pursued in this study.

The second methodological note concerns the unit of analysis i.e. what to analyse. Prominent at the moment is a distinction suggested by Boerzel and Risse (2003: 60). According to them, the study of Europeanization could be analytically positioned along three dimensions as: Europeanization (adjustment) of policies, Europeanization (adjustment) of politics, or Europeanization (adjustment) of the polity. Clearly, the three are related but for the sake of analytical clarity they could be examined separately. Thus, literature has emerged on the Europeanization of member states' executives and legislatures (for an overview see Bursens, 2007; Laffan, 2007 and Holzhacker, 2007); and on Europeanization of political processes of party politics and interest group representation (for an overview see Mair, 2007; Eising, 2007 and Ladrech, 2010). Below only the adjustment of policies is discussed i.e. the impact on domestic policy standards, on instruments, on problem-solving approaches, and on policy narratives and discourses (see Fig. 3.1. in Boerzel and Risse, 2003: 60) as this is the major concern of this study.

\subsection{THEORISING OMC'S INFLUENCE}

Having reviewed the main perspectives in the Europeanization literature a link has to be established between the existing theoretical achievements and the subject of this study - the domestic impact of the Open Method of Coordination. This section is therefore devoted to eliciting the expected mechanism of influence that OMC 
might have on the national level of policy-making from the perspective of the two main approaches in the Europeanization literature: rational choice institutionalism (RCI) and sociological institutionalism (SCI).

In the European system of multi-level governance the interaction between the national and the supranational level of governance varies depending on which competences are transferred to the supranational legislative and executive bodies. There are different forms of EU intervention in the process of domestic policymaking, which result from the specific allocation of competences (Knill and Lenshow, 2003: 2). Each form of EU intervention is associated with a different level of obligation i.e. the different modes of governance which vary in their obligatory nature (legal authority). Important is not only the scope i.e. which competences are Europeanized, but also the legal status of the rules for decision-making.

Rational choice institutionalism ${ }^{1}$ (RCI) would suggest that the choice to delegate competences to the supranational level is an outcome of a rational process, a calculation involving the maximisation of member states utility and preservation of sovereignty over decision-making. On the basis of this calculation they may decide to accord higher or lower degree of legal authority to the supranational institutions (varying from very strong delegation and enforcement powers to merely secretarial function). The mechanism of Europeanization acknowledged by this theory is adaptational pressure stemming from legal obligation. Consequently, the Europeanlevel institutionalisation is going to produce just as much impact as intended and codified by the Member States. All in all, rational choice institutionalism will not assign much credit modes of governance that are not "empowered" with a high level of legal authority. The OMC policy message is going to be implemented and will lead to policy adjustment in the domestic sphere only as long as the national government planned the same policy reforms outside the OMC framework. From this perspective, the frequent meetings in Brussels and the annual reporting and discussion of good practice is only 'cheap talk' that is not able to change the stable, policy preferences of the national government and public administration which are exogenous to the $\mathrm{OMC}$ process.

In contrast, sociological institutionalism (SCI) will argue that even though the EU institutions are empowered in a rather limited way under the new OMC process, they still might change the actors' behaviour. Institutions could namely influence behaviour by providing the cognitive scripts, categories and models through which the world is rendered meaningful to actors (Ioannou and Niemann, 2003: 32).

\footnotetext{
${ }^{1}$ Rational choice institutionalism defines institutions rather narrowly, as formal legalistic entities and sets of decision rules that impose obligations upon self-interested political actors (Rosamond, 2000: 115). Preference formation is regarded as (largely) exogenous to the institutional setting (Ioannou and Niemann, 2003: 25).
} 
Institutions not only facilitate and constrain the range of possible choices; they also influence certain ideas i.e. perceptions of the world, perceptions of problems and solutions, and perceptions of interests (Andersen, 2002: 131). In the case of the OMC the EU norms and the collective understandings attached to them are defused via the frequently organized meetings in the context of the OMC. They exert adaptational pressure on the domestic-level processes of policy-making, if the established EU norms and objectives do not resonate well with domestic norms and understandings (Boerzel and Risse, 2003: 58-59). This cognitive dissonance may eventually lead to behavioural change because of the repetition embodied in the organization of the Employment OMC policy process with its annually repeated routine and frequent meetings of national experts in the setting of the Employment Committee (EMCO) devoted to deliberation on common problems and the sharing of policy experience. This mechanism of repetitive framing of policy problem perceptions and cognitive beliefs streamlines the ideational environment in which the national levels of policymaking function by pushing for certain policy models and excluding others. In this way the OMC might exert Europeanization effects.

To summarise, two theoretical approaches for assessing the potential effects of European-level institutionalisation have been presented - rational choice and sociological institutionalism. Both provide insights into the main dependent variable of this study - the potential domestic policy adjustment instigated by different modes of EU governance. Rational choice institutionalism suggests that the main Europeanisation mechanism is adaptational pressure triggered by the obligations imposed by treaties, and other formally designed structures for collective decisionmaking. Hence, one should look at the formal level of obligation associated with each mode of governance and the capacity to sanction non-performance in order to formulate expectations about the processes of Europeanisation. Conversely, sociological institutionalism will be looking into the patterns and intensity of institutional interactions provided by the different modes, suggesting that the domestic impact is contingent upon processes of socialisation and norm internalization.

The two approaches outlined above represent the state-of-the art in theorising Europeanization. They do have some limitations, however. The first major limitation concerns the level of analysis. RCI-based studies are predominantly actor-centred, while SCI-based ones are often focused on structure. Arguably, this bias toward agency or structure precludes the possibility for a full-fledged analysis of the phenomenon under study. Secondly, it is very difficult to conceive of an appropriate measure of 'preferences' in the case of RCI, and of 'beliefs and norms' in the case of SCI. This problem is quite severe with regard to preferences due to lack of information and to the complexity of the process of collective preference formation, strategic behaviour (e.g. stating the appropriate or the socially preferred answer), and 
to the inability to 'look into the heads' of actors. Moreover, the appropriateness of the notion of 'preferences' when it comes to collective actors is doubtful. In the SCI framework of analysis beliefs/norms are similarly hard to identify albeit that in the long term they are more articulate and traceable in artefacts and behaviour. Finally, and perhaps most importantly, both RCI and SCI do not spell out in detail the actual social mechanisms underlying the policy-making process. If one 'zooms in' sufficiently into the political and policy processes, it has to be admitted that whichever of the two ontological views is adopted, policy processes could be conceptualised as a communicative exchange of some sort. Given that, politics and the processes of policy-making are struggles of linguistically wrapped worldviews. Hence, any analysis of social reality has to take into account communication and language. Yet, both RCI and SCI miss to problematize sufficiently discourse as a main vehicle/mechanism of preserving the status quo or enacting policy change. Due to all these limitations, this study adopts the theoretical perspective of discursive institutionalism.

\subsection{DISCURSIVE INSTITUTIONALISM}

By the middle of the 20th century, the conception that language is a transparent medium of exchange had been firmly replaced by the idea that human beings are everywhere preceded by language. Neither social reality, nor the 'natural' world have fixed intrinsic meanings which language reflects or expresses. Far from it, meaning is produced in and through language rather than reflected by language. Consider the following:

\section{"It makes a real difference whether you talk about childcare as a service that allows for work and private life to be combined, or about early education. The one is a reconciliation instrument, i.e. a means to an end, while the second is a good in its own right."}

(interview 9)

This quote from the interviews conducted during this research points out that social reality could be shaped discursively through different linguistic representations of the same phenomena. These linguistic representations albeit non-tangible and seemingly ephemeral could have very material and long-lasting consequences. In the example above, if childcare is accepted as an educational service that is 'good in its 
own right', then the argument for heavily subsidising of the childcare sector is easier to accept. Consequently, governmental policy actions could devise financial instruments that redistribute the state finances for childcare along the same lines as this is done for primary school education. It becomes clear, therefore, that language can be regarded as a tool in the 'arsenal' of skilful political actors that can empower or render redundant certain policy choices. Once language is conceived in these terms i.e. as competing discourses, competing ways of giving meaning to the world, which imply differences in the organization of social power, then it has to be accepted as an "important site of political struggle" (Weedon, 1997: 22-23).

For the last 50 years discursive approaches are on the rise in the social sciences, and especially prominent in sociology (Foucault, Laclau, Luhman) and policy studies (Fischer, Hajer, Yanow, Howarth). In general, they emphasize the importance of language and communication in the construction of the social world, identity building and behaviour. They bring to the forefront communicative exchanges, and regard them as the building blocks of social reality. Discourse "denotes the way in which we understand and act upon the social world in and through the productions and circulations of language and meaning" (Fitzpatrick, 2005: 38). Judith Butler defines discourse as "the limits of acceptable speech" (Butler, 1990). Moreover, discourse "can be defined as a relational ensemble of signifying sequences that weaves together semantic aspects of language and pragmatic aspects of action" (Torfing, 2005: 14). Therefore, discourse is to be viewed as both structure and practice. As 'structure' discourse is basically the fabric (the library) of the social: cognitive schemes, symbols, frames, narrative structures, rhetorical statements. As 'practice' discourse could be conceived of as the spinning machine of the social i.e. the vehicle of meaning production via conceptual articulations, rhetorical strategies (recombinations), (verbal) symbolic actions and rituals. A discursive social study then rests upon the assumption that to be able to comprehend social phenomena and their development (e.g. institution-building, evolution of policy-making), the processes of intersubjective production of meaning should be examined i.e. the processes of social interaction and meaning exchange - the practice of discourse. In turn, this will provide an understanding of the discursive structure and its evolution. According to Torfing (2005: 5):

"a discourse is forged and expanded by means of articulation, which is defined as a practice that establishes a relation among discursive elements that invokes a mutual modification of their identity. Articulations that manage to provide a credible principle upon which to read past, present and future events, and capture people's hearts and minds, become hegemonic." 
Hegemonic articulations (i.e. those that have achieved authority) are most often linked to sanctions and thus become social institutions. These are, in short, the ontological foundations of discursive institutionalism (DI).

DI is a relatively new and not very elaborated approach in political science . Nevertheless, there is consensus between scholars about two basic premises (Feindt and Oels, 2005: 161): "struggles about concepts, knowledge and meaning are an essential element of the political process"; and "political discourse has material and power effects as well as being the effect of material practices and power relations". In other words, language and knowledge need to be understood as an aspect of power and as exerting power effects. Beyond these common asumptions authors vary substantially in their epistemological and methodological approaches. Nevertheless, some of their conceptual insights are well reconcilable and can be combined in a single analytical approach. In terms of the theoritization of political processes the account of Kjær and Pedersen (2001) seems most convincing. Schmidt provides in turn useful conceptual tools to observe and analyse the micro-political processes (Schmidt, 2002, 2004, 2005, 2010).

The starting point for DI is the assumption that a certain assembly of ideas articulated in the public space over time turns into a rule-based system of concepts and categories. These 'systems of meaning that order the production of conceptions and interpretations of the social world in a particular context' (Kjær and Pedersen 2001: 220) are denoted as public discourses. The set of rules governing a discourse are referred to as institutions when these rules have attained some degree of authority and have been linked to sanctions and rewards (Andersen 1995 quoted in Lynggaard, 2007). From this perspective institutions, being authorized and sanctioned discourses (Lynggaard, 2007: 294), provide agents with an understanding of their interests and identities. On the other hand, agents produce and reproduce institutions through maintenance of or deviation from the existing discursive structures. Thus, the interaction between agents and structures could be conceptualised as a process of mutual constitution. Accordingly, political change appears (1) as new ideas are turned into discourse and (2) as discourse is turned into an institution (Lynggaard, 2007: 294) through the mobilisation (and restructuring) of discourse coalitions. According to Lynggaard (2007: 295) the process of ideas being turned into discourse is one of articulation, and the process of discourse being turned into institutions is one of institutionalization.

The discursive institutionalism suggested by Vivien Schmidt (2002, 2004 and 2005) distinguishes between 'cognitive' and 'normative' discourses. The cognitive side of discourse justifies ideas in terms of a logic of necessity. The normative side of discourse, legitimates ideas in terms of a logic of appropriateness (Schmidt, Vivien 2005: 7). This observation is close to the notion of framing discussed in the next section. Here it is important to note that this distinction is crucial in European 
integration studies, because the EU often provides discourse that includes only cognitive arguments (e.g. why Europe needs a certain policy). Subsequently, each MSs has to 'edit and translate' it to the national political conditions, has to add the normative dimension, and has to justify it in terms of dominant cultural, political and policy paradigms. This layer of normativity nationalises the policy discourse and allows for national policy debates to be held.

Insightful is also the distinction between communicative and coordinative discourses. According to Schmidt (2005: 10) the public sphere is made up of two overlapping spheres: the policy sphere and the political sphere. In the policy sphere, the domain of the 'coordinative discourse,' the main interlocutors are policy actors civil servants, elected officials, experts, and/or organized interests - who seek to coordinate agreement on (often technical) policies. In the political sphere, the domain of the 'communicative discourse,' the main interlocutors are political actors - political leaders, spokespeople, party activists - who communicate the policy program developed in the context of the coordinative discourse to the public made up of community leaders, activists, experts, organized interests, the media - for discussion, deliberation and, ideally, modification (Schmidt, Vivien 2005: 10).

The distinction between coordinative and communicative discourses is important because EU policies (legislation) are predominantly technical and often remain in the policy sphere i.e. are debated among policy-makers and specialised groups/publics. The coordinative discourse tends to be more focused on cognitive arguments, as policy actors debate policies' relative technical and scientific merits. The normative arguments concerning the appropriateness of such policies, although also important, are not necessarily articulated in this sphere unless they appeal to newly-emerging values or clash with long-standing ones, since if they resonate with existing values their normative legitimacy is often simply assumed (Schmidt, 2005: 11). Nevertheless, EU induced policy debates can be very salient also for the general public. In such cases (e.g. migration policy) in addition to the coordinative discourses also communicative discourses become important. The analyst has to be aware of this distinction, because the range of examined actors depends on the part of the public sphere involved and the respective type of discourse generated .

What makes discursive institutionalism particularly useful in studies of policy processes is that it stresses the mutual constitutiveness of agents and structures. It points namely to the dynamic interdependence between agents (as sources of experimentation and hence of new ideas), discourses (as the mechanisms for production of meaning), and institutions (as reflections of the dominant meaning structures at a given moment of time). This perspective also does justice to the dynamics of the political process (Schmidt, 2010: 4, 21). Typically, analyses employ the so-called 'bracketing technique', where at a certain step of the analysis one holds agency constant, while exploring its effects on structure (Checkel, 2001: 579), or 
alternatively, structures are taken for given and actors are analysed. Most importantly, DI shows the dynamics not only through the changes (or continuity) of ideas but also in the discursive interactions among policy actors, political actors, and publics: who speaks to whom about what when, how, and where (Schmidt, Vivien 2005:). This very dynamic, however, makes the job of the analyst difficult from a methodological perspective. The reflexivity of discourse constituting institutions, institutions constituting actors, and actors chosing whether to produce new or stick to old discourses, etc., excludes the conventional approach of singling out variables and constructing a neat causal story of what led to what. Nevertheless, this complexity is compensated methodologically by the fact that communication processes and public discourses are more tangible (leave clearer traces in policy documents, speeches, reports) than do actor's preferences and/ or normative beliefs.

\subsection{AN ANALYTICAL STRATEGY FOR THE STUDY OF EUROPEANIZATION}

Having discussed the state of the art in the study of the domestic policy impact of European integration, the existing pitfalls in modelling the processes, and the promising new avenue presented by the theory of discursive institutionalism (DI), the rest of the chapter will propose an analytical strategy for the study of the Europeanization effects of the EU (soft law) steering mechanisms. The strategy has three constitutive pillars (see Figure 1.4-1).

Figure 1.4-1 An analytical strategy for the study of the EU influence on domestic policy processes

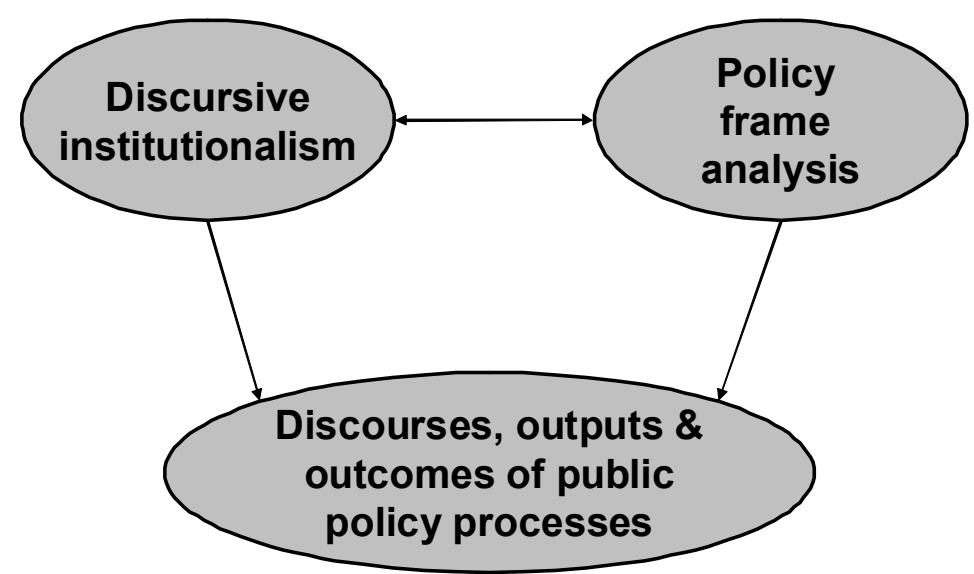


The first component is a theoretical framework based on the premises of discursive institutionalism. The second component is the methodological tool of policy frame analysis. Finally, the third component is a corresponding operationalization and research design that link the theoretical and methodological considerations to observables in the social reality, and thus allow for the conduct of an empirical study. This analytical strategy was applied to the case of EU influence on Dutch childcare provision policy in the chapters 4,5 and 6 .

\section{Theoretical model based on Discursive Institutionalism}

The discursive approaches to EU studies (Diez, 2001; Weaver, 2004) so far focus on the Europeanization of identities rather than on institutions and policies (Wiener and Diez, 2004: 10). What would it mean, however, to apply DI to Europeanization research? What sort of new mechanisms of influence of EU governance on the national level of policy-making does it suggest? If the application of rational choice institutionalism (RCI) and sociological institutionalism (SCI) to Europeanization puzzles could provide a guideline, then DI has to specify:

- mechanisms that describe in rather general terms (similar to RCI and SCI) how the level of European governance might influence the national level of policymaking;

and

- an analytical toolkit for unravelling this mechanism.

The latter is provided by policy frame analysis and will be discussed in the next section. As to the former, a general sketch of the mechanism of influence is provided by Kjaer and Pedersen (2001: 219). They analyse the global expansion of neoliberalism and neoliberal ideas but their argument is transferable to Europeanization processes. Thus, Europeanization:

"... could be analysed as a process in which actors within a particular national context select various relevant ... concepts and conceptions from ideas available to them and use them in ways that displace the existing order of interpretation and action and trigger a shift of policy attention, preferred policy models and opportunities for political action".

Kjaer and Pedersen (2001) 
The main mechanisms expected therefore are discursive recombination and coalition building. In the particular case of the Open Method of Coordination (OMC) the influence of the EU may reside in the enlargement of the sets of possible problematizations, and arguments available to domestic actors, and within this process certain policy problems/solutions may get to be emphasised over others.

In turn, this provides a back-up for certain domestic actors enabling them to legitimise their political claims and/or engage in new coalition configurations. Depending on the speed, direction and intensity of these coalition building/restructuring processes (these are very difficult to model in a formal way because they are very contingent on the policy and political constellations in the different member states at a given period of time) eventually a new discursive architecture will emerge that will result in a policy change.

Figure 1.4-2. Europeanization model flow based on discursive institutionalist premises

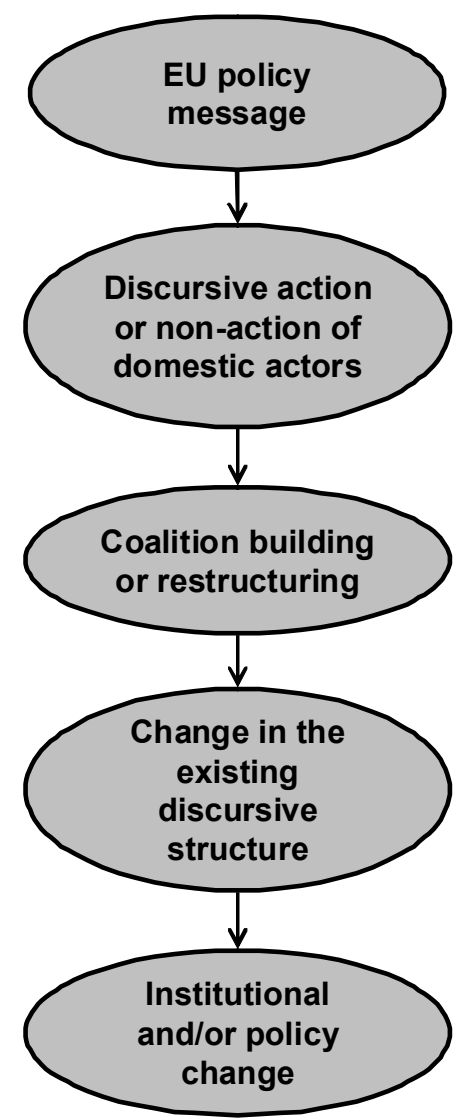


Figure 1.4-2 presents a schematic overview of the expected process. Once the EU policy frame is endorsed in Brussles, there are two reactions/possible scenarios at the national level: either it invokes certain actors to act upon it or it does not. If no actor reacts on the EU narrative this is either due to the fact that there is already alignment between the EU and the country's discourses (i.e. there is full compliance); or that there is discrepancy between the EU and the country's discourses but no domestic actor is interested in changing the status quo (i.e. non-compliance follows). These two cases are rather rare. Much more likely is that there are actors who get activated by the emergence of the EU discourse (for example because they were active in uploading it to the EU). They will then engage in (re)structuring of the existing discourse coalitions (i.e. they will start to mobilise, reactivate, tie, link and reshape policy frames), and hereby instigate a change in the domestic discursive infrastructure ${ }^{1}$ that ultimately results in a policy change. Within this process it is logical to expect (in the setting of the democratic governance of the EU member states) that if the restructured policy coalition has institutional access to decisionmaking processes the speed and magnitude of policy change will be higher. Hence, implementation of the EU act will be speedier and more complete if the discursive coalition that appropriates the EU frame in its own discourse is in office (part of the government coalition) or is at least parliamentary represented.

Based on this model the task of the empirical stage of the study is therefore to analyse how the EU policy message is translated into the domestic policy context (and by whom), and whether and how it subsequently triggers a shift in the existing domestic order of interpretation (if at all). In order to accomplish this, the DI framework needs to be combined or 'enriched' with an appropriate methodological tool to examine the policy process. In this study, this is done through policy frame analysis (PFA).

\section{Methodological approach: the policy frame analysis (PFA)}

Clearly, the theoretical model adopted in this study stems from constructivist premises. From the constructivist perspective, politics and policy-making acquire quite a different shape compared to the conventional view. Power remains the central object of interest and study, but the struggle for power is not anymore conceived of

\footnotetext{
${ }^{1}$ The domestic discursive architecture could be defined as the sum total of all existing policy discourses together with the actors that articulate them. In simple terms: who says what about this policy.
} 
as a contest of actors, interest groups, party platforms or candidate lists, but rather as a battle of alternative worldviews, a struggle for the establishment of a dominant meaning about social issues, as well as about the ability to define what is socially significant. In turn, policy making is not about the provision of the optimal public policy given a certain constellation of public problems, but about the contingent choice of possible (but not unique) problematizations of social reality. This constructivist conception of public policy-making is in sharp contrast with the traditional (rationalist) one in that it shifts the focus from the choice of an optimal solution to 'existing public problems' through the application of cost-benefit analysis, toward the production of meaning in policy-making, and the construction of public problems. Any description of an issue or a 'problem' is an interpretation, and interpretations involve judgement and choices (Bacchi, 1999: 1). Put differently, the objects of study are no longer public 'problems' but articulated (i.e. possible but not unique) problematizations (Foucault 1984: 257, 256). In the public policy process, during the interaction between the various policy actors, different visions about the "existing problems", their origins, and possible solutions are articulated. Thus, the policy process itself is a process of social construction, where the different actors articulate and reformulate their vision regarding the type of problem, its normative background, the possible accounts for its emergence, and the sort of solutions that could be applied.

\section{Policy Frames}

Against the background of the general political assumptions of DI, a study of policy-making processes requires an analytic tool which enables to illuminate (deconstruct) the processes through which social conditions and phenomena are initially perceived and depicted as 'problematic' and in need of public intervention. Put differently, the analyst has to investigate the process of selecting, emphasizing and organizing aspects of complex issues, a process often referred to as "framing". A frame is a selective representation of a social phenomenon. Similarly to a photo frame it represents a social issue in a certain light and within certain borders. Frames direct attention toward some elements while simultaneously diverting attention from other elements. They "highlight and contain at the same time that they exclude" (Yanow, 2000: 11). The discovery and exposition of frames then is the primary undertaking of the policy analyst, and frames are the basic units of analysis in policy studies. But what is a policy frame exactly? What is it made of? How could one recognise a frame in policy documents?

According to Rein and Schoen a frame "is a perspective from which an amorphous, ill-defined, problematic situation can be made sense of and acted on" (Rein and Schoen, 1993: 146). Dryzek maintains that "...each frame treats some 
topics as more salient than others, defines social problems in an unique fashion, commits itself to particular value judgements, and generally interprets the world in its own particular and partial way" (Dryzek, 1993: 222). According to van Gorp (2001:5) cited in Fischer (2003: 144) a frame is an "organizing principle that transforms fragmentary information into a structured and meaningful whole". Such frames, similarly to metaphors, select out some parts of reality at the expense of others, and in doing so, shape perceptions and understandings (Yanow, 2000: 12). Contending frames entail not just different policy discourses - different language, understandings, and perceptions - and potentially different courses of action, but also different values and different meanings (Yanow, 2000: 12). Verloo and Lombardo (2007: 33) assert that policy frames have two key dimensions: the "diagnosis" (what is the problem?) and the "prognosis" of a problem (what is the solution?). Thus, the diagnosis points out and defines the public problem, while the prognosis outlines a package of policy measures how to solve the identified public problem.

If a single conception is to be distilled form all of the above quotations, then policy frames could be defined as performing three main functions. Based on a set of normative values and cognitive believes they:

- name (point out) a social condition as problematic based on the perspective of certain normative belief system;

- offer an explanation about the problem and the relevant phenomena;

- propose a specific policy action/ non-action.

On the basis of this analysis it could be concluded that a policy frame is a perspective toward social reality that identifies problems, suggests explanations and proposes certain public policy actions that could remedy (solve) these problems. A policy frame therefore comprises the following four dimensions (see Figure 1.4-3): 
Figure 1.4-3. Policy frames and their four dimensions

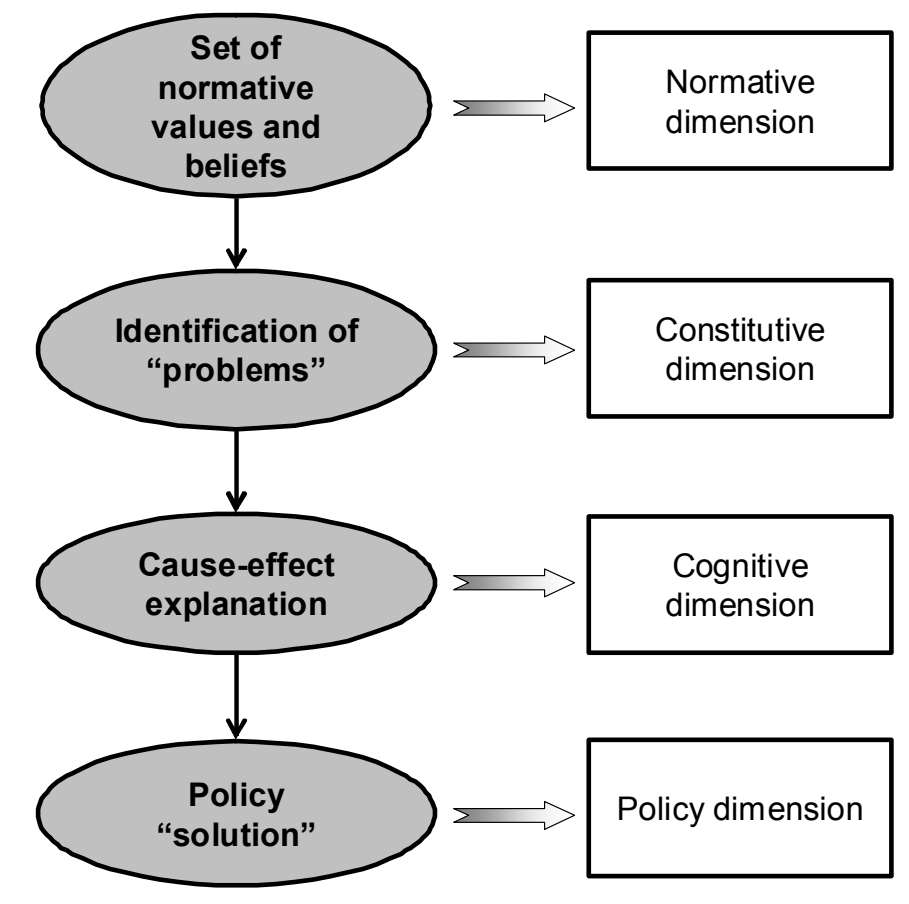

1. Normative dimension - pertains to the function of the frame to judge and attach values to phenomena from the social reality

The process of problematizing a policy field always departs from a set of normative values. Nothing can be labelled 'problematic' or 'not problematc', 'good' or 'bad' without a clear moral standpoint from which the analyst is able to observe, compare, and establish departure from or coincidence with the expected normative standard. For example, the thinning of the ozone layer will not be a 'problem' unless sustainability of life on Earth is regarded as valuable. Similarly, the slavery in North America would not be regarded as morally problematic, if the equality between people regardless of race and their equal right to self-determination were not upheld as key principles. In short, passing judgement as to what is problematic or not requires a normative standpoint.

2. Constitutive dimension - pertains to the function of the frame to label and identify various social phenomena as problems

According to Kingdon "Conditions become defined as problems when we come to believe that we should do something about them" (2003: 109) and this is precisely what the constitutive function of the policy frame refers to, namely the process of pointing at, identifying, naming the conditions and social phenomena as unacceptable, and in need of a remedy. It is the policy actors who are the carriers of a 
particular ideological load and normative system of beliefs, and it is they who suggest that certain social conditions and phenomena are to be considered problematic.

3. Cognitive dimension - pertains to the function of the frame to narrate about what has led to the problem and thus to present social reality in terms of cause-effect relations

Having identified a 'problem' the policy actor usually provides a story about cause-effect relations i.e. presents a narrative that links the problem with a 'solution' (for example a package of policy measures). This process of rationalization weaves into a coherent fabric the story about the unacceptable social condition and its origins with the story about the measures and actors that could remedy the situation. The cognitive dimension is the link between the constitutive and the policy dimensions of the frame.

4. Policy dimension - pertains to the function of the frame to outline a course of public actions that would remedy the problem.

This dimension contains the 'recipe' to render the social condition less problematic. It outlines public policy actions, defines measures and steps, and points toward concrete actors that might remedy the policy 'problem'.

Public policies are typically based on policy frames that implicitly or explicitly contain the four dimensions described above. Subsequently, the deconstruction of the constitutive, normative, cognitive and policy underpinnings of governmental programmes, actions and measures becomes the primary activity of the policy analyst.

\section{Technique of the Policy Frame Method}

Within public policy discourse (the sum total of all conceptions, possible angles, and ways in which a social phenomenon is presented and discussed) usually several policy frames compete for domination. The main objective of the policy frame analysis is to examine the general evolution (rise and decline) of the different frames i.e. of the different conceptualizations of the problem and solution at stake. By plotting this evolution, a lot could be inferred about the dynamics of public discourse. If this macro analysis is complemented with micro analysis of the framing activities (i.e. who stood behind and influenced these frames) the researcher can reconstruct the policy process and related outcomes.

A first step in the analysis is the identification of all available policy frames. This can be accomplished through examination of secondary literature on the subject, policy or expert reports, on the basis of a study of the rhetoric of public actors, or 
based on observations of the policy process in a state or in states with similar system design. Of course, the list of policy frames is only preliminary and the researcher should remain alert for the possibility that the documents contain different frames than the ones on the preliminary list. The researcher should therefore be open and add such 'unexpected' frames to the initial list.

The next decision is related to the stage of data gathering. From where could the discourses be derived? There are various sources of policy discourses that could be helpful for the formation of the dataset: political programmes (e.g. party manifestos), governmental strategies (e.g. the coalition agreements of newly elected government cabinets), parliamentary debates, ministerial memoranda or explanatory notes, etc. For the purposes of this study three distinct datasets were formed (see Figure 1.4-4).

Firstly, all EU secondary legislation (derived from the Eur-Lex database) and the Presidency Conclusions of the European Council summits (for the period 19982008) that contain "childcare" or childcare-related terms served as a dataset for the examination of the EU policy discourse (chapter 4). Secondly, the Dutch coalition agreements (regeerakkoorden) formed the dataset that allowed for the reconstruction of the general Dutch policy discourse (chapter 5). Finally, the dataset composed of the Dutch political party manifestos revealed the micro-discursive developments of frame restructuring and coalition building that led to the identified macro policy discourses (chapter 6).

When the dataset is complete the process of frame deconstruction (decoding of the frames) begins. This involves a qualitative content analysis, whereby the number of references to the search terms (e.g. "childcare") is documented and (wherever possible) each reference is assigned to one of the expected policy frames. To accomplish this, the immediate context where the reference is found is studied. This context is screened for whether it contains the constitutive and the cognitive dimensions of any of the expected frames from the preliminary list of policy frames. If so, then the reference could be counted as one occurrence of the respective policy frame.

The results of this process i.e. all references that were linked to a particular frame are duly recorded (for example in a table). Thus, per policy document is composed one record in this table. In the first column thereof is noted the total number of appearances of childcare-related terms in the document. This number is important for purposes of replication of the study. In the next columns the numbers of interpreted appearances of the various policy frames are noted. This allows for a relative overview of the weight of each policy frame in the document. The procedure is repeated until all documents are 'processed'. This procedure generates a dataset that can be processed statistically and the general dynamics of the framing process observed and analysed. This allows the formulation of inferences about which frames 
dominated during which periods, which ones appeared or disappeared when, etc. Moreover, such analysis of the general framing trends provides the input data for the micro-analysis of who stood behind the observed dynamics, which can be accomplished by policy frame analysis of individual discourses (e.g. of a political party), actor-based process tracing and expert interviews (see Chapter 6). In this study the method of policy frame analysis is demonstrated in Chapters the 4, 5, and 6.

\section{Figure 1.4-4. Datasets for the policy frame analyses}

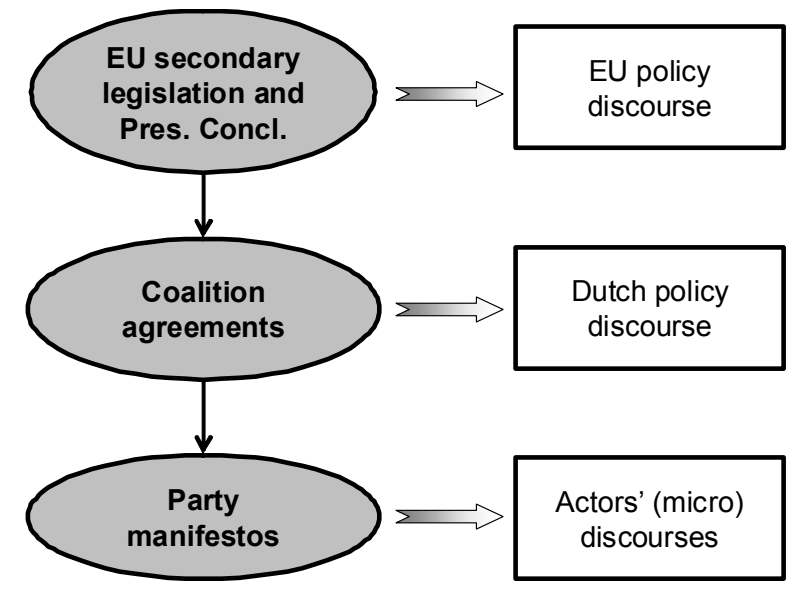

\section{Case selection}

As outlined in the Introduction, the ambition of this thesis is primarily methodological. This study is geared to developing an analytical framework that will enable the systematic examination of the domestic adaptation processes as a reaction to an EU soft steering mode - the OMC. The aim is to encompass the whole policy system - the actors, the existing structures, the ideas that are (have been) in circulation, the history of the public policy filed and the general cultural and political environment. Due to the comprehensive background research required only one empirical case will be elaborated. This will allow for a thorough examination of the processes and mechanisms at stake, and moreover for a focused and detailed test of the proposed method. Furthermore, the elaboration and testing of an analytical framework does not require (in the initial stages at least) a medium or a large- $\mathrm{N}$ study - a single case study will suffice to gauge the added value of the new analytical approach.

Moreover, due to the complexity of the processes of practical implementation, it is difficult to imagine a large scale study of such processes. "Research into practical implementation, by nature, is explorative and qualitative" (Versluis et al., 2011: 203). The researcher needs to collect a lot of data about the national actors, their positions, the development of the policy field in the domestic public sphere, the leading 
ideational paradigms and their development through time. This is time-consuming and in some cases difficult work. That is why in the field of EU studies qualitative studies prevail (Versluis et al., 2011: 198). This thesis will make no exception to the general trend and will elaborate a single qualitative case study. The reasons for this are not only the in the time-consuming and difficult nature of such research, but also the aim of this work to explore the mechanisms at work comprehensively and to investigate the influence of the OMC onto the domestic level from the bottom-updown' perspective (see Section 1.1.).

In practice, three choices have to be made:

$\checkmark$ Choice of an OMC process i.e. of a policy area to be studied

$\checkmark$ Choice of a concrete OMC guideline from this policy area to be examined

$\checkmark$ Choice of a member state where the implementation of the guideline will be traced

The OMC process that will be closely investigated in this study is the Employment OMC (European Employment Strategy - EES). The choice of this policy area is grounded in the fact that the Employment OMC (endorsed in 1997) was the first coordination process that follows an annual cycle and therefore provides ample empirical data, which allows the accomplishment of the study over a 10-year period $(1998$ - 2008). The selection of a 'tangible' OMC process (i.e. one with fixed guidelines, objectives, targets, role of committees and EU institutions; etc) is crucial because the new mode of governance is anyhow "soft" i.e. does not create legal obligation for the member states to implement. Therefore, it is important to choose an $\mathrm{OMC}$ process that leaves a clear trace (observables) at the EU and the national levels of governance, and can be grasped by the researcher (Kroeger, 2009: 8-9).

Having selected the policy area, the subsequent narrowing of the research design demands a choice of a particular Employment guideline to be studied further. Out of the five Employment guidelines that form part of the Integrated Guidelines for Growth and Jobs (IGGJ) in 2005 (see Annex A) the one concerning childcare provision was chosen. The main reason for this selection is that this objective is linked to a particular quantitative target: "by year 2010 member states should provide childcare to at least $90 \%$ of children between three years old and the mandatory school age and at least $33 \%$ of children under three years of age"1. That facilitates tracking progress. Given that the study examines a soft EU governance process, it is of importance to select a field where a tangible measure of implementation is

${ }^{1}$ Endorsed by the Barcelona European Council of 2002. 
available e.g. progress in the coverage rate of childcare provision. All other quantitative targets endorsed in the field of employment policy (see Annex B) are linked to levels of (un)employment which is a composite and cyclical indicator which makes it much more difficult to establish the relation between the indicator and the factors causing the observed increase or decrease. A further argument to back up the choice of the 'childcare guideline' is the salience of the issue in virtually all member states during the first decade of the new millennium, as well as the sufficient amount of reliable data that could be pooled for the entire period of the study.

While almost all European countries provide care to children from age 3 to the mandatory school age as part of their educational mission, care for under-3-yearsolds, essential for mothers' employment, is much less developed outside Scandinavia (Orloff, 2002: 78). With the definition of the 33\% Barcelona target the member states committed themselves to take actions in this field of social service provision. This is not an easy task to implement however, especially given the substantial variation in gender relations throughout Europe. Systems of social provision in the EU reflect different visions on how to care for the youngest. There are two principal strategies: encouragement of paid work (and necessary services to allow people with caregiving responsibilities to enter paid employment) or cash benefits from the state for staying at home to care (Orloff, 2002,: 72). Gaining access to employment is the predominant strategy today, particularly in the English-speaking countries and in Scandinavia, while 'maternalist' strategies to attain state economic support for fulltime mothering were more common in the past and retain some viability in many continental European countries, notably Ireland, Italy, and Germany (Orloff, 2002: 72; Ostner, 1993; Bock and Thane, 1991). These two strategies reflect alternative visions about the role of women in society: in the first case women are viewed as fulltime workers as are men (with care-giving publicly provided, and shared in the private sphere); in the second women are viewed as full-time mothers, part time workers and principal caregivers (Orloff 2002).

The Employment OMC (via the 'childcare guideline') clearly fosters the policy strategy of encouraging paid work. This is to be understood in the context of decreasing competitiveness, the need to mobilize all labour resources, and the devotion to sustain the European Social Model - three of the core commitments rooted in the Lisbon agenda, the implementation of which is not in line with the vision of (at best) part-time working women. Against this background, this research focuses on the impact of the OMC processes on domestic policy dynamics, and subsequently studies the adaptations that have taken place in one member state in order to come in line with the Barcelona target.

The final step in the case selection process concerns the selection of a member state where the impact of the EES is studied. A real test-case for impact of the new governance mechanism would be member states, where the OMC rationale demands 
a substantial policy adjustment ${ }^{1}$. Without doubt in the case of childcare policy these will be the member states from the so-called conservative welfare state cluster, which in terms of gender relations pursue policies encouraging full-time mothering and disencourage mothers to take jobs and paid employment. The Netherlands is a particularly interesting case in this context. Although in terms of levels of social spending it might qualify for the Social democratic cluster of welfare states, in terms of state maintenance of the traditional male breadwinner model the Netherlands is one of the European champions (Bussemaker 1998; Bussemaker and Kersbergen ; Kersbergen and Kremer 2008). Up until the 1990s it pursued policies that kept women away from the labour market and assumed that 'the average female' aspires the life-course of a housewife/ homemaker, whose primary occupation is unpaid work in the private realm of the family home. With regard to the concrete development of formal childcare policy until the beginning of the 1990s the Netherlands only supported childcare facilities for children whose parents were unable to care for them. This is reflected in the fact that there were 0.83 places in childcare facilities per 100 Dutch children in 1990, which is extremely low (VWS, 1997). Given the low levels of childcare provision at the beginning of the 1990s, it is interesting to explore how the European Employment Strategy - which encourages female paid employment and growth of childcare facilities - has been implemented in the Netherlands (for the period from 1998 to 2008), and what impact it had on the national policy-making process. At the end of the first decade of the $2000 \mathrm{~s}$ the Netherlands demonstrates one of the highest levels of female labour market participation in the EU and a substantial growth of childcare facilities (CEC, Report on Progress on Equality between Women and Men, 2010). Can this policy performance be attributed to the influence of the Lisbon Strategy and of the OMC mechanism? In the last 10 years the number of childcare places has doubled (Monitor Capaciteit Kinderopvang, 2010). How can this spectacular growth be accounted for? And is this (at least partially) due to the EES?

\section{Research design and Operationalisation}

This section aims to link the theoretical and methodological discussion above to concrete observations in the childcare policy process at the EU and at the national

\footnotetext{
${ }^{1}$ It is less important to examine countries that have been in compliance with the OMC policy rationale. Moreover, in such case it would be very difficult to isolate the OMC influence and to establish whether the policy adjustments observed are not due to natural evolution of the policy course taken earlier. Furthermore, choosing the least likely case is very informative because any impact would reveal/ mean a lot for the other cases.
} 
level. To that end, it will outline the type and sources of empirical observations that need to be collected and the methods for data collection and analysis in order to examine the influence of the Open Method of Coordination on the domestic level of policy-making.

This research objective calls for a public policy analysis i.e. an analysis of the activities undertaken at the EU and at the national level of governance so that the goals set within the OMC framework are achieved. There is an abundance of definitions about public policy and each of them emphasizes different aspects of the phenomenon (for overviews see Parsons, 1995; Hill, 2005 and Versluis et al., 2011). Nevertheless, most definitions converge around the following common understandings: public policies are activities of government (Versluis et al., 2011: 12), and hence in order to examine public policies one should analyse what governments say, do, and achieve (see Figure 1.4-5).

\section{Figure 1.4-5. Operationalisation for public policy analysis}

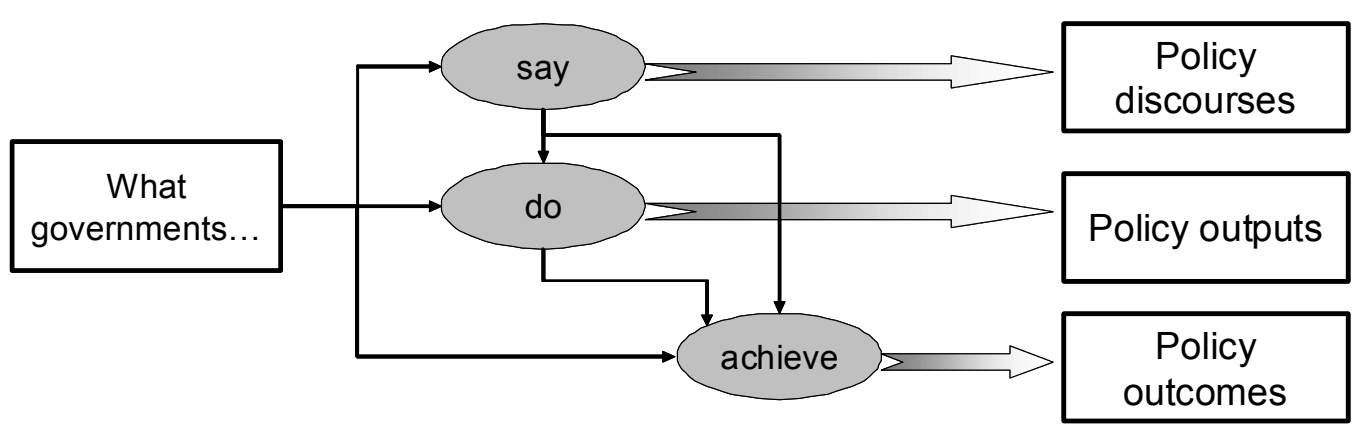

The division between policy outputs and policy outcomes is based on the literature on policy analysis and resides on the observation that what governments do is not always and necessarily leading to the desired policy outcomes. To provide a basic definition and line of distinction - "policy outputs are what government does; policy outcomes are what government achieves. Outputs are the activity; outcomes are the effects, both intended and unforseen" (Hague and Harrop, 2001: 277). Indeed, it could be expected from a democratically elected and accountable to the voters government that what it says/promises regarding certain policy developments should get materialised in concrete policy actions (or non actions) which in turn will lead to certain goals. This neat image of the policy process is often misleading however (Bovens, 1998). To the contrary, governments may express the intention to achieve certain policy outcomes and to commit to them rhetorically, but due to unforeseen circumstances (e.g. sudden need for budgetary cuts, or incorrect calculations of the actual costs of the policy programme) or purposive non-action 
they may not to be able to implement the intended policy. Furthermore, even if everything planned is duly put in place, it may not always lead to the desired outcomes (e.g. because the policy model of cause-effect relations is not adequate. Hence, what governments say (discourse), what governments do (outputs) and what governments achieve (outcomes) are related but the correlation is not always easy to predict. That is why, while recognizing the correlation between them, for the analytical purposes of this study, it is useful to examine separately the influence of the EU level on all three policy observables.

The systematic study of policy discourses, outputs and outcomes is not only the standard approach in the examination of general public policy, this is also the research approach advised by scholars of Europeanization and of the OMC mode of governance. Boerzel and Risse suggest for example to examine the adjustment of domestic policy standards, of instruments, of problem-solving approaches, and of policy narratives and discourses (see Fig. 3.1. in Boerzel and Risse, 2003: 60). Moreover, in the OMC literature, Zeitlin suggests that the OMC influence can be measured by indicators of the cognitive, political and programmatic shifts (Zeitlin, 2009: 217).

For the operationalisation of the policy discourses, outputs and outcomes in this study the following indicators are chosen:

a. policy discourses - alignment between the European and the national policy frames

b. policy outputs - new policy instrument (e.g. new benefit scheme) or new institution (e.g. creation of a specialised agency), which are introduced after the introduction of $\mathrm{OMC}$

c. policy outcomes - actual quantitative progress toward the EU target (e.g. statistical increase of $\mathrm{X}$ percentage points)

The policy discourses will be studied via the method of policy frame analysis PFA) as outlined in the previous section). In the childcare case, a policy output could be a new law on the stimulation of childcare facilities, or the introduction of a special tax rebate i.e. some sort of governmental activity. These policy outputs can be studied via documentary analysis of policy programmes and documents. A policy outcome, on the other hand, is the actual growth in the number of childcare facilities and the available places in them; or the number of preschoolers (for the Netherlands these are children up to 4 year-old) that visit daycare centres. An indicator of the policy outcomes is already defined by the EU level of governance - the Barcelona target of 33\% childcare coverage rate. Given that this statistical indicator suffers from some flaws (see section 5.4 for details) in this study an additional indicator will be used in order to complement the analysis and present a more thorough review of the actual achievements of the Netherlands with regard to provision of childcare facilities 
for 0 to 3 year-olds. Concretely, the growth in the number of available childcare places per 100 children in the age 0-4 in formal childcare facilities in the Netherlands will be studied (see section 5.4).

While the method for examining the policy outputs and outcomes is rather clear and straight-forward - mapping the evolution of the governmental actions and achievements and establishing the degree of convergence to the EU prescriptions the method for the examination of the policy discourses and the conclusions drawn from such an analysis needs certain clarifications. In order to examine the influences of EU childcare discourses on the discursive interactions that took place in the field of childcare policy in the Netherlands, this study has to compare the dynamics of policy framing at the EU level and in the Dutch childcare discourse.

The first step in the analysis will be identification of the EU policy frame i.e. of the policy message that the EU 'radiates' or disperses to its members states via the mechanisms of the OMC (chapter 4). Secondly, the general policy discourse in the Netherlands has to be studied with a view to mapping out the dynamics of policy framing within the domestic context (chapter 5). The findings of these individual discourse analytical studies will be juxtaposed with the aim to outline the systematic influence (if any) of the EU discourse on the national one. Clearly, a precondition to claim EU influence would be that the two discourses are/get aligned after the introduction of the EES guidelines (in 1998), and moreover that the EU policy frame precedes the domination of the national one. Whatever the results of this macrodiscursive study, it could then be complemented by micro-discursive studies that aim to outline the precise mechanisms of how the EU framing influences the domestic policy sphere by demonstrating (again via policy frame analysis but this time of the individual actors' discourses) who engaged in coalition building and coalition restructuring, how (through the articulations of which actors) and when the EU frame established dominance, etc. Related to this last step in the analysis is the methodological remark about the distinction between individual-level framing and collective issue definition. Studying the process of framing only at the individual level has little chance of elucidating collective-level changes in the discourse. At the same time, researchers focusing only on aggregate-level framing will be unable to understand the forces that led to the collective frame without recognizing the microlevel forces that are at play (Baumgartner and Mahoney, 2008: 436). This is why, the methodological design of the study previews two separate research techniques. On the one hand, policy frame analysis will capture the macro-level processes (i.e. how the issue has been developing through the years - frame evolution, recombination of frame dimensions, etc.) On the other hand, the methods of expert interviews and process tracing will be employed to study the micro processes (i.e. who stood behind the macro-frame dynamics, who pushed for which frame, who introduced which novelty, interpretation or recombination of existing frames). 
To summarize, in a quest to establish OMC's influence on the national processes of policy making, this study will look on the one hand for convergence of the national policy discourse with the EU discourse on childcare policy. On the other hand, the study will track progress toward the $33 \%$ EU target. Finally, the activities of the Dutch government in the period 1998-2008 in the field of childcare will be surveyed for the establishment of new policy instruments (e.g. new benefit or tax measure) or of a new institution (e.g. creation of a specialised agency), which are introduced after the beginning of the European Employment Strategy, and which were driven by it according to the policy actors.

The period under study will cover the first decade of implementation of the European Employment Strategy i.e. 1998 to 2008. The methods applied for the examination of the actors' view on the EU impact are process tracing and interviews. Finally, based on the triangulated data from the PFA, the documentary analysis of policy documents and position papers, and from the semi-structured interviews with the main policy actors, this study aims to identify the mechanism of influence that the OMC initiates.

This chapter elaborated an analytical strategy in order to examine the impact of the open method of coordination (OMC) in the field of employment policy on the domestic level of policy-making. The proposed research approach departs from constructivist premises and applies the theory of discursive institutionalism to the Europeanization agenda in EU studies. The main methodological tool through which the discourses will be 'caught' and analysed is policy-frame analysis. Finally, in order to establish the exact effects on the Dutch policy process, the study will look into the degree of convergence between the European and the Dutch childcare policy outputs, outcomes and discourses. To that end, policy frame analysis will be performed on party manifestos (for the political parties discourse), which will be complemented with interviews with main actors in the process, and documentary and statistical data analysis. The three main indicators on the dependent variable and the envisioned research methods in the study are displayed on (see Figure 1.4-6). 
Figure 1.4-6 Methods for data analysis applied in the study

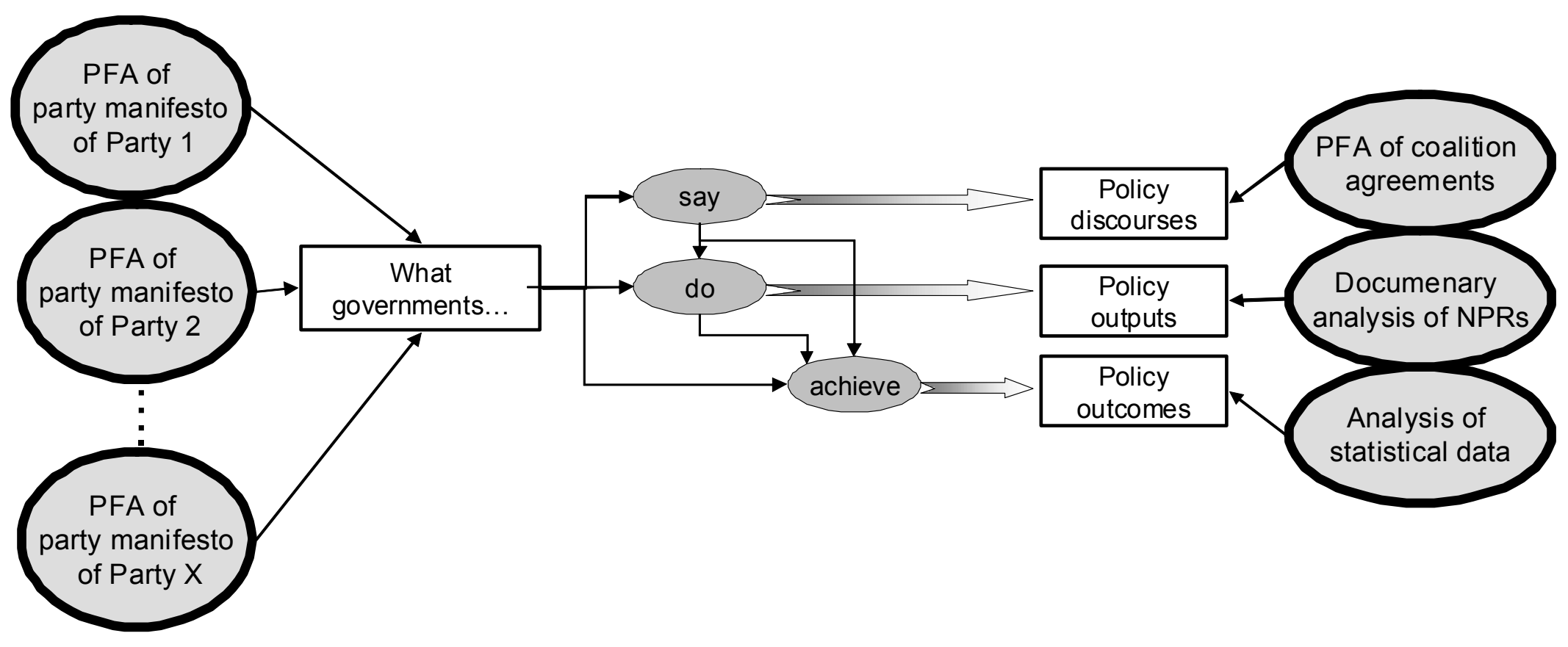




\section{THE OPEN METHOD OF \\ COORDINATION AS A NEW MODE OF EU GOVERNANCE}

This chapter ${ }^{1}$ examines the emergence and institutional features of the Open Method of Coordination (OMC) as a new mode of European governance. More concretely, the chapter addresses the following questions: why did member states agree to cooperate at the EU level in the field of employment policy? Why was a soft mode of governance - the Open Method of Coordination - chosen as the appropriate institutional form such cooperation should take? What processes and actors are involved in the employment policy coordination?

\subsection{THE ORIGINS OF THE EMPLOYMENT POLICY COORDINATION}

During the 1990s the member states of the EU were increasingly exposed to numerous challenges in their employment policy-making (e.g. aging populations, changing household and family structures, decreasing economic competitiveness, rising unemployment, etc.) The various pressures stemming form the national and global levels had to be dealt with in the context of Economic and Monetary Union (EMU), i.e. without possibility to apply monetary tools and under conditions of coordinated fiscal policy (due to the need to meet the convergence criteria to qualify for the EMU). In the mid-1990s the unemployment had risen to unprecedented levels and this compelled the European governments to turn to the EU level in their 
quest for solutions. Due to the aspiration to create and join the EMU the EU member states came under increasing pressure to reconstruct their welfare states and to increase the competitiveness of their economies "separately but harmoniously" (Zeitlin 2005: 4). There were also some other factors that played a role, namely the EFTA enlargement of 1995 (which brought three new member states that were particularly interested in promoting social policy cooperation at the EU level), as well as the need to develop the EU's social dimension in order to tackle the growing popular discontent with the predominantly liberal-economic character of the European integration process (Arnold and Cameron 2001). The combined effect of all these factors accounts for the increased demand for EU cooperation in the mid 1990s.

However, the combination of these functional pressures is, in itself, not sufficient to explain the institutionalisation of a new policy area at the EU level of governance. They represent only one side of the coin, namely the demand for European cooperation. There has to be a match between such demand and the supply of European level cooperation in order for new policy areas to be attracted to the EU centre of gravity and to become institutionalised in some form at the supranational level. Tackling elevated levels of unemployment and the need to catchup in the global competitiveness race had been on the agenda of West European countries since at least the middle of the 1980s. It was only in the late 1990s, however, that EU leaders became prepared to initiate EU level cooperation. In other words, only at this point was the demand for integration met by a sufficient degree of supply. How can we account for this development? Why were the member states only then ready to address such common problems with common means?

The answer demands a careful investigation of the partisan composition of the European Council. At the time when the Employment title of the Amsterdam Treaty was negotiated (1997), the majority of EU governments in office were, for the first time in the Union's history, dominated by left-of-centre parties (Arnold and Cameron 2001; Manow, Schaefer and Zorn 2004; Schaefer 2004). Concretely, Arnold and Cameron found that the extent to which a particular government supported or opposed the development of EU-wide employment measures was strongly related to the extent to which a leftist or a rightist political grouping controlled that government at the time of the IGC. The research showed a strong correlation $(r=0.70)$ between the extent of control of government by parties of the Left and support for the development of EU-wide measures. Conversely, government control by parties of the centre-right, broadly defined, strongly correlated $(\mathrm{r}=0.71)$ with opposition to the development of EU-wide employment measures (Arnold and Cameron 2001: 21).

According to Manow, Schaefer and Zorn (2004: 30), prior to Amsterdam, Britain, France and Germany had all been strictly opposed to bringing employment policy into the treaties since they feared higher EU spending and excessive 
intervention on the part of the European Commission. After the electoral swing to the left in the wake of the British and French general elections of 1997, however, Germany appeared to be left isolated. Yet the German coalition government proved to be less opposed to the employment title then had been generally believed and reported (Johansson 1999: 95). Albeit that their previous administrations had been strong opponents of the employment title, at the Amsterdam summit of 1997, the new governments in France and the UK agreed to support it. In particular, the new French government of Prime Minister Lionel Jospin insisted on the inclusion of the employment title and even threatened to reject the proposed Stability Pact (Goetschy 1999: 126; Jenson and Pochet 2002, : 8) if the employment provisions were not accepted. In the end, the European Council summit adopted both the Stability and Growth Pact and the new Employment Title (Manow, Schaefer and Zorn 2004: 30). The new British government supported the title because it closely reflected the centre-left programme of Prime Minister Tony Blair (Pollack 2000: 269). In fact, the agreement was believed to simply represent the export of the UK's new reform model to the EU level. In other words, the unique constellation of predominantly left-of-centre parties in the European Council between 1997 and 2002 provided a 'green light' for EU level cooperation in previously contentious policy areas such as employment policy regulation, social exclusion and pension reform.

These findings are far from surprising, given that social democratic governments had a strong incentive to develop the social dimension of European integration - this was expected to secure electoral gains via the prominent fight against unemployment. More importantly, however, at the end of the 1990s the Left had acknowledged the importance of sustaining economic competitiveness in order to provide for a high level of welfare. There was a clear trend among EU member states towards 'active welfare' policies that attempted to integrate efficiency and redistribution concerns (Wincott 2003). This was also not surprising since under conditions of strong fiscal discipline (due to EMU) and high unemployment (large spending for benefits), the governmental budgets were under continuous pressure. The paradigm of active labour market policies therefore seemed 'the right solution' to the unemployment and sustainable public finances problem. The central assumption of this new wave of leftist economic thinking resided in the idea that welfare is a productive factor. In other words, the belief that economic efficiency and social justice were in mutual opposition was beginning to give way to the novel governance agenda of combining competitiveness and social cohesion - the 'third way' politics championed by Tony Blair in the UK.

To summarise, alongside the 'demand' for EU solutions, at the end of the 1990s there was also strong support and incentives for the 'supply' of EU level cooperation. More precisely, it was the unprecedented domination of member state governments by left-of-centre parties between 1997 and 2002 that assured the 
convergence of preferences at the 1996-7 IGC which endorsed the Employment title of the treaty of Amsterdam. This cleared the way for a 'third way' strategy aiming simultaneously at the reinforcement of both European competitiveness and of the European Social model in an age of globalisation challenges - the European Employment Strategy. The match between supply and demand for European-level cooperation marked the beginning of a quest for the appropriate institutional form such cooperation should take.

\subsection{INSTITUTIONAL CHOICE AND THE EMERGANCE OF THE OMC}

The employment policy field is characterised by a high level of heterogeneity among both the aims and policy approaches followed by the different states of the EU. Moreover, this is an area with strong distributional effects (and thus electoral implications) and its communitarisation would require a substantial reshuffling of domestic policy structures. These are the two main reasons why the EU governments would be reluctant to delegate competences to the supranational level and put in place more binding or obligatory forms of cooperation as argued by Schaefer (2006) and by Abbot and Snidal (2000). In fact, there were two camps: some member states were willing to institutionalise a binding form of cooperation by delegating substantial powers to the EU (e.g. Austria, Sweden), while for the UK, conversely, anything remotely binding would push the country away from any discussion and certainly away from the negotiation table.

According to research into member state positions in 1995 on the inclusion of an employment title in the treaties (Arnold 2002: 7), member state governments fell into one of three clusters. The variation in the preferences toward the institutional form was contingent upon the substantive policy content the new Strategy was going to embody. The first group of countries (Sweden, Austria, Belgium and Denmark) was interested in a reasonably binding coordination procedure, including recommendations and, if needed, sanctions. A second group of countries (the Netherlands, Luxembourg, Greece, Portugal and Finland) was highly interested in the inclusion of an employment title in the treaty but did not want it to go beyond the elements already included in the Essen Presidency Conclusions of 1994 (where legal sanctions were not foreseen). A final group of countries (Spain, France, the United Kingdom and Germany) was rather hostile to the introduction of a new employment title or chapter. This was based both on a belief that no added value could be achieved through it and that if any effect could be expected, it would be one which would merely raise the risk of increasing budgetary consequences for the member states (Arnold 2002: 7). In other words, there was agreement that something needed 
to be done at the EU level yet disagreement with regard to the institutional form that such cooperation should take.

It is not surprising that different member states took different positions toward the degree of bindingness of the employment coordination process. On the one hand, it was clear that the EU would initiate considerable reforms of many existing national welfare state arrangements. Such reforms would be expected to substantially shift the domestic power balance which might well translate into popularity losses and potentially even into electoral defeats for the ruling parties. On the other hand, there remains a persistent divergence of domestic institutions in Europe, which perform differently in terms of efficiency and equity. A familiar grouping based on earlier political sociology (Esping-Anderson 1990) partitions welfare systems into four regimes: a liberal regime (encompassing Anglo-Saxon countries); a conservative regime (encompassing continental countries); a Mediterranean regime ${ }^{1}$; and a social democratic regime (encompassing Nordic countries). Under such conditions of heterogeneity, many governments (rightfully) feared that a common EU policy might prove to be unable to accommodate divergent national interests. For this reason, it was to be expected that governments adopted cautious positions at the EU level and shied away from committing themselves to any binding arrangements in the field of social policy.

Under these conditions of policy diversity and divergence in the degree of commitment, the prevalent form of European-level institutionalisation - the Community method - was not a viable option. It is not well-equipped for such situations of high heterogeneity since it is, by definition, a mode of governance that brings about harmonisation. When it comes to the policy areas in question, however, harmonisation is the path to be avoided, given the structural and ideological differences among the member states. What is more, in the concrete field of social policy regulation, the Community method had essentially exhausted its credibility with the failed attempt to endorse the Social Charter as part of the Maastricht Treaty (Hantrais 2000; Pochet 2004). Finally, national governments wanted to maintain some degree of control over tools that they considered essential for their political future (Dehousse 2002: 6), especially once these were predominantly socialdemocratic governments.

Similarly to the Community method, the other institutional form available that of the intergovernmental method - also did not offer a feasible solution. The need for unanimity coupled with the binding nature of agreements achieved under the Intergovernmental method often leads to decisions that represent a very slow

1 According to Sapir (2005), the Continental and the Mediterranean models are unsustainable and must be reformed in the direction of greater efficiency (Sapir 2005: 10). 
advance from the status quo. Moreover, the intergovernmental method is also averse to situations of policy uncertainty since the parties would simply not sign an intergovernmental agreement under such conditions. The EU, however, needed concerted and effective action to be devised and implemented despite the high level of heterogeneity and policy uncertainty.

To summarise, on the one hand there was a clear inclination to use the existing European institutions, given both the spillover effects of the delegation of previous policies to the EU level and the availability of 'Brussels bureaucrats' to support the process (Stevens and Stevens 2001). On the other hand, the two typical patterns of EU policy-making - the Community and the Intergovernmental methods - did not offer feasible alternatives for establishing EU level cooperation. Agreement on Communitarisation would be difficult to achieve since it involved a high level of obligation, to which governments were reluctant to commit. Equally, the intergovernmental method would also not have been the most effective institutional configuration to adopt in pursuit of the ambitious goals, given both its tendency to produce lowest common denominator solutions (or no solutions at all) in situations of high interest heterogeneity and its low level of delegation. And yet centripetal forces (described in the first section) were pressuring member state governments to instigate some form of cooperation at the EU level. The time was ripe for a new approach.

As Renaud Dehousse observed, in situations where political choices aren't pointing in the same direction, the typical EU solution is to invent a new institutional arrangement' (Dehousse 2005: 6). The solution that gradually emerged in the second half of the 1990s and which was then embodied in the Employment title of the TEC, was to 'decouple' complex policy problems and to some extent 'mute' the most acute political controversies by devising a new mode of governance (Radaelli 2003: 20). Inspiration for it came from the coordination procedure in the field of fiscal and economic policies (the Broad Economic Policy Guidelines). Periodic monitoring of national policy performance, based on commonly endorsed guidelines and indicators, were already an established way of streamlining the diverse fiscal and economic cycles throughout the EU and of organising the process of economic convergence needed to assure the proper launch and functioning of the EMU. Given the similar initial conditions (heterogeneity of national circumstances and interests) and the analogous objectives (convergence of domestic politicians toward common goals), this instrument seemed suited for application to the contentious policy area of employment.

In global governance the resort to multilateral monitoring procedures is quite common in cases where no binding agreement can be achieved, yet some coordinated common policy objective has to be reached: "if you can't bind them watch them" (Schaefer, 2006: 199). In fact, in the employment policy field such a 
procedure already existed - the annual Jobs Study ${ }^{1}$ of the Organisation for Economic Cooperation and Development (OECD). The Employment coordination procedure of the EU was in many respects (both procedurally but also ideationally) inspired by the OECD model not the least because the membership of the two organisations largely coincided. The European Employment Strategy (EES) is however more institutionalised than the OECD and procedurally relied on more densely scheduled meetings (see Section 2.4. below and Schaefer, 2006a for comparison).

In terms of substantive agreement and ideational influence, the EES borrowed heavily from the OECD's Job Study (Dostal, 2004). The Jobs Study aimed to explain the rising unemployment levels in Europe and argued against the Keynesian paradigm. Conversely, it popularised the neo-liberal view that labour markets should be less regulated and that wage replacement payments should be scaled down (Dostal, 2004: 441-442). Interventions on the labour market were acceptable only on the supply side mainly by active labour market measures (e.g. activation of the unemployed via retraining).

In this new vein of policy thinking the Swedish model of employment policy was seen as an example to be followed by the rest of the EU (Larsson, 2001; Arnold, 2002). In essence this model combines flexible labour market norms (i.e. easy hiring and firing procedures) and high levels of social protection and security in case of not favourable market conditions, but also intensive competence and skills retraining. The Swedish model was considered a highly social yet competitive and sustainable model of socio-economic governance (Sapir, 2006). Nevertheless, not all $15 \mathrm{EU}$ member states could agree to (immediately) follow it, because of path dependency and the unpopularity of policy measures that would have ensued from applying the model directly. That is why the objectives of the EES were accepted in principle as a long-term goal, but the process was 'packaged' in soft law, and therefore no sanctions were previewed in case of poor implementation.

Keeping in mind that on substantive level the EES is actually an 'upload' to the EU level of governance of the Swedish model of employment and social policy, it is interesting to recast a glance at the group of member states that supported a binding procedure at the EU level, namely Sweden, Austria, Belgium and Denmark. These are all countries that in many respects apply similar to the Swedish model of economic governance, and an upload of it at the EU level would not have demanded high implementation costs. Conversely, for the Netherlands, Luxembourg, Greece, Portugal, Finland Spain, France, the United Kingdom and Germany the costs and the need for policy adaptation would have been substantially higher, and hence these

1 The Jobs Study was initiated in 1994 and involves annual policy recommendations to the member states. 
countries were interested in cooperation as far as it remains non-binding (Arnold, 2002).

During the Lisbon European Council of 2000 the template of the employment coordination procedure was extended to other policy areas such as social exclusion, research and innovation, information society and enterprise policy (Hodson and Maher 2001: 726) under the name of the 'Open Method of Coordination' (OMC). Currently, it is used in the literature as a generic label of various coordination procedures.

It is visible from the above that the OMC is a framework of political steering where the EU level is involved in strategic objective and target setting (creating in this way a set of non-binding regulations). It facilitates and monitors implementation and provides a forum for the discussion of policy approaches and the common evaluation of progress, which is likely to generate cross-jurisdictional policy learning. The OMC perches on the fence between the Community method on the one side and the intergovernmental method on the other. While it "coaxes member states into coordinating their national public actions within a collectively decided framework and spreads widely into different policy areas, it cuts across national-EU borders through the use of persuasion rather than coercion" (Borras and Jacobsson 2004: 187). The process is based on soft law, remains to a large extent voluntary and is thus entirely dependent on the political will of the participating member states.

In short, the EU discovered a way 'to deal with the growing pressure for European solutions under conditions of politically salient diversity' (Scharpf, 2001: 11). That's why the OMC became 'a virtual template for Community policy-making in complex, domestically sensitive areas where the diversity in interests and institutions among the member states precludes harmonization, but inaction is politically unacceptable and economically or socially harmful' (Visser 2005: 178).

What is more, the OMC was a solution which closely reflected the ideational underpinnings of the Lisbon process. Dehousse (2002: 7; 2005: 8) claims that the neo-liberal Lisbon ideology is also mirrored in the institutional choice - the vocabulary of the OMC is full of references to the market: 'management by objectives', 'self-evaluation', 'peer control' (in the same vein of thought see Goetschy 2001). Finally, it also addresses the problem of policy uncertainty by installing a deliberative and iterative routine which allows for revision in case of new information.

Thus, the method of open coordination emerged as the appropriate institutional solution since firstly it did not involve sovereignty losses and secondly, because it accommodated heterogeneity by establishing a policy-making process of low obligation and moderate delegation. It was presented as a third way between 'pure integration' on the one hand and the logic of genuine intergovernmental 
cooperation on the other (Dehousse 2002: 4; Portuguese Presidency 2000: 4). It might seem strange that social democratic parties should opt for this third path of institutionalisation and shy away from the communitarisation of social policy, even though they dominated the EU agenda and had an unparalleled opportunity to do so. Having a strong majority (between 1997 and 2002) in the European Council, why did these governments prefer to put in place such a 'harmless' mode of governance such as the OMC instead of establishing supranational institutions? According to Manow, Schaefer and Zorn (2004: 29) two factors explain this outcome. Firstly, the Left had become far less interventionist - and instead more 'Blairist' - than in the past. Secondly, the enthusiasm for further integration had vanished in the wake of Maastricht (also confirmed by the data of Arnold and Cameron 2001). As a result, social democratic governments failed to build supranational institutions that could effectively commit their successors (Manow, Schaefer and Zorn 2004: 29) and instead opted for the new governance formula of open policy coordination.

\subsection{THE VARIOUS OMC PROCESSES AND THEIR FEATURES}

At the Lisbon European Council in 2000, the EU member states coined the term 'Open Method of Coordination' (OMC) and launched it in the policy areas of social inclusion, research and innovation, and information society. It was further extended by the Stockholm European Council of 2001 to the areas of educational and vocational training and pensions (European Council 2001a).

From the definition of the European Council (see Section 1.2.), different frameworks of policy coordination have developed in practice depending on the policy area in which the method has been applied (Borras and Jacobsson 2004; de la Porte and Pochet 2003; Radaelli 2003). This led the Belgian Minister for Social Affairs and Pensions, Frank Vandenbroucke, to claim that 'open co-ordination is a kind of a cookbook that contains various recipes, lighter and heavier ones' (Vandenbroucke 2001: 30). 
Table 2.3-1. Defining properties of three OMC processes

\begin{tabular}{|c|c|c|c|}
\hline & Employment & Pension reform & Research \\
\hline $\begin{array}{l}\text { Established by } \\
\text { and operational } \\
\text { since }\end{array}$ & $\begin{array}{c}\text { Art } 128 \text { TEC; since } \\
1998\end{array}$ & $\begin{array}{l}\text { Stockholm European } \\
\text { Council of March } \\
\text { 2001; since July } 2001\end{array}$ & $\begin{array}{l}\text { Lisbon European } \\
\text { Council of March } \\
\text { 2000; since } 2003\end{array}$ \\
\hline $\begin{array}{l}\text { Type of regu- } \\
\text { latory } \\
\text { instrument }\end{array}$ & $\begin{array}{c}\text { Annual employment } \\
\text { guidelines }\end{array}$ & $\begin{array}{l}\text { Broad common } \\
\text { objectives }\end{array}$ & $\begin{array}{l}\text { Action Plan } \\
\text { 'Investing in } \\
\text { Research' }\end{array}$ \\
\hline $\begin{array}{l}\text { Evaluation } \\
\text { instrument }\end{array}$ & $\begin{array}{l}\text { Annual National } \\
\text { Action Plans }\end{array}$ & $\begin{array}{c}\text { Every three to four } \\
\text { years national strategy } \\
\text { reports }\end{array}$ & $\begin{array}{c}\text { Annual report of } \\
\text { the CREST }\end{array}$ \\
\hline $\begin{array}{l}\text { Sanction } \\
\text { mechanism }\end{array}$ & $\begin{array}{l}\text { Recommendations; } \\
\text { peer pressure; } \\
\text { benchmarking; } \\
\text { reports }\end{array}$ & Peer pressure & $\begin{array}{l}\text { Peer pressure; } \\
\text { benchmarking } \\
\text { reports } \\
\text { (Scoreboards) }\end{array}$ \\
\hline $\begin{array}{l}\text { Operational } \\
\text { interface }\end{array}$ & $\begin{array}{l}\text { European } \\
\text { Commission }\end{array}$ & $\begin{array}{l}\text { European } \\
\text { Commission }\end{array}$ & CREST \\
\hline $\begin{array}{l}\text { Preparatory } \\
\text { committee }\end{array}$ & $\begin{array}{c}\text { Employment } \\
\text { Committee (EMCO) }\end{array}$ & $\begin{array}{c}\text { Social Protection } \\
\text { Committee and } \\
\text { Economic Policy } \\
\text { Committee (SPC \& } \\
\text { EPC) }\end{array}$ & $\begin{array}{l}\text { Scientific and } \\
\text { Technical } \\
\text { Committee } \\
\text { (CREST) }\end{array}$ \\
\hline $\begin{array}{l}\text { Participation of } \\
\text { NGO's }\end{array}$ & $\begin{array}{l}\text { Replicates national } \\
\text { patterns }\end{array}$ & $\begin{array}{l}\text { Replicates national } \\
\text { patterns }\end{array}$ & $\begin{array}{l}\text { Appointed experts } \\
\text { in the OMC } \\
\text { subgroups }\end{array}$ \\
\hline
\end{tabular}

Source: Radulova 2007, based on Abbott, Keohane, Moravcsik and Snidal 2000

Table 2.3-1 provides comparative data of three policy areas to demonstrate this variation. As illustrated there are considerable differences in the OMC modalities and procedures. For example, the employment OMC makes use of annual guidelines, National Action Plans (NAPs) and recommendations to individual member state governments. By contrast, the national strategy reports in the area of pension reform are only due every three to four years. There are no guidelines but instead 'broad 
common objectives'. Recommendations to individual member states are not foreseen. This makes the Pensions OMC process much 'lighter' in terms of the requirements of member state compliance. In the case of the Research OMC, where not even specific guidelines or broad objectives have been endorsed by the Council, member states are merely required to adhere in their policies to the action lines identified at the EU level. The first Research OMC cycle (concluded in October 2004) was more of an information gathering exercise than a regulatory process (interview 23).

The variation between the different OMC processes (Employment, Social Exclusion, Research, etc.) could be conceptualised in terms of the degree of legalization they entail. Each OMC process can be regarded as an international agreement. International agreements are characterised by certain level of bindingness, degree of delegation of competences to international institutions, specific method of evaluation of implementation, mechanism that monitors whether the declared commitments are fulfilled, enforcement mechanisms, etc. In the International Relations literature a concept has been developed that allegedly encompasses all these features and allows for comparison between the different cases of international cooperation i.e. between the different international agreements. The concept of legalisation is defined by Abbott, Keohane, Moravcsik and Snidal (2000: 401) as a particular form of institutionalisation characterised by three components: obligation, precision and delegation. The variation in the three components leads to a variation in the degree of legalisation of the international agreement. If we apply the measure of legalisation to the different OMC processes adopted by the EU, we can observe coordination mechanisms of a 'heavily legalised' nature (where all three elements are strongly present e.g. employment policy), to 'lighter' ones (where the levels of obligation, precision and delegation are much more relaxed e.g. research policy). Below the three dimensions are discussed in greater detail.

Obligation means that states or other actors are bound by a rule or commitment or by a set of rules or commitments. Specifically, it means that they are "legally-bound by a rule or commitment in the sense that their behaviour thereunder is subject to scrutiny under the general rules, procedures and discourse of international law and often of domestic law as well" (Abbott, Keohane, Moravcsik and Snidal 2000: 401). Given that we are discussing international public law, in practical terms this category demands a measure of "the subjective acceptance by states of a particular rule as a legal rule or not, i.e. as binding or non-binding as a matter of international law" (Abbott, Keohane, Moravcsik and Snidal 2000: 409, footnote 14). For the purposes of comparison between OMC processes, this subjective acceptance is operationalised by differentiating between coordination procedures that have been codified in the treaties and coordination procedures that are based on a European Council mandate. The rationale of distinction here is that if 
member states wished to demonstrate that they felt legally-bound to coordinate their policies, they would have enshrined this in the primary law of the Union.

Precision "narrows the scope for reasonable interpretation" (Abbott, Keohane, Moravcsik and Snidal 2000: 412) and restrains opportunistic behaviour. A precise rule specifies clearly and unambiguously what is expected of a state or other actor in a particular set of circumstances (in terms of both the intended objective and the means of achieving it). In the context of OMC, precision will be deemed high when both the long-term objective and the means to achieve it are specified in the OMC guidelines. For example, the Employment $\mathrm{OMC}$ aims at 60 per cent female employment by 2010 and specifies moreover that one manner to achieve this objective is through provision of available and affordable childcare (i.e. a specific policy solution is put forward and given priority over others such as parental leave or other leave instruments).

Precision could be deemed low when a specific objective is set, yet the EU level does not foster a concrete policy solution. In that case member states rely on their own discretion about how the objective should be achieved. In the case of research, for example, member states set the objective of raising investment in $R \& D$ to 3 per cent of GDP (of which two-thirds should be financed by the private sector). However, no particular policy solution is favoured and nothing more than 'fields of work' are identified at the supranational level, e.g. the encouragement of researchintensive small and medium sized enterprises (SMEs) should be fostered and research-conducive fiscal measures should be designed, etc. Hence, when member states have both freedom of interpretation and discretion, precision will therefore be considered low.

Delegation is "the extent to which states and other actors entrust authority to designated third parties - including courts, arbitrators and administrative organisations - to implement agreements" (Abbott, Keohane, Moravcsik and Snidal 2000: 415). Following Abbott and Snidal, a distinction should be made between 'managerial' delegation, i.e. the power to apply and elaborate agreed rules, and 'enforcement' delegation, i.e. the power to evaluate, judge and sanction performance (Abbott and Snidal 2000: 430).

The level of 'managerial' delegation of an OMC mechanism could be considered high if the member states have endowed the Commission with the power to take care of the procedural routine of an $\mathrm{OMC}$ iteration, i.e. to issue guidance notes, to monitor the process of implementation and to collect and summarise data about performance; in short, to act as a mediator and operational interface for the OMC mechanisms. Conversely, if the principles (the member states) have not endowed an agent (such as the Commission) with managerial powers but have rather retained them themselves (e.g. empowering an intergovernmental body such as the 
Scientific and Technical Research Committee (CREST) committee instead), the managerial delegation will be considered low.

Enforcement delegation in the case of an OMC mechanism is high when a third party (e.g. the Commission) has the power to propose recommendations to countries that underperform or are deemed to be on the wrong track towards the commonly desired outcome/objective.

Table 2.3-2. Properties of OMC

\begin{tabular}{|c|c|c|}
\hline Category & Indicator & Measure \\
\hline \multirow[t]{2}{*}{ Obligation } & Treaty based & High \\
\hline & $\begin{array}{l}\text { Mandated by the } \\
\text { European Union }\end{array}$ & Low \\
\hline \multirow[t]{2}{*}{ Precision } & $\begin{array}{l}\text { EU sets both: policy } \\
\text { objectives and policy } \\
\text { approaches }\end{array}$ & High \\
\hline & $\begin{array}{c}\text { EU sets only policy } \\
\text { objectives and/or targets }\end{array}$ & Low \\
\hline \multirow[t]{2}{*}{ Managerial delegation } & $\begin{array}{c}\text { Supranational operational } \\
\text { interface }\end{array}$ & High \\
\hline & $\begin{array}{l}\text { Intergovernmental } \\
\text { operational interface }\end{array}$ & Low \\
\hline \multirow[t]{2}{*}{ Enforcement delegation } & $\begin{array}{l}\text { Possibility to issue } \\
\text { recommendations }\end{array}$ & High \\
\hline & $\begin{array}{l}\text { Only peer pressure } \\
\text { and/or comparative tables }\end{array}$ & Low \\
\hline
\end{tabular}

Source: Radulova 2007, based on Abbott, Keohane, Moravcsik and Snidal 2000

The application of the analytical framework of Abbott, Keohane, Moravcsik and Snidal (2000) with the respective interpretation and coding for the specificities of the OMC procedure presented above yields Table 2.3-2. 
When the properties of the OMC processes of Employment and Research from Table 2.3-1 are translated into the modes of coordination procedures presented in Table 2.3-2, the following Table 2.3-3 emerges:

Table 2.3-3. Types of OMC processes

\begin{tabular}{|c|c|c|}
\hline & Employment & Research \\
\hline \hline Obligation & Treaty based & High \\
\hline Managerial delegation & $\begin{array}{c}\text { EU sets both: policy } \\
\text { objectives and policy } \\
\text { approaches }\end{array}$ & High \\
\hline Enforcement delegation & $\begin{array}{c}\text { Possibility to issue } \\
\text { recommendations }\end{array}$ & High \\
\hline interface & High \\
\hline Type of OMC procedure & Heavy & Light \\
\hline
\end{tabular}

Source: Radulova 2007, based on Abbott, Keohane, Moravcsik and Snidal 2000

The table confirms the metaphor that the OMC is a cookbook of lighter and heavier recipes. The Open Method of Coordination can indeed be seen as a variation on a theme "with a convergence of labels and a diversity in procedural set-ups" (Gornitzka 2005: 2). It is beyond the scope of this chapter to establish why the method acquired different properties when applied to different policy areas (but see de Ruiter, 2008). The aim of this section was to present the variation between the OMC mechanisms via the concept of legalization thus demonstrating that in the main field of examination in this study - employment policy the OMC has taken one of its 'heaviest' forms. 


\subsection{THE OMC IN EMPLOYMENT POLICY: PROCESS AND ACTORS}

The Employment OMC process aims to raise the overall EU employment rate through encouraging the adoption of active labour market policy measures. The main implementation tool is the so-called European Employment Strategy (EES). The EES, also known as the 'Luxembourg Process', was initiated in 1997 and plays the central role in coordinating EU policies designed to create 'more and better jobs'. It has been operational since 1998, when the first European Employment guidelines were endorsed by the Council of Ministers. As will be revealed below, it has a highly developed procedural routine (art. 128 TEC or art. 148 under TFEU).

The main objective of the EES is the activation of the European labour force and the reform of member state labour market policies through a package of guidelines endorsed at the supranational level. The common guidelines provide direction for the national policy-making efforts. How these guidelines are approved and what other processes and actors are involved in the Employment OMC will be discussed in the following sections.

\section{Agenda-setting and policy formulation}

The endorsement of the Employment policy guidelines could be regarded as the beginning of the annual coordination cycle. They are set at the EU level, based on a proposal from the Commission and are discussed by representatives of the member states in the Employment Committee (EMCO). The European Parliament is then consulted, but the final decision rests with the Council of Ministers acting under QMV (art. 128 TEC or art. 148 of TFEU).

DG Employment and Social Affairs drafts the guidelines at the beginning of the year. Subsequently, they are subject to interservice consultation i.e. other Commission services (e.g. DG Education and Culture and especially DG Economic and Financial Affairs) discuss them as well and suggest amendments. Eventually the guidelines are adopted by the college of Commissioners.

Once the Commission has adopted the guidelines, they are passed on to the Council of Ministers, the Committee of Regions, the Economic and Social Committee, and to the European Parliament. The Employment guidelines are discussed in-depth in the Employment Committee (EMCO) during 2 or 3 meetings. The EMCO is an official preparatory body of the Council i.e. it contributes to the preparation of Council proceedings (according to the List of Preparatory bodies of the Council). Established by TEC (art. 130), it formulates opinions at request of the 
Commission or the Council. It is composed by representatives of Member states, it is chaired by a MS, but not the same as the one holding the Presidency - it has its own chair, elected for 2 years. Its Secretariat is provided by the Commission. There certainly is close contact between the chair of EMCO and the Commission during the drafting stage (interview 26). As identified by Jacobsson and Vifell (2003), it is important for the Commission to have an indication of EMCO's stance in advance. Indeed, most of the changes to the draft come from the EMCO discussion (interviews 19 and 26). Then the draft also formally passes through COREPER but there is typically no discussion there. On the Council's agenda the guidelines are usually an A point i.e. are not discussed by the ministers but only rubber-stamped (interview 19).

The stages of agenda-setting and policy formulation could be schematically illustrated as follows (see Figure 2.4-1):

Figure 2.4-1 Agenda-setting and policy formulation in the European Employment Strategy

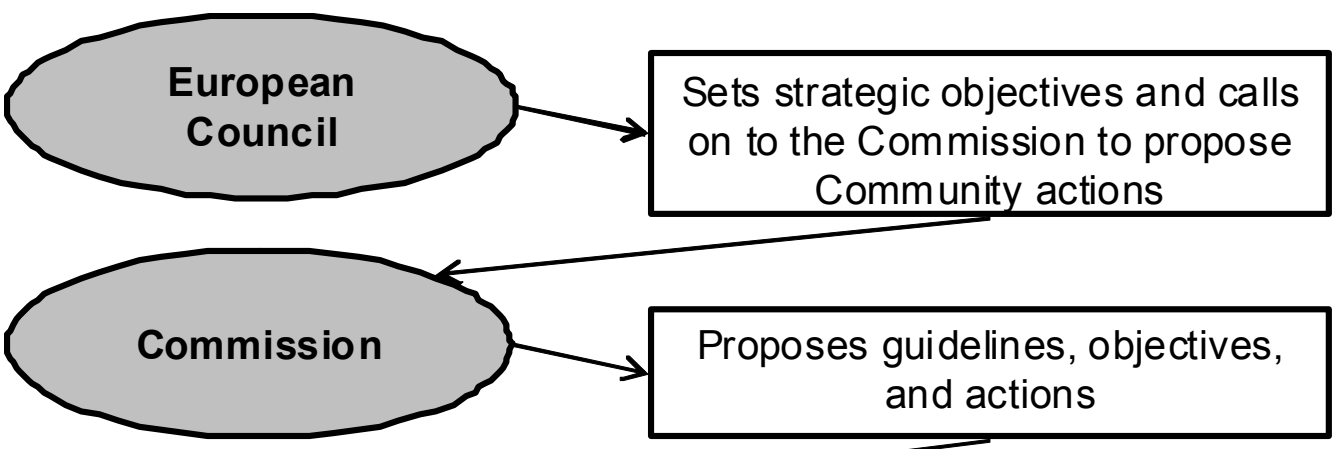

Intergovernmental preparatory committee (EMCO)
Discusses and negotiates (problem-solving) the guidelines, objectives, and actions objectives, and actions 


\section{Implementation}

Implementation is to be achieved through national implementation measures prepared by each member state. These are supposed to accommodate the European guidelines and to provide a translation of the EU targets into the different national contexts. Each member state's implementation has to adjust the national-level strategies according to the European-wide policy objectives (if needed).

Parallel to the efforts taking place in the member states, the Commission organises 'good practice' exercises and compiles benchmarking reports in order to enhance mutual learning. The primary function of identifying a 'good practice' is to distil lessons from the success achieved by particular policy-makers (interview 26). The function of the benchmarking reports is to exercise peer pressure on states that are not yet achieving - or not conforming to - the standards set by the EU. The objective is to establish a framework of common policy discourse where the potential benefits of certain 'good practices' and the benchmarking results are analysed by the member states and lessons are drawn. The idea is that civil servants can pool, study and comparatively evaluate the experiences of national and local experiments and, in the light of the lessons learned, improve knowledge and efficiency (Overdevest 2002: 18). Moreover, this is a 'soft' method of inducing the non-complying member states to revise their actions.

The so-called "Mutual Learning Programme" is the umbrella term for the various 'good practice' activities organized by the Commission. The Programme consists of thematic reviews and of peer reviews. The former are focused on key challenges or policy priorities relevant for labour market policy-makers (e.g. flexicurity, lifelong learning, active aging). The latter review specific policies and measures of a concrete member state. The member states (in co-ordination with EMCO) submit proposals of good practice and if selected host the peer review and present the selected good practice to the interested peer member states. The Commission also attends. Its role is essentially the one of facilitator i.e. it is not there to assess in any way the practice that is being reviewed or to judge whether it is transferable (interview 26). Given that the participation is voluntary, the peer review sessions are only modestly attended ${ }^{1}$. According to a Commission official, the limiting factor is that it is usually a very specific component of the Member state's policy mix that is reviewed (interview 26). And it is often not really transferable as it is

\footnotetext{
${ }^{1}$ See http://www.mutual-learning-employment.net/peer-reviews/ (accessed on 16 May 2010).
} 
so dependent on the particular labour market structure of the country. Nevertheless, the Mutual Learning Programme is considered as an important part of the OMC process by Commission officials because of the positive encouragement of member states to learn from each other (interview 26). In this context, it is important to note the particular definition of learning applied in the Commission "obtaining info that is potentially useful for national employment policies" (interviews 20, 23 and 26). Such a definition is substantially different from what is typically denoted by learning in academic literature, namely apart from the information component mentioned above, typically policy learning involves certain adjustment of behaviour as well, which however does not seem to be in the minds of the practitioners.

The implementation stage ends with the compilation of the National Progress Reports (NPRs). An important actor in this process are the so-called 'country desks'. A country desk is a Commission service unit under DG EMPL, which is mainly responsible for administering the way three to four member states spend the European Social Fund allocations. Within the Employment coordination procedure the country desks act as a link between the Commission and the national administrations - the day-to-day management of the Employment policy coordination. At the beginning of the annual cycle, the member states contact the country desks in order to clarify what is meant here or there in the annual guidelines, or about what the Commission expects in this or that regard, etc. (interview 26).

Later on, when the member states start drafting the NPRs, the country desks provide guidance about the way in which the member state reports its progress with regard to the different Employment guidelines (interview 26). Hence, the draft of NRPs would typically be the result of quite close contacts between the country desks and the national administrations. The stage of implementation is schematically illustrated on Figure 2.4-2. 
Figure 2.4-2 Implementation in the European Employment Strategy

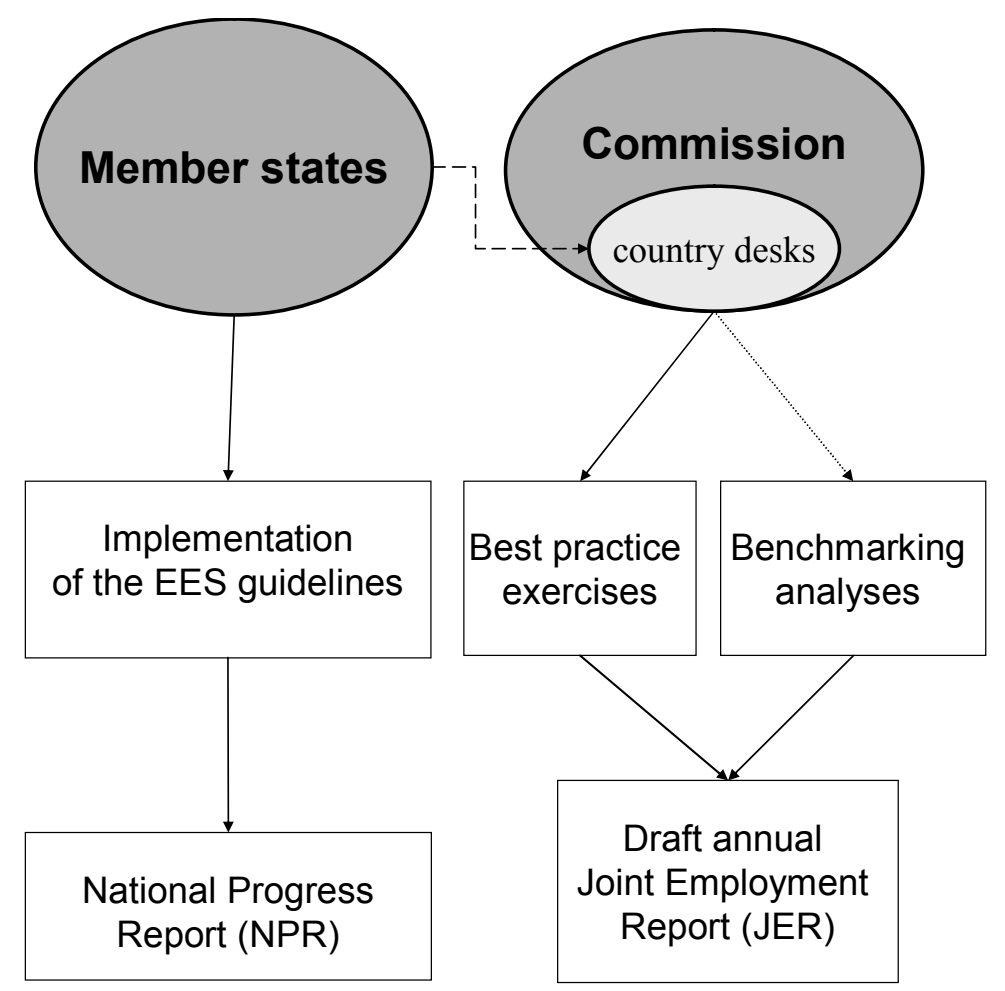

\section{Policy review}

Each autumn the National Action Plans (NAPs) or National Reform Programmes (NRPs) - as renamed after 2005 - are due. These reports outline the employment policy related actions that have taken place during the last year in each member state and report about the individual progress toward the EU guidelines. The plans demonstrate the different approaches and alternative ways employed by each member state in achieving the common aims. As such, they are sources for the evaluation of good practice and the identification of effective actions within the diverse national contexts.

The Commission reviews them, and more or less simultaneously they are also reviewed by the Employment Committee (EMCO). The peer review in EMCO follows the format of the Cambridge review process, where each member state presents and there are 2 countries that act as key examiners. The other member states attend the presentations and participate in the discussion. Since 1 May 2004 when the number of member states reached 25 , this system of full mutual review became no 
longer feasible. Thus, since the autumn of 2004 the member states are divided into groups during the review i.e. a country no longer gets to hear all NPRs (interview 26). In this format a country's policy makers see only 5 maximum 6 peer presentations in detail. This has been one of the consequences of the Eastern enlargement of the EU on the procedural aspects of the OMC process.

Parallel to EMCO's Cambridge review, the Commission studies the NPRs indepth and drafts towards the end of the year its proposal for the Joint Employment Report (JER). The annual JER aims to report to the European Council of the following year (the so-called Spring Council) about the employment situation in the Community and on the implementation of the guidelines for employment. JER contains analysis of the employment policies of the EU for the past year, the socalled "country fiches" drafted by the DG EMPL country desks, and recommendations toward individual member states. According to article 128 TEC (art. 148 TFEU), the JER is to be jointly adopted by the Commission and the Council. A country fiche contains an examination of the member state policy of the past year and also a progress analysis (guideline by guideline). The country fiches are the main analytical ground for the formulation of the annual country recommendations - the sole sanctioning mechanism that the OMC involves.

Before the Commission formulates the recommendations, however, the socalled bilateral meetings between Commission officials and a delegation of the member states take place. These meetings aim to discuss the draft country fiches prepared by the Commission's country desks. The bilaterals concentrate on two main topics: validity of the data and the interpretation of it (interview 26). The member states are given the opportunity to verify whether everything in the assembled country fiche is acceptable for them. Moreover, the bilaterals provide the opportunity for member states to get an orientation about the upcoming Commission recommendations, and hence also to 'negotiate' a more favourable Commission opinion on their progress (interview 15). Naturally, the member states do not like to receive recommendations, which display them in a bad light - they are not worried so much about the opinion of the Commission as such, but more so that their domestic press and political opponents are going to use a potential negative opinion (interview 26). Given that the recommendations may produce substantial domestic resonance, in the past the aim was to receive as less recommendations as possible - member states literally counted them up (interview 26). More recently, the attitude has changed because the countries realised that receiving a recommendation does not necessarily mean that the country is not doing well, but that it is deemed by the Commission that it can do better. Interestingly, a recommendation is sometimes even welcome by the national authorities (in particular by the Ministries of Employment), because a tough recommendation coming from the EU may unlock some domestic opportunities to claim more resources. Hence, on the one hand, the member states 
are quite attentive toward the recommendations and toward the benchmarking reports - they do not seem willing to find themselves at the bottom of the Commission tables. On the other hand, the policy-makers learned how to use the Commission recommendations to their advantage either by reflecting on the 'objective' third party advice, or even more pragmatically: by using the recommendation to enlarge their policy budgets.

Once the bilateral meetings have taken place, DG EMPL prepares the draftJER, which - as stated already - includes country-by-country analysis and policy recommendations. Similarly to the Employment guidelines, the draft is then subject to interservice consultation (i.e. other DGs may comment). Typically it is not altered much during this process (interview 26). Most interested are DG Education, DG Enterprise and DG ECOFIN. Occasionally also DG Taxation would be interested (since the Commission often requests the taxation on lower paid workers to be cut). The last very important instance before the college of Commissioners is the weekly meeting of the chefs de cabinet. As already established in the academic literature at this stage the draft may be extensively revised (Hix, 1999: 35; Nugent, 2003: 123).

When the draft JER is adopted by the Commission at the beginning of each year, it is then discussed in EMCO (the main preparatory body within the Council hierarchy with regard to the Employment OMC) and adopted by the Council in early March before the Spring Council, which typically takes place in the third week of March each year.

On the basis of the identified priorities by the Spring European summit new annual guidelines may be proposed by the Commission, or the guidelines of the previous year are readopted by the Council. Hereby the next OMC iteration is initiated.

The stage of policy review could be schematically illustrated as follows (see Figure 2.4-3): 
Figure 2.4-3 Policy Review in the European Employment Strategy

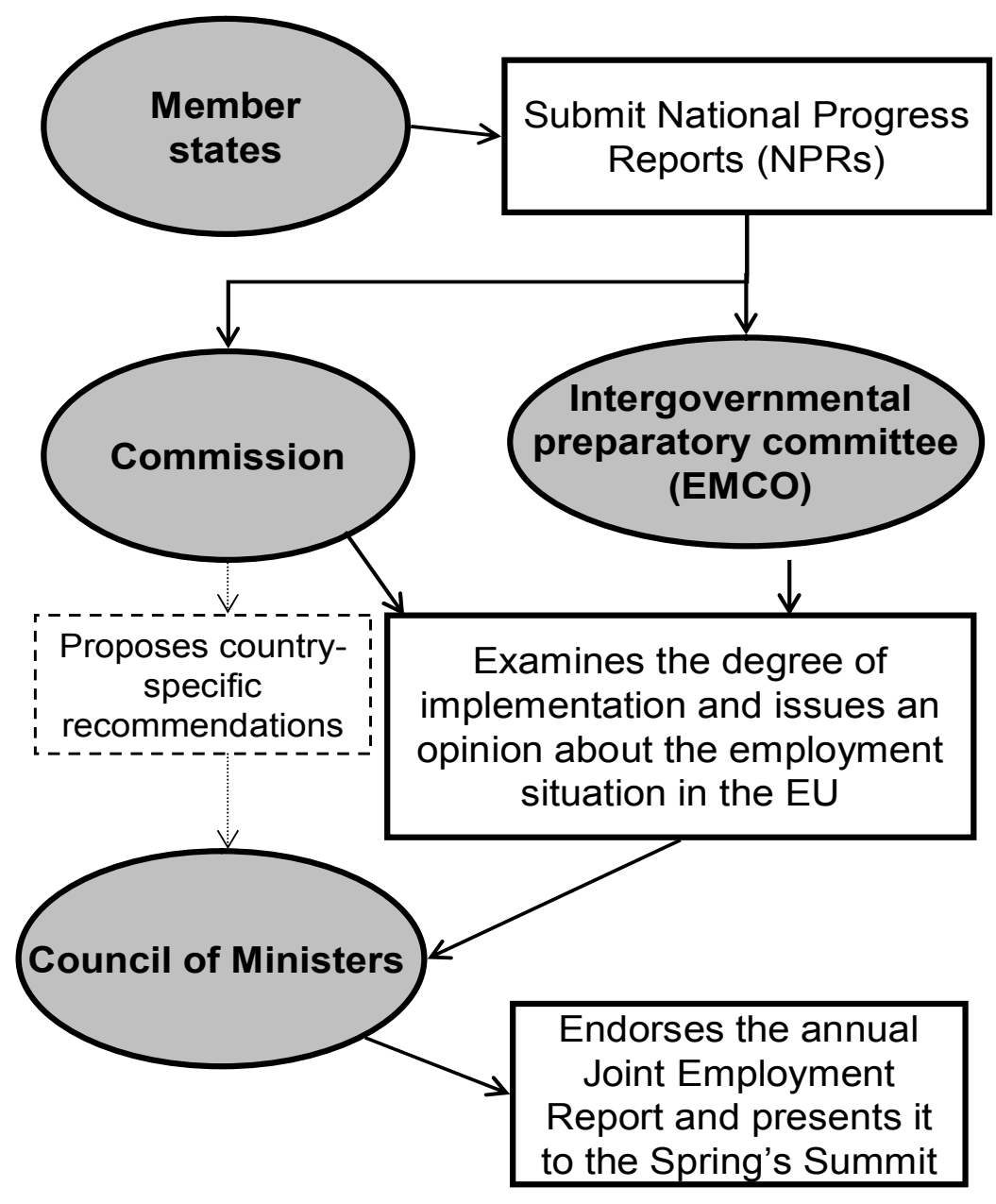

\subsection{THE OMC: A PLATFORM FOR POLICY LEARNING?}

Next to the low degree of obligation (discussed in Section 2.3.), learning - the non-coercive change of normative and cognitive policy views - is the second OMC feature most discussed (Borras and Jabsson, 2004; Radaelli, 2003) and even celebrated (Telo, 2002; Rodrigues, 2001; 2002) by academic analysts. Indeed, the potential for (social) learning is perhaps the most interesting feature of the OMC (Hartlapp and 
Falkner, 2009), and arguably the main reason this steering mechanism based on soft law to be called, a "new mode of EU governance" (as argued in the Introduction).

Learning can be defined in various ways (for an overview see Hartlapp, 2009) but all definitions revolve around two events: the enlargement of the available information for the actors and the adjustment of the policy (objectives, programmes, techniques, etc.) ${ }^{1}$. The available information can be enlarged in three ways (Hartlapp, 2009: 3): through own experience, via knowledge about effects of previous decisions and actions of others, and through deliberative discussion with peers. Respectively, three different types of learning could be distinguished. The first (and most common) type of learning is the reflexion on own experience i.e. based on self-observation and self-actualization. The second type of policy learning is learning from others - when governments based on the knowledge of the other countries' policy decisions and results adjust the domestic policies ${ }^{2}$. The last type of learning also involves the presence of others but the main difference is that countries learn together, not from each other. This type of learning is associated with experimentation and deliberative techniques of decision-making (Sabel and Zeitlin, 2008), and assumes that through many interactions and exchange of experimental results the participating actors will reach a state of agreement while during the process they will also socialise in the commonly developed paradigm and thus will alter their initial policy ideas, strategies and preferences (Hartlapp, 2009: 3).

The expectation that the act of deliberation will induce behavioural change and learning mirrors a core assumption of the deliberative school: that social communication can bring about changes in the core properties of actors (Checkel, 2001: 4). Therefore the stimulation of cross-jurisdictional learning is an important criterion for the assessment of the deliberative nature of a decision-making process.

The organization of the policy cycle of the European Employment Strategy (EES) presented in Section 2.4. reveals that the Employment OMC has the potential to instigate all the three different forms of learning discussed above. The annual National Progress Reports (NPRs) reveal the domestic policy achievements (and potential bottlenecks) in the implementation of the annual Guidelines. This is how they encourage the first type of learning - based on reflections upon own experience. Furthermore, the Mutual Learning Programme organized by the Commission and involving the discussion of good practices and comparative studies of the countries' performance clearly aims to trigger the second type of learning - learning form others (or lesson-drawing). Finally, the Cambridge Review in EMCO and generally the

\footnotetext{
${ }^{1}$ For example a prominent definition in public policy analysis conceptualizes learning as: "a deliberate attempt to adjust the goals or techniques of policy in response to past experience and new information" (Hall, 1993: 278).

2 This type of learning has been conceptualized as lesson-drawing by Richard Rose (1993).
} 
continuous discussions among national experts (e.g. about the annual draft employment guidelines or the draft Joint Employment Report in EMCO) might promote the third type of learning - learning with others.

To summarise, the OMC is a mode of EU governance that installs various institutional and procedural elements that are expected to generate policy learning. The empirical stage of the study will examine to what extent this indeed proved to be the case in the Netherlands (see chapter 6). 
3. Chapter

\section{CHILDCARE PROVISION AS A PUBLIC POLICY CONCERN AND CHILDCARE \\ RELATED POLICY FRAMES IN THE MEMBER STATES AND AT THE EU LEVEL}

This chapter presents the policy area chosen for closer examination in this study, namely childcare provision. The origins of the policy as a public concern are outlined, as well as the ways in which the different European welfare states have organised the formal provision of childcare. The second part of the chapter presents the six childcare-related policy frames examined in this study. The analysis surveys the six 'problems' of contemporary policy-making which are allegedly 'solved' by formal childcare. This review will prepare the ground for the application of the policy frame method in the ensuing chapters 4,5 , and 6 .

\subsection{CHILDCARE: AN ISSUE OF PRIVATE OR OF PUBLIC POLICY?}

Care for dependants, and childcare in particular, resides at the core of the gender relations in society. After the end of the Second World War the predominant 'gender contract' in West European societies displayed the characteristics of the socalled male-breadwinner model. According to the arrangements of this model, the care for the children is considered a female job that takes place within the family. The families, in turn, rely for income on the male breadwinner, who engages in paid work and earns a 'family wage' (Fraser, 1994: 591). Conversely, the female - the wife, the 
daughter or the sister - is active in the private realm of the family home, and is primarily occupied with the (unpaid) work of care for the children, the elderly, the sick, etc. The public realm (i.e. the one of visible, paid and recognised work) was dominated by men, the private - unpaid and hardly praised - by women.

This clear-cut gendered division of labour began to progressively erode since the 1970s. The boundaries between the private and the public spheres were blurred due to emancipation, modern life-style choices and feminist ideology. As Selma Sevenhuijsen points out there has been a relocation of care from women to men, from inside to the outside, from the private to the public (Sevenhuijsen, 2003: 15-16). Indeed, for the last 35 years the demands for the redistribution - or more equal distribution - of house- and care work between men and women, on the one hand, and for the upgrading of the status of care work and the opening of the labour market to women, on the other hand (Lutz, 2007: 187), have been rather successful in the countries of the European Union. This has to do with a number of socioeconomic transformations that take place in contemporary postindustrialized countries. These are summarized by Catherine Hakim (2000: 7; 43-83) under the heading "New Scenario". She argues that five separate social changes which started in the late 20th century are producing a qualitatively different new scenario of options and opportunities for women at the dawn of the new millennium. These are:

1. The contraceptive revolution i.e. the divorce between sexual activity and reproduction

2. The equal opportunities revolution, which ensured that for the first time in history women had an equal access to all positions, occupations and careers in the labour market.

3. The expansion of white-collar occupations, which are far more attractive to women than most blue-collar occupations.

4. The creation of jobs for secondary earners, i.e. for people who do not want to give priority to paid work at the expense of other life interests.

5. The increasing importance of attitudes, values, and personal preferences in the lifestyle choices of affluent modern societies (Hakim, 2000: 7).

The "New Scenario" facilitated female economic independence and reshuffled the power balance between the sexes. From the 1970s onwards, it was not exclusively the family father who extracted an income from the labour market (Bonoli, 2007: 495). On a different scale and with different magnitude in the particular countries, European women embraced a career different from the so-called 'marriage career' (Hakim, 2000) i.e. the one of housewives, home-makers and child-rearers. One of the main issues that arose consequently was the question of how to continue to provide 
and organise (child)care under the changed socio-economic circumstances. The issue of care irrevocably entered the public realm, climbed to the political agenda in most member states of the European Union, and everywhere public authorities accordingly developed "measures to reconcile work and private life". The typical policy instruments included in the 'reconciliation packages' were (Gerhard et al., 2005: 1):

- Regulation of part-time work, maternity and parental leave (time instruments)

- Provision and management of childcare facilities (services instruments)

- Taxation system, provision of allowances and social transfers (money instruments)

Naturally, different states have devised different policy mixes from these policy instruments, and have thus placed greater emphasis at one or another mode to reconcile private life and work. These choices were dependent on cultural characteristics and previous policy decisions, and were therefore very much influenced by the welfare regime type. Without a doubt, the welfare state as a social institution plays a significant role (by its impact on resource levels) in reproducing or altering traditional family structures and gender relations, on the division of roles, and on power relations between women and men (Korpi, 2000; Orloff, 1996).

\subsection{THE WELFARE STATE AS PROVIDER OF CHILDCARE AND WELFARE REGIME TYPES}

The manner in which the provision of social services in general and of childcare facilities in particular is organised in a country depends on "the distinctive arrangement between the market, state, society and family by which resources produced in the private economy are channelled into social institutions that fail to secure their means of income themselves" i.e. it depends on the welfare state regime type (van Kersbergen, 1995: 190). Without a doubt, the welfare state as a social institution plays a significant role in reproducing or altering traditional family structures and consequently in altering the patterns of female employment by its impact on resource levels, on the division of roles, and on power relations between women and men (Korpi, 2000; Orloff, 1996).

It has been firmly established in the literature that different European states have organized the above mentioned arrangements differently as they have opted for a particular approach to social welfare. The most influential typology of the welfare 
states to date is suggested by Gosta Esping-Andersen (1990). He outlines three main welfare regime types, namely the Corporatist-Conservative (also known as Continental), the Social-Democratic (also known as Nordic) and the Liberal (also known as Anglo-Saxon) models according to the key variables decommodification ${ }^{1}$ and stratification ${ }^{2}$. Below the three models are briefly discussed from the perspective of gender and organisation of childcare.

Liberal regimes are the least prone to decommodification with the state providing only a 'safety net' for the ones unable to take part in the labour market. As a matter of principle the market is the preferred policy solution, state intervention is minimised and social risks are individualised. Assistance is means-tested and universal transfers are modest. Notable features of this regime are sustained social inequalities and great earning differentials (Esping-Andersen, 1996: 16).

True to the principle of non-intervention, the state provides only modest level of childcare services/ facilities. The principle manner in the organization of childcare is through reliance on the market - both on the demand (parental fees) and supply side (commercial or employer provision). As far as the state is involved it takes part through tax deductions or credits. This regime type allows for gender equality and postindustrial job growth at the expense of deepening class and racial inequality. This is evident from the most typical form of childcare - 'nannies' for the rich and better off families (Mahon, 2002: 7).

Social-democratic regimes rest upon the fundamental principles of egalitarianism and universalism. The social-democratic political parties, that were the dominant force behind social reform, pursued a welfare state that would promote an equality of the highest standards, not an equality of minimal needs that was pursued elsewhere (Esping-Andersen, 1990: 27). In the Nordic countries the service provision is comprehensive, and benefits are generous and equal to all. Market dependency is virtually abolished, thus rendering this cluster of welfare states the most decommodified and the least stratified.

This regime type is also very supportive of defamilisation measures, however, and in contrast to the Liberal regime, the principle provider is the state, and not the market. Publicly provided and financed childcare constitutes an important pillar of this regime. In contrast to the corporatist-subsidiarity model (see below), the principle is not to wait until the family's capacity to aid is exhausted, but to preemptively socialize the costs of family-hood (Esping-Andersen, 1990: 28). The Social-

1 "Decommodification occurs when a service is rendered as a matter of right, and when a person can maintain a livelihood without reliance on the market" (Esping-Andersen, 1990: 22).

2 'Stratification' refers to the degree to which policies maintain or remedy the societal structural inequalities (Ibid: 23) 
Democratic welfare state has installed the most gender-equal regime to date - the two-earner, double-career household is a norm; and in comparison with everywhere else, the poverty rate among female-headed families is insignificant (EspingAndersen, 1996: 13).

The states of the Corporatist-Conservative welfare regime cluster reacted to the processes of deindustrialization and on the crises of the 1970s with a strategy of labour (supply) reduction i.e. the cure to unemployment forwarded by this regime type was labour market exit (primarily through early retirement and policies discouraging female labour market participation). This has arguably produced an 'insider-outsider' divide, with a small, predominantly male, 'insider' workforce enjoying high wages, expensive social rights, and strong job security, combined with a swelling population of 'outsiders' depending either on the male breadwinner's pay or on welfare state transfers (Esping-Andersen, 1996: 18). This kind of system has a tendency to augment labour market rigidities. The consequence is that voters and trade unions will defend the existing rights of the 'insiders' as forcefully as possible. There is an implicit conspiracy to safeguard the prime-age male worker even when this harms his wife's, sons' and daughters' employment prospects" (EspingAndersen, 1996: 19).

A further crucial feature of the Conservative regime is the commitment to the defence and maintenance of the traditional family and its functions - the family has been the unit of benefits, and benefits have been conferred upon the head of the household, the breadwinner (Bussemaker and Kersbergen, 1999: 18). In this regime families (mothers, sisters, grandparents) are assumed to be the principle source of care. This is due to the adherence to the Christian (conservative) values and to the principle of subsidiarity. The state traditionally focused on cash transfers to households rather than on the direct provision of services. Active labour market policies have never been an integral ingredient of this regime (Bussemaker and Kersbergen, 1999: 17). The underdeveloped social service sector coupled with tax disincentives and even with explicit policies of encouragement for women to leave the labour market - for instance, after marriage or first child - props up the male breadwinner model (Bussemaker and van Kersbergen, 1999: 19). Thus, married women's right of social protection were derived essentially from the labour force activity of their spouse - the male breadwinner (Hantrais, 2000: 20). As a matter of principle, the state would intervene and compensate for family failure, and not for market failure (the latter is the case with the Liberal welfare cluster of states).

To summarise, from the perspective of gender and organisation of childcare provision, both the Liberal and the Social-Democratic welfare regime type are encouraging defamiliazation (albeit through different means), whereas the Corporatist welfare regime type generally encourages childcare provision within the family i.e. aims to preserve traditional care patterns. 


\subsection{FEMINIST CRITIQUE ON THE MAINSTREAM WELFARE REGIME CLASSIFICATIONS}

Esping-Andersen's regime typology is very influential and often referred to, however it has also been widely criticized by the feminist scholarship of the welfare state for its limited consideration of gender. Hakim (2000: 30) identifies a male bias: "virtually all modern market theory rests on research evidence from men, and hence on the employment patterns typical of male breadwinners in full-time continuous employment throughout adult life". In particular, Esping-Andersen is accused of taking into account only paid labour i.e. considering only the official labour market, and neglecting the so-called "labour of love" i.e. the unpaid work of care toward the elderly and the children, which takes place in the family i.e. outside the official labour market (Sainsbury, 1999: 77). Indeed, 'decommodification' - the central variable in Esping-Andersen's analysis - is rendered somewhat void of meaning when gender is taken into account because it presupposes that labour is commodified, which is not necessarily the case with the work of women. Women's family responsibilities prevent them to enter the labour market and thus their work is neither commodified nor decommodified. In other words, the concept of 'decommodification' is not very informative with regard to the bulk of female work - the unpaid care work within the family .

The sharpness of the analytical categories aside, the very empirical results of Esping-Andersen are contestable when the welfare state clusters are examined from the perspective of gender. Thus for example, it seems that there is a huge variation in the Conservative welfare group when it comes to the underlying assumptions and actual organization of childcare. In particular, countries like France and Belgium have levels of childcare provision close to the ones in the Social-democratic welfare regime, whereas Germany and Austria have thus far proved resistant to change. The Netherlands is classified in the social-democratic cluster by Esping-Andersen, but gender-wise it has been a 'typical' conservative regime until it has undergone significant changes with the introduction of the so-called "combination scenario" in 1999 (see Ch. 4 for details). Furthermore, there are differences among the Nordic social democratic welfare regimes, which are visible in the sphere of childcare (Bergqvist et al., 1999). For example, Norway was a laggard in adoption of genderequal policies and has treated women primarily as wives and mothers for much longer than the other Nordic countries (Leira, 1989, 1992). Evidently, when it comes 
to childcare provision policies Esping-Andersen's welfare states' grouping is not fully informative both on conceptual and empirical levels.

The feminist literature on welfare states has attempted to remedy the mainstream classification models. Jane Lewis (1992, 1997, 2001) outlines 3 regimes according to the gender division of labour. Thus, depending on whether the woman takes full, part-time or no part in the process of paid work on the labour market, the regimes can be classified as 'weak', 'moderate' or 'strong' male-breadwinner models (Lewis, 1992, 1997).

Hakim (2000: 6-7) also identifies 3 types of regimes, based this time on three ideal-types of women's preference models:

- home-centered

- adaptive

- work-centered

These models are constructed according to the preferences of women toward participation in the labour market and women largely vary in their subscription under each of these models. Policies should recognize that and not assume only female workers or only female care-givers (Hakim, 2000: 7). The trouble with this suggestion is that it is very individualistic and agency-focused. Hakim's model is controversial because it highlights choice and underplays constraints (Lewis, 2001: 158) i.e. it disregards the potential influence of institutional and policy variables upon the choice of individuals and the interrelated nature of social policy and social practice. In addition, similar to the model of Lewis, it is hard for a researcher to discriminate between the different regimes. This is due to the fact that in order to classify a state under any of the models the researcher needs to examine the preferences of the whole female population of certain country, which is highly unfeasible.

Similarly to Hakim, Monique Kremer departs from observations on the behavioural level for her classification. She identifies 5 separate regimes based on the so-called 'ideals of care". The underlying idea is that the organization of childcare in a society has a lot to do with deeply rooted cultural ideals about the division of labour between the sexes, but also about what is best for a child i.e. how will a child get the best upbringing - through home-care or through a combination of home- and extrafamilial (organized) care. Thus, Kremer arrives at five separate models, each of which underlies a specific 'ideal of care' (Kremer, 2002: 129-131):

- full-time mother care

- parental sharing

- intergenerational care

- professional care 
- surrogate mother

This division is informative as far as it points to the importance of cultural variables, but it is restricted to the behavioural level, and pays little attention to the level of prescription i.e. to the structural constraints introduced by formal state policies, which could foster or discourage certain individual behaviour/ preferences.

In order to bridge the gap between social policy and social practice Sainsbury (1999) suggested the concept of 'gender policy regimes'. Again, the point of departure is the underlying ideologies and practices i.e. the principles and norms that prescribe the tasks, obligations, and rights of the two sexes, but the novelty is that a concrete set of policy features are examined, which allows for establishment of more precise variation between the different regimes. Thus, according to the varying regime attributes such as: 'basis of entitlement', 'recipient of benefits', 'taxation', 'employment and wage policies', 'remuneration of caring work', and others, Sainsbury distinguishes between three main gender policy regimes: 'male breadwinner', 'separate gender roles', and 'individual earner-carer' (Sainsbury, 1999: 78-79).

The 'male breadwinner' policy regime rests upon a strict division of labour among the sexes. The social benefits are distributed unequally, and are directed toward the male head of the family, who receives them on behalf of his dependents. Married women are assumed to be supported by their husbands. Unmarried women with children are considered anomalous and respectively do not enter the policy calculations (Sainsbury, 1999: 78). This was the regime in the Netherlands until the mid 1980s (see Chapter 5).

The 'separate gender roles' regime emphasizes the significance of differences between the sexes, and social rights are allocated on the basis of these differences (Sainsbury, 1999: 78). Similarly to the 'male breadwinner' regime it assumes that the male is predominantly earner and the female is predominantly carer i.e. that there is a strict division of labour between the sexes, however, the social and tax benefits are functionally separated, and part-time presence in the 'other camp' is not excluded. In other words women are entitled to benefits for their caring responsibilities, and that independently of their husbands. Thus, irrespective of their marital status women might enjoy financial help, which allows unmarried/ single mothers to participate in the general social policy framework.

The 'individual earner-carer' policy regime marks a sharp difference from the previous 2 regimes. Its fundamental assumption is that both, the male and the female, are earners and carers at the same time i.e. confers rights upon both sexes independently and equally. Social rights and tax obligations are attached to the individual rather than the family, and policies are structured to enable women to become workers and men to become caregivers (Sainsbury, 1999: 79). This is the model that functions in Scandinavia and that the EU propagates at present via the 
European Employment Strategy. In order to substantiate this claim the next chapter will analyse the EU childcare discourse. The main objective is to examine how childcare has been conceptualised for the purposes of EU public-policy making throughout the years of European integration (1951-2008) and whether the endorsement of the European Employment Strategy (EES) in 1997 has made an impact (and in which way) on this process. In preparation of this analysis the rest of this chapter will present the childcare-related policy frames that could be derived from the existing contemporary policy literature.

\subsection{CHILDCARE AS A PUBLIC POLICY SOLUTION AND CHILDCARE RELATED POLICY FRAMES}

Public support for non-home based childcare is a relatively recent phenomenon in the public policies of Western Europe. Well into the 1980s - and in some cases until much later (Weishoupt 2009) - most continental countries were designing and applying policy measures to sustain the 'male breadwinner' policy regime (see the previous section). Sweden was an exception of this policy line as already in $197213 \%$ of Swedish children were visiting public day-care centres (Bjoernberg 2002), and childcare was used as a policy instrument to reconcile work and family obligations. Until the beginning of the 1970s, however, anywhere out of Scandinavia childcare facilities were mainly considered places for children from "problem" and/or poor families. These were places which a child would visit exceptionally rather than habitually. This rather negative general public image of childcare gradually began to change after the onset of female emancipation in the late 1960s. For example, the British Women's Liberation Movement claimed 24-hour community-controlled childcare services as one of their Four Demands (Marchbank 1996: 9). Thus, the issue of non-home based childcare and provision of sufficient capacity of daycare facilities entered the public sphere of all West European countries and kept on coming back on the agenda of many governments throughout the 1980s and 1990s. In principle, the Social-Democrats were the main supporters of the enlargement of childcare capacities (Weishaupt, 2009).

In the public debates since the 1980s, childcare services have been associated with various public policy problems. Rubio (2007) identifies the following public 'concerns' that available and affordable childcare facilities could allegedly remedy: gender inequality, decreasing economic growth and/ or competitiveness, low fertility and demographic stagnation, social exclusion and child poverty, and/or early education (see also Bacchi 1999; Lewis 2006; CEC, 2008). All of these perceived 
public problems (or rather problematizations) have, at different times and by different political and social actors (e.g. trade unions, political parties, interest groups) been linked to childcare provision as a feasible policy solution.

For the sake of the accomplishment of the policy frame analysis (performed in the following chapters) these problematiztions indicated by experts have to be elaborated in full-fledged policy frames i.e. each of their 4 dimensions have to be specified. A detailed description of these dimensions is in practice a operationalization of the frames, and prepares the ground for the empirical stage, where these frames (or at least their constitutive and policy dimensions) have to be identified and counted in the documents selected for analysis.

Table 3.4-1 presents elaborated versions of the six problems as policy frames i.e. stating the problem (constitutive dimension); the most common narrative about the problem and about its origin (cognitive dimension); the belief system upon which the problem has become perceived as problematic in the first place (normative dimension); the proposed public policy action (the policy dimension). In this study the policy solution remains constant - provision of affordable and high quality childcare facilities. 
Table 3.4-1. Policy frames related to childcare provision

\begin{tabular}{|c|c|c|c|c|c|c|}
\hline Frames & $\begin{array}{c}\text { Female labour } \\
\text { market participation } \\
\text { (Gender equality) - } \\
\text { F1 }\end{array}$ & $\begin{array}{c}\text { Female labour } \\
\text { market participation } \\
\text { (Economic } \\
\text { competitiveness) - } \\
\text { F2 }\end{array}$ & $\begin{array}{c}\text { Demographic } \\
\text { problems (fertility, } \\
\text { greying population) } \\
\quad-\text { F3 }\end{array}$ & $\begin{array}{c}\text { Early education } \\
\text { and socialisation - } \\
\text { F4 }\end{array}$ & $\begin{array}{l}\text { Poverty and social } \\
\text { exclusion - F5 }\end{array}$ & $\begin{array}{l}\text { Integration of } \\
\text { migrant children - } \\
\text { F6 }\end{array}$ \\
\hline $\begin{array}{l}\text { Constitutive } \\
\text { dimension (need } \\
\text { for public } \\
\text { intervention) - } \\
\text { What is the } \\
\text { problem? }\end{array}$ & $\begin{array}{c}\text { Women are } \\
\text { oppressed, genders } \\
\text { are unequal }\end{array}$ & $\begin{array}{l}\text { Economic growth is } \\
\text { slow, relative } \\
\text { competitive position } \\
\text { not strong enough }\end{array}$ & $\begin{array}{l}\text { Demographic crisis } \\
\text { (low number of } \\
\text { births, greying } \\
\text { population, pension } \\
\text { gap, shrinking } \\
\text { labour force) }\end{array}$ & $\begin{array}{c}\text { Education needs } \\
\text { to start as early as } \\
\text { possible }\end{array}$ & $\begin{array}{l}\text { Marginalisation of } \\
\text { poor children, } \\
\text { high welfare } \\
\text { expenditures }\end{array}$ & $\begin{array}{c}\text { Follow up } \\
\text { generations of } \\
\text { migrant workers } \\
\text { do not integrate in } \\
\text { the mainstream } \\
\text { society }\end{array}$ \\
\hline $\begin{array}{l}\text { Cognitive } \\
\text { dimension } \\
\text { (narrative about } \\
\text { the phenomenon } \\
\text { and cause effect } \\
\text { relations) - what } \\
\text { has led to the } \\
\text { problem? }\end{array}$ & $\begin{array}{l}\text { Women are } \\
\text { restricted to } \\
\text { activities within the } \\
\text { private sphere, do } \\
\text { not have access to } \\
\text { paid work, } \\
\text { participation in } \\
\text { public life, which } \\
\text { leads to their } \\
\text { dependence, lack of } \\
\text { dignity and equality. }\end{array}$ & $\begin{array}{l}\text { Women's labour } \\
\text { market non- } \\
\text { participation } \\
\text { represents untapped } \\
\text { potential. The more } \\
\text { women enter the } \\
\text { labour market, the } \\
\text { greater the labour } \\
\text { force, the higher the } \\
\text { economic growth } \\
\text { and competitiveness. }\end{array}$ & $\begin{array}{l}\text { Women bare less } \\
\text { children later in } \\
\text { their lives (if at all) } \\
\text { because of } \\
\text { individualisation } \\
\text { processes, career } \\
\text { demands, economic } \\
\text { difficulties, etc. }\end{array}$ & $\begin{array}{l}\text { The earlier one } \\
\text { starts with } \\
\text { education, the } \\
\text { better the } \\
\text { educational } \\
\text { results, the more } \\
\text { holistic the } \\
\text { approach to public } \\
\text { education; the } \\
\text { better the } \\
\text { education the } \\
\text { higher the human } \\
\text { capital value. }\end{array}$ & $\begin{array}{l}\text { Single mothers } \\
\text { take too much of } \\
\text { the social pot, } \\
\text { their children live } \\
\text { on the margins of } \\
\text { society } \\
\text { (criminality, drug } \\
\text { abuse, etc.) Lack } \\
\text { of socialisation, } \\
\text { education and } \\
\text { work lead to social } \\
\text { exclusion. }\end{array}$ & $\begin{array}{c}\text { Lack of } \\
\text { appropriate social } \\
\text { and cultural } \\
\text { exchanges that will } \\
\text { cultivate long term } \\
\text { behavioural } \\
\text { patterns and } \\
\text { socialization in } \\
\text { mainstream } \\
\text { society }\end{array}$ \\
\hline
\end{tabular}




\begin{tabular}{|c|c|c|c|c|c|c|}
\hline Frames & $\begin{array}{c}\text { Female labour } \\
\text { market participation } \\
\text { (Gender equality) - } \\
\text { F1 }\end{array}$ & $\begin{array}{c}\text { Female labour } \\
\text { market participation } \\
\text { (Economic } \\
\text { competitiveness) - } \\
\text { F2 }\end{array}$ & $\begin{array}{c}\text { Demographic } \\
\text { problems (fertility, } \\
\text { greying population) } \\
\text { - F3 }\end{array}$ & $\begin{array}{l}\text { Early education } \\
\text { and socialisation - } \\
\text { F4 }\end{array}$ & $\begin{array}{l}\text { Poverty and social } \\
\text { exclusion - F5 }\end{array}$ & $\begin{array}{l}\text { Integration of } \\
\text { migrant children - } \\
\text { F6 }\end{array}$ \\
\hline $\begin{array}{l}\text { Normative } \\
\text { dimension (values, } \\
\text { moral beliefs) - } \\
\text { why does the } \\
\text { problem exist? } \\
\text { What sort of } \\
\text { values you need in } \\
\text { order to see this as } \\
\text { a problem? }\end{array}$ & $\begin{array}{l}\text { Human rights, } \\
\text { equality among } \\
\text { people regardless of } \\
\text { gender, right to } \\
\text { personal growth } \\
\text { and self- } \\
\text { improvement, equal } \\
\text { rights and } \\
\text { responsibilities } \\
\text { within the family, } \\
\text { sharing }\end{array}$ & $\begin{array}{c}\text { Economic efficiency } \\
\text { and growth, material } \\
\text { wellbeing }\end{array}$ & $\begin{array}{l}\text { Social reproduction } \\
\text { and cohesion, } \\
\text { economic efficiency }\end{array}$ & $\begin{array}{c}\text { Knowledge } \\
\text { society, knowledge } \\
\text { economy }\end{array}$ & $\begin{array}{c}\text { Solidarity, equal } \\
\text { life chances, social } \\
\text { cohesion }\end{array}$ & $\begin{array}{l}\text { Social cohesion, } \\
\text { homogeneous } \\
\text { concept of } \\
\text { citizenship, and } \\
\text { social integration } \\
\text { of minorities }\end{array}$ \\
\hline $\begin{array}{c}\text { Policy dimension } \\
\text { (public actions) - } \\
\text { what can be done } \\
\text { about it? }\end{array}$ & \multicolumn{6}{|c|}{ Provision of accessible and economically affordable childcare facilities. } \\
\hline
\end{tabular}


Next to the academic analyses, the European Commission's Expert Group on Gender and Employment Issues (EGGE) has issued a report on the provision of childcare services in the EU where the same 5 policy frames are reported, and childcare is seen as a remedy to gender equality (F1), decreasing economic growth and effectiveness of the welfare state (F2), demographic crisis (F3), social exclusion (F4) and early child development (F5) (Plantenga and Remery, 2009). Below these five policy problems are discussed in greater detail.

\section{Frame 1: Gender Inequality}

If one embraces the normative values of equality among people regardless of gender (equal human rights, right to personal growth and self-improvement and equal rights and responsibilities within the family), the problem of gender inequality is easily discerned. Social reality is viewed as gender-biased from this perspective. More men than women are active in public life, men are more often chosen for representatives in national assemblies, predominantly men sit at the top management seats of big business corporations, and men get better pay and have less discontinuous employment careers, etc. Conversely, women are underrepresented in public and corporate top levels, are less present on the labour market (especially once they give birth), and are more often economically dependent on their partners. The cognitive story (cause-effect narrative) is the following: Due to the patriarchal and androcentric organization of society, women are for centuries long restricted to activities within the private sphere, i.e. predominantly perform domestic (unpaid and hardly valued) work, rarely have access to paid work, participation in public life and education, which leads to their dependence and an unequal position in relation to men. It is subsequently argued that if women work, they will become financially independent, advance professionally, reach higher stages in their careers, and ultimately decrease the inequality gap. Clearly, in order to enter paid employment women have to be 'freed' from (parts of) the unpaid work they usually perform. The policy solution is seen in daycare facilities for children and/or in the redistribution of tasks at home between the partners. It is crucial to underline the importance of the concept of sharing and redistribution of tasks in this context, because if gender equality policies are understood narrowly (i.e. only in terms of facilitating the access to paid employment) they would not ameliorate the position of women. To the contrary, it might even aggravate it since paid employment without equal sharing of unpaid responsibilities leads to the so-called "double shift". The notion of the "double shift" describes the everyday reality of most women who have careers and raise families - 
they hold one job for which they are paid, and another one (at home) for which they are not (Hochschild and Machung 1989; Williams 2000). It is therefore crucial to have a broad interpretation of the concept of gender equality (i.e. as equal sharing of paid and unpaid work), if this problem is to be addressed properly. Therefore, in this study the policy frame of gender equality will be considered present in documents only if next to childcare facilities a reference is made to equal sharing of unpaid work.

An example of such a policy frame is provided by the Commission's Communication of 2006 "A Roadmap for equality between women and men 20062010” (COM(2006) 92 of 01.03.2006). Page 5 thereof reads:

\section{"2.3. Better reconciliation policies for both women and men}

Services and structures are adapting too slowly to a situation where both women and men work. Few men take parental leave or work part-time (7.4\% compared to 32.6\% for women); women remain the main carers of children and other dependants. Men should be encouraged to take up family responsibilities, in particular through incentives to take parental and paternity leaves and to share leave entitlements with women.

Key actions

The Commission will

-...

- support the achievement of the Barcelona targets on childcare and the development of other care facilities through the Structural Funds and the exchange of good practices"

\section{Frame 2: Economic competitiveness and welfare state reform}

Based on the criteria of economic efficiency, growth, and material prosperity, European economic performance is often considered to be lagging behind compared with the USA and East Asia. Subsequently, the problems of decreasing competitiveness and inefficient welfare regimes emerge (Sapir 2006: 369-374). The cognitive link between these problems of decreasing economic competitiveness and childcare is female labour market participation. It is namely believed that higher 
availability of quality childcare facilities would lead to higher levels of female employment (and hence GDP). Moreover, women would not burden anymore the welfare state through benefits of various sorts. The reasoning behind this expectation follows a characteristic rationalist account of costs and benefits. It is pointed out that economic theory suggests two approaches to understanding the effects of childcare on women's employment:

1) Value of care work (availability) - childcare arrangements affect the value a woman places on her time at home. Good childcare alternatives reduce the attractiveness/value of full-time care-giving work at home.

2) Childcare costs as a tax on mothers' wages (affordability) - an increase in childcare costs will have the same effect as lowering of the wages, in that it will reduce both the propensity to remain employed and the amount of hours worked. Conversely, the lower the costs, the higher the expected labour market participation of women.

Both approaches predict that improvements in women's childcare options (greater availability and/or lower costs) will be associated with increases in employment, and this prediction is supported by a large body of empirical research (Connelly 1992; Ribar 1995; Van der Lippe 2001 2003). Since from this perspective care responsibilities are viewed to constitute a major obstacle to (full) employment the public provision (or subsidy) of affordable childcare is seen as the policy solution.

An example of this policy frame is provided by the Commission's Report of 2008 "Implementation of the Barcelona objectives concerning childcare facilities for pre-school-age children" (COM(2008) 638). Page 2 thereof states:

"The development of childcare facilities gives parents more freedom to choose bow to organise their time and thus better reconcile their working life with family life. This applies in particular to women, who, faced with inadequate childcare options, are more likely than men to have to give up work or to choose working arrangements which prevent them from fully exploiting their talents. The European economy is thus deprived of their productive potential, at a time when it is having to contend with economic and demographic challenges."

\section{Frame 3: Demographic crisis}

This frame has its normative grounds in the values of social preservation, reproduction, and cohesion, as well as economic efficiency. From this angle, low 
levels of fertility constitute a major problem because societies shrink, older people relatively increase in numbers compared to young people, the labour force stagnates and tensions in the pension system occur. The cognitive story with relevance to childcare here is that nowadays women bare less children and relatively late in their lives (if at all) because of the pursuit of a career, which does not fit well with the care responsibilities for a child. Once a baby comes into a woman's life, most often her career plans are put on hold. That is why, in the European societies, where individualisation processes are booming regardless of gender, less and less women decide to have (several) children. Their choice might be different had more childcare facilities been available argue the policy-makers. Once partially freed from their care responsibilities, and thus able to pursue their career plans, women would bare more children - so the argument goes. The demographic crisis could therefore be partially resolved by the policy solution of rising the number and affordability of childcare facilities. An example of this policy frame is provided by the Commission's Green Paper of 2005 "Confronting demographic change: a new solidarity between the generations". Page 5 thereof reads (CEC(2005) 94):

"The low fertility rate is the result of obstacles to private choices: late access to employment, job instability, expensive bousing and lack of incentives (family benefits, parental leave, child care, equal pay). Incentives of this kind can have a positive impact on the birth rate and increase employment, especially female employment, as certain countries have shown."

\section{Frame 4 Social exclusion}

This is the oldest policy frame related to childcare. This is the frame that presents childcare as a welfare service/measure that has to be provided for families and parents that cannot take care of the children themselves, but have to rely on the state itself. This type of childcare concerns a small number of children on a regular basis and is rather a temporary measure (while the parents have a medical condition or are disabled, etc.) This is a very different conception of childcare from the one studied in this book, namely of regularized outsourcing of the care for children to formally organized for the purpose childcare facilities.

From the normative basis of solidarity, equal life chances, and social cohesion the phenomenon of social exclusion i.e. individuals living at the margins of society, without a job and in poverty, is a major problem. The cognitive side of this frame develops the narrative that children of socially excluded people do not have the capacity and skills to integrate in society, and are therefore more prone to anti-social behaviour, drug and alcohol abuse, school dropout, etc. As a policy solution is 
suggested again childcare provision. It is expected that pedagogically sound childcare could socialise and educate socially excluded children how to behave appropriately in society and thus to foster greater life chances and realisation than their parents.

An example of this policy frame is provided by the party manifesto of 2002 of the Dutch Christian-Democrats (CDA). Page 42 thereof states ${ }^{1}$ :

\begin{abstract}
"The parents are first and foremost the responsible ones to arrange the childcare they need. The governmental policy is directed to the creation of conditions where the private initiative has priority. Investment of governmental means will be directed to the households that are least able to sustain the childcare expenses".
\end{abstract}

Nowadays this frame comes also in a more encompassing version in policy documents. The contemporary discourse regarding social inclusion aims, namely, to integrate also 'disabled' (in the broadest sense of the word) children i.e. less advantaged children not in terms of income but in terms of physical or mental development.

\title{
Frame 5 Early education and socialisation
}

Early childhood development i.e. socialisation and education could hardly be presented as a problem but rather as a public policy issue that developed countries pursue in their public policies in order to foster social development, cohesion, and long-term material prosperity. Departing form these normative values education is an important manner to foster a culturally cohesive society and economically prosperous labour force, the latter is particularly important in the era of knowledge economies. The cognitive story that reveals the place of childcare in this argument is that the earlier one starts with education, the better the educational results, the more holistic the approach to public education; the higher the value of the human capital and respectively the better the economic performance in the future. Childcare is therefore seen as a means from an early age to socialise and prepare children for their

\footnotetext{
1 Author's own translation. The original text reads as follows: "De ouders zijn primair zelf verantwoordelijk voor het regelen van kinderopvang. Het overheidsbeleid richt zich op het scheppen van voorwaarden, waarbij het particulier initiatief prioriteit krijgt. Inzet van overheidsmiddelen richt zich op de minst draagkrachtige huishoudens."
} 
educational path. Respectively, childcare outside the home in a qualitatively and pedagogically sound organisation is considered a policy solution preferable to private care.

An example of this policy frame is provided by the Dutch coalition agreement of 2007 (between the Christian-Democrats, the Social-Democrats and the Christian Union). Page 23 thereof states ${ }^{1}$ :

"Living together begins with playing together. There will be a harmonization of the regulatory framework (including the financial contributions to parents) related to the education provided by childcare facilities, playgroups and pre-school. The most important issues that have to be addressed are the segregation in the childcare and playgroups, the increase of the quality and the improved transition to the first year of the basic school. The schools will retain the possibility to offer O-groups."

\section{Frame 6 Integration of migrant children}

If normative values such as social cohesion, citizenship and social tolerance are leading the policy analysis, the phenomenon of poor integration of second and third generation migrants in Western Europe represents a public problem. The fact that the (grand)children of migrant workers who arrived in the 1950s and 1960s remain at the margins (relatively apart) form the core of society, do not integrate, remain speaking predominantly their own language, are long-term unemployed, etc. is not considered welcome by public policy actors. The cognitive dimension of this policy frame claims that taking part into day-care and regular visits to childcare facilities provide the opportunity for social/ cultural exchanges that facilitates socialisation processes and long-term integration in society, and ultimately social cohesion. As a policy solution is suggested again childcare provision. It is expected that pedagogically sound childcare could socialise and educate migrant (grand)children, and ultimately provide greater social cohesion.

An example of this policy frame is again found in the Dutch coalition agreement of 2007. Page 22 thereof states ${ }^{1}$ :

\footnotetext{
1 Author's own translation. The original text reads as follows: “Samen leven begint met samen spelen. De regelgeving ten aanzien van kinderopvang, peuterspeelzalen en voor- en vroegschoolse educatie, waaronder de financiële tegemoetkoming aan ouders, wordt geharmoniseerd. Belangrijkste oogmerken zijn het tegengaan van segregatie in de kinderopvang/peuterspeelzalen, het verhogen van de kwaliteit en het verbeteren van de aansluiting op het eerste jaar van de basisschool. Scholen behouden de mogelijkheid een 0-groep aan te bieden."
} 
"Not only from the ones that will be arriving to the Netherlands will be required to have knowledge of the language and the customs, but also by the ones that live already in the country should be addressed the problem of lacking language skills. All children for whom at the age of 3 is determined language underdevelopment should be addressed by the childcare facilities, the playgroups, the pre-school (group 0) or by special (phasein) classes. The parents of such children will be immediately engaged in these actions through the broad education duty."

All the six problems and policy frames discussed above could and are used by proponents of the childcare policy solution in the EU members states. This already provides a preliminary answer to the question why childcare is such a popular policy solution at the EU level. Clearly, the fact that it "clicks" so well with major contemporary debates and policy problems assures its dominance in the process of reconciliation policy-making. More importantly - perhaps even crucially for the successful career of childcare at the EU level - there has been a good resonance (arguably even a perfect match) between the childcare policy solution and neo-liberal as well as third-way politics economic values. This argument is developed further in the next chepter which traces the occurrence and evolution of the above-mentioned policy frames in the EU childcare discourse (as reflected in secondary EU legislation).

\footnotetext{
${ }^{1}$ Author's own translation. The original text reads as follows: 'Niet alleen van wie naar hier komt, mag kennis van taal en gewoonten verlangd worden; bij allen die hier wonen, moet taalachterstand worden aangepakt. Daartoe komt er een breed programma om taalachterstanden weg te werken. Kinderen waarbij op driejarige leeftijd door het consultatiebureau of elders een taalachterstand wordt geconstateerd, zullen via kinderopvang/peuterspeelzalen, voor- en vroegschoolse educatie (groep 0) en aparte (schakel)klassen op het vereiste niveau worden gebracht. De ouders van die kinderen worden hierbij direct betrokken via een verbrede leerplicht.
} 


\section{CONSTRUCTING CHILDCARE POLICY IN EUROPEAN GOVERNANCE: THE CAREER OF A POLICY SOLUTION AT THE EU LEVEL}

The previous chapter presented the emergence of childcare as a public policy concern. It furthermore outlined six policy frames derived from various national discourses, all of which suggest childcare as a possible solution to a public 'problem'. The questions that this chapter ${ }^{1}$ addresses are: how does the European Union (as an overarching layer of governance beyond the nation state) manages this diversity of problematizations? Which one(s) received priority in the action plans of the EU and are reflected in the European Employment Strategy? To that end the chapter traces the presence and dynamic development of the six frames in secondary EU legislation. This allows for a distilling of the EU policy discourse and of the specific policy frame that the EU propagates via the mechanisms of the Open Method of Coordination. On the basis of these findings, the concrete study of the Dutch implementation of the childcare guideline of the European Employment Strategy can advance in the chapters 5 and 6 . 


\subsection{HISTORICAL OVERVIEW OF EU POLICY DEVELOPMENTS IN THE FIELD OF GENDER EQUALITY AND RECONCILIATION OF WORK AND} FAMILY LIFE

The European Union's policy in the field of gender equality has three thematic directions - equal pay, equal treatment and reconciliation of employment and family life. Not all three were present at the beginning of the process of European institution-building, however. Initially, only the principle of equal pay was enshrined in article 119 of the founding Treaty of Rome (1957). Moreover, as asserted by Linda Hantrais (2000: 14), this had little to do with the actual equal treatment of the sexes. It was rather meant as a measure establishing equal and fair competition between the member states, by preventing any one country from gaining a competitive edge by paying women at lower rates than men (Stratigaki, 2000: 14).

It was not until the 1970s that equal treatment issues gained prominence on the European agenda fuelled by the ideas of second-wave feminism of the late 1960s and early 1970s (Mazey, 1998: 133). The far-reaching 'gender revolution' that took place at that time changed profoundly the traditional views on women's place in society, and cleared the way for women not only to participate incidentally in the labour markets but also to develop more continuous working patterns (Hantrais, 2000: 5). Three Council directives were the actual manifestation of the policy shift at the European level: Council Directive 75/117/EEC on equal pay, Council Directive $76 / 207 /$ EEC on equal treatment of men and women in access to employment, and Council Directive 79/7/EEC on equal treatment of men and women in matters of social security. Albeit an important step forward for women's individualized rights, these three pieces of legislation were not concerned with creating an encompassing policy of positive measures to compensate women for the tensions they experience between professional and unpaid (care) work (Hantrais, 2000: 14; Hoskyns, 1996).

The first Commission initiative explicitly devoted to the reconciliation of employment and family life was the Communication on family policies of 1989 (COM (89) 363 final). The Communication recognised the importance of female labour to the economy, and discussed the need to introduce measures that enable parents to reconcile their occupational and family obligations. Reconciliation measures kept firmly their place on the European agenda in the third Community Action Programme on Equal opportunities (1991-1995), which urged the member states to reduce barriers to women's employment. Moreover, the Council adopted a Recommendation on Child care (92/241/EEC) thus recognising the link between 
good care facilities and paid female labour. This Recommendation encouraged the member states to develop and/or promote initiatives to "enable women and men to reconcile their occupational, family and upbringing responsibilities arising from the care of children". The recommendation also defined childcare broadly and proposed that measures were needed in four areas: childcare services, leave for employed parents, family-friendly policies at the workplace, and measures to promote the increased participation of men in the care for, and the upbringing of children. The member states could not agree on setting concrete targets with regard to minimum childcare facilities provision, therefore such targets were not included in the Recommendation. Another 10 years would elapse before the member states reached consensus on this issue, and agree upon the Barcelona targets of 2002 (see below).

The next milestone in the EU's gender equality policy was the adoption of three Directives, which at present constitute the basic framework of national reconciliation policies in Europe. These three Directives were the Pregnant Workers Directive of 1992, the Parental Leave Directive of 1996 and the Part-Time Work Directive of 1997. The first two Directives have a direct impact on the leave schemes in relation to maternity and parenting. The Pregnant workers Directive provides, among others, for minimum entitlement of 14 weeks for pregnant women in employment. During that period women are entitled to receive an allowance, which must at least be equivalent to the benefits received during periods of sickness. The Parental Leave Directive prescribes a minimum of 3 months leave for both parents i.e. grants an individual right to both male and female employees. Furthermore, the Directive contains a number of soft-law provisions that aim at encouraging better reconciliation between professional and family life, and importantly foster men's participation in care work. Finally, the Part-time Work Directive pursues two broad objectives: a social one, outlawing discrimination against part-time workers; and an economic one, aiming to improve the flexibility and performance of the labour markets by stimulating the use of part-time work (Falkner et al., 2005: 159).

With the Treaty of Amsterdam (1997) key gender equality concepts entered the primary legislation of the European Union. First of all, Article 2 of the Treaty establishing the European Community (TEC) officially enshrined the principle of equality between men and women. Furthermore, Article 3(2) of TEC introduced gender mainstreaming as a principle of European policy-making. Moreover, Article 141(4) of TEC practically encourages 'positive action' measures toward the underrepresented sex.

The year 1997 is also known for the launch of the European Employment Strategy (EES also known as the 'Luxemburg process'). While the promotion of gender equality has been an explicit objective of the EES since its inception in 1997 (Fagan et al., 2005), its weight in the larger package of the Employment strategy varied through the years. It is therefore useful to examine the three stages of the EES 
in terms of their implications for gender equality in general and work-life balance in particular (see Fagan et al., 2006; Rubery et al., 2002; 2005). The first stage encompassed the period, from the Luxembourg Summit of 1997, where the EES was officially launched, until the Barcelona European Council of 2002. In this first period, the EES was based on four pillars: employability, entrepreneurship, adaptability and equal opportunities. Gender equality was, therefore, one of the four building blocks of this new strategy (see A for the thematic content and the major transformations of the Strategy). In the first stage of the EES, Pillar IV on Equal Opportunities consisted of four specific guidelines, including reconciling work and family life and facilitating the return to the labour market, which were combined into one single guideline in 2001. During this first stage, the female employment target of 60 per cent to be attained by 2010 was put forward by the Lisbon European Council of 2000, and the midterm rate of 57 per cent to be attained by 2005 was set by the Stockholm European Council of 2001.

The EES was revised and entered into a second stage with the Barcelona European Council of March 2002, which replaced the pillar structure with the three 'overarching objectives' of full employment, job quality and productivity, and social cohesion and inclusion, to be achieved through 10 'priorities for action'. Gender equality, within this framework, became one of these as priority number six, losing some of the visibility it enjoyed under the previous structure, but still being relevant for the three overarching objectives (Rubery et al., 2003; 2004). Nevertheless, some visibility was regained at the Barcelona Summit of 2002 where the European Council for the first time established European targets in the field of work-life balance. At this summit the member states committed to achieve by 2010 a childcare coverage rates of 90 per cent for children between three years old and the mandatory school age, and at least 33 per cent for children under three years of age. Furthermore, other targets endorsed at the summit (e.g. about gender gaps in employment, unemployment and pay) showed the importance attached to increasing female employment rates (Rubery et al., 2004).

In 2005, the EES entered its third stage with the midterm review of the Lisbon strategy. Under the revised Lisbon Programme, the EES was streamlined with the Broad Economic Policy Guidelines, resulting in the Integrated Guidelines for Growth and Jobs. This new framework covers actions in 'three main areas': knowledge and innovation for growth, making Europe a more attractive place to invest and work, and creating more and better jobs. It is of significance that there is no direct reference to women or gender in the final document. This evokes a concern about a further loss of visibility of the gender equality policy objective (Fagan et al., 2006). Still, the Employment Guidelines 2005-2008 (numbers 17 to 24 of the new Integrated Guidelines) make explicit references to the importance of increasing female participation and reducing gender gaps in employment, unemployment and 
pay; and of promoting better reconciliation of work and private life and the provision of accessible and affordable childcare facilities (particularly GL 18: Promote a lifecycle approach to work).

Moreover, in March 2006, the Commission adopted a Roadmap for equality between women and men (COM(2006) 92 final), outlining six priority areas for EU action on gender equality, including equal economic independence for women and men, and reconciliation of private and professional life, whereby it made significant references to Lisbon and Barcelona objectives. Under the heading 'Enhancing Reconciliation of Work, Private and Family Life', the Roadmap underlined the importance of: (i) flexible working arrangements for both women and men; (ii) increasing care services to tackle the demographic challenges facing Europe; and (iii) better reconciliation policies for both women and men, with a view to encouraging men to take up family responsibilities, in particular through incentives to take parental and paternity leaves and to share leave entitlements with women.

On this basis, a European Pact for Gender Equality was annexed to the Presidency Conclusions of the Brussels European Council meeting of March $2006^{1}$. It encourages action at the Member State and EU levels in a number of fields, including the promotion of a better work-life balance for all. The Pact underlines the importance of achieving the Barcelona childcare targets, improving the provision of childcare facilities for other dependants, and promoting parental leave for both women and men. The Pact was envisaged to be integrated into the follow-up mechanisms of the Partnership for Growth and Employment, and to promote the implementation of gender mainstreaming within the streamlined Lisbon Strategy. Within this framework, Member States were encouraged to include a gender equality perspective in their National Reform Programmes (NRP), and the European Commission and Council were invited to do so in their Annual Progress Reports. Nevertheless, the Pact did not go beyond a limited perspective on gender equality, underlining its importance for making 'full use of the productive potential of the European labour force', and of meeting the demographic challenges, rather than conceiving it as an objective in itself. It thus illustrated further the claims that gender equality is mainly conceived as a means to achieve the goals of high economic growth and employment levels and increased competitiveness in Europe.

After this brief review of the general development of the equal opportunities policy at the EU level, the chapter will zoom into the dynamics of childcare policy framing. The aim of this analysis is to deconstruct the EU childcare discourse, and to examine the changes brought about in this discourse by the European Employment Strategy (if any).

\footnotetext{
${ }^{1}$ See the Presidency Conclusions of the Brussels European Council of 23 and 24 March 2006.
} 


\subsection{DYNAMICS OF CHILDCARE POLICY FRAMING AT THE EU LEVEL}

This section reports the results of the policy frame analysis, which was elaborated in order to trace the dynamics of linking policy problems to the policy solution of childcare at EU-level. The main objective was to examine how childcare has been conceptualised for the purposes of EU public policy making throughout the years of European integration, and whether the endorsement of the EES in 1997 has made an impact on this process. In short, this section traces the 'career' of childcare as a policy solution at the EU level of governance.

Table 4.2-1 Steps in the dataset formation

\begin{tabular}{|l|c|c|c|}
\hline \multicolumn{1}{|c|}{ Search term } & No of hits & Relevant hits & New hits \\
\hline \hline EES acquis: & 11 & 11 & 11 \\
All EES guidelines & 7 & 7 & 7 \\
\hline $\begin{array}{l}\text { All EES implementation } \\
\text { recommendations }\end{array}$ & 46 & 41 & 41 \\
\hline Presidency Conclusions & 44 & 15 & 13 \\
\hline Search terms (in Eur-Lex): & & & \\
\hline "child-care" and "child care" & 99 & 25 & 9 \\
\hline "childcare" & 9 & 3 & 2 \\
\hline "child-minding" & 7 & 0 & 0 \\
\hline "crèche" & 14 & 0 & 0 \\
\hline "daycare" & 21 & 0 & 0 \\
\hline "child" AND "rear" & "child" AND "rearing" & 0 & 0 \\
\hline
\end{tabular}

Source: Radulova, 2009 
It does so by examining secondary legislative acts derived from the database of European Law (Eur-Lex) for the whole period of European integration (1950s to 2008).

Based on a keyword search in the database of EU law Eur-Lex (secondary legislation), a dataset of 83 documents was formed (see Table 4.2-1 for the steps in the formation of the dataset). First of all, the EES 'acquis' entered the dataset, i.e. all EES guidelines and all EES implementation reports (18 in total), as well as all Presidency Conclusions starting from the 1997 Amsterdam summit. Secondly, a search was performed in the Eur-Lex database under different search terms all signifying non-home based childcare (e.g. crèche, child care, daycare, etc.) From all the documents (i.e. pieces of legislation that include the search term) only the relevant and new ${ }^{1}$ hits entered the dataset. For example, the Council Decisions and Council Recommendations related to the EES did not enter twice into the database - they were filtered during the selection of new documents. On the next step a new search term was looked up in Eur-Lex and again only the relevant and new documents entered the dataset. Following this procedure, a dataset of 83 documents was formed $^{2}$. The latter was subsequently examined through qualitative content analysis, whereby the number of references to childcare (or related term) as a policy solution was documented and (wherever possible) each reference was assigned to one of the 6 policy frames discussed in Chapter 3. To accomplish that the immediate context of the reference was studied. If it contained the constitutive and cognitive dimensions of any of the frames described in Chapter 3, then the reference would be counted as indicative of the respective policy frame. Only rarely did the documents refer to the normative dimensions of the policy frames, and that is quite understandable (political) values, norms or principles are hardly ever explicit in policy documents. That is why the presence of the normative dimension was not considered as necessary for the existence of the policy frame. The occurrence of each of the three frames in the Presidency Conclusions is presented in Table 4.2-2.

${ }^{1}$ By relevant is meant that only these documents were examined that were significant for the study of childcare as a policy measure. There is, for example, great use of the word "childcare" in legislation related to the Single Market and in toy safety regulations. Such use of the term was not relevant for this study, therefore the respective hits were filtered out and did not enter the dataset. Moreover, a track was kept of the new to the dataset documents. For example, from the 25 relevant documents yielded by the search term "childcare" 14 were already present in the dataset because they appear in 'the EES acquis'. Therefore, only the remaining 9 documents entered the dataset.

2 The method of formation of the dataset is consistent with the model for cyclical corpus-building for qualitative research advanced by Bauer and Aarts. The idea of the model is that the researcher begins by selecting a small but relevant and homogeneous corpus (in this case the EES acquis), and then adds up more material up to the point when, following the law of diminishing returns, new data no longer yield up new hits (Bauer, 2000,: 31-34). 
Table 4.2-2 Frequency distribution of the childcare related policy frames in the Presidency Conclusions from 1997 to 2008

\begin{tabular}{|c|c|c|c|c|c|}
\hline \multirow[t]{2}{*}{ Month/Year } & \multirow[t]{2}{*}{ European Council of: } & \multicolumn{4}{|c|}{ Nr of references } \\
\hline & & Total & F1 & F2 & F3 \\
\hline June 1997 & Amsterdam & 0 & & & \\
\hline November 1997 & $\begin{array}{l}\text { Luxembourg } \\
\text { (Employment Summit) }\end{array}$ & 1 & & 1 & \\
\hline December 1997 & Luxembourg & 0 & & & \\
\hline June 1998 & Cardiff & 1 & 1 & & \\
\hline December 1998 & Vienna & 0 & & & \\
\hline January 1999 & Cologne & 0 & & & \\
\hline March 1999 & Berlin & 0 & & & \\
\hline October 1999 & Tampere & 0 & & & \\
\hline December 1999 & Helsinki & 0 & & & \\
\hline March 2000 & Lisbon & 1 & 1 & & \\
\hline June 2000 & Feira & 0 & & & \\
\hline October 2000 & Bieritz & 0 & & & \\
\hline December 2000 & Nice & 2 & 1 & 1 & \\
\hline March 2001 & Stockholm & 1 & & & \\
\hline June 2001 & Gothenburg & 0 & & & \\
\hline October 2001 & Ghent & 0 & & & \\
\hline December 2001 & Laeken & 0 & & & \\
\hline March 2002 & Barcelona & 4 & 1 & 2 & \\
\hline June 2002 & Seville & 0 & & & \\
\hline October 2002 & Brussels & 0 & & & \\
\hline December 2002 & Copenhagen & 0 & & & \\
\hline March 2003 & Brussels & 1 & & 1 & \\
\hline
\end{tabular}




\begin{tabular}{|c|c|c|c|c|c|}
\hline \multirow[t]{2}{*}{ Month/Year } & \multirow[t]{2}{*}{ European Council of: } & \multicolumn{4}{|c|}{ Nr of references } \\
\hline & & Total & $F 1$ & F2 & F3 \\
\hline June 2003 & Thessaloniki & 0 & & & \\
\hline October 2003 & Brussels & 0 & & & \\
\hline December 2003 & Brussels & 0 & & & \\
\hline March 2004 & Brussels & 0 & & & \\
\hline June 2004 & Brussels & 0 & & & \\
\hline November 2004 & Brussels & 0 & & & \\
\hline December 2004 & Brussels & 0 & & & \\
\hline March 2005 & Brussels & 2 & & 1 & \\
\hline June 2005 & Brussels & 0 & & & \\
\hline December 2005 & Brussels & 0 & & & \\
\hline March 2006 & Brussels & 3 & 2 & 1 & 1 \\
\hline June 2006 & Brussels & 0 & & & \\
\hline December 2006 & Brussels & 0 & & & \\
\hline March 2007 & Brussels & 0 & & & \\
\hline June 2007 & Brussels & 0 & & & \\
\hline December 2007 & Brussels & 0 & & & \\
\hline March 2008 & Brussels & 1 & & 1 & \\
\hline June 2008 & Brussels & 0 & & & \\
\hline October 2008 & Brussels & 0 & & & \\
\hline & Total: & 17 & 6 & 8 & 1 \\
\hline
\end{tabular}

Source: Radulova (2009)

The relevant rows i.e. the Presidency Conclusions that return hits related to the childcare search terms were integrated into the main document database derived from the Eur-Lex (see Table 4.2-3). 
Table 4.2-3 Frequency distribution of the childcare related policy frames in the dataset

\begin{tabular}{|c|c|c|c|c|c|c|}
\hline Year & Document type & Topic & \multicolumn{4}{|c|}{$N r$ of references } \\
\hline & & & Total & F1 & F2 & F3 \\
\hline 1986 & Council Resolution & Equal opportunities & 1 & 1 & & \\
\hline 1988 & Council Resolution & $\begin{array}{l}\text { Workforce participation } \\
\text { of women }\end{array}$ & 1 & 1 & & \\
\hline 1992 & $\begin{array}{l}\text { Council } \\
\text { Recommendation }\end{array}$ & Childcare & 15 & 6 & & \\
\hline 1994 & Council Resolution & $\begin{array}{l}\text { Workforce participation } \\
\text { of women }\end{array}$ & 2 & 2 & & \\
\hline 1995 & Council Decision & Equal Opportunities & 1 & & & \\
\hline 1996 & $\begin{array}{l}\text { Council } \\
\text { Recommendation }\end{array}$ & Equal Opportunities & 2 & 1 & 1 & \\
\hline 1997 & $\begin{array}{l}\text { Presidency } \\
\text { Conclusions }\end{array}$ & $\begin{array}{l}\text { Luxembourg European } \\
\text { Council }\end{array}$ & 1 & & 1 & \\
\hline 1998 & $\begin{array}{l}\text { Commission } \\
\text { Recommendation }\end{array}$ & Home Work & 1 & 1 & & \\
\hline 1998 & $\begin{array}{l}\text { Council } \\
\text { Recommendation }\end{array}$ & BEPG & 1 & & & \\
\hline 1998 & $\begin{array}{l}\text { Commission Special } \\
\text { Report }\end{array}$ & $\begin{array}{l}\text { Equal Opportunities via } \\
\text { ESF }\end{array}$ & 5 & 1 & & \\
\hline 1998 & $\begin{array}{l}\text { Presidency } \\
\text { Conclusions }\end{array}$ & $\begin{array}{l}\text { Cardiff European } \\
\text { Council }\end{array}$ & 1 & 1 & & \\
\hline 1998 & Council Resolution & EES guidelines & 2 & & 1 & \\
\hline 1999 & $\begin{array}{l}\text { Council } \\
\text { Recommendation }\end{array}$ & BEPG & 2 & & 2 & \\
\hline
\end{tabular}




\begin{tabular}{|c|c|c|c|c|c|c|}
\hline Year & Document type & Topic & \multicolumn{4}{|c|}{ Nr of references } \\
\hline & & & Total & F1 & F2 & F3 \\
\hline 1999 & Commission & Structural funds & 5 & 1 & 1 & \\
\hline 1999 & Council Resolution & EES guidelines & 2 & 1 & 1 & \\
\hline 2000 & $\begin{array}{l}\text { Council } \\
\text { Recommendation }\end{array}$ & EES implementation & 2 & 2 & 1 & \\
\hline 2000 & $\begin{array}{l}\text { Council } \\
\text { Recommendation }\end{array}$ & BEPG & 2 & & 2 & \\
\hline 2000 & $\begin{array}{l}\text { Presidency } \\
\text { Conclusions }\end{array}$ & $\begin{array}{l}\text { Lisbon European } \\
\text { Council }\end{array}$ & 1 & 1 & & \\
\hline 2000 & Council Resolution & $\begin{array}{l}\text { Balanced sharing of } \\
\text { family responsibility }\end{array}$ & 2 & 2 & & \\
\hline 2000 & Council Decision & EES guidelines & 2 & 1 & 1 & \\
\hline 2000 & $\begin{array}{l}\text { Presidency } \\
\text { Conclusions }\end{array}$ & Nice European Council & 2 & 1 & 1 & \\
\hline 2001 & Council Decision & Gender Equality & 2 & 1 & & \\
\hline 2001 & $\begin{array}{l}\text { Presidency } \\
\text { Conclusions }\end{array}$ & $\begin{array}{l}\text { Stockholm European } \\
\text { Council }\end{array}$ & 1 & & & \\
\hline 2001 & $\begin{array}{l}\text { Council } \\
\text { Recommendation }\end{array}$ & EES implementation & 6 & 3 & 2 & \\
\hline 2001 & $\begin{array}{l}\text { Council } \\
\text { Recommendation }\end{array}$ & BEPG & 3 & 1 & 1 & \\
\hline 2001 & Council Decision & EES guidelines & 2 & 1 & 1 & \\
\hline 2002 & $\begin{array}{l}\text { Council } \\
\text { Recommendation }\end{array}$ & EES implementation & 13 & 5 & 3 & \\
\hline
\end{tabular}




\begin{tabular}{|c|c|c|c|c|c|c|}
\hline Year & Document type & Topic & \multicolumn{4}{|c|}{$\mathrm{Nr}$ of references } \\
\hline & & & Total & F1 & $F 2$ & F3 \\
\hline 2002 & $\begin{array}{l}\text { Presidency } \\
\text { Conclusions }\end{array}$ & $\begin{array}{l}\text { Barcelona European } \\
\text { Council }\end{array}$ & 4 & 1 & 2 & \\
\hline 2002 & $\begin{array}{l}\text { Council } \\
\text { Recommendation }\end{array}$ & BEPG & 8 & 1 & 5 & \\
\hline 2002 & Council Decision & EES guidelines & 2 & 1 & 1 & \\
\hline 2003 & $\begin{array}{l}\text { Presidency } \\
\text { Conclusions }\end{array}$ & $\begin{array}{l}\text { Brussels European } \\
\text { Council }\end{array}$ & 1 & & 1 & \\
\hline 2003 & $\begin{array}{l}\text { Council } \\
\text { Recommendation }\end{array}$ & BEPG & 3 & & 3 & \\
\hline 2003 & Council Decision & EES guidelines & 5 & 1 & 2 & \\
\hline 2003 & $\begin{array}{l}\text { Council } \\
\text { Recommendation }\end{array}$ & EES implementation & 12 & 3 & 5 & \\
\hline 2004 & $\begin{array}{l}\text { Council } \\
\text { Recommendation }\end{array}$ & EES implementation & 11 & 1 & 10 & \\
\hline 2004 & Council Decision & EES guidelines & 5 & 1 & 2 & \\
\hline 2005 & $\begin{array}{l}\text { Presidency } \\
\text { Conclusions }\end{array}$ & $\begin{array}{l}\text { Brussels European } \\
\text { Council }\end{array}$ & 2 & & 1 & \\
\hline 2005 & Council Decision & EES guidelines & 2 & & 1 & \\
\hline 2006 & $\begin{array}{l}\text { Council } \\
\text { Conclusions }\end{array}$ & Youth Pact & 1 & 1 & & \\
\hline 2006 & $\begin{array}{l}\text { Directive of EP and } \\
\text { Council }\end{array}$ & Equal opportunities & 1 & 1 & & \\
\hline 2006 & $\begin{array}{l}\text { Presidency } \\
\text { Conclusions }\end{array}$ & $\begin{array}{l}\text { Brussels European } \\
\text { Council }\end{array}$ & 3 & 2 & 1 & 1 \\
\hline
\end{tabular}




\begin{tabular}{|c|c|c|c|c|c|c|}
\hline \multirow[t]{2}{*}{ Year } & \multirow[t]{2}{*}{ Document type } & \multirow[t]{2}{*}{ Topic } & \multicolumn{4}{|c|}{ Nr of references } \\
\hline & & & Total & F1 & $F 2$ & F3 \\
\hline 2006 & Council Decision & EES guidelines & 2 & & 1 & \\
\hline 2006 & Council Decision & Rural Development & 3 & & 1 & \\
\hline 2006 & $\begin{array}{l}\text { Regulation of EP } \\
\text { and Council }\end{array}$ & ESF & 1 & & 1 & \\
\hline 2006 & $\begin{array}{l}\text { Corrigendum to } \\
\text { Council Regulation }\end{array}$ & $\begin{array}{l}\text { ESF, ERDF, Cohesion } \\
\text { fund }\end{array}$ & 1 & 1 & 1 & \\
\hline 2006 & Council Decision & Guidelines on cohesion & 1 & 1 & & \\
\hline 2007 & $\begin{array}{l}\text { Council } \\
\text { Conclusions }\end{array}$ & Alliance for Families & 9 & 1 & 2 & \\
\hline 2007 & $\begin{array}{l}\text { Council } \\
\text { Recommendation }\end{array}$ & $\begin{array}{l}\text { BEPG and EES } \\
\text { implementation } \\
\text { +update }\end{array}$ & 9 & 1 & 3 & \\
\hline 2007 & Council Decision & EES guidelines & 2 & & 1 & \\
\hline 2008 & $\begin{array}{l}\text { Council } \\
\text { Recommendation }\end{array}$ & $\begin{array}{l}\text { BEPG and EES } \\
\text { implementation } \\
\text { +update }\end{array}$ & 10 & 1 & 5 & \\
\hline 2008 & $\begin{array}{l}\text { Presidency } \\
\text { Conclusions }\end{array}$ & $\begin{array}{l}\text { Brussels European } \\
\text { Council }\end{array}$ & 1 & & 1 & \\
\hline 2008 & Council Decision & EES guidelines & 3 & & 2 & \\
\hline & Total: & & 182 & 52 & 71 & 1 \\
\hline
\end{tabular}

Source: Radulova (2009)

"Childcare" and its derivatives and synonyms appear 182 times in the 83 documents. Not all of these references are attributable to a policy frame, however. For example, the 1992 Recommendation on Child care is often referred to in other documents, i.e. the term 'childcare' is simply mentioned without signifying a policy 
frame. In the remaining 124 references a full-fledged policy frame - or at least its constitutive and policy dimension - could be discerned. In 52 cases childcare is linked to gender inequality (F1), in 71 cases to competitiveness (F2), and in 1 case to the demographic crisis in Europe (F3). Evidently, childcare as a policy solution has been mainly linked to the public problems of gender inequality and decreasing economic competitiveness, and the 'demography' policy frame is almost absent (only 1 reference). Therefore, the analysis in the rest of the article will focus only on the dynamics of representation and interplay between policy frames F1 and F2.

When the 'careers' (i.e. presence and frequency of appearance) of the two frames are plotted together on a graph, the following findings emerge (see Figure 4.2-1 and Figure 4.2-3):

1. F1 is the oldest policy frame in EU secondary legislation. The first reference linking childcare to the problem of gender inequality dates back to 1986. This late appearance is not at all surprising given that in the $12 \mathrm{EU}$ member states of the time public policy measures for childcare only became a prominent issue in the 1980s.

2. F2 only appears 10 years later (in 1996, i.e. two years before the endorsement of the first set of EES guidelines).

3. F1 is dominant until 1999 when it 'hands over the lead' to F2.

4. In the period from 1998 to 2002 (i.e. during the first 5 years of EES) the two policy frames co-exist in relative parity (20 references to F1 and 17 references to F2).

5. As from 2002 onwards, F2 clearly dominates over F1 (18 references to F1 and 52 references to $\mathrm{F} 2$ ). 
Figure 4.2-1 Frequency distribution by policy frame

(dynamics of interplay between F1 and F2)

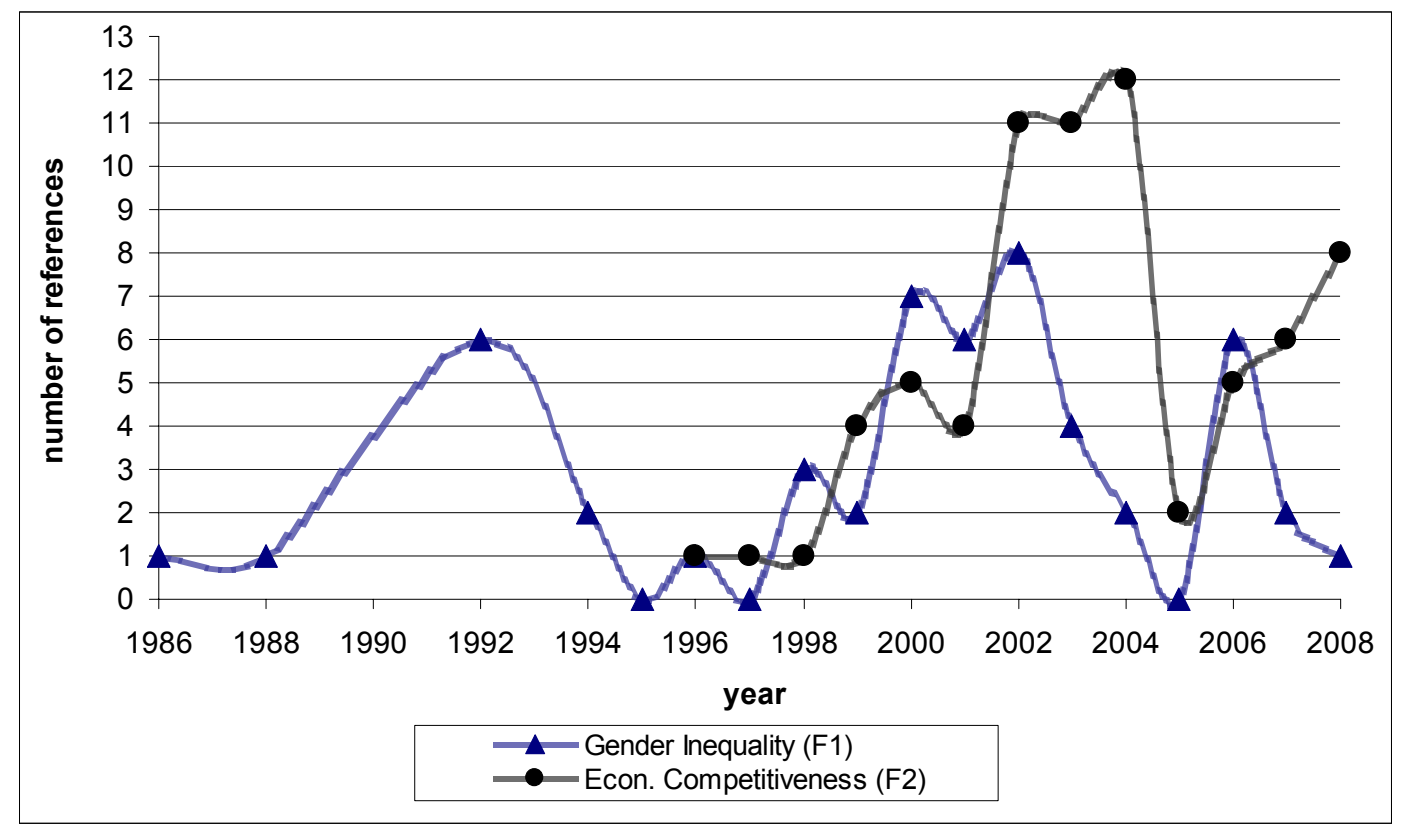

The conclusion that could be drawn from the data is that the EES has exercised a strong effect on the meaning of childcare and the types of policy problems it might potentially remedy as a policy solution. Up to the introduction of the employment OMC, childcare was linked only to the issue of gender equality, whereas the introduction of the EES coincides with the emergence of F2 in policy documents, i.e. with the linking of childcare to the issue of low female labour market participation and decreasing competitiveness. Furthermore, the findings reveal that three distinct periods in the 'career' of childcare could be set apart: up to 1998 (i.e. before the EES) when F1 is dominant, from 1998 to 2002 (i.e. after the introduction of the EES and until the first major reform of the EES guidelines) when F1 and F2 exist in relative parity, and from 2002 onwards when F2 clearly dominates over F1 (see Figure 4.2-3). 
Figure 4.2-2 Relative proportions of policy frames F1 and F2 in secondary EU legislation

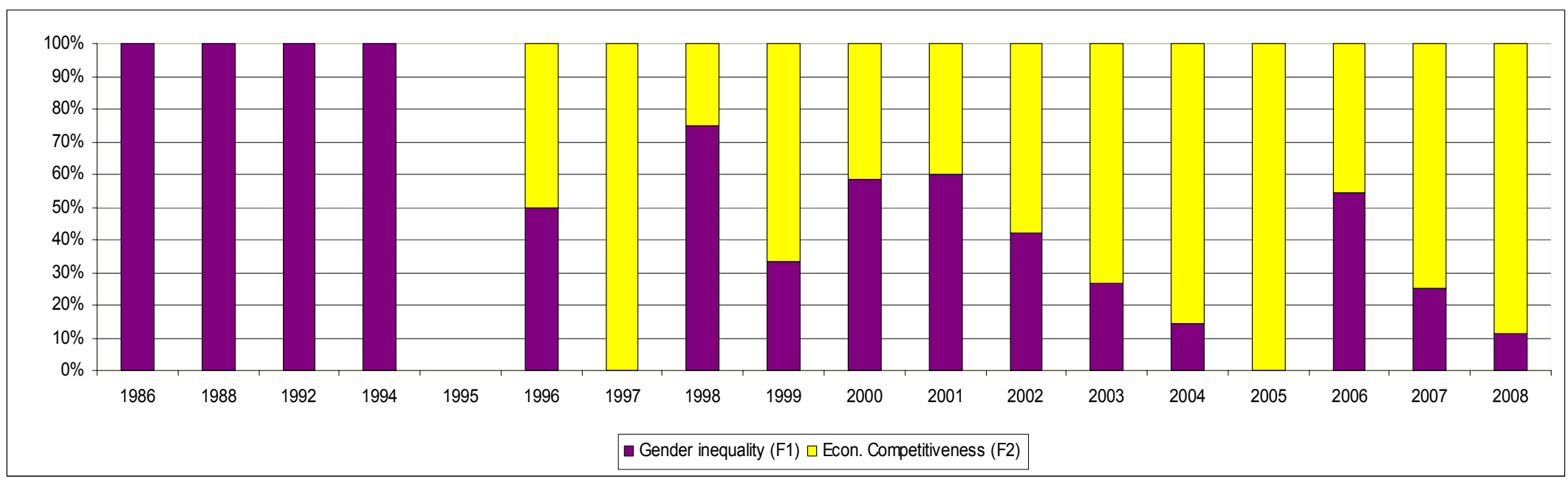

Source: Radulova (2009) 


\section{Figure 4.2-3 Three periods in the 'career' of the childcare solution}

\section{at the EU level of governance}

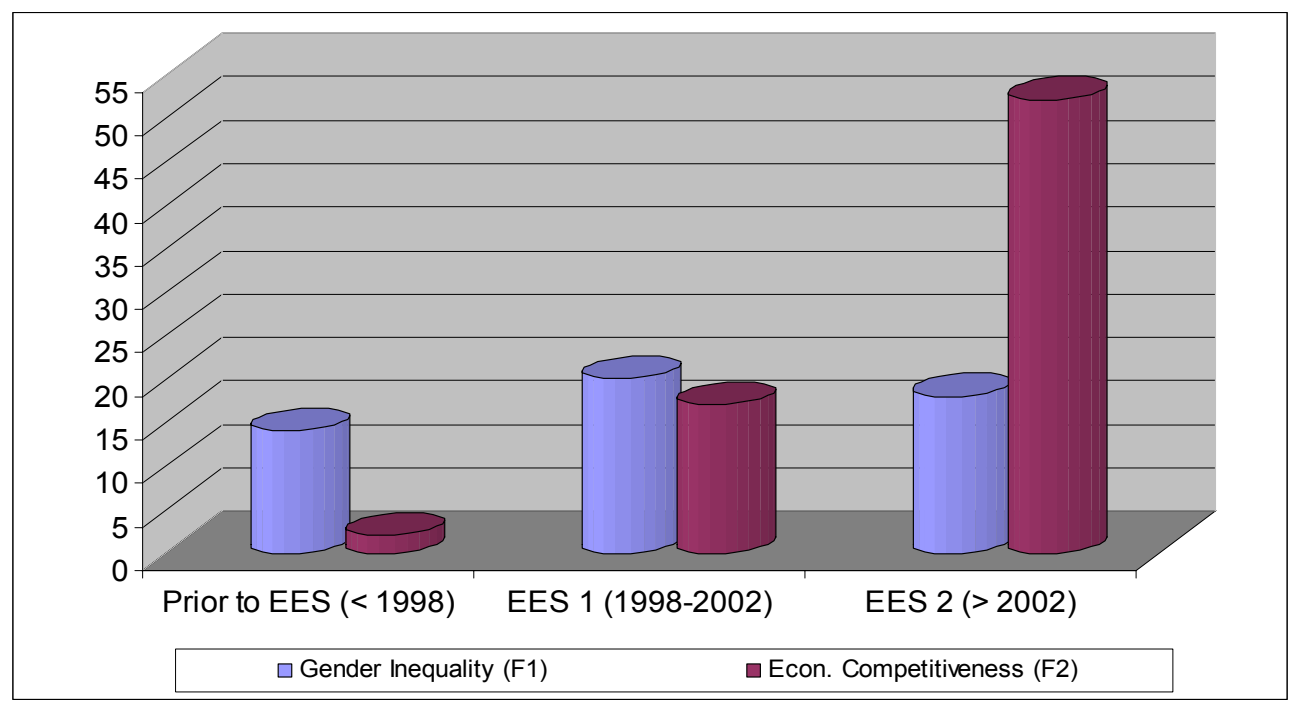

Source: Radulova (2009)

\section{Period 1: Dominance of gender equality concerns (until 1998)}

In the period before the introduction of the EES (up to 1998), the policy frame of gender inequality (F1) undoubtedly dominated EU policy making (14 out of 16 references could be attributed to this policy frame). An example of this policy frame is to be found in the 1992 Council recommendation on child care. There are six references to F1 in this policy document. Moreover, it contains all the elements of the gender inequality policy frame.

The normative dimension (based on the values of solidarity, equality, sharing, and equal opportunities) is outlined in article 6 of this Council recommendation:

\section{"Article 6 Sharing of responsibilities}

As regards responsibilities arising from the care and upbringing of children, it is recommended that Member States should promote and encourage, with due respect for freedom of the individual, 
increased participation by men, in order to achieve a more equal sharing of parental responsibilities between men and women and to enable women to have a more effective role in the labour market."

The constitutive dimension and a cognitive story are outlined in the preamble of the same 1992 Council recommendation:

"Whereas inadequate provision of child-care services at prices affordable to parents and other initiatives to reconcile responsibility for the family and the upbringing of children with the employment, or with the education and training of parents in order to obtain employment constitutes a major barrier to women's access to and more effective participation in the labour market, on equal terms with men, the effective participation of women in all areas of society and the effective use of their talents, skills and abilities in the current demographic situation;"

Finally, the policy dimension is the very raison d'etre of the document. Other documents where F1 is present in this period are several Council resolutions on equal opportunities or workforce participation of women (see Table 4.2-3).

It is visible from these citations that up to the mid-/late 1990s the dynamics of framing in the EU was favouring the policy frame of gender inequality. It has to be underlined however that this dominant frame was 'wrapped up' in Council resolutions or recommendations i.e. in instruments of non-binding nature. Moreover, these instruments were not part of a larger policy-making mechanism but had the character of a 'one-shot' event. In the following periods analyzed by the study, the legislation is again soft but they are supported by a larger process of steering (the $\mathrm{OMC})$, which arguably increases the potential influence of the policy frame.

\section{Period 2: Gradual turn to economic competitiveness concerns}

$$
(1998-2002)
$$

From 1998 onwards the policy discourse and the respective framing processes change. In this period a new conceptualisation emerges in policy documents: childcare is seen as a means of boosting EU's competitiveness by rising the employment rate of women and respectively the GDP growth. Up to 2002 this new conceptualisation co-existed in relative parity with the policy frame of gender inequality (20 references are attributable to F1 and 17 to F2). 
An example of framing from this period can be found in the EES guidelines of 1999. Guideline 21 thereof states:

\section{"Reconciling work and family life}

Policies on career breaks, parental leave and part-time work, as well as flexible working arrangements which serve the interests of both employers and employees, are of particular importance to women and men. Implementation of the various Directives and social partner agreements in this area should be accelerated and monitored regularly. There must be an adequate provision of good quality care for children and other dependents in order to support women's and men's entry and continued participation in the labour market. An equal sharing of family responsibilities is crucial in this respect. In order to strengthen equal opportunities, Member States and the social partners will:

21. Design, implement and promote family-friendly policies, including affordable, accessible and high quality care services for children and other dependents, as well as parental and other leave schemes."

Clearly, this guideline is about labour market participation (F2) but nevertheless still mentions "equal sharing" of unpaid work (F1) as an important element of a good reconciliation strategy.

Another illustration of the economic competitiveness frame (F2) can be found in the following policy recommendation directed to Ireland in 2001 (Council Recommendation of 19 January 2001 on the implementation of member states' employment policies):

\section{"Ireland should therefore:}

1. push abead with its comprehensive strategy aimed at increasing the proportion of women in employment, removing tax barriers and increasing child care places; and take action with the aim of reducing the gender pay gap..."

From the citations above a gradual turn in the framing of childcare could be discerned (from F1 to F2). Nevertheless, the policy frame of gender inequality (F1) is still very much present in the policy documents of this period. After the 5-year review of the EES, however, the normative and cognitive beliefs underlying childcare policy making decisively take the 'competitiveness' direction. 


\section{Period 3: Prevalence of economic competitiveness concerns}

(after 2002)

From 2002 onwards (with the first major reform of the EES guidelines) the competitiveness frame (F2) clearly dominates and the gender equality one (F1) resides in the background. In this period, there are only 18 references to F1, while 52 are devoted to F2. At the same time interpretations of public policy problems based on economic competitiveness arguments become leading at the EU level not only in the field of childcare (Hermans 2005).

At the beginning of this period, the European Council approved two quantitative targets in the field of childcare to be achieved by the member states until 20101:

"Member states should remove disincentives to female labour participation and strive, taking into account the demand for childcare facilities and in line with national patterns of provision, to provide childcare by 2010 to at least $90 \%$ of children between the 3 years old and the mandatory school age and at least 33\% of children under 3 years of age".

Already in this citation a narrow concept of reconciliation becomes visible. While up to 2002 the EES guidelines encouraged labour participation of women, but also stressed equal sharing of unpaid work as indispensable part of the reconciliation package (see guideline 21 of 1999 cited above), as of 2002, policy documents are stripped of any "sharing rhetoric" and speak directly and without any deviations about raising 'female labour participation'.

Another citation from this same period illustrates the point well. In 2005, the reform of the Lisbon strategy (currently referred to as Lisbon II or the Strategy of Growth and Jobs) brought about the merger of the EES guidelines and the Broad Economic Policy Guidelines. Reconciliation and respectively childcare have since then been part of the Integrated Guidelines for Growth and Jobs. Thus, guideline No. 18 of the 2005 Integrated Guidelines states:

"Promote a lifecycle approach to work, through: 
- a renewed endeavour to build employment pathways for young people and reduce youth unemployment, as called for in the European Youth Pact,

- resolute action to increase female participation and reduce gender gaps in employment, unemployment and pay,

- better reconciliation of work and private life and the provision of accessible and affordable childcare facilities and care for other dependants,

$-\ldots .$.

Similarly to the Barcelona objective, in this 18th guideline again in a very laconic style childcare is advanced as a means to increase labour market participation. With the endorsement of the 2002 EES guidelines the prevalence of economic concerns over gender inequality ones, i.e. the replacement of F1 by F2 as a leading conceptualization of the childcare policy solution is definite. Subsequently, the policy rhetoric abandons the earlier broader notion of reconciliation as sharing of paid and unpaid work. Instead, documents reveal a narrow conception of reconciliation - as only a measure to facilitate combination of work and caring tasks of women in the context of raising their participation rate in the labour market.

\subsection{CONCLUSIONS: WHAT VISION OF CHILDCARE DOES THE EU PROPAGATE?}

The European Employment Strategy (EES) can be conceptualised as a supranational steering mechanism that installs ideational and organizational mechanisms that aim to influence the normative and cognitive foundations of reconciliation policies in the EU member states by diffusion and iterative repetition of particular visions of appropriate policy. This chapter focused on the shift in the normative underpinnings of childcare policy at the EU level of governance triggered by the EES. To that end, the evolution of framing of childcare as a policy solution was traced in secondary EC legislation for the entire period of European integration. The empirical findings establish that prior to the endorsement of the EES in 1998 childcare was a policy solution almost exclusively linked to the problem of gender inequality. Since the introduction of the Employment OMC, however, the policy discourse changed considerably - the new overarching objective of increasing economic competitiveness installed a dominance of rational (economic) interpretations of public problems (and their solutions). Thus, the EES gradually 'redesigned' the initial (originally feminist) reading of what childcare is about, and diffused a much narrower notion of childcare that presents it as a tool that fosters 
female labour market participation. The study therefore confirms the expectation that the EES refocused the concept of reconciliation toward competitiveness. From 2002 onwards, this conceptualization (F2) of the policy problem became the dominant frame at least at the EU level of governance. Whether this has also become the case in the member states will be examined in the next section for the case of the Netherlands. 


\section{CASE STUDY: THE INFLUENCE OF THE EUROPEAN EMPLOYMENT STRATEGY ON THE DUTCH CHILDCARE POLICY- MAKING}

In the following two chapters is presented the case study of this thesis. Together they provide an overview of the Dutch public policy on childcare. Chapter 5 traces the evolution of the cultural norms, institutional and public policy developments, and the dynamics of the policy discourse on childcare. The aim is to examine the extent to which the Dutch childcare policy outputs, outcomes and discourses converge toward the EU's prescriptions. In the ensuing chapter 6 the procedural aspects of the policy process are reviewed, and the actors' standpoints (e.g. the trade unions, employer's organizations, political parties, etc.) are examined. The aim is to establish the extent to which the European Employment Strategy (EES) has had an impact on the Dutch policy-making process i.e. on the dominant discourses, policy instruments, programmes and their effects. 
5. Chapter

\section{THE DUTCH CHILDCARE POLICY STRUCTURES}

This chapter starts with an outline of the evolution of the cultural attitudes toward formal childcare, then provides an overview of the public policy measures undertaken by the Dutch government prior to the endorsement of the European Employment Strategy in 1997, before diving into the concrete primary data analysis of the three dependent variables of the study: policy discourses, policy outputs and policy outcomes in the period 1998-2008. The aim is to systematically examine the developments in the Dutch childcare policy, from the recognition that the care for children has a public policy dimension and is not entirely a private issue, through the various conceptualisations of the 'problem' of childcare and the respective public policy instruments employed, to the present-day state of affairs in this policy field. The aim of this analysis is to discern any EU influence on the Dutch policy developments. The chapter will demonstrate how ruling cultural views and prior policy developments set the stage and shape the childcare policy observed in the second half of the 2000s.

\subsection{THE ATTITUDE TOWARD PARENTING AND \\ CHILDCARE IN THE NETHERLANDS: A CULTURAL CHRONICLE}

The Netherlands has a long history of adherence to the so-called housewife model' (also known as the male breadwinner/ woman homemaker model or only as the male breadwinner model - Lewis, 1992). According to Schama (quoted in Pfau- 
Efinger, 2004), the housewife model thrived in the Netherlands as early as the 17th century, much earlier than anywhere else in Europe (Schama, 1988). Similarly, Brouns and Zwinkels observe that the family ideal of separation between the public and private sphere and the related responsibilities emerged in the course of the 18th and 19th centuries, and was particularly pursued by the city bourgeoisie in their 'civilizing offensive' of the 19th century (Brouns and Zwinkels, 1995: 263). Moreover, childhood had become an independent phase of life much earlier than elsewhere in Europe, and children where of greater importance to society (Pfau-Effinger, 2004: 104). Women were in charge for the upbringing of the children, and as such they were also seen as the primary sources of moral values and norms. They were the main responsible to provide and cultivate these into their children and therefore were highly esteemed and enjoyed great social respect and importance. Furthermore, Dutch women had the right to private property and inheritance. In short, they enjoyed greater rights and a social position much different from the one of their fellow females around Europe i.e. one of subordinance and obedience to the malehusband (Pfau-Effinger, 2004: 106).

While for Western Europe the housewife ideal was coupled with the arrival of the industrialization and modern capitalism (Brouns and Zwinkels, 1995: 57), in the Netherlands this was already the case for large groups of society before the industrialization. The industrialization only confirmed the already ongoing social processes. Subsequently, childcare was already exclusively performed by the mother at home. Only (poor) families where parents worked in the factories, had to send their children to the so-called "bewaarscholen" (surveillance schools). The children stayed there in big numbers and under bad conditions, while old women (the ones incapable to work in the factories) took care for them. Upbringing was never performed by these 'schools', hygiene was also highly unsatisfactory (IJzendoorn et al., 2004). Because of that in 1869 an organization was formed to reform the 'bewaarscholen'. New "bewaarplaatsen" (surveillance places) emerged where hygiene was the primary objective and which were governed by committees of well-off city ladies. Nevertheless, childcare outside the home was viewed by the society as far from the ideal situation and only as a solution in case of family failure to manage on its own. Much more preferred was the option where the mother takes care of the children at home, while the father is engaged in paid employment (i.e. acts as the breadwinner). This is also the model for which the trade unions pleaded (PfauEffinger, 2004).

At the beginning of the 20th century the trade unions were successful in their demands to assure the so-called "family wage" for the (usually) male breadwinner. From then on it was rarely needed that women worked. The housewife model proliferated among all social classes, and became the norm in the Netherlands. It is therefore since the dawn of the 20th c. that the Dutch society at large embraced two 
conceptions that would be deeply ingrained in the culture of the Low countries for nearly a century - the male-breadwinner model of the family, and the notion that childcare outside the family is not good for the children. By striving for the housewife ideal and the related mothering ideal the majority of the Dutch followed a firm cultural and behavioural norm that would only begin to crack in the 1980s and 1990s.

The heydays of the male breadwinner model were the 1950s. In this decade it was not conceivable for a woman to be anywhere else but at home taking care for dependents and for the household. "De plaats van de vrouw is thuis" (the woman's place is at home) indicates the deep embeddedness of this norm in Dutch gender culture (Pfau-Effinger, 2004: 109). The pillarised structure of society kept these dominant cultural norms well in place (Andeweg).

There was also a strong political consensus against working women. The governmental policy reflected the dominant cultural conceptions - women were fired once they got married or once they gave birth to their first child (Pfau-Effinger, 2004). Consequently, the social norm postulated that in 'good families' children are cared for at home, and that childcare outside the home is only for failing families. Similarly, post WWII the welfare state was based on the assumption of the gendered division of labour and actively discouraged women (via the tax and social security system) to remain in paid employment after marriage (Bussemaker and Kersbergen, 1999; Kersbergen and Kremer, 2008). Given that mothers stayed at home, clearly, only parents with 'abnormal' family situations made use of formal childcare services, and one needed an indication for it (interview 12 and 13). This was also the policy line pursued by all political parties (Kremer, 2005: 158). Moreover, the Dutch breadwinners were doing well enough to afford to keep their wives at home. The fact that the families were rich, and that the pillars were supporting the existing gender norms, explains why no movement away from the status quo happened until the 1960s (Kremer, 2005: 160).

The late 1960s witnessed a profound transformation not only of gender norms but of all sorts of moral, religious, political views, beliefs and principles. Within a very short period of time, known as the "cultural revolution", the Dutch society was fundamentally secularized and liberalized (Rooden, quoted in Pfau-Effinger, 2004). Among all other social changes the cultural revolution, reinforced by the feminist liberation movement (that peaked in the 1970s), led to the gradual erosion of the male breadwinner model.

The 1970s witnessed the erosion of the 'old' believe that the place of the woman was at home, and that a good mother is one that is entirely dedicated to the care for the children and to the household. It became acceptable for a mother to engage in paid employment and to work outside the home. It has to be underlined, however, that the significant change in attitudes toward female employment was not coupled with a comparable alteration in the Dutch conception of 'childhood' and 
children's upbringing (Pfau-Effinger, 2004: 113). The care for the children remained (ideally conceived) within the realm of the private sphere, preferably by the mother herself or other relatives (most often the grandparents). The idea that women might enter the labour market and that mothers might work was new, but the ideal that children should be raised at home and cared for by their mothers (or at least by some other close relative) remained untouched. It became acceptable for women to work, but the image that children would be cared for outside the home by strangers was not acceptable. Upbringing outside the home was not viewed as a valuable asset- to the contrary, and women themselves did not find it a good idea. That is why they would not enter the labour market until their children went to school, and then would only work part-time.

The 1980s brought the debates about the reform of the welfare state. The new agenda of cutting the spendings of the welfare state and the 'activation/breaking the benefit dependency' model resonated well with the emerging discourse that pointed to housewives as wasted human capital (untapped labour market potential). The general socio-cultural trend of growing number of women who entered the labour market matched nicely the emerging reform programme. With women massively 'invading' the labour market the question how to assure reconciliation between work and family responsibilities became more and more pressing. There were two policy measures suggested in this regard: part-time work and daycare centres. The latter policy instrument did not develop much during the 1980s, however. Due to the still firm belief of the Dutch in the family upbringing and the profound conviction that daycare centres are not the appropriate place for it, the government preferred to search for other alternatives to the work-care dilemma, and chose instead for support of families via fiscal measures (see section 5.2.).

Instead of resorting to formal childcare Dutch women chose to work parttime. In practice this meant that most women would withdraw from the labour market when their children are small, and would return to it on a part-time basis once the youngest went to school (at 4 years of age). They might engage in full-time employment once the youngest child reached the age of 12 but such cases were rather rare. In other words, for the period of active motherhood the only form of employment deemed acceptable by mothers themselves and society at large was parttime work (Knijn, 1994). Mothers believed that their primary task in life was the upbringing of the children. Consequently, they gave a higher priority to what they perceived as the well-being of the child than to their own professional career, and were prepared to organise their leisure time around the leisure activities of their children (Knijn, 1994).

This is how in the course of the 1980s the Dutch male breadwinner model was replaced by a 'one-and-a-half' earner model i.e. women worked part time so that they could remain the principal carers for the children. In this context, it is important to 
underline that had it not been for the expansion of the service sector, and the concerted effort to create jobs for secondary earners (and more generally, the availability of part-time work, which seems to have been key to Dutch economic revival in the 1980s - see Visser, 1997) no transformation of the Dutch gender model would have taken place.

In the 1990s, with working women (albeit part-time) becoming the norm, it became more and more acceptable for children to visit day-care centres for a couple of days a week. The problem then was that the country did not dispose of enough capacity to accommodate the increasing need of formal childcare and long waiting lists emerged (especially in the Randstad). All efforts therefore focused on enlarging the existing capacities and on improving the availability of places. State stimulatory measures were introduced and employers arranged company day-care centres (bedrijfscreches).

This policy was successful, and during the 2000s an ever growing number of children visited childcare facilities (see Table 5.4-1). Nevertheless, the days in the daycare centre are ideally kept at a minimum - max 3 days a week. The majority of the Dutch still consider formal childcare the necessary evil and look upon it with distrust (Portegijs, 2008: 45 and 135). The Balkenende IV cabinet (in office from 2007 to 2010) aimed to address this attitude by stressing the positive socialisation effects and educational added value of childcare. In April 2007 the cooperating brancheorganizations launched, with the support of the government, the campaign "Dat gun je ieder kind"1. In the messages of this campaign childcare is presented as boosting children's development and educational capabilities from an early age. Whether this is indeed the case and whether this new policy programme (inspired by the "socialisation" policy frame - F5) will be successful is a separate issue. What is clear is that the number of childcare places and the children visiting them have been growing, although on a part-time basis (see Table 5.4-1).

Another important cultural development from the 1990s and the 2000s was the emergence of the 'parental sharing' ideal (Kremers). It was the ideational mirror of two parallel processes in the Dutch society, namely that women wanted and started working, while men were willing to stay more at home and take a greater share in the caring and upbringing of their children. The latter process is a European-wide trend. Its materialisation, however, is difficult anywhere outside Scandinavia due to the lack of state support (traditionally very strong in Scandinavia) or the impossibility of families to miss percentage of the male income. The Netherlands, where part-time work is well-organized and well-paid, and where the GDP per capita is one of the

1 "You would like your child to enjoy childcare". 
highest in Europe can afford this. Hence, the take-up rate ${ }^{1}$ in the country is one of the highest in Europe (European Commission, Gender equality report 2010).

All in all, nowadays the typical Dutch family rarely sends its children to daycare for more than 3 full days a week (interview 8). This is why the status quo at the moment is a model of the family based on two $3 / 4$ earners among the higher educated Dutch citizens, and among the rest of the families the 1 and $1 / 2$ model is still the ruling one (Portegijs, 2008: 45 and 135).

To summarise, this section presented a cultural chronicle of the Dutch gender relations, parenting and childcare attitude. The literature review established that in the Netherlands there were two cultural ideals - the mothering and the housewife ideal that shaped the views and the mindset toward the provision of out-of-home (formal) childcare. The development of these two ideals was traced, and it was revealed that in the course of the 1970s and 80s the housewife ideal (i.e. the male breadwinner model of the family) gave way to a gender order where women's participation in the labour market is considered an acceptable and normal fact of reality. Contrary to the dismantlement of the housewife ideal, only minor transformation took place with the mothering ideal. The Dutch remain to the present day attached to the idea that they themselves (or close relatives) will be the principal care-takers of their children. Yet still the mothering ideal got transformed into the 'parental sharing' ideal. The fact that part-time jobs in the Netherlands are not precarious, and allow for a good standard of living, even at a $3 / 4$ level of income, facilitates the realisation of this cultural preference.

\subsection{PUBLIC POLICY DEVELOPMENTS}

Childcare was hardly seen as a public problem until the end of the Second World War. Prior to that, daycare centres in the contemporary meaning of the word did not exist. "Bewaarscholen" and "bewaarplaatsen" (surveillance schools or places) did exist but they were visited by children with an anomalous family situation e.g. where the parent(s) were dead or incapable to take care of their children (see also section 5.1.). After the WWII, with the growth of the welfare state the centres for childcare started to receive subsidies and became part of the welfare policy. Nevertheless, they remained arrangements for the poor children that were growing up under atypical conditions. Actually, it was the welfare state that was seen as the

\footnotetext{
1 This rate indicates the number of parents who are entitled and make use of parental leave compared to all parents who are entitled to parental leave.
} 
necessary institutional structure to assure that children are taken care of well i.e. at home by their mothers. It has been a long-standing assumption and a major standpoint of the Dutch welfare state that care activities are performed informally i.e. within the family unit. Moreover, this was an indicator for the proper functioning of the welfare state as it was believed that in a successful welfare state families did not need childcare because the state was rich enough to allow women to stay at home and care. In the 1960s public childcare was even regarded as something immoral in a well-developed welfare state (Bussemaker, 1998: 71). "By an all-pervading system of breadwinner facilities, women were defined as mothers, destined for the private sphere, whereas men were responsible for the public sphere, the world of paid employment” (Plantenga, 1999: 157).

From the end of the 1960s onwards, the cultural visions about the social role of women began to change substantially upon insistence of some groups within the feminist movement for greater gender equality, including access to paid employment. Childcare gained gradually public character i.e. began to be seen as an issue that does not solely concern the private sphere. Consequently, for the first time the Dutch government received demands for the organization of mass-scale out-of-home (formal) childcare. The first societal group to spell out the link between the public provision of childcare and gender equality (in this research this is denoted as policy frame 1 or F1) was Man-Vrouw-Maatschappij (the Man-Woman-Society), which together with Dolle Mina organised a series of crèche-actions (Peters, 1999: 96). The government however turned a blind eye to these demands (IJzendoorn et al., 2004: 16). One of the reasons for that is that the feminist movement itself was divided on the issue. Some feminist groups demanded childcare, others were firmly against it due to the mothering ideal (interview 11). The latter insisted on women remaining the principal carers for household and children, but that this unpaid work became officially recognised and paid for. Due to these divisions, no concerted push for action came from these societal pressure groups. In terms of this research: the problem of gender equality (P1) was prominent and high on the agenda, but the policy solutions were sought in facilitating access to paid employment. No influential actor $^{1}$ coupled P1 to childcare. Subsequently, the government did not stimulate childcare during the 1960s. Nevertheless, some changes did come about in the late 1960s. The "bewaarplaats" was replaced by the "crèche" or the "kinderdagverblijf". Furthermore, next to caring (verzorging), upbringing functions (opvoeding) became also part of the description of a day-care centre (IJzendoorn et al., 2004) Finally, in 1965 the first peuterspeelzaalen (toddler playgroups) emerged. The rationale behind these public facilities for children was to assure socialisation, to support parents in their upbringing (opvoeding) responsibilities and to prepare for school. These

\footnotetext{
${ }^{1}$ No one from the Parliament or from the governing coalition.
} 
services have always been available for a couple of hours per day only, and were not meant as an instrument to reconcile work and private life.

Throughout the 1970s women groups were regularly placing the issue of childcare on to the public agenda, but despite the growing need for childcare facilities (due to the growing numbers of working women), governmental action was not initiated. Nevertheless, the private sector responded partially to the women's claims, and in the decade of the 70s company daycare centres emerged (bedrijfcreches) in sectors where women were greatly needed (FNV, 2006). Still, these were corporate initiatives, and no governmental action was undertaken. According to the Childcare nota of FNV from 2006 this is due to the fact that the mothering ideal was not only still strong culturally, but also embedded in the normative stance of one of the main political actors, the Christian Democrats (Christen Democratisch Appel or CDA). According to the CDA position at the time, mothers would ideally stay at home and care for the children (interview 11 and see also section 6.2.1.6.) Given that the CDA was the main partner in all coalition governments (see Table 5.5-1 below) it acted as a gatekeeper with enormous influence (interview 14) and (Peters, 1999: 114). It is not surprising therefore that also in this decade there was no governmental commitment to the support of formal childcare. Until the 1990s this service remained atypical for the average Dutch family, and the majority of children going to day-care centres were "problem cases".

Basically, throughout the 1980s nothing changed with regard to policy programmes and instruments for childcare - the state simply did not deem public actions necessary. There was a short exception to this policy line in 1981. The van Agt II government ${ }^{1}$, where the Labour Party (Partij van de Arbeid or PvdA) was strongly represented, formulated for the first time a state policy on childcare. This was a breakthrough, yet this government lasted less than a year (until May 1982) and its policy was not continued by the ensuing cabinets (Peters, 1999: 97). Instead the Lubbers $^{2}$ era arrived, characterised by aspirations to reform the welfare state, and for which the keywords were 'saving', 'decentralization' and 'personal responsibility'. In the debates about the welfare state reform the Dutch politicians became strong advocates of the market and the 'community' (Kremer, 2005: 158) as the primary sources of welfare. They stressed the personal responsibility for one's wellbeing and the need to diminish the role of the state therein.

1 The state secretary for emancipation in this cabinet was Heidi d'Ancona - one of the founders of the Man-Vrouw Maatschappij.

2 Named after Ruud Lubbers - the Prime Minister who served 2 terms in office and who defined and accomplished the welfare state reform of the Netherlands in the 1990s. 
In this context a key agreement on how to accomplish the reform of the welfare state - the so-called 'Wassenaar consensus' - was reached in 1982 between the government and the Social partners. The main elements of this agreement, which would become the cornerstone of the Dutch economic reform and revival, included the freezing of wages, the fighting of unemployment via part-time jobs, and the raising of female employment (Visser and Hemerijk, 1997). This is how female employment became not only an emancipation goal but also an instrument to accomplish the welfare state reform in the Netherlands. Moreover, from a rather marginalised feminist objective it became part of the mainstream policy agenda.

This radical change in the attitude of political actors toward female employment did not induce a follow-up change in the views toward childcare. Hence, next to public policy problem P1 (gender inequality) now also P2 (low female labour market participation) was articulated in the public sphere but again the solution was not sought in childcare due to the deep entrenchment of the mothering/ home-based upbringing ideal. Hence, the solution to P2 was sought in part-time work. Part-time work assured that women could work (while their children are at school) and could care (once the school-day is over and the children are back home). Thus, throughout the 1980s women massively entered the labour market but worked predominantly part- time in order to be personally able to take care for their children.

In 1984, in order to stimulate the female labour market participation, the government introduced a fiscal rebate for second earners in families with children younger than 12. This decision can be regarded as the beginning of the end of the male-breadwinner model at public level (which until then was supported by different institutions of the welfare state). It was explicitly chosen not to stimulate childcare facilities directly, but to give families extra money and to allow them to find individual solutions. Hence, in the mid 1980s the Dutch government again did not stimulate the growth of childcare facilities but opted for an alternative policy measure.

The turning point in the official stance on childcare came at the end of the 1980s. The decisive push came from the Employers as they realised that in order to attract women to fill in the job vacancies or to keep their present female employees after having given birth, childcare has to be provided (interview 12). Leave periods or money transfers were not a viable solution, because such instruments keep women away from paid employment. Conversely, the childcare service was a perfect match between the need to attract (or keep) women on the labour market and the care for the children. It was therefore largely a push from the employers that placed the issue of the needed growth of childcare facilities firmly on the public agenda (interview 12). The issue had been advocated in the public sphere for already more than 15 years by the Labour party ( $\mathrm{PvdA})$, the FNV trade union and various women's organizations, and supported by the Liberals (the D66 and the VVD), but until the end of the 1980s 
it was linked to a different problem e.g. gender equality (see also section 6.3). Once women began to be seen as an untapped resource of labour by the employers and the government acknowledged the need of their human capital, the governmental position toward childcare began to change. Throughout the 1990s and the first decade of the 21st century this would be the dominant policy frame in Dutch childcare policy-making (see section 5.3). Childcare has started losing its negative image, but is still not well accepted in society. It is seen as the "necessary evil" and used as less as possible - for 2 to 3 days a week.

The concrete beginning of a consciously pursued public childcare policy in the Netherlands is considered to be the abolishment in 1988 of the special fiscal rebate of 1984. Ensuing the advice of a special committee (Oort committee) this rebate was discontinued and 130 million guilders became available. The Ministry of Public health, Wellbeing and Sport (VWS) asked several prominent governmental advisory committees for advice on how to allocate the money and, more generally, how to approach childcare in public policy at the beginning of the 1990s. The received advice emphasized the quick maximisation of the available childcare places especially through cheap forms of childcare (e.g. the guest-parent model "gastouders"). From the letter asking for advise as well as from the interpretation of it by the advisory committees it is obvious that the government regarded childcare predominantly as an instrument to stimulate female labour market participation (SER, 1989: 16). This was the second attempt since 1981 to develop Dutch public policy on childcare. This time however it surpassed the policy formulation stage and was actually implemented.

In 1989 the new cabinet's coalition agreement (formed after the 2nd chamber elections of September 1989) included 130 million per year for childcare (Peters, 1999: 98). The concrete governmental act endorsed by the VWS Ministry was the Stimuleringsmaatregel Kinderopvang 1990-1993 (Stimulatory Measure Childcare 1990-1993). Albeit of temporary nature, the act can be regarded as the official start of the Dutch public policy on childcare. The subsidy measure was extended until 1996 when childcare policy was transferred to the portfolios of the municipal authorities (Plantenga, 1999: 160).

To summarise, until the 1980s childcare facilities in the Netherlands were a welfare measure administrated by the Ministry for Public Health, Wellbeing and Sport (VWS). These were places for deprived children, whose mothers (for various reasons) could not take care of them e.g. were handicapped or in a psychiatric clinic. Formal childcare was a provision for abnormal family situations. A typical working family did not use it, and "one needed an indication in order to use childcare services" (interview 12). As of the 1980s it was realised that childcare might serve as a reconciliation measure and might facilitate the ongoing emancipation of women. Company day-care centres emerged and long waiting lists became the reality. The big public investment in childcare began in the Netherlands only at the beginning of the 
1990s following the realisation that the provision of formal childcare might improve the labour market participation of women, a goal pursued by all major policy actors. From then on childcare provision became part of the portfolio of the Ministry for Social Affairs and Employment.

In sum, at the time when the proposal for an European Employment Strategy (EES) was tabled in 1997, the Netherlands had already for nearly 10 years stimulated the domestic growth of childcare facilities. That is why the policy prescriptions of the EES with regard to childcare were welcome by the Netherlands as long as they were not binding (interview 9). The Strategy itself was not a direct 'upload' of the Dutch position at the EU level - the ideational roots of the EES are in Scandinavia (see also Section 2.2.), where the policy of provision of non-home based childcare has long traditions and high (pedagogical) quality. Nevertheless, the Netherlands aspired for similar levels of availability of the childcare service, so it was not difficult to agree on the childcare goals of the EES.

\subsection{POLICY OUTPUTS AFTER THE INTRODUCTION OF THE EES}

This section continues reviewing the childcare policy developments in the Netherlands but zooms in the policy outputs between 1998 and 2008 (i.e. the first 10 years after the introduction of the EES) in much greater detail than in the previous section in order to examine the domestic impact of the EES. By scrutinizing the first 10 years of implementation of the EES this section aims to establish to what extent the policy developments in the field of childcare changed after the endorsement of the EES.

The policy outputs are 'captured' by an overview (year-by-year) of the activities that the Dutch government undertook in the 10-year period under scrutiny. These activities are derived from the National Action Plans as provided by the Dutch government in the context of the EES. These plans report all policy actions undertaken by the national administration for implementation of each EES guideline. A year by year discussion of these self-reported activities will demonstrate everything that has been undertaken with regard to the policy of reconciliation of work and family life and childcare in particular. Clearly, this review will not be a sufficient 'proof that the EES has been the initiation of these policy activities, but at least a list of policy activities will be presented as to what has happened after the introduction of the EES. This will serve as a basis for comparison with the period before the EES, and major departures from the status quo before the EES will become immediately 
evident. It will then be subject of further analysis (via documentary analysis and via interviews with policy actors) to determine whether the identified policy actions were induced by the EES.

\section{Policy activities from 1998 to 2008}

In its first National Action Plan in the context of the EES (from 1998) the government declares the removal of any existing barriers to increased female labour market participation as one of its main employment policy priorities (NAP 1998: 5). To that end reconciliation of work and family life is placed high on the governmental agenda (p. 5). Consequently, the main instrument is "more, and more affordable childcare facilities" (p. 13). Existing childcare facilities are qualified as "inadequate" (p. 31). In this context, it is not surprising that the concrete policy actions that were undertaken are related to initial research and orientation. Concretely, a study was conducted about the expected need for childcare places up until 2010, and a costbenefit analysis of an adequate childcare system was undertaken (p. 13).

Further in the NAP of 1998 under the section devoted to Guideline 17 (the childcare guideline - see Annex A) it is again stressed that the childcare situation is not "adequate" (p. 32) and that "an increase in childcare is essential" if the objective of higher levels of female participation is to be achieved (p. 33). The plan aimed at the creation of 20,000 new childcare places for 0-12 year-olds within the following 4 years.

To summarise, in the first year of the new European Employment Strategy (EES) the Dutch government presented an inventory of the policy status-quo and undertook initial policy research (cost-benefit analysis and prognosis of the needs). Furthermore, the existing facilities were labelled "inadequate" and a policy intention was declared for the creation of 20,000 new places in the 4 forthcoming years. In sum, the whole NAP was quite well synchronised with the policy prescriptions of the EES.

The National Action Plan of $\mathbf{1 9 9 9}$ is to a large extent a confirmation and extension of the policy line of 1998. This is hardly surprising given that the ruling coalition was voted to stay in office (during the elections of 1998) and the Kok II government came to power. Thus, reconciliation of work and family life remained among the three main employment policy priorities (NAP 1999: 2). In the NAP it was stated that the new coalition agreement was committed to boosting the childcare facilities in the country via funding subsidies to municipalities and via fiscal measures (p. 55). The ambitious 4 -year plan amounts to 181 million euro. 
Under the section devoted to Guideline 21 (in 1999 this was the childcare guideline - see Annex A) next to the renewed commitment to the plan to create 20,000 new childcare places, the NAP reports 2 new policy initiatives as of 1 January 1999 (p. 55):

- the tax relief for employer's childcare costs introduced in 1996 was raised from $20 \%$ to $30 \%$;

- 2500 jobs were created in child care as part of the scheme to create jobs for the long-term unemployed.

To summarise, in 1999 a 4-year plan of serious financial commitment was launched that aimed to increase the capacity of childcare facilities. Moreover, the Dutch government provided the employers with a bonus tax relief of $10 \%$ so that they could easier meet the childcare contributions of their employees. Thus, at the end of 1999 the employers' tax substractable contribution to the childcare costs of their employees was $30 \%$.

The NAP of 2000 sticks to the policy line of the two previous years. The participation of women on the labour market is found (again) insufficient, and its increase is among the top-three priorities in the field of employment (p. 7). The instruments to achieve this goal are childcare facilities, leave schemes, part time jobs and tax incentives (p. 25). The childcare 'solution' is always mentioned first among the list of instruments. Moreover, it is explicitly stated that it "is high on the policy agenda" (p. 21), indicating that among the available instruments it has priority.

In addition to the ongoing activities from previous years, in 2000 three new measures are undertaken by the government with regard to childcare. Firstly, intentions are expressed to regulate the quality, structure, funding and monitoring of formal childcare through a Childcare (Basic Provision) Act. The law is allegedly in preparation and is expected to come in force after 2002 (p. 21). Secondly, The Netwerkbureau Uitbreiding Kinderopvang (the Network Office for Childcare facility Growth) is established with the mandate to gather statistics and track the quantitative increase of childcare places that results from the undertaken policy actions. Thirdly, the Social Partners were consulted about the inclusion of childcare provisions in more collective labour agreements (CLA). At the end of $199955 \%$ of the CLA in the Netherlands included such provisions (p. 21).

Furthermore, the NAP of 2000 commented on how the Netherlands addressed the EU's recommendation of 1999, where it was suggested inter alia that the country should remove the barriers to female labour market participation (p. 24). Interestingly, the government admits that at the beginning of the new millennium the Dutch social security system "still retains elements of the male breadwinner model". A commitment is therefore expressed to review all social-security schemes with a 
view to discontinue schemes that encourage women to stay away from the labour market (p. 25).

In 2001 the policy commitment to increase women's labour market participation is upheld as a top priority for the government. What is more, in February the Netherlands endorses a national quantitative target that is higher than the one of the EU. Instead of $60 \%$ female labour market participation to be reached by 2010 (the Lisbon target of 2000) the Netherlands commits to the higher 65\% (p. 8). Furthermore, a new observatory instrument is launched - the 'equal right monitor', which aims to track inter alia the amount of hours that women work and the organization of family responsibilities and work (p. 26).

In the context of the implementation of Guideline 18 (in 2001 this is the childcare guideline - see Annex A) next to the enumeration of the already existing initiatives there is only one new programme that offers childcare facilities to job seekers (p. 28). There are no Council recommendations related to childcare policy in 2001.

In 2002, during the last year of the Kok II cabinet, there are no surprises in terms of implementation of the EES guidelines. Labour force participation of women is again a top priority, and the government aims to achieve $65 \%$ female participation by 2010 (p. 11). A novelty represents the commitment "to meet the total demand for childcare" (p. 11). This is expected to be the result of the Childcare (Basic Provision) Act that will "produce a free market in childcare" and will lead to "adequate supply" (p. 22). The Act, which was supposed to enter into force in 2003, is postponed for 2004 in order to assure "proper implementation" (p. 22, footnote 15). Next to this policy intention, a new fiscal instrument (tax credit) was launched in 2002. Families where both parents work, and where the children visit formal childcare facilities would receive a tax deduction for their childcare costs depending on the income levels (p. 16). Furthermore, the government launched a new scheme that provides childcare to jobseekers who are in the process of reintegrating on the labour market (p. 34). Moreover, more fiscal resources were made available for the financial instrument (KOA scheme) that provides daycare services to lone parents on benefits who accept to follow a programme for reintegration on the labour market (p. 34).

Interestingly, the NAP of 2002 also provides a policy evaluation of the Kok II government. Firstly, the NAP of 2002 reports successful implementation of the 4year scheme for expanding daycare launched in 1998 (p. 21-22). This expansion has led to the achievement of approximately $25 \%$ coverage rate ${ }^{1}$ for under-3-year-olds ( $\mathrm{p}$. 22). In other words, during the first 4 years of implementation of the EES and under

1 This number converges with the calculated in this study coverage rate, namely $23,53 \%$ for 2002 (see section 5.4 .) 
the PvdA-led coalition governemnt, the Netherlands continuously committed policy resources to the expansion of childcare facilities, and these efforts set the country firmly on the way toward achieving the coverage rate that the EU requires from its member states in the context of the EES.

Secondly, the year 2002 is an assessment year for the 5-year existence of the EES. The NAP of 2002 reports that in general the EES is seen as a useful tool by the Dutch government, and as a positive development in the wider EU context (p. 39). The focus on active labour market policies of the EES and the coherent, comprehensive approach of the EES is considered to provide a viable framework for reforms both domestically and in the EU. Consequently, the Netherlands is in favour of continuation of the Strategy beyond 2002 provided some administrative/ procedural elements are altered, in particular the bureaucratic character of the process and the slow pace of achieving the desired targets (p. 39). In terms of substantive policies the Netherlands is viewed as complying with the EU guidelines ${ }^{1}$. In the few areas where the Dutch performance is lagging behind (participation of older workers and women, or the high level of inactivity) the EES has been instrumental in taking a number of measures, but the policy agenda has not changed in any substantial way (p. 39) i.e. similar intentions and policy actions would have been undertaken by the government even if the EES did not exist. Nevertheless, the agreements at the EU level confirmed the domestically chosen approach.

The NAP of $\mathbf{2 0 0 3}$ reiterates that female labour market participation is a priority for the government, and stresses the new fiscal measure (introduced in 2002) that stimulates secondary earners by an extra tax credit (p. 5). With regard to childcare the NAP provides statistical data about the increase of childcare places in the country until 2002, and underlines that the target of 10,000 additional places during 2003 is reached (p. 19). The long expected Childcare Act was yet again postponed for the beginning of 2005 .

The NAP of 2004 is to a large extent a continuation of the 2003 one. The EES guidelines and the policy priorities remained the same, and not much has changed with regard to the implementation either. In terms of strategic priorities, the main focus is again on participation and the supply of labour (fully in line with the EES). Next to the typical considerations of how to get more people on the labour market, the document reports that consultations have taken place about the potential encouragement of more working hours e.g. how to get the so-called 'small part-time jobs' to grow to 'big part-time jobs', and how to encourage the flow from 'big parttime jobs' to 'full-time jobs' (p. 13). With regard to childcare the NAP reports the

\footnotetext{
1 This assessment comes from the 2 reports commissioned by the government that aim to review the Dutch experiences with the implementation of the EES.
} 
latest statistics about the growth of the available childcare places (p. 24). Furthermore, the NAP indicates that the new Childcare (Basic Provision) Act that will expectedly come into force on 1 January 2005 will tackle the issue of affordability of childcare (p. 25). Indeed, in 2003 the Netherlands received their second Council recommendation on childcare that suggested that the government should assure higher level of affordability of the service (p. 43).

In 2005 the EES witnesses major reform due to the revision of the Lisbon strategy (after 5 year of implementation). As of 2005 the Employment policy coordination becomes part of the so-called Integrated Guidelines for Growth and Jobs - the new policy instrument introduced with the revised Lisbon strategy (as of 2005 - the Strategy for Growth and Jobs). The guidelines package includes the former broad economic policy guidelines (BEPGs) and the Employment guidelines. Childcare is treated in integrated guideline number 18 "Promote a lifecycle approach to work". Under the new revised Strategy for Growth and Jobs, the member states are invited to submit by the end of the year 2005 not national action plans (NAPs) but national reform programmes (NRPs). The NRPs are to be specified for at least 2 years, and each year the Commission expects member states to submit an annual report about the implementation of the multiannual national reform programme. The European Council decided furthermore not to alter the newly endorsed guidelines for at least two years.

As a follow-up the Dutch government presented its three-year national strategy in the autumn of 2005. The document contained a strong commitment to (women's) labour market participation, and reconciliation of work and family life remains top policy priority (p. 10). Regarding childcare, the most important policy action is the long-awaited Basic Provision of Childcare Act (Wet basisvoorziening kinderopvang, Wbk) that entered into force on 1 January 2005. This Act regulates the funding of childcare, the minimum quality criteria and guarantees basic standards of childcare nationwide (p. 50). The basic principles of the Act are freedom of choice for parents, more scope for market forces, and tripartite funding, whereby the government, employers and parents all share the costs of childcare. Under the new Childcare Act parents began receiving an income-based contribution from the state towards their costs for childcare.

Next to this major update of the legal basis on which the provision of childcare resides, in 2005 there has been also a reflection as to how to make the childcare service more affordable. Following the Commission's recommendation for greater affordability the Dutch government reserved EUR 200 million as of 2006 onwards, and stated that an obligatory employers' contribution might be introduced from 2006 onwards (p. 50).

The year 2006 was in many respects a follow-up year that deepened the reforms that began in 2005. As planned, from 2006 onwards the Dutch government 
began the implementation of the plan that devoted EUR 200 million for the improvement of the childcare affordability in the Netherlands. The funds were distributed as follows: 130 million for increase of the childcare allowance for middleand higher-income groups, 35 million for expansion of the existing facilities for preschool and after-school care, 30 million for improvement of the care facilities during school lunch breaks, and about EUR 5 million for the increase of quality and supervision (p. 45). Furthermore, the NPR report reveals the policy plans for 2007. In particular, the cabinet intended to increase the budget with another 125 million and to make the employer's contribution to the costs of child care compulsory as of 2007 (p. 45)

Interestingly, the NRP of 2006 refers to the potential role of childcare policy in assuring the inclusion of the ethnic minorities (policy frame F6). In particular, the government sees a role for pre-school facilities in teaching the Dutch language and in combating potential language development delays (p. 40).

A new coalition government (CDA, PvdA and CU) took office in early 2007. With regard to employment policy priorities not much changed: the increase in the participation of women, older workers and minorities remained the target as the inactivity of these groups was considered 'unused labour capacity' (p. 8). What changes is the level of determination and financial commitment to the goals - the planned budget for 2008 previewed the significant EUR 2,850 million for measures that boost labour market participation (p. 12). From these 700 million were to be spent on childcare as this is the main policy solution that allows for higher participation levels of women (p. 8). According to the presented analysis threequarters of the unused labour potential (in hours) are attributable to the female inactivity on the labour market (p. 44). In order to increase the number of hours worked by women, the new cabinet aimed to set up a Task Force "Part-time Plus" by the end of 2007 (p. 46). Moreover, paid employment was to be made more attractive as a new tax credit - the Supplementary Combination Tax Credit - was planned to be introduced on 1 January 2009 (p. 45). Furthermore, the transferability of the general tax credit - a remnant of the past when the male breadwinner was the norm - was to be phased out by $5 \%$ yearly for a period of 20 Years (p. 45).

Next to these general fiscal measures to stimulate the sector, several major changes took place with regard to the public support for childcare. Given that the PvdA had a strong presence in the new cabinet, and since the PvdA has had a decade-long commitment for the public support of childcare (see section 6.2.1.3), it is not surprising that the arrival of the new government led to major policy developments. First of all, childcare was moved to the Education ministry, and the childcare portfolio provision was given to the State Secretaries for Education Sharon Dijksma (from the Social Democratic party PvdA). Secondly, affordability was increased by making the employer's contribution obligatory, and by increasing the 
governmental contribution (p. 45). Thirdly, childcare became a universal social provision in the Netherlands as everyone could benefit from the newly facilitated access to childcare regardless of the amount of worked hours per week. These novelties in the public support for childcare, introduced in 2007, represent the most comprehensive and generous package of measures that the Netherlands ever had.

In 2008 the cabinet continues with the implementation of its governmental programme that is regarded as "closely aligned with the Lisbon strategy" (p. 3). The measures planned for 2008 and directed to boosting women's participation are implemented: the supplementary combination tax credit was introduced, the transferability of the general tax credit began to be gradually phased out (over a 15year period), and the Task force "Part-time Plus" was established (p.5). With regard to childcare, the comprehensive fiscal package introduced in 2007 turned out to be so successful that the budget had to be decreased.

In sum, in 2008 (the last year of the current study), the government continued with the stimulation package measures started in 2007 . The new cabinet's programme was well appreciated by society, and the measures were so successful that the government had to devise ways to confine the budgetary growth that was coupled with the successful implementation of the scheme.

\section{Analysis of the policy outputs from 1998 to 2008}

During the 10-year period analysed in this study there were 5 different cabinets in power. Not a single one of them served a full 4-year term, but 2 could be considered to have been long enough in office, and for which the pursuit of a defined policy line could be identified: the Kok II cabinet (a coalition government by PvdA, VVD and D66) and the Balkenende II cabinet (a coalition government of CDA, VVD, and D66). Despite their political rivalry, the two cabinets of PvdA and of CDA followed a similar policy line with regard to childcare. Given that the strategic priority with regard to employment policy has been the increase of the labour market participation of women, all National Action Plans (NAPs until 2005) and National Progress Reports (NPRs as of 2005 onwards) underline the commitment to facilitate the reconciliation of family and work life and to boosting childcare provision, which is regarded as the main tool to achieve female labour market participation.

Without doubt the 10-year period examined in this study (1998-2008) was the decade of most intensive growth of the Dutch childcare policy. Rapid development was demonstrated not only in terms of expansion of the existing capacities, but also in terms of professionalization of the service, public regulation and policy support. Many initiatives were undertaken. The most important among them are summarised in Table 5.3-1. 
Table 5.3-1 Main policy actions in the evolution of the Dutch childcare policy in the period $1998-2008$

\begin{tabular}{|c|c|c|c|}
\hline Years & Regulatory instruments & Fiscal instruments & Other actions \\
\hline 1998 & & & $\begin{array}{l}\text { 1) Cost-benefit analysis } \\
\text { of the adequate } \\
\text { childcare provision } \\
\text { system that the } \\
\text { Netherlands needs } \\
\text { 2) Initial orientation of } \\
\text { the existing and } \\
\text { prognosis of the needed } \\
\text { childcare places }\end{array}$ \\
\hline 1999 & & $\begin{array}{l}\text { 1) A four-year plan is } \\
\text { launched that aims to } \\
\text { increase the capacity of } \\
\text { childcare places } \\
\text { 2) A } 10 \% \text { increase of the } \\
\text { tax relief for employers' } \\
\text { who cover the childcare } \\
\text { costs of their employees } \\
\text { (the total bonus amounts } \\
\text { to } 30 \% \text { ) }\end{array}$ & \\
\hline 2000 & $\begin{array}{l}\text { A new Law - Childcare } \\
\text { Basic Provision Act is in } \\
\text { preparation }\end{array}$ & & $\begin{array}{l}\text { Consultations with } \\
\text { Social Partners that aim } \\
\text { for inclusion of } \\
\text { childcare provisions in } \\
\text { the CLAs } \\
\text { The Netwerkbureau } \\
\text { Uitbreiding } \\
\text { Kinderopvang is } \\
\text { established }\end{array}$ \\
\hline 2001 & & $\begin{array}{l}\text { New policy programme } \\
\text { that provides childcare to } \\
\text { jobseekers }\end{array}$ & $\begin{array}{l}\text { A national quantitative } \\
\text { target for female labour } \\
\text { market participation is } \\
\text { set at } 65 \% \text { ( } 5 \% \text { higher } \\
\text { than the EU target) }\end{array}$ \\
\hline
\end{tabular}




\begin{tabular}{|c|c|c|c|}
\hline Years & Regulatory instruments & Fiscal instruments & Other actions \\
\hline 2002 & & $\begin{array}{l}\text { 1) A tax credit is } \\
\text { introduced for the } \\
\text { childcare costs of families } \\
\text { where both parents work } \\
\text { 2) The KOA scheme } \\
\text { acquires more funding } \\
\text { (under the scheme lone } \\
\text { parents could benefit from } \\
\text { childcare services if they } \\
\text { accept to follow a } \\
\text { reintegration trajectory) }\end{array}$ & \\
\hline 2005 & $\begin{array}{l}\text { The Basic Provision of } \\
\text { Childcare Act comes } \\
\text { into force }\end{array}$ & & \\
\hline 2006 & & $\begin{array}{l}\text { A new EUR } 200 \text { million } \\
\text { scheme is launched with } \\
\text { the aim to make childcare } \\
\text { more affordable }\end{array}$ & \\
\hline 2007 & $\begin{array}{l}\text { The employers' } \\
\text { contribution to the } \\
\text { childcare costs of } \\
\text { employees is made } \\
\text { obligatory }\end{array}$ & $\begin{array}{l}\text { Decision to phase-out the } \\
\text { transferability of the } \\
\text { general tax credit } \\
\text { The state's contribution to } \\
\text { the childcare costs of } \\
\text { employees is increased }\end{array}$ & $\begin{array}{l}\text { Childcare provision } \\
\text { becomes part of the } \\
\text { portfolio of the } \\
\text { Education and Science } \\
\text { Ministry }\end{array}$ \\
\hline 2008 & & $\begin{array}{l}\text { The Supplementary } \\
\text { Combination Tax Credit is } \\
\text { introduced (a tax credit for } \\
\text { families with double } \\
\text { earners) }\end{array}$ & $\begin{array}{l}\text { Task Force "Part-time } \\
\text { Plus" is established }\end{array}$ \\
\hline
\end{tabular}


Given all these developments it can be concluded that the first 10 years of implementation of the EES coincide with the hardest growth of childcare provisions in the Netherlands. Taken overall the chapter so far revealed that in a period of 20 years the Netherlands developed a whole new policy field from scratch. The policy actors elaborated a regulatory framework and numerous financial instruments in an area that was not recognised as a field of public policy concern until 30 years ago.

The most important among them are the adoption of the Law on the Basic Provision of Childcare (in force since 2005), the tax credit measures for families with two earners (the Combination Tax Credit of 2002 and the Supplementary Tax Combination Credit of 2008); the continuous increase of the coverage of the childcare costs (on behalf of the state); and the encouragement of the increase of the employers' contribution.

\subsection{POLICY OUTCOMES}

Having reviewed the policy developments in the previous section, this section presents the dynamics of the policy outcomes to which these policy outputs led. According to the operationalisation adopted in this study (see the Introduction) the policy outcomes with regard to childcare policy will be measured by 2 indicators - the number of childcare places in day-care facilities, and the coverage rate i.e. the number of children visiting day-care facilities as percentage of all Dutch children in the ages 04 years old ${ }^{1}$.

The numbers presented below are based on data from the Netwerkbureau Uitbreiding Kinderopvang (which functioned from 2000 to 2003) and its successor Netwerkbureau Kinderopvang (which was established in 2008, and has a mandate of 3 years). Both were created by the government to monitor the policy effects of the pursued policy of enlargement of childcare places. These offices prepared reports about the number of childcare places in day-care facilities and about the number of children visiting based data gathered by the Dutch municipalities. The first measurement was in 1999, the first report from the series Monitor Childcare (Monitor Uitbreiding/ Capaciteit Kinderopvang) came out in 2000. This is the most reliable source of information related to the dynamics of policy outcomes as it is used

\footnotetext{
${ }^{1}$ Ideally, this indictor would converge with the Barcelona target, which focuses on 2 groups: 0-3 year old, and 3-12 year old. It has to be noted, however, that in the Netherlands there is no statistics gathered for up to 3 years old. Due to the specifics of the educational model of the Netherlands (elementary school starts at 4) statistics is gathered for up to 4 and until 12 years of age.
} 
by the government and the national statistics office (Centraal Bureau voor de Statistiek - CBS), which in turn reports to Eurostat.

Unfortunately, the Networks did not gather data for all the years since 1989 (when the governmental support for childcare begins). That's why the table below is completed with data from the Ministries' newsletters and other sources. In the last row of the table the source of data with regard to childcare places is indicated (see Table 5.4-1).

Thus, in row 1 the number of (full-time) available childcare places is presented. The second row of the table reports the demographic developments ${ }^{1}$ for the studied period.

Row 3 calculates the capacity of childcare facilities in the Netherlands by dividing the total number of childcare places (row 1) to the number of children in the ages $0-4$ in the respective year.

In row 4 is presented the intensity of use of one childcare place. It varies from 1,2 to 2 , but on average for the Netherlands the intensity rate is 1,8 ("Monitor Uitbreiding Kinderopvang", 2000).

Finally, row 5 calculates the coverage rate (to which the Barcelona target of $33 \%$ refers) by multiplying the capacity and intensity of use. 
Table 5.4-1 Number of childcare places and childcare facilities coverage rate in the Netherlands (1989 - 2008)

\begin{tabular}{|c|c|c|c|c|c|c|c|c|c|c|c|}
\hline & 1989 & 1993 & 1995 & 1997 & 1999 & 2000 & 2001 & 2002 & 2003 & 2006 & 2008 \\
\hline $\begin{array}{l}\text { Number of childcare } \\
\text { places (0-4 years) }\end{array}$ & 12085 & 52520 & 53420 & 66000 & 71238 & 79298 & 93345 & 107211 & 114150 & 129811 & 146566 \\
\hline $\begin{array}{c}\text { Number of children (0-4 } \\
\text { years) }\end{array}$ & 738000 & 783000 & 785000 & 775000 & 778000 & 790000 & 808000 & 820000 & 820000 & 785000 & 747000 \\
\hline $\begin{array}{c}\text { Capacity (no. of childcare } \\
\text { places per } 100 \text { children } 0 \text { - } \\
4 \text { years) }\end{array}$ & 1.64 & 6.71 & 6.81 & 8.52 & 9.16 & 10.04 & 11.55 & 13.07 & 13.92 & 16.54 & 19.62 \\
\hline $\begin{array}{l}\text { Intensity of use (no. of } \\
\text { children using } 1 \text { childcare } \\
\text { place) }\end{array}$ & 1.2 & 1.2 & 1.8 & 1.8 & 1.8 & 1.8 & 1.8 & 1.8 & 1.8 & 2 & 2 \\
\hline $\begin{array}{l}\text { Coverage rate = capacity } x \\
\text { intensity of use (the } \\
\text { Barcelona target) }\end{array}$ & 1.97 & 8.05 & 12.26 & 15.34 & 16.49 & 18.07 & 20.79 & 23.53 & 25.06 & 33.08 & 39.24 \\
\hline $\begin{array}{l}\text { Sources used for the Number of } \\
\text { childcare places and the intensity } \\
\text { of use: }\end{array}$ & $\begin{array}{l}\text { Ministry } \\
\text { VWS } \\
\text { report "Zes } \\
\text { Jaar } \\
\text { Stimuliering } \\
\text { smaatregel } \\
\text { Kinderopva } \\
\text { ng", } 1997\end{array}$ & $\begin{array}{c}\text { Ministry } \\
\text { VWS } \\
\text { report “Zes } \\
\text { Jaar } \\
\text { Stimuliering } \\
\text { smaatregel } \\
\text { Kinderopva } \\
\text { ng", } 1997\end{array}$ & $\begin{array}{c}\text { Emancipati } \\
\text { eraad (OR } \\
\text { 19-ER/IV/ } \\
\text { 1996) }\end{array}$ & $\begin{array}{l}\text { Ministry } \\
\text { VWS } \\
\text { bulletin } \\
\text { from } \\
22.01 .1998 \\
\text { and from } \\
08.06 .1999\end{array}$ & $\begin{array}{l}\text { Monitor } \\
\text { Uitbreiding } \\
\text { Kinderopva } \\
\text { ng, } 2003\end{array}$ & $\begin{array}{l}\text { Monitor } \\
\text { Uitbreiding } \\
\text { Kinderopva } \\
\text { ng, } 2003\end{array}$ & $\begin{array}{l}\text { Monitor } \\
\text { Uitbreiding } \\
\text { Kinderopva } \\
\text { ng, } 2003\end{array}$ & $\begin{array}{l}\text { Monitor } \\
\text { Uitbreiding } \\
\text { Kinderopva } \\
\text { ng, } 2003\end{array}$ & $\begin{array}{l}\text { Monitor } \\
\text { Uitbreiding } \\
\text { Kinderopva } \\
\text { ng, } 2003\end{array}$ & $\begin{array}{l}\text { Monitor } \\
\text { Capaciteit } \\
\text { Kinderopva } \\
\text { ng, } 2010\end{array}$ & $\begin{array}{l}\text { Monitor } \\
\text { Capaciteit } \\
\text { Kinderopva } \\
\text { ng, 2010 }\end{array}$ \\
\hline
\end{tabular}


It is visible that since the beginning of the governmental support for childcare facilities the number of available places constantly rises (see Figure 5.4-1). In 1989, when the first stimulatory act was launched, the Netherlands had merely 12,000 places. In 1997, when the EES was endorsed, the number of places had grown more than 5 times to 66,000 places. At the end of the studied period - in 2008 - the number of childcare places was more than 146,000.

Figure 5.4-1 Growth in the number of childcare places in the Netherlands (1989-2008)

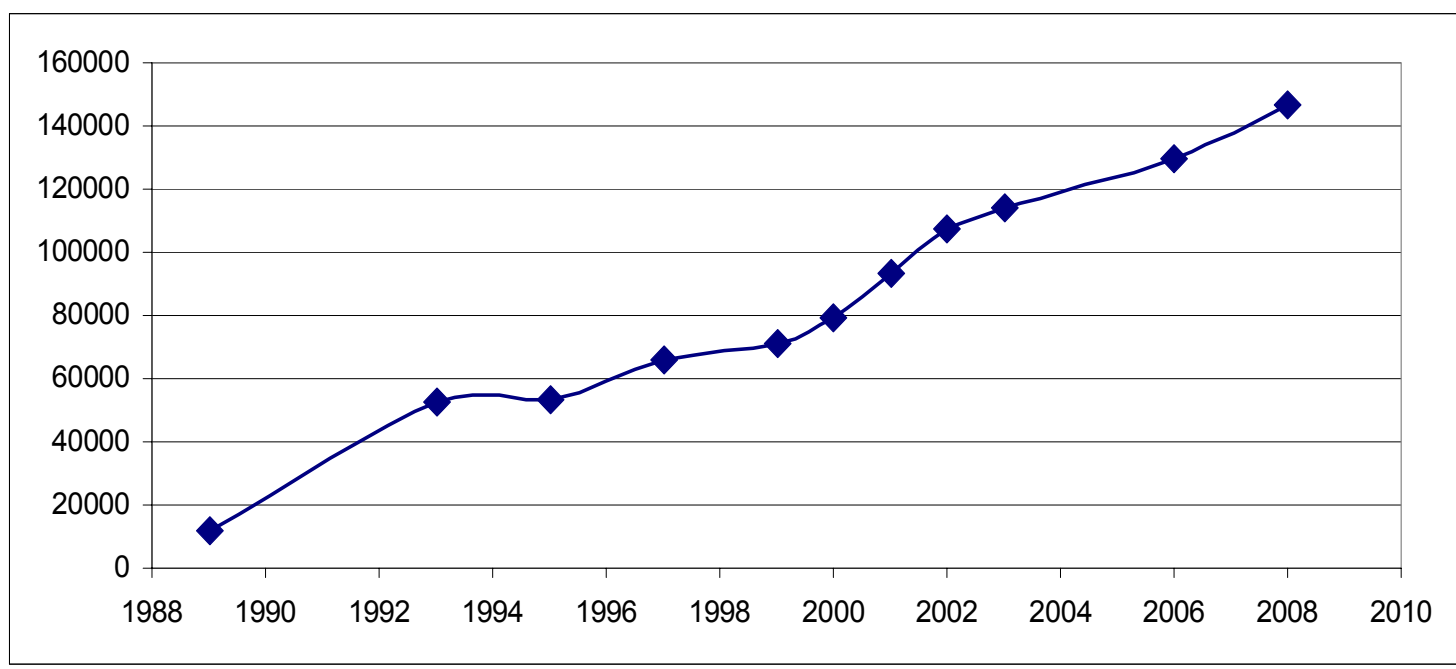

Due to the relatively constant intensity of use of one place $(1,8-2$ children per place) and the rather constant total number of children in this age group for the country as a whole, this spectacular growth in number of places translates in an exponential growth in the coverage rate (see Figure 5.4-2). It continuously grows from 5\% at the beginning of state stimulation in 1989 to nearly $40 \%$ at the end of 2008. The target of $33 \%$ childcare coverage rate for children between 0 and 3 years of age fixed by the EU in 2002 is reached in 2006 (4 years before the 2010 deadline). In other words, more and more children have access and make use of day-care facilities. Moreover, the trend is growing. It has to be underlined, however, that children only visit daycare facilities for 2-3 days a week (see Table 5.4-2). 
Figure 5.4-2 The Dutch childcare coverage rate 1989-2008 (in \%)

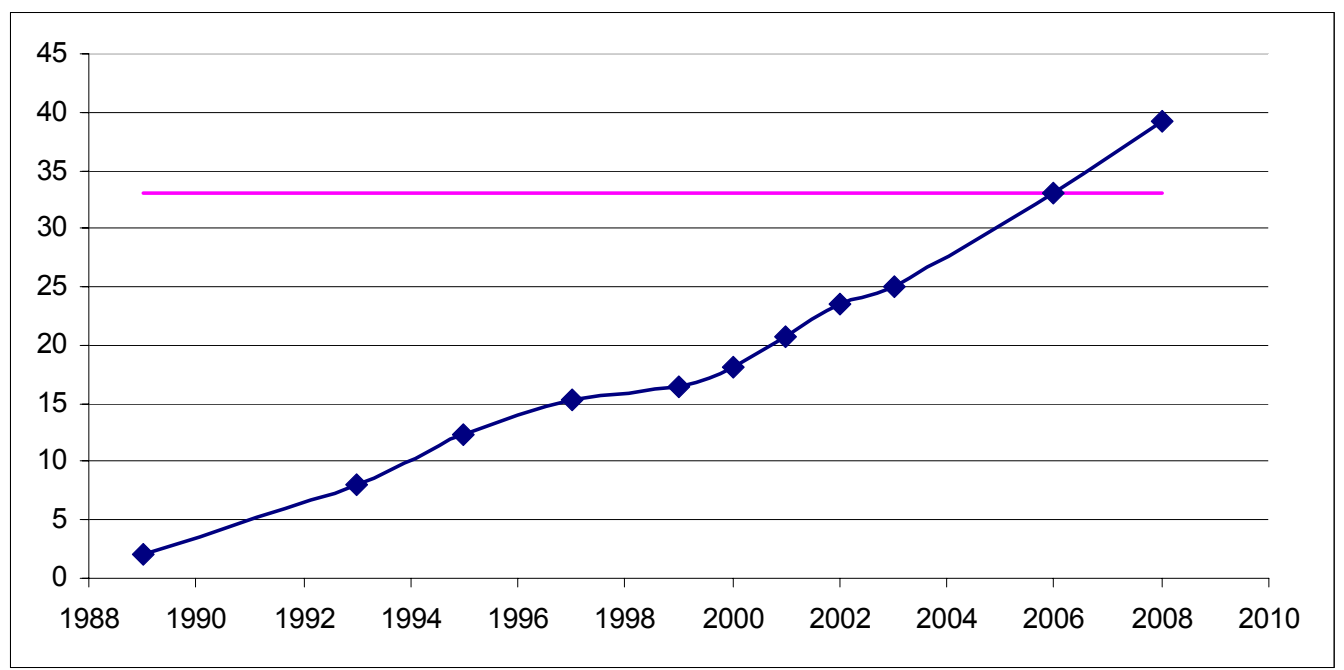

This is consistent and understandable given the cultural attitudes of the Dutch toward parenting but indicates that high levels of childcare coverage in the Netherlands does not necessarily mean high level of female labour market participation, which (as already demonstrated in Chapter 4) is the ultimate goal of the EU childcare guidelines. In other words, formally the Netherlands fulfils the Barcelona target but in fact the Dutch coverage rate is much lower if re-calculated in full-time equivalents (see Table 5.4-2).

Table 5.4-2 Coverage rate in the Netherlands according to the hours spent in the daycare facility per week (0-3 years old, in \%)

\begin{tabular}{|c|c|c|c|c|}
\hline \multicolumn{1}{|c|}{ (0-3 years) } & 2005 & 2006 & 2007 & 2008 \\
\hline \hline $\begin{array}{l}\text { Daycare up to 30 hours } \\
\text { Per week }\end{array}$ & 36 & 41 & 39 & 41 \\
\hline $\begin{array}{l}\text { Daycare for more than 30 } \\
\text { hours per week }\end{array}$ & 4 & 4 & 4 & 6 \\
\hline
\end{tabular}

Source: EU Statistics on Income and Living Conditions (SILC) from May 2010 1

1 The statistics is derived from the Commission's report on the progress of the Growth and Jobs (Lisbon) Strategy "Indicators for monitoring the Employment Guidelines including indicators for additional employment analysis", accessed on 21 June 2010, at: http:// ec.europa.eu/social/main.jsp?catId=477\&langId=en) 
The data reveal that a steady number of children (4\%) make use of formal childcare for more than 30 hours per usual week. This number is 10 times lower than the number of children visiting childcare for less than 30 hours a week - a number that at the end of the studied period stabilizes around $40 \%$. In practice these numbers translate into: the majority of children visiting daycare centres in the Netherlands do so for not more than 30 hours a week (a standard daycare day is 10 hours). This situation has its mirror image in Denmark - a member state that is considered exemplary in terms of childcare provision in the context of the Lisbon Strategy (see Table 5.4-3). There only about 7-8\% visit daycare for less than 30 hours a week. The majority of children (63-65\%) do so for more than 30 hours a week. This indicates that the labour market participation (weighted according to full-time equivalents) is considerably higher in Denmark than it is in the Netherlands.

\section{Table 5.4-3 Coverage rate in Denmark according to the hours spent in the daycare facility per week (0-3 years old, in \%)}

\begin{tabular}{|c|c|c|c|c|}
\hline \multicolumn{1}{|c|}{ (0-3 years) } & 2005 & 2006 & 2007 & 2008 \\
\hline \hline $\begin{array}{l}\text { Daycare up to 30 hours } \\
\text { per week }\end{array}$ & 13 & 7 & 7 & 8 \\
\hline $\begin{array}{l}\text { Daycare for more than 30 } \\
\text { hours per week }\end{array}$ & 60 & 66 & 63 & 65 \\
\hline
\end{tabular}

Source: EU Statistics on Income and Living Conditions (SILC) from May 2010

In light of this comparison, it is hardly surprising that the rise in childcare facilities and the options for daycare in the Netherlands has not led to significantly higher levels of female labour market participation. It seems that contemporary Dutch women work just as much as the previous generations despite the improved daycare options. The fact that the part-time jobs in the Netherlands allow for maintaining a very good standard of living even at a $3 / 4$ level of income introduces a 'luxury problem'. Basically, the Dutch (women) do not have to work full time to live well (interview 8). So they do not. Consequently, the labour supply is not very elastic to the availability of childcare. Hence, the main effect of the governmental stimulation of childcare facilities is not higher levels of participation but rather the fact that informal care (by grandparents or neighbours) was brought up to the real economy and has been formalised (see for example the analysis of MEV 2008, Speciale Ontwerpen, Section 6.2. "Arbeidsmarktparticipatie van vrouwen”).

The most important conclusion from the statistics above is that at the time of endorsement of the EES the coverage rate in the Netherlands was half $(15-16 \%)$ of 
the aspired by the EU 33\% Barcelona target, whereas already by 2008 the coverage rate was doubled and the Netherlands had fulfilled the Barcelona target. Hence, at the end of this section it could be stated that even though the Netherlands started from a rather low level, the Dutch policy outcomes demonstrate full alignment with the EU targets on childcare provision, the Barcelona target being achieved already in 2006 (i.e. 4 years in advance). This might be indicative of policy influence stemming from the EES and the method of open coordination (OMC). Nevertheless, the observed correlation between the Dutch policy performance and the EES does not necessarily indicate causation - the observed developments might be due to alternative (e.g. domestic) factors. Is the Employment $\mathrm{OMC}$ process the inducing factor? In a quest for the underlying reasons for the spectacular growth of childcare facilities in the Netherlands and the role of the EU therein, the analysis now turns to the policy discourses i.e. to the normative and cognitive underpinnings of the Dutch childcare policy making.

\subsection{POLCY DISCOURSES}

This section examines the dominant policy discourses in Dutch childcare policy-making and their dynamic evolution since the end of the WWII. As a main source of data for this analysis the coalition agreements are used, which are a reliable source of the policy intentions of the ruling parties and set the tone for governmental actions during the mandate of the cabinet. Thus, they could be considered a proxy of the development of the Dutch policy discourses.

Examined were all coalition agreements available in written form since the end of the WWII. As pointed out by Timmermans written coalition agreements exist since 1963 (Timmermans, 2003). Therefore the dataset for this study consisted of 15 coalition agreements (see Table 5.5-1). 
Table 5.5-1 Childcare-related policy frames in Dutch coalition agreements (1963-2006)

\begin{tabular}{|c|c|c|c|c|c|c|c|c|}
\hline $\begin{array}{l}\text { Year } \\
\text { of the } \\
\text { agree- } \\
\text { ment }\end{array}$ & Coalition partners* & $\begin{array}{c}\text { Total number } \\
\text { of references } \\
\text { to childcare }\end{array}$ & F1 & $\mathrm{F} 2$ & F3 & F4 & F5 & F6 \\
\hline 1963 & $\boldsymbol{K} \boldsymbol{V P} / \mathrm{ARP} / \mathrm{CHU} / \mathrm{VVD}$ & 0 & & & & & & \\
\hline 1965 & PvdA/KVP/ARP & 0 & & & & & & \\
\hline 1967 & $\boldsymbol{K} \boldsymbol{V P} / \mathrm{ARP} / \mathrm{CHU} / \mathrm{VDD}$ & 0 & & & & & & \\
\hline 1971 & $\begin{array}{c}\mathrm{KVP} / \boldsymbol{A R \boldsymbol { R }} / \mathrm{CHU} / \mathrm{VVD} \\
/ \mathrm{DS} 70\end{array}$ & 0 & & & & & & \\
\hline 1973 & $\begin{array}{l}\mathrm{PPR} / \boldsymbol{P} \boldsymbol{v d A} / \mathrm{D} 66 / \mathrm{KVP} / \\
\mathrm{ARP}\end{array}$ & 0 & & & & & & \\
\hline 1977 & $\boldsymbol{C D A} / \mathrm{VVD}$ & 1 & 1 & & & & & \\
\hline 1981 & $\operatorname{PvdA} / \mathrm{D} 66 / \boldsymbol{C D A}$ & 1 & 1 & & & & & \\
\hline 1982 & $\boldsymbol{C D A} / \mathrm{VVD}$ & 1 & 1 & & & & & \\
\hline 1986 & $\boldsymbol{C D A}$ /VVD & 1 & 1 & & & & & \\
\hline 1989 & $\mathrm{PvdA} / \boldsymbol{C D} \boldsymbol{A}$ & 8 & 1 & 3 & & & & \\
\hline 1994 & 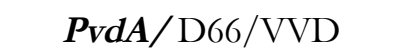 & 4 & & 2 & & & & \\
\hline
\end{tabular}

Introduction of the European Employment Strategy

\begin{tabular}{|l|c|c|c|c|c|c|c|c|}
\hline \hline 1998 & PvdA/D66/VVD & 23 & 1 & 3 & & & & \\
\hline 2002 & $\boldsymbol{C D A} / \mathrm{VVD} / \mathrm{LPF}$ & 2 & & & & & & \\
\hline 2003 & D66/CDA/VVD & 3 & & 1 & & & & \\
\hline 2007 & PvdA/CDA/CU & 6 & & 1 & & & 1 & 1 \\
\hline
\end{tabular}

* Source: Andeweg, 2005 and own calculations. The party of the Prime

Minister is indicated in Italic and Bold. 
From Table 5.5-1 it is visible that the coalition agreements include only the policy frames related to gender inequality (F1) and competitiveness (F2). Although different frames that link childcare to various public policy problems exist in the discourse of the actors (see Chapter 6), when it comes to collective societal action only the gender equality policy frame (F1) and the competitiveness frame (F2) are of relevance in the Netherlands. An example of F1 is this excerpt from the coalition agreement of $1989^{1}$ :

"One of the consequences of the emancipation and of the growth in the number of single-parent families is that the demand for childcare services strongly increases. That is why this subject will be specifically addressed together with the social partners - given their importance and responsibility so that the businesses themselves offer more possibilities."

On the other hand, an example of F2 is to be found in this excerpt from the coalition agreement of $1998^{1}$ :

"The lack of sufficient number of childcare facilities seems to be the reason for many women to stop or not to begin working. The policy on enlarging the childcare facilities will be continued. "

Naturally, it is important to discover the dynamics of interplay between these 2 frames i.e. which emerged when in the set of examined coalition agreements, which of the frames was dominant during which period etc. (see Figure 5.5-1).

Several conclusions can be drawn from the analysis of Table 5.5-1 and Figure 5.5-1 above:

- Childcare enters the main public policy discourse (as reflected in coalition agreements) in the late 1970s. The first references date from 1977.

\footnotetext{
1 Author's own translation. The original text in Dutch reads: " Een van de gevolgen van de emancipatie en van de groei van het aantal eenouder-gezinnen, is dat de vraag naar kinderopvang sterk toeneemt. Dit onderwerp zal daarom nadrukkelijk betrokken worden in het overleg met de sociale partners - gezien ook hun belang en verantwoordelijkheid -, opdat het bedrijfsleven zelf meer mogelijkheden zal bieden."
} 
- Up to the mid 1980s the dominant policy frame was F1 i.e. the leading interpretation was to view childcare as a solution to gender inequalities. Up to then, however, there was no governmental effort to support the growth of childcare (see section 5.2.). In other words, the view of childcare as forwarding the emancipation processes was not able to generate real policy measures. Exactly in 1989, when F2 displaced F1 as the leading policy frame, the real stimulation of childcare facilities begins in the Netherlands.

Figure 5.5-1 Relative proportions of policy frames F1 and F2 in Dutch coalition agreements

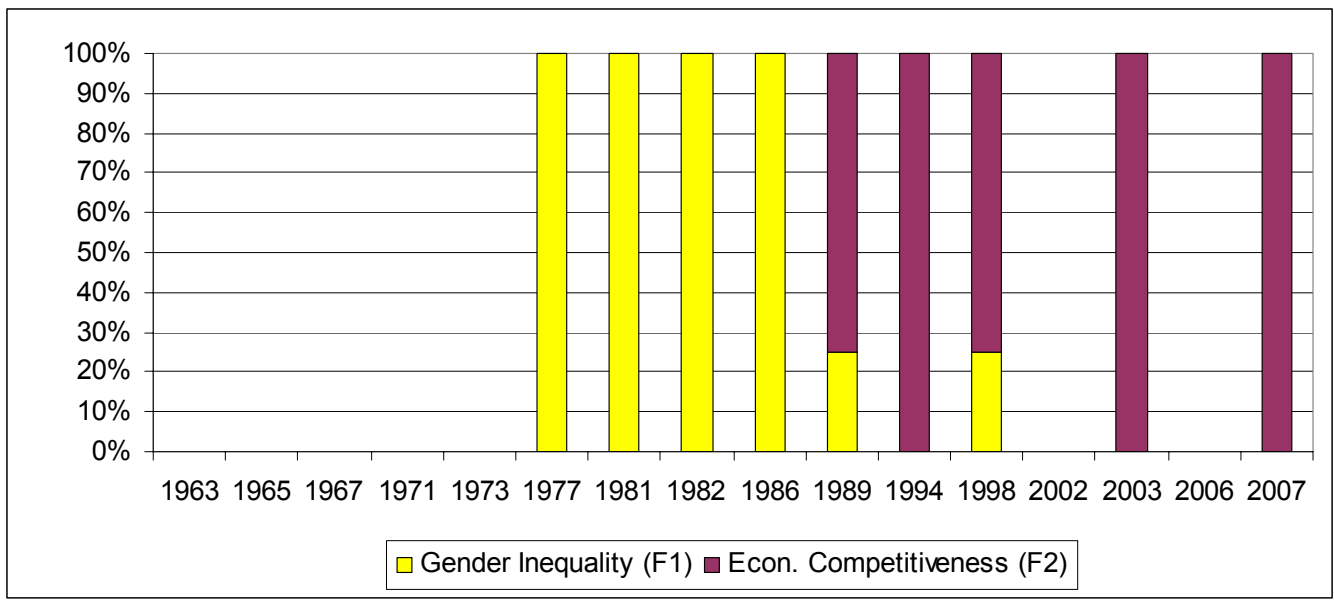

- As of 1989 F2 enters the Dutch governmental policy discourse, and immediately becomes the dominant frame. Moreover, since then concrete policy measures are issued. Hence, only when coupled to the issue of competitiveness childcare facilities received the massive funding that women's organisations and the Unions had been advocating.

- As of 1989 until present F2 is the dominant interpretation of the childcare issue. Again this is similar to the EU level of governance (see chapter 4), showing a full convergence between the EU and the Dutch policy discourses. The emergence of the EES does not seem to have brought any change in the policy discourses of the Netherlands.

1 Author's own translation. The original text in Dutch reads: "Het ontbreken van voldoende opvangmogelijkheden blijkt voor veel vrouwen een reden om met werken te stoppen of er niet aan te beginnen. Het beleid tot verruiming van de kinderopvang wordt voortgezet." 
- Since the last cabinet (Balkenende IV, in which the PvdA was a major coalition partner) also policy frame F5 (early education and socialization) is gaining importance. The PvdA has advocated for F5 already since the late 1970s (see section 5.2.1.3.) but only 30 years later their claim found a place on the governmental agenda. This could be explained by the fact that after the great emphasis on availability and growth of the number of childcare places, at present more attention is devoted to the quality of the services (interview 4). Therefore, much more actors could support the PvdA's standpoint. The expectation is that the view on childcare as being an educational service alongside being a reconciliation measure will become even more prominent in the future. Arguably, this is due to the fact that F5 could be the normative legitimization of the competitiveness frame (F2) i.e. the two frames go well together. This potential future policy development notwithstanding, for the present study F5 is of little relevance.

From the above analysis it could be concluded that from 1998 onwards (the year when the European Employment Strategy (EES) was introduced) the Dutch policy discourses converge fully to the EU policy frame. This convergence and continuous alignment of the policy discourses during the studied period is indicative of the influence of the EES on the domestic level. The dynamics of framing was also similar - initially F1 is the sole policy frame linked to childcare, then F2 emerges, and for the last 20 years F2 is also the dominant frame (see Figure 5.5-1). The main difference resides in the fact that in the Dutch process of childcare framing the appearance of F2 (in 1989) precedes the appearance of F2 at the EU level (in 1996). Hence, a causal relation between the EES and the Dutch policy discourse cannot be established.

\subsection{CONCLUSION: CONVERGENCE TO THE EU POLICY PRESCRIPTIONS?}

Given all these developments it can be concluded that the 10 years examined by this study (the first 10 years of implementation of the EES) coincide with the fastest growth of childcare provisions in the Netherlands. Taken overall, this chapter made clear that within a period of 20 years (1989-2009) the Netherlands developed from scratch a policy on childcare provision (based on regulatory framework and financial instruments) in a field that was not recognised as an area of public policy concern until 30 years ago. 
Was there an influence coming from the EU level of governance in these developments? In order to address this question the chapter reviewed the Dutch policy structures - the historic background, the policy outputs for the period 19982008, and the policy outcomes. From the latter two indicators was established high degree of convergence between the EU norm and the domestic policy developments. Both indicators demonstrated full alignment with the EU policy prescriptions. These findings suggest high degree of Europeanization of the childcare policy in the Netherlands. The examination of the policy discourses, however, revealed that the commitment to enlarging the existing childcare capacities existed already in 1989. This indicates that it most likely was not the EES that instigated the policy changes in the Netherlands. Given that the domestic discourse preceded the EU one it is impossible to claim the presence of a causal relationship and hence Europeanization.

Nevertheless, even though pronounced Europeanization influence (actual discursive shifts) could not be discerned, one could ask whether the EU exercised influence by maintaining the status quo i.e. by keeping the existing discursive structure (F2) in place even though its dominance originated from domestic policy developments. To address this question, and to unravel the forces behind the observed policy developments, the analysis will zoom into the positions of the national policy community actors. 
- 154 - 


\section{THE DUTCH CHILDCARE POLICY PROCESS AND ACTORS}

This chapter brings the actors into the analysis. First, it describes the organization of the Dutch childcare policy process. Based on interviews with the main policy actors it outlines the annual cycle of implementation of the EES in the Netherlands. Second, the chapter reviews the evolution in the position of the main Dutch policy-making actors on formal childcare since the 1970s (via interviews, documentary and policy frame analysis). Moreover, it elaborates on the coalition building dynamics and suggests why the policy outputs and outcomes (presented in the previous Chapter 5) look the way they do. The aim is to reveal - this time from the perspective of actors - to what extent the observed convergence at the level of discourses, outputs and outcomes established in Chapter 5 can be attributed to the EU's influence, and more generally to outline the impact of the EU policy-process on the Dutch childcare policy-making.

\subsection{THE DUTCH CHILDCARE POLICY PROCESS}

Childcare policy-making in the Netherlands takes place at three different 'levels', each of which is organizationally related to the other two but focuses on distinct aspects of the process of childcare provision. Most of the actors have structured their internal organization according to these three levels (interviews 1, 2, $5,12,15)$. 
Firstly, there is the sectoral level which is focused on issues such as: safety conditions on the working place, salary levels and the quality of service provision, and where the national standard of provision of formal childcare services is defined. This is the level where the yearly collective labour agreement (CLA) is negotiated. It is dominated by the two main sectoral organizations of the providers of childcare services - the MO-groep (Maatschappelijk Ondernemers Groep) and de BKN (Branchevereniging ondernemers in de kinderopvang), by the members of the Social Partners (FNV, CNV, MKB, VNO-NCW), and the parental organization of the Netherlands - the BOINK. This is the level where the technical standards and the work-conditions in the policy field are defined. Basically, this is the level where the core of the Dutch childcare provision is defined.

Secondly, there is the level of national policy-making. This level looks into how childcare provision relates to other national policies such as primary education, reconciliation of work and family life or female labour market participation. Unlike the sectoral level (which is very self-centred) at the national level the links with other policies are explored, and childcare is regarded as one among several policy measures of the employment and educational policy mix of the country. The Social Partners are again very prominent actors at this level but the leading role is reserved for the government. The structured dialogue between the parties is organised at the Labour Foundation (Stichting van de Arbeid) and in the Social and Economic Council (Social-Economische Raad).

Finally, there is the international level. It is concerned with the international dimension of the national policies and with the domestic implications of international agreements. Here again the links with other state policies are explored but this time the overarching policy processes taken in consideration are in the framework of international agreements to which the Netherlands committed. In the case studied here this is the European Employment Strategy (the Jobs and Growth Agenda). Similar, to the national level, the government is the leading actor, who consults on a regular basis the Social Partners. There are two specific committees of the SocialEconomische Raad (SER): on social economic policy and on international affairs, where discussions and consultations take place before the national position is formulated.

Albeit the organizational ties, these three levels are rather disconnected when it comes to substance of the performed work and the themes they deal with. There are coupling moments when, for example, at the level of the trade union federations' central offices, a policy position is prepared which involves consultations at the local and national as well as international levels (interview 5) or when a session at the Labour Foundation is prepared, but on the whole there is specialisation between the different levels and rarely do they mingle. 
Given that this study is focused on the influence of the EU's employment policy on the domestic processes of policymaking, in the following section the process of implementation of the EES in the Netherlands will be described. In doing so, the role of the three levels of childcare policy-making and the different actors will be outlined.

\section{The implementation of the EES in the Netherlands}

The implementation of the childcare policy guideline of the EES in the Netherlands involves three distinct processes: the drafting of the annual National Progress Report, the preparation of the annual Spring summit of the European Council and the participation of the Netherlands in the EES-related discussions in Brussels. Below these processes are traced and the principle actors and their interactions are discussed. The reconstruction outlined in the following sections is not described in any policy document and is therefore entirely based on data derived from interviews with policy actors (interviews with 1, 2, 5, 10, 12, and 15).

\subsubsection{The preparation of the annual National Progress Report}

As at the EU level, the yearly EES cycle in the Netherlands begins with the endorsement of the EES guidelines by the Spring European Council (end of March). On the basis of the guidelines (and of the country recommendations from the previous year) during the spring period the Ministry of Economic Affairs (EZ) and the Ministry of Social Affairs and Employment (SWZ) draft a National Progress Report (NPR). Leading is the Ministry of Economic Affairs as it is headed by the Dutch $\mathrm{Mr} / \mathrm{Mrs}$ Lisbon $^{1}$. The NPR is an extensive report that comments on the general economic situation in the Netherlands, and provides an overview of the undertaken (or the soon to be undertaken) actions in the framework of each EES guideline. During the drafting stage the two main ministries (EZ and SWZ) invite

\footnotetext{
${ }^{1}$ During the 2005 reform of the Lisbon Strategy, and in an attempt to enhance the political profile of the EU strategy domestically, the member states agreed to appoint a national Mr or Mrs Lisbon who is responsible for the national implementation, and who (being a prominent policy figure) increases the visibility of the Strategy in domestic debates.
} 
other ministries (e.g. the Education or the Welfare and Housing ministry) to provide input. The draft is then sent to the Social Partners with an invitation to react on it.

A typical element of the yearly cycle is the visit of a Commission's delegation to the Netherlands. This usually takes place at the beginning of the summer period. The delegation includes representatives from various DGs. The Dutch side is represented by civil servants from the main ministries involved in the Lisbon (Growth and Jobs) Strategy, and by representatives of the Social Partners. The meeting is devoted to discussing the major policy priorities, the general economic and labour market situation, and the implementation of the guidelines. In case the Commission plans to issue any recommendation toward the NL this will also be discussed, and the ground will be tested as to how the domestic actors react on it.

At the beginning of the summer period the reactions of the Social Partners on the draft NPR become available, and throughout the summer the two ministries (EZ and SWZ) work on finalising the report. This involves consultations between the Social Partners and the two Ministries on the reactions and comments received. When the ministries regard the remarks made by the Social Partners as an improvement of the text or as a useful addition, these remarks will normally be included. This is often the case and the Social Partners feel listened to (interview 5). When there is disagreement, however, the government keeps its original text. This clearly indicates the government's final word and responsibility for the NPR. The Social Partners are consulted, but do not need to agree with all aspects of the final version. The EU Growth and Jobs Strategy is first and foremost a government-led process. That is why the Social Partners also produce their own document highlighting their contribution to the Lisbon strategy. This document is sent to the European Commission as an annex to the Dutch NPR. In this procedure there is room for consultation of other stakeholders as well. Local and regional authorities are consulted in the same way as the Social Partners. This has led to local and regional governments adding own best practises to the text of the NPR.

At the beginning of September the final version of the NPR is sent to the second chamber of the national Parliament and to the European Commission. Usually, there is hardly any attention to this report in the Dutch Parliament, because September is the month of the 'throne speech' (Prinsjesdag), when the yearly governmental budget is presented. All the attention is therefore focused on the start of the new parliamentary season and on the domestic political agenda, and the National Lisbon report simply gets lost in the pile of papers the parliamentarians receive in this period.

Contrary to the reception in the Hague, the Dutch NPR is very much awaited in Brussels. Throughout the autumn period the Commission reviews all member states' reports, considers all the policy achievements and possible future courses of action and on that basis prepares the annual Joint Employment Report. This report 
might include country-specific recommendations which the member states are expected to consider and address in the next annual iterations.

\subsubsection{The preparation of the Spring Summit of the European Council}

The consultation procedure between the government and the policy stakeholders in preparation for the Dutch contribution to the Spring European Council does not follow a clear template but has evolved in the course of the years. In the beginning of the 2000s informal summits between the government and the Social Partners were taking place shortly before the Spring Council. These consultations were not extensively prepared. Since 2004 the Socio-Economic Council $^{1}$ (SER) started a procedure in which one of its committees - Commissie Internationaal Sociaal-Economische Aangelegenheden - the committee on International Socio-economic Relations (the ISEA committee) - was charged with the preparation of the Spring Council. This preparation benefited the Social Partners when meeting with government later on within the Labour Foundation ${ }^{2}$ (SvdA).

Since 2005 the preparation by the SER-committee has gained importance since it has evolved into a consultation between the committee and the Secretary of State for European Affairs. In 2008 the Secretary of State (Frans Timmermans) was joined by the minister for Economic Affairs (Mrs Maria van der Hoeven) acting in her capacity of the Dutch Mrs. Lisbon. These consultations between government ministers and the SER were still followed by informal summits between the government and the Social Partners shortly before the Spring Summit.

Nowadays the bulk of the preparation for the European Council's Spring Summit is done by 2 committees of the SER. The aim is to present a well-rounded advice to the Dutch government regarding two main questions: what is good for the Netherlands in the context of the Lisbon Strategy; and what is good for Europe as a whole. With the former question deals the committee "Sociaal-economisch beleid" (SEB) of the SER, and with the latter - the Commissie International Social-

\footnotetext{
1 The Social and Economic Council ('Sociaal Economische Raad - SER') was established in 1990 and is the most important advisory body of the government in the field of socio-economic policy. The Council consists of representatives of trade union confederations, representatives of employer organizations, and independent experts. The government can ask the SER to advise on important socio-economic issues, but the SER can also give advice on its own initiative. The government is not legally obliged to adopt the received advice, but given the Polder Model (consultation culture) in the Netherlands, ignoring it is not typical.

2 The Labour Foundation ("Stichting van de Arbeid - SvdA") is the official central consultative forum for employers' and trade union representatives.
} 
Economische Aangelegenheden (ISEA committee). In practice this means that the secretaries of the two committees - SEB and ISEA - together prepare a draft position document. They take into account the background documents and reports presented by the Commission (e.g. the annual Joint Employment Report), and seek other background materials (e.g. national and international statistical reports and studies). They also take into account the so-called informal interdepartmental committee report' which is a paper that elaborates on the annual proposal by the Commission, and basically is an analysis prepared by the Dutch civil servants from various ministries who interpret what the Commission suggests in the light of the ongoing Dutch policy processes. This is a very thorough and influential document, and the SER committees always study it carefully before issuing their own advice (interview 15). Actually, the Minister him/herself insists on the civil servants sending this confidential governmental document to the SER because (s)he would really like to know whether the suggestions/ interpretations in the report would be supported by the most influential policy actors in the country. On the basis of all these reports, the Secretaries of the two SER committees prepare a draft advice. This document covers: firstly, what the Netherlands should be aiming at in the context of the Lisbon strategy (what is good for the Netherland), and secondly, what the Dutch representatives should be aiming to achieve as EU-wide commitments (what is good for the EU as a whole). This draft together with the set of background documents are then sent to the SEB and ISEA members. After deliberations the SER committees come up with advice to the government, but again (similarly to the NPR process) the final decision as to what the Netherlands will argue in Brussels belongs to the government itself.

\subsubsection{Representing the Netherlands in Brussels ${ }^{1}$}

Apart from the Spring summit (where the strategic framework of the Strategy is outlined), there are 2 other fora where the EES is shaped: the Council of Ministers (EBSCO Council) where the annual employment policy guidelines and the Joint Employment Report (including the country recommendations) are adopted, and the Employment Committee (EMCO) meetings where senior civil servants debate the more operational aspects of the Strategy. Thus, the participation of the Netherlands

\footnotetext{
1 This section is partly based on the article "The OMC - an Opaque Method of Consideration or Deliberative Governance in Action?" (Radulova, 2007), and reports interview data with EMCO members (see interviews 10, $16,18,21,22,24,25,27,28)$.
} 
in the EES involves representing the country at these EMCO meetings and at the EBSCO Council.

Similarly to the European Council summits the preparation of the Council of Ministers' sessions involves national coordination and consultation with the Social Partners. Prior to an EBSCO Council the government formulates a national position regarding the issues on the agenda. Then the policy stakeholders are consulted by the staff of the Ministry. Therefore, 4-5 times a year the main actors of the Dutch socioeconomic governance sit together with civil servants from the respective ministries and discuss the upcoming meeting of the EBSCO Council. The Social Partners feel that they are usually listened to (interviews 1 and 5). Due to the Polder Model culture it is rare that the input received will not be taken into account. The civil servants are well aware that all major policy stakeholders lobby and work with parliamentarians (interview 5). Hence, and this happens from time to time, the government might receive a parliamentary question that is related to the issues of the EES. Therefore the civil servants are always attentive and if possible try to accommodate the position of the Social Partners in the national position.

The preparation of the national representation for the working parties in Brussels (e.g. in the EMCO committee meetings) deviates from the culture of broad consultation that is so popular and practiced in the Netherlands. The EMCO is a technocratic forum which prepares the annual employment guidelines, reviews the National Action Plans (or NPRs after 2005) and accomplishes the peer review of national policy approaches in the framework of the so-called Cambridge Review process. Due to these yearly responsibilities of a rather intergovernmental nature, it is not surprising that the committee sessions and their national preparation do not follow the broad consultation pattern applied for the preparation of the summits or the Council meetings. Moreover, at this level the member states are represented by civil servants ${ }^{1}$, and the objective is not decision-making as such but rather preparation and intergovernmental (or rather inter-bureaucratic) policy exchange. Nevertheless, agreements reached at the level of EMCO are only rubber-stamped by the EBSCO Council, meaning that this advisory committee has at least informal decision-making powers.

The EMCO meetings in the Netherlands are prepared by civil servants from the International Affairs directorate of the Social Affairs Ministry (SZW). These officials generally do not have intensive contacts with the other levels of the national

\footnotetext{
1 The Committee consists of two ordinary and two alternate members from each member state and of two members from the Commission. It is headed by a chairman elected for two years. The EMCO is to contribute to the Luxembourg process (employment policy coordination) but also to the other related processes e.g. the Broad Economic Policy Guidelines (BEPGs).
} 
administration (interview 10). Naturally, they follow the domestic policy process, and "have a feeling" about the 'manoeuvring space' (interview 10). There is no need therefore for the formulation of an explicit mandate. Once the agenda is sent by the Commission, the civil servants identify which national directorates are involved in the previewed topics, and should be consulted (interviews 2 and 10). In most cases the (alternate) EMCO member will take the lead in drafting "a sort of instruction with speaking notes", which is then circulated and comments and additions are requested from the specialised directorates of the ministry. Sometimes input is requested from other ministries. In all cases these requests are addressed to the departments/directorates who deal with the international dimensions of policies. The typical mode of communication is via the telephone, rarely meetings are required (interviews 2 and 10). This and the rather junior level of the civil servants involved makes the EES national coordination 'light' compared to the highly formalised procedure followed before an European Council or a Council of Ministers' meeting.

Once at EMCO in Brussels, the crucial issues are allegedly 'pre-cooked' during informal meetings of likeminded countries (e.g. Denmark, the Netherlands, Sweden, and Finland), which are gradually 'opened' for other members states prior to the meeting (interviews 10, 16 and 22). To decide outside the committee meeting venue is the standard approach when it comes to sensitive issues or in situations of deadlock during the discussions. Similarly to the preparatory phase, the national delegates feel they can rely to a great deal on their personal discretion as long as the final outcome remains within the strategic frame formulated by the government and the Social Partners regarding the general development of the EES (ibid).

The reporting procedure on the outcomes of the EMCO meetings back in The Hague resembles largely the preparatory phase: the EMCO delegate drafts a report (2 to 3 pages) to his direct supervisor and a brief memo is sent to colleagues from other directorates who might potentially be affected by the discussions at the EU level (interview 10).

Regarding the potential of the EMCO meetings to generate policy learning the civil servants find it difficult to provide an unequivocal answer. They certainly seem to individually learn a lot about the existing international policy approaches and experiences (all interviewed EMCO members stated this). Whether this individual 'upgrade of beliefs' then gets translated to the wider policy community at the national level and the exact mechanism thereof is difficult to determine. The interviewees stated that the process is rather indirect and very gradual. A citation from an interview (interview 10) describes the process:

"It is not a very straight-forward process... it is not that you bear about something done elsewhere and you jump on it. No, you hear during one EMCO meeting about 
the Danish approach to flexicurity, you hear it for a second time... the idea lingers on during several discussions, and it sort of grows in your system. And then if the issue is debated at the national level, then I or some of my colleagues will mention that we have beard about the Danish approach and how successful they are. So it might be that a Dutch delegation would go and visit them on a bilateral basis."

From the above it could be concluded that whether policy learning will be generated is contingent upon the extent to which the issue is already to some extent debated in the national public sphere and that the EU processes hardly change the set domestic agenda in the field of employment policy. Moreover, the international knowledge will remain passive in the heads of the civil servants until provoked by a national debate on the subject or explicitly requested (in the form of report or study on the subject). This is important because it indicates that the officials have the role of gatekeepers with regard to the penetration of international experiences shared in the framework of the Open Method of Coordination. Whether and what will be the magnitude of cross-country policy learning is hence up to their efforts to act as transmission belts. This points to the conclusion that 'learning from others' - the second type of learning process that might be instigated by the OMC (Hartlapp, $2009)$ is rather rare and difficult to delineate. The EMCO meetings provide ample information and the discussions create a common pool of experiences. The circle of officials, however, who have access to (and for that matter take interest in) this depository of information about existing policy approaches is very limited.

\section{The European Employment Strategy in the Netherlands - administrative governance in action}

From all of the above it could be concluded that the childcare policy process and the EES implementation in the Netherlands are functionally specialised. On the one hand, the process of childcare policy making takes place at 3 rather disconnected levels: the sectoral, the national and the international. The main actors in the sectoral process of childcare policy-making are the two branche organizations (representing the childcare providing companies), the trade unions, the local (health) authorities, and the parental organizations. The national level of policy-making is populated by the central government, the Social Partners, and the Dutch parental organization BOINK. The main actor in the international level of policy-making is the government (via its civil servants). Due to the famous Polder model the government habitually consults the Social Partners on issues of employment policy (and thus on the EES) but ultimately the government is the main decision-maker when it comes to the processes of international policy-making such as the EES. 
Indeed, a systematic tracing of the process of implementation of the EES in the Netherlands reveals that the government is the engine and ultimately responsible for the EES in the Netherlands. This is confirmed not only by the conducted interviews but is also stated in the Dutch National Action Plans sent to the Commission (e.g. the NAP of 2004: 34). Furthermore, the findings presented in this section suggest that also in terms of the EES there are three distinct supranational for a for decision-making involved. Firstly, at the highest level of strategic decisionmaking are the European Council discussions (mainly during the Spring Council). Here the strategic framework of the policy coordination process is adopted, and quantitative targets are endorsed. At this level the Netherlands are represented by the Prime Minister and the Dutch position is extensively debated with the Social Partners within the SER and the Labour Foundation. The second level is that of the EBSCO Council where the Netherlands are represented by its Ministers. At this level all major decisions that have a bearing on the annual EES cycle are adopted: the guidelines, the overall employment report and (possibly) the country recommendations. Also for this level the Dutch mandate and policy position are prepared in a broad consultation with the Social Partners via the highly institutionalised forums of the SER and the Labour Foundation. The third - working party - level, however, is 'managed' by a restricted group of officials who have an extensive background in international affairs/negotiations, and who are hardly ever in contact with the levels busy with the 'real' policy-making 'on the ground'. Consultations beyond the ministerial departments hardly take place. The civil servants rather freely decide on how they will represent their country in the EMCO discussions. A mandate is usually not prepared. Nevertheless, they definitely act within the defined by the European Council strategic and by the Dutch annual framework of the EES process. Thus, they act within the 'realm of the possible' as fixed by the top political (elected) level. Still, the method of Open Coordination grants the national bureaucracy (non-elected) more leeway in the formulation of policy than the typical procedure under the Community method (lack of ample a priori and a posteriori control).

\section{The learning dimension of the OMC: a depository of policy}

\section{approaches}

Based on the empirical findings about the organization of the policy process at the national level and the actors' interactions identified above this section addresses one of the main questions in the debate about the effectiveness of the OMC as a steering mode: whether it induces policy learning among the states of the EU.

If learning is defined as: "a deliberate attempt to adjust the goals or techniques of policy in response to past experience and new information" (Hall, 1993: 278), and 
the three types of learning defined by Hartlapp (2009) are judged against the collected empirical material about the Dutch Employment Coordination experiences, then it could be concluded that the OMC triggers in the Netherlands learning of all the three types distinguished by Hartlapp (see Section 2.5.)

The first type of learning (learning from reflections upon own experiences) is stimulated by the obligation to submit an annual report (the NAPs/ NPRs) on the various policy actions and the achieved policy outcomes. This iterative routine inevitably prompts mechanisms of self-reflection and self evaluation for example about the Dutch performance in the R\&D field (interviews 2, 10, 15). Moreover, the policy actors which get to comment yearly on the NPRs, e.g. the Social Partners, also act as a stimulator of the national policy self-reflection, because the revisions inevitably provide a forum for criticism and the government collects a lot of feedback (12). What is more, the sheer fact that the issues come back yearly reminds the government what they have done and what worked.

Concerning the second type of learning (the learning from others or 'lessondrawing' in the vocabulary of Richard Rose), this study discovered that the Netherlands did not learn much from peer member states. There were two prominent fields: the approach toward unemployment and the debate reflecting on flexicurity (both inspired by the Danish model). Concretely, it seems that the way in which the unemployed are helped to find a new job changed in the Netherlands due to the EES (interviews 12 and 15). Apparently, prior to the EES the Dutch employment policy was very reactive and would only intervene in those cases where after two years the unemployed did not find a new job. Clearly, by then the person becomes quite disconnected from the work floor and her skills and professional knowledge get outdated. Conversely, the active labour market policy paradigm (embedded in the EES), and the concrete quantitative targets endorsed by the European Council (see Appendix B) require for a start a much earlier intervention in cases of unemployment, a push for a quick start with reintegration trajectories, and within these trajectories provides re-training courses and other skills upgrades that increase the employability of the person. This is the policy practiced currently by the Dutch government, and according to the conducted interviews this is due to the influence of the EU is very visible in this field. Furthermore, the EU debate on flexicurity allegedly prompted the government and the Social Partners to rethink and redefine the Dutch concept and application of 'flexicurity' (interview 15). Subsequently, this reflection (for example within the Committee on Social and Economic policy of SER) led to redefinition of various national flexicurity policy measures. This is another area where the EU process of open coordination has had a visible effect. In turn, the Netherlands was an example for other member states with good practices such as innovation vouchers and reduction of governmental red-tape 
(interviews 5, 12, 15). On the whole, such instances of lesson-drawing from and to the Netherlands remained limited.

Finally, the Netherlands also engaged to some extent in the third type of learning - the learning with others - which is supposed to take the form of deliberative, experimental learning (Cohen, 1996; Sabel and Zeitlin, 2003). This is most visible in the discussions and endorsement of common indicators for measuring progress toward the OMC objectives in the field of Employment and Social Inclusion (interview 10). In particular, the work of the sub-committees on Indicators (attached to the Employment Committee and the Social Protection Committee) is exemplary with regard to this third type of learning with others. Due to the group effort the EU as a whole agreed on a set of common indicators to be applied in gathering national statistics about policy performance. Thus, apparently, the common discussions of the Indicators groups were very useful for the EU dialogue with regard to measuring unemployment and reintegration on the labour market (interview 10). Nevertheless, this is the only example that an interviewee mentioned regarding the deliberative type of learning. In the concrete case of childcare, the Dutch continued using their national methods for tracking in the number of places and the students who visit them. Hence, even though a specific indicator was endorsed at the EU level to measure progress on the Barcelona target, this development did not have a national follow-up. As a more general conclusion, despite the initial expectations, not much deliberative learning was prompted by the method of open coordination.

Based on these findings it can be concluded that the main mechanism through which the OMC seems to influence (and even steer) the domestic policy processes is learning through repetition. According to the collected interview data, the yearly reiteration and the obligatory discussion about the national policy performance each time the National Reform Programme is prepared, remind the policy community that employment policy is a field where more efforts are needed.

"The Netherlands is one of the best pupils in Lisbon terms. We usually get very good policy evaluations and few policy recommendations. Nevertheless, every year two advices come back: improve the labour market participation of women, elderly and of vulnerable groups, and increase the R\&D spending. These issues quite rightly are mentioned every year by the European Commission, and this creates certain pressure on the government to act." 
Such testimonials, together with the finding that it is mostly the first type of policy learning (learning from own experience - see section 6.1.) that is generated by the OMC mechanism, point to the conclusion that the Europeanization effect of the OMC resides in its organization as a repetitive routine. This induces a continuous self-reflection and self-actualization of the domestic policy approaches. Crucial is also the fact that the domestic actors receive repetitively policy advices from Brussels (interview 5) i.e. there is a permanent 'transmission' of the same policy message. This exercises an enduring pressure on the domestic policy actors to align the existing national policy discourses with the EU discourse. This process is furthermore facilitated by the emergence of a common EU-wide policy paradigm (on activation and employability), in which the national administration gets socialised via discussions during the regularized meetings in Brussels.

The examples above concern substantive learning about policy approaches that actually materialised in policy changes in the Netherlands. The pertinent question that needs to be addressed however is: if learning takes place then who learns? From the interviews with policy actors, it seems that the OMC instigates learning among civil servants only. It did so by creating a depository of knowledge about policy approaches and activities in different member states regarding the same type of policy problems. That is to say that the OMC acts as a forum for socialization and policy learning predominantly between the national bureaucracies, for exchange of ideas, best practices and experiences about the formulation and implementation of various policy approaches that do not necessarily materialise in policy change, yet may later become useful (interviews 1, 5 and 10). This depository remains latent in the short term, but in the long term ideational convergence is created among the participating civil servants, and common EU-wide policy paradigms could emerge and get accepted by all member states (as was observed with regard to active labour market policies or flexicurity in the first half of the 2000s).

Three caveats are in order however. Firstly, such processes demand a lot of time to materialise and the civil servants that participate in them should remain the same. Rotation of the membership in the OMC committees for example is a clear break with the idea of policy learning. Such rotation is a common practice in the EMCO (interviews 10, 16, 24, 27) indicating that learning and socialisation is difficult to take place in Brussels. Secondly, even if the membership is more stable, it is composed of civil servants from the International Affairs departments of the respective ministries of the member states. Not only they are not involved in the direct policy-formulation back home, but moreover having been selected for, and working on the international aspects of policies, this group of civil servants are already quite inclined to be receptive for the policy message coming from the EU level of governance (interviews 10, 19 and 22). Thirdly, even if via the exchange and interaction in the OMC framework common paradigms may emerge they still need 
contextualization and adaptation to the national/ local reality before implementation could occur. During this contextualization processes a lot gets altered in terms of original meaning and intention so it is doubtful whether the outcome of this process could eventually be described as learning.

Despite these caveats it became clear from the interviews that the policy superstructures generated in the framework of the OMC (e.g. the paradigm of active labour market policies and the flexicurity debate) do act as ordering schemes for the national policy-makers. They become the new points of reference in the light of which policy-makers frame the national actions and report about them.

\section{Reflections on the organization of the method and several critiques}

All in all, the Dutch policy-makers believe that the Growth and Jobs Strategy is a useful process for both the Netherlands and the EU as a whole. The interviews revealed that there is a general agreement that the country was following EES relevant policies already in the mid-1980s (with the national reforms of the welfare state following the Wassenar agreement). Hence, the EU and the Dutch policies are well aligned for nearly two decades. Nevertheless, a process at the EU level is deemed needed and relevant because it provides a yearly "check-up" of the governmental agenda and the undertaken activities, and allows for an 'objective' judgement of the policy performance (interviews 12 and 15). This 'check-up' does not get a wide coverage and never spurs a larger discussion in the national public sphere. Nevertheless for those few interested in the EU dimension of Dutch policy-making, the yearly OMC cycle in Employment provides an external mirror and an occasion for a discussion. This is why the Dutch policy-makers support the process interviews 2, 10 and 15). What seems to be also relevant is the perception among them of the usefulness of the OMC for maintaining an EU-wide discussion about economic policy. According to some of the interviewees, within a monetary union it is very important to have a forum and a proper discussion about the employment policies of the individual member states and about the strategic objectives for the Union as a whole (interviews 6,10 and 15). In this context, the OMC is deemed the appropriate governance method to be practiced because of its low level of obligation. The general attitude is that binding regulation from the EU in this field does not make any sense and would not be acceptable neither by the Dutch politicians, nor seen as legitimate by the Dutch people (interviews 1, 5 and 6). This is why, although the Dutch policy- 
makers believe that the OMC could be procedurally improved (see below), they are also supportive of the current OMC formula of cooperation (interviews 5, 6, 10, 15).

The interviews revealed several criticisms related to the assumptions behind and the organization of the Open Method of Coordination. Firstly, policy-makers regard the simultaneous objectives to name and shame (to rank and compare) and to encourage countries to learn from each other as contradictory. The moment the national policy performance is portrayed as not that good; national representatives become defensive and feel obliged to present their country in the best light possible (interview 10). In reality, all member states want to look good during the Brussels (EMCO) meetings and peer review sessions, hence they focus exclusively on the national policy performance and disregard the open invitation for a group reflection (interviews 16, 19, 24 and 26). This seems to be the common practice, and nothing in the examined case suggests that the OMC's method of 'learning from and with others' will bear fruit (interviews 12 and 15):

"As it currently stands the member states have to explain and defend their policy choices and policy performance... this is not the right environment for learning. If you are on the defensive - you do not listen to the others."

(interview 15)

The second main criticism and suggestion for improvement is linked to the need of a higher degree of politisation of the process. According to the interviewees, influence will be exercised only when the method is better embedded in the domestic political cycle (interviews 6 and 19). This is a rather unrealistic expectation in the case of the Netherlands, however. One of the crucial elements of the annual cycle of the OMC - the adoption of the National Progress Report - at present competes with Prinsjesdag.

Furthermore, it is expected that increased domestic media attention would be beneficial for the influence of the process at the national level (interview 26). In the Netherlands, however, for several years already the EU is not a very popular level of governance. Hence, the domestic actors are very cautious in using "the EU card" even if it would support their arguments because it "might backfire" (interview 1). The EU is generally a very elitist project in the NL (interview 5 and 6). Only a restricted number of policy-makers participate in it and understand it (interview 1), hence politisation of EU policy debates in the media, and in particular of the OMC discussions will hardly take place. 
Finally, the policy-makers noted that the coordination procedure in terms of thematic directions and targets has to be simplified and streamlined (interview 15). Until 2005 there were more than five open coordination mechanisms (each with its specific length and inner logic), and the policy makers had to prepare separate reports for all of them. Since 2005 they were somewhat mainstreamed (via the Integrated Guideline for Growth and Jobs), but in general the processes remain fairly complex to oversee and prepare, so further simplification will be welcome (interview 15).

\subsection{POLICY ACTORS}

Having revealed the procedural aspects of the implementation of the EES in the Netherlands and the typical pattern of actors' interactions, this section reviews the evolution in the position of the main actors in Dutch policy-making toward childcare since the 1970s (when the public policy dimension of the care for the children was acknowledged). The studied actors include the political parties (who define the strategic vision), the Ministries of Social Affairs and of Education and Science (the former was responsible for childcare until 2007, while since the cabinet change in 2007 until 2010 childcare was in the portfolio of the latter), the Trade Unions, the Employer's organizations, and the Dutch parental organization (BOINK). Policy frame analysis was the preferred method for data analysis of the actors' position. This method was applied to the position of the political parties as this was easily accessible in party manifestos. For the other actors (the Social partners and the NGOs) the method of the interview was used, complemented with documentary analysis of position papers. The objective of the actors' analysis is to establish the extent of EU influence on the Dutch childcare policy process and outcomes.

\section{Political parties}

The Dutch political parties can be positioned according to 2 dimensions: socioeconomic (commonly referred to as the left-right dimension), and ethical/religious (commonly referred to as the conservative-progressive dimension) (Andeweg, 2005: 60). These dimensions are important for the current analysis because, as will be revealed below, the position of a political party toward childcare is determined by the general party position toward more or less intervention of the state in the economy, and the likelihood of adoption of more libertarian (permissive) policies. In general, progressive parties support the organization of childcare in a formal setting outside 
the family, while conservative parties are slower in adopting such views. Moreover, leftist parties are prepared to stimulate the use of childcare facilities i.e. to develop and subsidise the sector, while rightist parties prefer policy solutions involving minimum public investment.

Andeweg (based on data from Laver and Mair (1999) orders the Dutch parties according to the dimensions above in the following way:

From Left to Right: SP, GL, PvDA, D66, CDA, VVD

From Progressive to Conservative: D66, GL, PvDA, VVD, SP, CDA

Indeed, as will be revealed below this order is a good predictor of the childcare position of the political actor. The progressive-conservative dimension forecasts fairly well whether the political party will be supportive of formal organization of childcare outside the family, while the 'left-right' dimension predicts the position toward financial support (i.e. budgetary spending) for the use of childcare facilities. As the analysis of the previous section also demonstrated: once the $\operatorname{PvdA}$ came to power at the end of the 1980s the childcare policy witnessed a real boost (the other 2 progressive parties D66 and GL were never a leading coalition partner in any postwar cabinet).

The rest of this section presents the results of the policy frame analysis of the party manifestos of the main Dutch political parties. The dataset consisted of the party manifestos of 6 political parties for the period 1963 to $2006 .^{1}$ The analysis involved the same method as applied to coalition agreements and the EU legislation i.e. the presence and prominence of the 6 main childcare policy frames was examined via qualitative content analysis of the texts of the party manifestos. Below for each of the parties a table is presented displaying the dynamics of all policy frames and a graph that displays only the dynamics among the two most prominent frames - F1 and F2.

\subsubsection{D66}

The most progressive Dutch party (Andeweg, 2005: 60) D66 was among the first political actors to discuss the public organization of childcare in the national

\footnotetext{
1 The author is grateful to the Comparative Electronic Manifestos Project which supplied the electronic versions of the original texts (Paul Pennings and Hans Keman, Vrije Universiteit Amsterdam, in cooperation with the Social Science Reserach Centre Berlin (Andrea Volkens, Hans-Dieter Klingemann) the Zentralarchiv für empirische Sozialforschung, GESIS, Universität zu Köln, and the Manifesto Research Group (chairman: Ian Budge). Financed by the Netherlands Organization for Scientific Research (NWO project 480-42-005).
} 
public sphere. The first reference is in the manifesto of 1977, and is linked to the 'problem' of gender inequality (p. 13):

"The emancipation policy should be directed to the provision of equal chances to develop for both men and women. Concretely this means:

....

to remove the relative backward position of the woman as an employee

- work opportunities for people after a break in their employment through provision of childcare in order to allow reintegration in the working process;... ",

As of 1989 the economic competitiveness frame (F2) entered the D66 discourse and quickly established a dominant position. Below is an example of F2 from the 1989 party manifesto (p. 27)2:

\section{"CHILDCARE}

D66 stands for an extensive system of childcare facilities, pregnancy and parental leave. In this way men and women could maintain their band with the labour market in combination with the care for the children."

D66 also emphasizes childcare as a welfare measure (F4). In the party manifesto from 1994 this frame is twice articulated (p. 53) ${ }^{3}$ :

"In childcare policy it has to be emphasized the offer of facilities that will allow the care for children with special needs."

1 Author's own translation. The original text in Dutch reads: "Emancipatie moet gericht zijn op gelijke ontplooiingsmogelijkheden en gelijke kansen voor vrouwen en mannen. Dat betekent voor:

achterstand van de vrouw als werknemer op te heffen;

- werkgelegenheid of ww/wwv voor mensen die na een onderbreking door kinderopvang weer aan het arbeidsproces willen deelnemen;..."

2 Author's own translation. The original text in Dutch reads: "KINDEROPVANG

D66 staat een uitgebreider systeem van kinderopvang, bevallings- en ouderschapsverlof voor. Zo kunnen vrouwen en mannen de band met de arbeidsmarkt behouden, in combinatie met de verzorging van kinderen."

${ }^{3}$ Author's own translation. The original text in Dutch reads: "Bij kinderopvang moeten met nadruk ook faciliteiten worden geboden voor de opvang van kinderen die bijzondere zorg behoeven." 
Since the introduction of the European Employment Strategy (EES) this political party is firmly aligned with the EU discourse (see Table 6.2-1 and Figure 6.2-1).

Figure 6.2-1 Relative proportions of childcare-related policy frames in party manifestos of D66

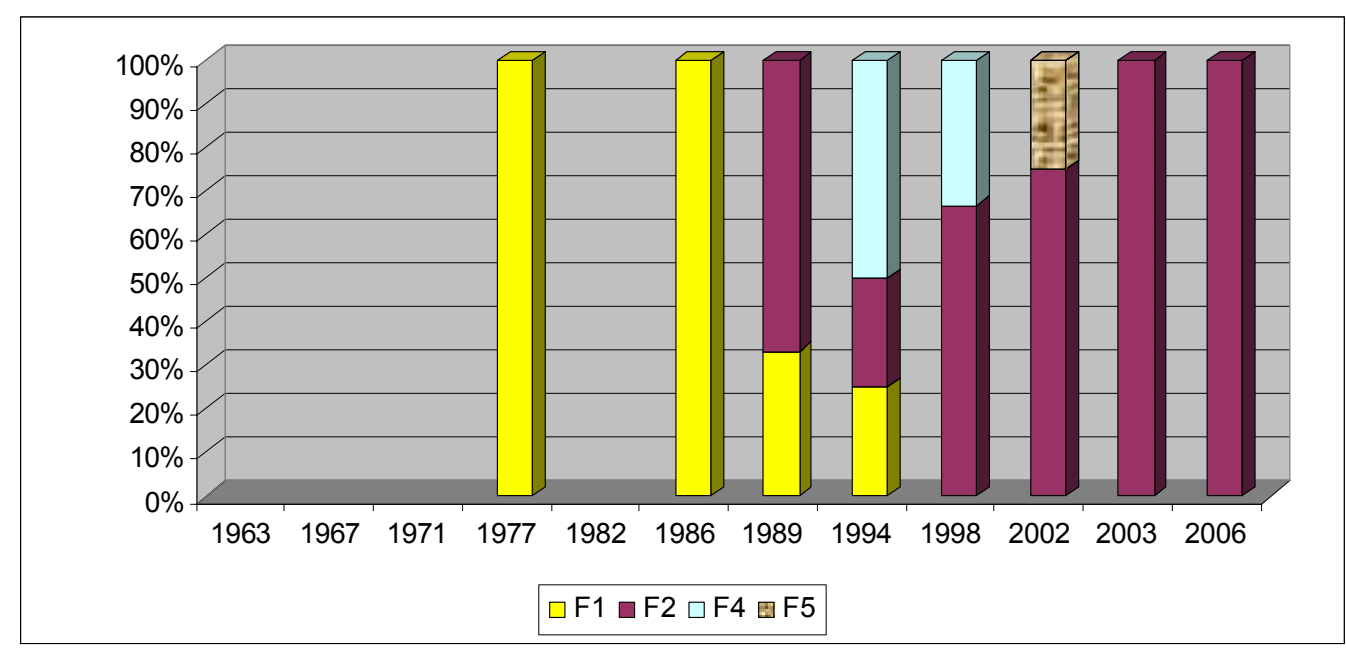


Table 6.2-1 Childcare-related policy frames in party manifestos of D66 (19632006)

\begin{tabular}{|c|c|c|c|c|c|c|c|}
\hline $\begin{array}{l}\text { Year of } \\
\text { the } \\
\text { manifesto }\end{array}$ & $\begin{array}{c}\text { Total } \\
\text { number }\end{array}$ & $\mathrm{F} 1$ & $\mathrm{~F} 2$ & F3 & F4 & F5 & F6 \\
\hline 1963 & - & & & & & & \\
\hline 1967 & 0 & & & & & & \\
\hline 1971 & 0 & & & & & & \\
\hline 1977 & 2 & 1 & & & & & \\
\hline 1982 & - & & & & & & \\
\hline 1986 & 2 & 2 & & & & & \\
\hline 1989 & 8 & 1 & 2 & & & & \\
\hline 1994 & 5 & 1 & 1 & & 2 & & \\
\hline 1998 & 4 & & 2 & & 1 & & \\
\hline 2002 & 5 & & 3 & & & & 1 \\
\hline 2003 & 1 & & 1 & & & & \\
\hline 2006 & 6 & & 2 & & & & \\
\hline
\end{tabular}

All in all, the range of problems for which childcare is proposed as a solution by this political actor is rather limited - gender inequality, competitiveness and social exclusion. It is observed that since the introduction of the EES the discourse of D66 is aligned with the EU discourse. Europeanization influence cannot be discerned however because the dominant position of $\mathrm{F} 2$ was established already in 1989 (10 years before the EES). 


\subsubsection{GroenLinks (GL)}

The Green party participates in elections since $1989^{1}$, and articulates a position on childcare from its first manifesto. Most prominent are the policy frames of gender inequality and competitiveness (F1 and F2) but it is difficult to determine a domination of any of the two. They seem to co-exist in parity in the GroenLinks discourse on childcare (see Table 6.2-2).

\section{Table 6.2-2 Childcare-related policy frames in party manifestos of GroenLinks (1963-2006)}

\begin{tabular}{|c|c|c|c|c|c|c|c|}
\hline $\begin{array}{l}\text { Year of } \\
\text { the } \\
\text { manifesto }\end{array}$ & $\begin{array}{l}\text { Total } \\
\text { number }\end{array}$ & F1 & F2 & F3 & F4 & F5 & F6 \\
\hline 1963 & - & & & & & & \\
\hline 1967 & - & & & & & & \\
\hline 1971 & - & & & & & & \\
\hline 1977 & - & & & & & & \\
\hline 1982 & - & & & & & & \\
\hline 1986 & - & & & & & & \\
\hline 1989 & 10 & 2 & 1 & & & & \\
\hline 1994 & 5 & 1 & & & & & \\
\hline 1998 & 2 & & 1 & & & & \\
\hline 2002 & 10 & & & & 1 & 1 & \\
\hline 2003 & 2 & 1 & & & & & \\
\hline 2006 & 7 & 1 & 2 & & 1 & & \\
\hline
\end{tabular}

\footnotetext{
${ }^{1}$ GroenLinks was the name chosen by 4 leftist Dutch parties to participate in the national elections of 1989 . The party itself was formed in 1990.
} 
The two frames are presented as complementary - labour market participation will lead to greater levels of financial independence and hence increased equality ${ }^{1}$ :

\begin{abstract}
"GroenLinks finds the financial independence of every person very important. Unfortunately only $48 \%$ of women earn sufficiently so that they can support themselves. That is why we think that the labour market participation of women should be stimulated. This is good for the Netherlands because we are in great need of working women. And this is good for the women themselves."
\end{abstract}

Furthermore, F4 and F5 are present in the manifestos but they are negligible in terms of frequency.

\title{
Figure 6.2-2. Relative proportions of childcare-related policy frames in party
} manifestos of GroenLinks

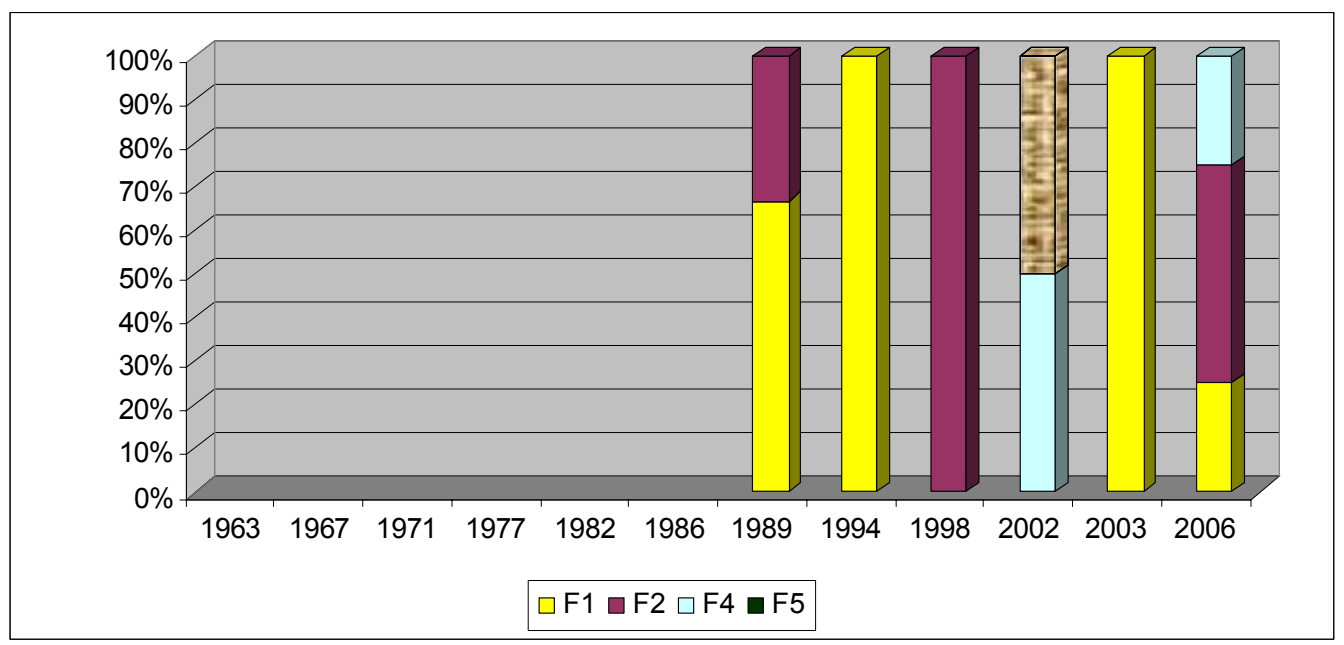

Overall, the data do not reveal the domination of any policy frame since the introduction of the EES in 1998 (see Figure 6.2-2). Purely numerically F2 prevails

\footnotetext{
1 Author's own translation. The original text in Dutch is found on the official website of the GroenLinks party http://standpunten.groenlinks.nl/kinder+opvang (accessed on 3 May 2010): "GroenLinks vindt het ook van groot belang dat iedereen economisch zelfstandig kan zijn. Helaas verdient slechts $48 \%$ van de vrouwen voldoende om er van te kunnen leven. Wij vinden daarom dat de arbeidsparticipatie van vrouwen moet worden bevorderd. Dat is goed voor Nederland, want we hebben al die werkende vrouwen hard nodig. En het is goed voor vrouwen zelf."
} 
over F1 but given the low number of observations it will not be well-grounded to claim that any frame dominates. Nevertheless, the prominence of F2 indicates that the Green's view on childcare is supportive of the EU frame, or rather that the EU frame resonates well with the party's discourse. It is however not possible to discern any Europeanization effects.

\subsubsection{Partij van de Arbeid (PvdA)}

The Labour Party (PvdA) and the Conservative Liberals (VVD) are the first political parties to take a stance on childcare. At the beginning of the $1970 \mathrm{~s} \operatorname{PvdA}$ linked the problem of gender inequality with the provision of formal childcare services. This is visible from its party manifesto of $1971^{1}$ (p. 3):

\section{"12. Equality of women and men}

Men and women participate in an equally valuable way in public life. To that end there will be: a) Enlargement of the work opportunities in the parttime sector for women as much as for men..... c) Good and affordable daycare centres. d) Individual taxation of income of men and women, taking into account the possibility to sustain the tax burden. e)......"

Up to 1982 this is the dominant policy frame in the party discourse on childcare (see Table 6.2-3). The gender equality frame (F1) is present until 2002, but much more prominent since the mid 1980s is the economic competitiveness policy frame (F2) which entered the party discourse in the manifesto of 1982 and clearly dominates over the other possible interpretations to date. Hereby an example of this frame from the PvdA manifesto of $2003^{2}$ (p.3):

1 Author's own translation. The original text in Dutch: “12. Gelijkstelling van man en vrouw Man en vrouw nemen op gelijkwaardige wijze deel aan het maatschappelijk leven. Daartoe worden: a) De werkgelegenheden in de parttime sector zowel voor mannen als voor vrouwen uitgebreid. De overheid geeft hierbij zelf het voorbeeld en stimuleert het bedrijfsleven. b) De werk- en schooltijden zoveel mogelijk met elkaar in overeenstemming gebracht. c) Goede en betaalbare kindercentra beschikbaar gesteld. d) De belastingen op inkomens zodanig gewijzigd dat, met inachtneming van het draagkrachtbeginsel, vrouw en man individueel worden aangeslagen. e) De her- en bijscholingsmogelijkheden uitgebreid."

2 Author's own translation. The original text in Dutch: "De kinderopvang wordt verbeterd en verder uitgebreid. Ook buitenschoolse en tussenschoolse opvang voor schoolkinderen wordt uitgebreid, zodat kinderen goed verzorgd zijn en ouders zonder zorgen kunnen werken." 
"The childcare services will be improved and enlarged. Also the after-school and the lunch childcare services for children who go to school will be expanded, so that cbildren are well taken care of and parents can work without any worries."

It is interesting to note that the PvdA accords to childcare also a role in the battle against social exclusion, and that the party regards childcare as part of the educational system since 1977. This has the important implication that the PvdA will be inclined to financially support childcare via the budget (something which will not be done until 30 years later).

Table 6.2-3 Childcare-related policy frames in party manifestos of PvdA (1963-2006)

\begin{tabular}{|c|c|c|c|c|c|c|c|}
\hline $\begin{array}{c}\text { Year of } \\
\text { the } \\
\text { manifesto }\end{array}$ & $\begin{array}{c}\text { Total } \\
\text { number }\end{array}$ & $\mathrm{F} 1$ & $\mathrm{~F} 2$ & F3 & F4 & F5 & F6 \\
\hline 1963 & 0 & & & & & & \\
\hline 1967 & 0 & & & & & & \\
\hline 1971 & 1 & 1 & & & & & \\
\hline 1977 & 3 & & & & & 1 & \\
\hline 1982 & 3 & 1 & 2 & & & & \\
\hline 1986 & 5 & & 1 & & & 2 & \\
\hline 1989 & 5 & 1 & 2 & & & & \\
\hline 1994 & 5 & & 2 & & 2 & & \\
\hline 1998 & 7 & & 3 & & 1 & 1 & \\
\hline 2002 & 17 & 1 & 5 & & & 2 & 1 \\
\hline 2003 & 3 & & 1 & & & 1 & \\
\hline 2006 & 18 & & 3 & & & 2 & 1 \\
\hline
\end{tabular}


Figure 6.2-3. Relative proportions of childcare-related policy frames in party manifestos of PvdA

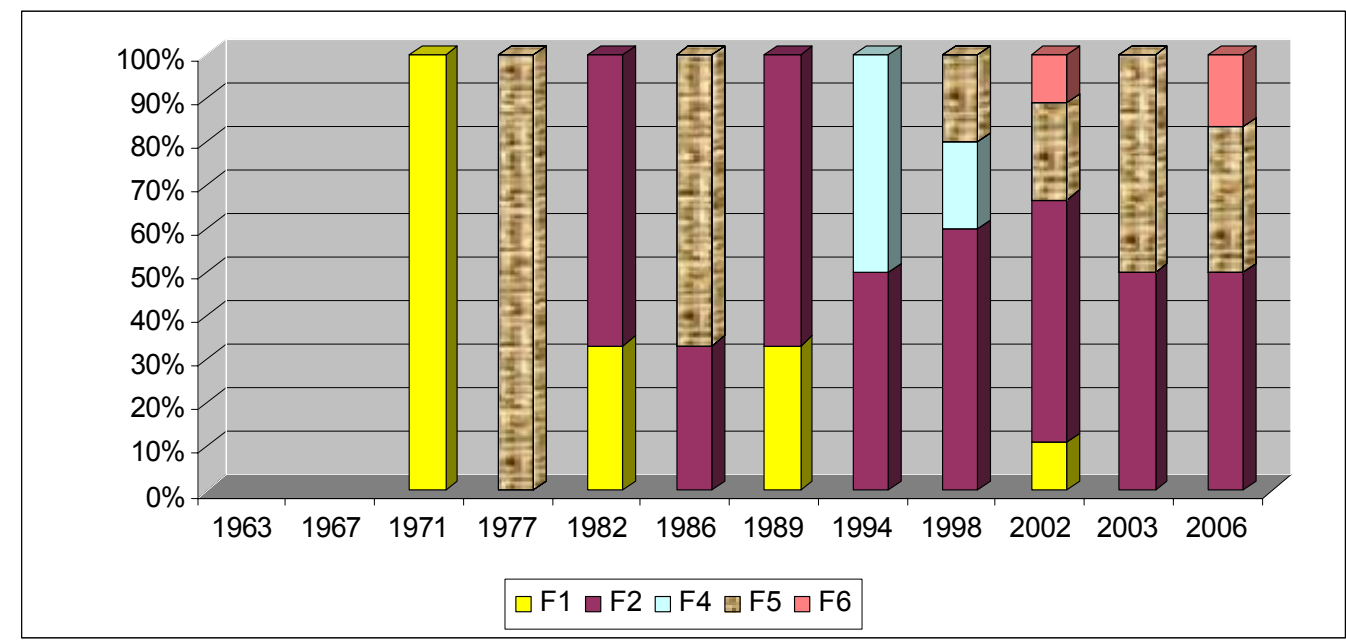

An interesting feature of the PvdA discourse on childcare is that it has the broadest vision with regard to the possible applications of childcare as a policy solution: with the exception of the demography frame (which is generally not popular in the Netherlands) all contemporary public policy visions of childcare are present in the party manifestos of the PvdA. This means that the Dutch Labour party recognizes the various applications of the 'childcare' solution. In any case much more so than the other political parties (see Figure 6.2-3.).

The data reveal beyond any doubt that the discourse of this political party was not influenced by the introduction of the EES. Already at the beginning of the 1970s the PvdA was one of the greatest proponents of the growth of the childcare sector in the Netherlands. Since 1981, more than 15 years before any Europeanization of the field, the competitiveness policy frame is dominant in the discourse of the Dutch Social Democrats. 


\title{
6.2.1.4. Volkspartij voor Vrijheid en Democratie (VVD)
}

The People's party for freedom and democracy VVD - the Dutch Liberal conservative party - was together with the PvdA the first to include childcare in its party manifesto. The manifesto from 1971 links the problem of gender inequality to the solution of childcare ${ }^{1}$ (p. 14):

\author{
"12. The Woman \\ A. ......
}

E. Where necessary the establishment of playgroups, facilities to stay for lunch for children who go to school, crèches and other childcare facilities will be stimulated. ....."

It, has to be noted, however, that after this one reference as early as 1971 the VVD's manifestos will remain silent about the subject until 1986 (see Table 6.2-4). As of 1986 the policy frame of competitiveness (F2) appears in the VVD discourse and is dominant to this day (and hence in line with the EU discourse). Apart from two references to F4 and F5 in 1986 - the VVD discourse is generally devoted to F1 and F2.

\footnotetext{
1 Author's own translation. The original text in Dutch:

"12. DE VROUW
}

A. Verwezenlijking van het wettelijk recht op gelijke waardering en gelijke beloning voor gelijkwaardige arbeid voor vrouw en man. De overheid moet hierbij het goede voorbeeld geven en aan ambtenaressen dezelfde aanstellingsen promotiekansen bieden als aan ambtenaren. Het verdrag van de ILO (International Labour Organisation) moet worden geratificeerd.

B. Verbetering van de belastingheffing voor de gehuwde vrouw zodanig dat daarbij meer rekening wordt gehouden met haar zelfstandige positie.

C. Part time betrekkingen: ook hier kan de overheid het goede voorbeeld geven.

D. Het op korte termijn tot stand brengen van een wetswijziging die bepaalt dat het beding in een arbeidsovereenkomst met een vrouw dat haar bij huwelijk ontslag wordt verleend, nietig wordt verklaard.

E. Waar nodig moet de op- en inrichting worden bevorderd van peuterspeelzalen, overblijfmogelijkheden voor schoolkinderen, crèches en andere opvangmogelijkheden. Overheidstoezicht op het voldoen aan vast te stellen wettelijke normen is gewenst deskundige leiding is noodzakelijk.." 
Table 6.2-4 Childcare-related policy frames in party manifestos of VVD (1963-2006)

\begin{tabular}{|c|c|c|c|c|c|c|c|}
\hline $\begin{array}{c}\text { Year of } \\
\text { the } \\
\text { manifesto }\end{array}$ & $\begin{array}{c}\text { Total } \\
\text { number }\end{array}$ & F1 & F2 & F3 & F4 & F5 & F6 \\
\hline 1963 & 0 & & & & & & \\
\hline 1967 & 0 & & & & & & \\
\hline 1971 & 1 & 1 & & & & & \\
\hline 1977 & - & & & & & & \\
\hline 1982 & 0 & & & & & & \\
\hline 1986 & 3 & 1 & 1 & & 1 & 1 & \\
\hline 1989 & 3 & 1 & 1 & & & & \\
\hline 1994 & 0 & & & & & & \\
\hline 1998 & 4 & 1 & 1 & & & & \\
\hline 2002 & 8 & & 1 & & & & \\
\hline 2003 & 1 & & 1 & & & & \\
\hline 2006 & 2 & & 1 & & & & \\
\hline
\end{tabular}

All in all, the range of problems for which childcare is proposed as a solution by this political actor is rather limited - gender inequality, competitiveness and early education. It is clearly visible from the data (see Table 6.2-4 and Figure 6.2-4) that since the introduction of the EES the discourse of VVD is fully in line with the EU discourse. Causal influence cannot be established however because the dominant position of $\mathrm{F} 2$ was established already in 1989 (10 years before the EES). 
Figure 6.2-4. Relative proportions of childcare-related policy frames in party manifestos of VVD

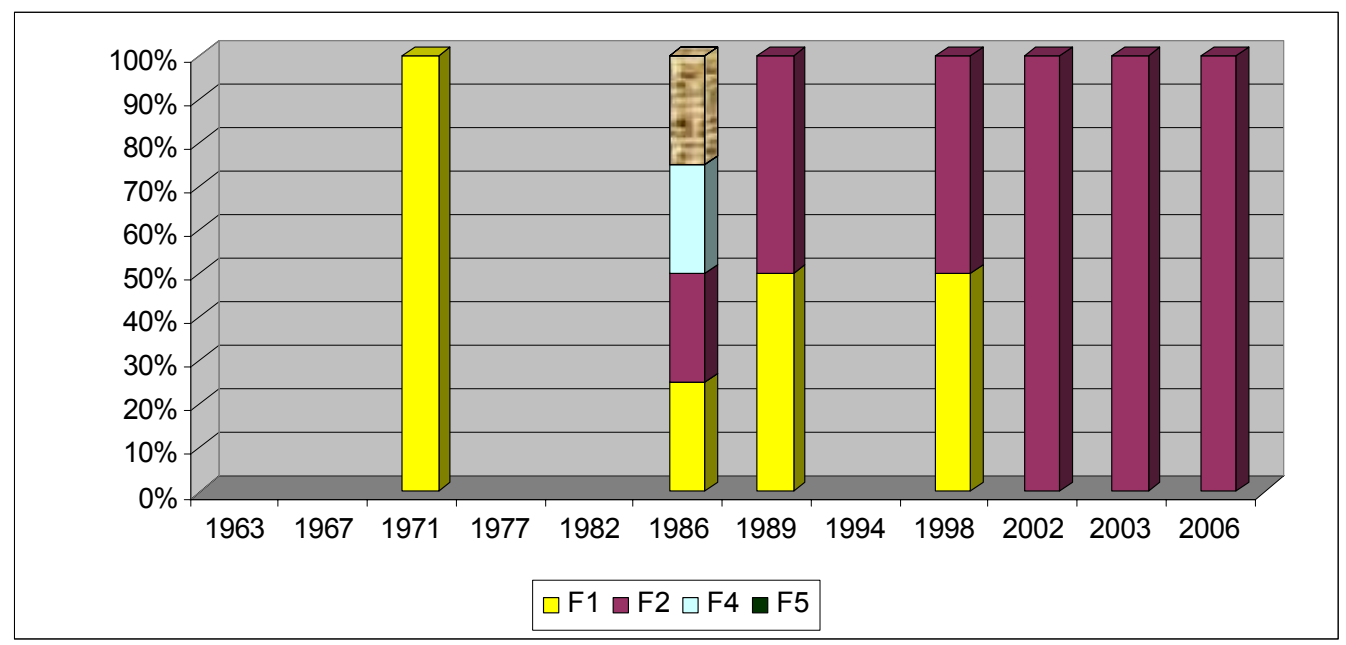

\subsubsection{Socialistische Partij (SP)}

The Socialist party takes part in elections since 1998 but devotes attention to childcare only since 2002 (see Table 6.2-5 and Figure 6.2-5). The dominant discourse in the last 3 manifestos is definitely the one on competitiveness (F2). Hereby an example form the 2002 manifesto $^{1}$ (p. 11):

"Therefore we should offer to lone parents on social benefits all the possibilities to get into paid employment, for example by providing sufficient cbildcare, but without obliging them to apply for jobs until the cbildren bave to go to school."

${ }^{1}$ Author's own translation. The original text in Dutch: "Zo moeten we alleenstaande ouders in de bijstand wel alle mogelijkheden bieden om betaald te gaan werken, bijvoorbeeld door te zorgen voor voldoende kinderopvang, maar hen niet achtervolgen met een sollicitatieplicht, zolang de kinderen nog leerplichtig zijn. 
Figure 6.2-5. Relative proportions of childcare-related policy frames in party manifestos of SP

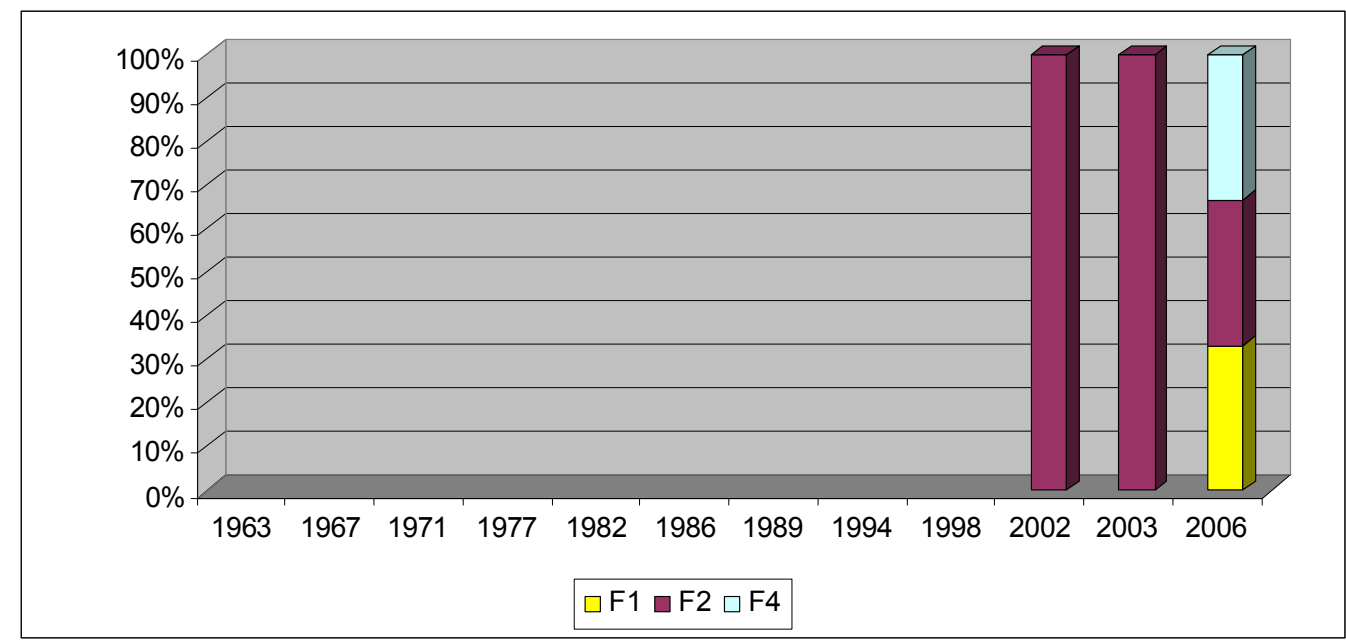

In the manifesto of 2006 the party points at childcare as a solution not only of competitiveness (F2) but also to gender inequality (F1) and to social exclusion (F4). The example of $\mathrm{F} 1$ is ${ }^{1}$ :

"In order to give to women greater chance to take part in the working process the current constraints should be removed, for example through better and more affordable childcare. Equal pay for equal work should be guaranteed. Men and women should acquire more possibilities to combine work and care."

and the example of F4 from the same 2006 manifesto of the Socialists is ${ }^{2}$ :

1 Author's own translation. The original text in Dutch: “Om vrouwen meer kans te geven aan het arbeidsproces deel te nemen moeten bestaande hindernissen worden weggenomen, onder andere door meer, betere en betaalbare kinderopvang. Gelijke beloning voor gelijk werk moet worden gewaarborgd. Mannen en vrouwen moeten meer mogelijkheden krijgen om zorgtaken en arbeid te combineren."

2 Author's own translation. The original text in Dutch: "Kinderopvang dient betaalbaar te zijn en van goede kwaliteit. De inkomensafhankelijke bijdrage wordt gehalveerd. Kwaliteitseisen voor kinderopvang worden wettelijk vastgelegd. Ook voor kinderen met een specifieke sociale of medische indicatie moet goede opvang worden gegarandeerd." 
"Childcare should be affordable and of good quality. The income-dependent own contribution will be halved. ... Also for children with a special social or medical indication should be guaranteed good childcare".

Given the lack of pre-EES history, it is difficult from party manifestos alone to establish the Level of Europeanization. Nevertheless, the appearance and F1 and F4 alongside F2 in 2006 indicates that it is hardly the EU that shapes the standpoint of this actor.

Table 6.2-5 Childcare-related policy frames in party manifestos of SP (19632006)

\begin{tabular}{|l|c|l|l|l|l|l|l|}
\hline $\begin{array}{c}\text { Year of } \\
\text { the } \\
\text { manifesto }\end{array}$ & $\begin{array}{c}\text { Total } \\
\text { number }\end{array}$ & F1 & F2 & F3 & F4 & F5 & F6 \\
\hline \hline 1963 & - & & & & & & \\
\hline 1967 & - & & & & & & \\
\hline 1971 & - & & & & & & \\
\hline 1977 & - & & & & & & \\
\hline 1982 & - & & & & & & \\
\hline 1986 & - & & & & & & \\
\hline 1989 & - & & & & & & \\
\hline 1994 & - & & & & & & \\
\hline 1998 & 0 & & & & & & \\
\hline 2002 & 7 & & 1 & & & & \\
\hline 2003 & 7 & & 1 & & & 1 & \\
\hline 2006 & 4 & 1 & 1 & & & & \\
\hline
\end{tabular}




\subsubsection{Christen Democratisch Appèl (CDA)}

The Christian-Democrats were rather late in discussing the public role in childcare provision. The first reference in a party manifesto is from 1982 (i.e. 10 years after parties such as PvdA and VVD). This is hardly surprising given the conservative background and ideology of the party, and the party's position that it is ideal for each child to be raised at home by the mother/relatives. This is also suggested from the fact that the F1 policy frame (childcare as a solution to gender inequalities) appears only twice in the CDA party manifestos during the 1980s (see Table 6.2-6). The Dutch Christian Democrats were never strong proponents of emancipation. During the same decade F4 (i.e. childcare as a welfare/social exclusion measure) was also popular in the CDA discourse. This is hardly surprising given the ideological background of this party. Since the end of the 1990s the party also articulates that childcare might be a solution to integration problems (F6). In two consecutive manifestos (from 1998 and 2002) the CDA underlines that the socialization function of childcare might help in integrating the children of second and third generation immigrants. Hereby an illustration of this frame from the 2002 manifesto (p. 40)1:

"It is recommendable to link integration courses to the orientation of the people taking the courses. For example, combined trajectories that include working, childcare and [social] integration must be possible."

All in all, despite the relatively wide range of problems for which childcare is proposed as a solution by this political actor, the competitiveness frame takes the lead in the CDA discourse (see Table 6.2-6 and Figure 6.2-6). Again, similarly to the other political party discourses, the data reveal no influence of the EU in the formation of the party position - the dominant position of F2 was established already in 1989 (10 years before the EES).

${ }^{1}$ Author's own translation. The original text in dutch reads: "Het verdient aanbeveling bij inburgeringcursussen aan te sluiten bij oriëntatie van de cursisten. Zo moeten er meer gecombineerde trajecten van werken, inburgering en kinderopvang mogelijk worden." 
Table 6.2-6 Childcare-related policy frames in party manifestos of CDA (1963-2006)

\begin{tabular}{|c|c|c|c|c|c|c|c|}
\hline $\begin{array}{l}\text { Year of } \\
\text { the } \\
\text { manifesto }\end{array}$ & $\begin{array}{c}\text { Total } \\
\text { number }\end{array}$ & $\mathrm{F} 1$ & $\mathrm{~F} 2$ & F3 & F4 & F5 & F6 \\
\hline 1963 & 0 & & & & & & \\
\hline 1967 & 0 & & & & & & \\
\hline 1971 & 0 & & & & & & \\
\hline 1977 & 0 & & & & & & \\
\hline 1982 & 2 & & & & 1 & & \\
\hline 1986 & 5 & 1 & & & & & \\
\hline 1989 & 7 & 1 & 2 & & 2 & & \\
\hline 1994 & 6 & & & & & & \\
\hline 1998 & 6 & & 2 & & & & 1 \\
\hline 2002 & 16 & & 2 & & & & 1 \\
\hline 2006 & 7 & & 3 & & & & \\
\hline
\end{tabular}


Figure 6.2-6. Relative proportions of childcare-related policy frames in party manifestos of CDA

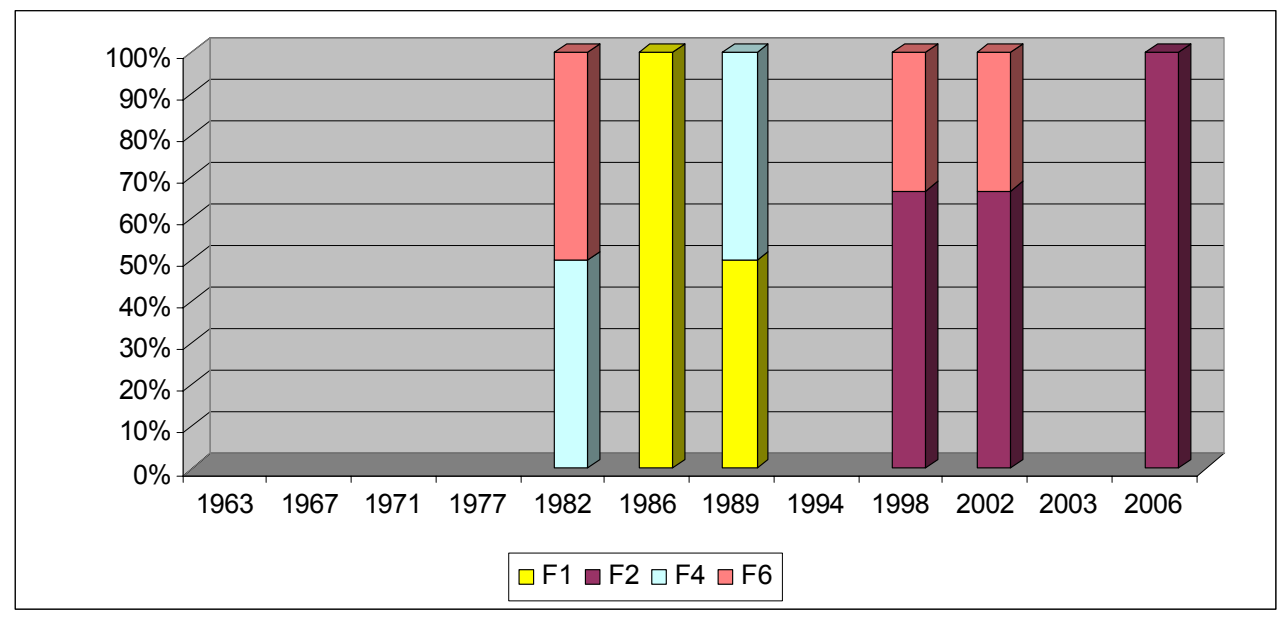

The overall conclusion that could be drawn from the policy frame analysis of the party manifestos is that the majority of the Dutch political parties converge in terms of discourse to the EU policy frame. Nevertheless, Europeanization effects cannot be established because the dominant position of F2 in the Dutch political party discourses is visible already from the beginning of the 1980s, and is rather to be associated with the period of radical Liberal reforms of this decade (the Lubbers era) than to the adoption of EU policy frames (which only took place at the end of the 1990s).

\section{Trade union federations}

There are 3 trade union federations in the Netherlands: the FNV, the CNV and the MHP. With almost 1.4 million members ${ }^{1}$ the FNV is by far the biggest among the three. The CNV represents 360.000 people and the MHP - 160.000. The sections below briefly present each federation, review their standpoints regarding childcare, and the potential EU influence therein.

1 The data about the membership numbers were taken from the respective websites: www.fnv.nl; www.cnv.nl; and www.vakcentralemhp.nl (accessed on: 24 May 2010). 


\subsubsection{Federatie Nederlandse Vakbeweging (FNV)}

The Dutch Trade Union Federation (FNV) represents 19 trade unions with a total of approximately 1.4 million members. It was founded in 1976 as a federation of two existing unions: the Catholic NKV and the social-democratic NVV. The Protestant CNV also took part in the initial talks, but it refused to fully merge into the new union. The federation was founded because of declining membership, due to depillarization and increasing political polarization between left and right. The two fused officially in 1982. Wim Kok (who will later serve as prime minister of the Netherlands, between 1994 and 2002) had already been chair of NVV between 1973 and 1976, so he was the obvious choice for chairing the new organization. He remained the head of the FNV until 1986 when he entered parliament for the PvdA. Hence, although the FNV is officially independent of other organizations, in reality there are strong ideological and personal links between the trade union and the social-democratic party - the PvdA.

Given its ideological proximity with the social-democrats it is not surprising that the FNV mirrors to a large extent the standpoints on childcare expressed by the PvdA. From the FNV Childcare Nota of 2006 (p. 2) it is visible that since its creation in 1976 the FNV was aiming at a universal benefit status for the childcare service (i.e. independent of whether parents work and of their income - childcare is assured by the state on the same basis as school education for example). Since at the end of the 1970s and the beginning of the 1980s the government was not that much interested in supporting childcare, the FNV adopted a different strategy, namely to assure that via the collective labour agreements (CAOs) the employers contributed to the childcare costs of their employees (interview 9). Due to these efforts, according to the FNV data, in 2005 three quarters (3/4) of all parents enjoyed partial coverage of the childcare costs by their employers.

In terms of policy frames, in the key FNV document - the Childcare nota five of the policy frames (F1 to F5) are mentioned already in the introduction by Wilna Wind (FNV nota on Childcare, 2006). Interestingly, there is a prioritization between the frames: F1 and F5 are taken as most important (starting point), while F2 comes second on the list. F4 and F3 are also mentioned but they seem to be only adding up to the argument (the use of universal childcare provision) rather than being the main problem to be addressed via childcare provision. This prioritization is where the FNV discourse does not resemble the PvdA discourse where there is no explicit ranking between the frames.

Further in the document the commitment to providing chances to women (F1) is elaborated. It is stated that women have to be supported in their wish to continue 
working and that childcare is a means to achieve this. Moreover, the fact that women have begun to work much more hours since the 1960s is seen as due to the improved technologies that cut the hours spent on household maintenance in half and not so much on better sharing of unpaid work between the partners.

With regard to female labour market participation (F2) the FNV states that it is expected from women to work more hours once childcare provision is universal ( $\mathrm{p}$. 7-8). This argument is supported by a reference to the present situation where women work more and more even though not so much support is available. It is therefore expected that if greater support is provided the numbers will grow further and further.

To summarise, the FNV trade union is one of the oldest and most active proponents of childcare in the Netherlands. From the documentary analysis it became visible that the main reasons for this actor to support childcare is in order to increase gender equality (F1) and children's socialisation/education (F5). Hence, there are substantial differences between the EU (propagating childcare for the sake of increased competitiveness - F2) and the FNV discourse. Moreover, the 2 interviews conducted at FNV confirmed that the trade union's discourse is entirely shaped by domestic developments (interviews 1 and 9).

\subsubsection{Christelijk Nationaal Vakverbond (CNV)}

The CNV (the National Federation of Christian Trade Unions) is a federation of eleven trade unions. It is not a typical trade union federation as it does not come from a Socialist/Communist background where the Conflict paradigm ${ }^{1}$ is central. "The CNV was founded in 1909 by people who rejected the class struggle, and instead oriented themselves toward a corporatist model of the economy i.e. toward cooperating with the employers" (interview 5). Furthermore, the CNV comes from the Christian Democratic tradition which stresses the importance of the family and of the own responsibility for one's wellbeing.

These two particularities of the CNV - the non-conflict perspective to work relations and the Christian Democratic ideology - shape the standpoint of the trade union on formal childcare. Concretely, the CNV does not emphasize (as much as FNV) that women should work, and that therefore the country needs childcare

1 The 'conflict paradigm' denotes the opposition between labour and capital i.e. between workers and employers (capitalists). 
facilities. Instead the official position is that: "Men and women are free to choose what they want to do in their lives and they are responsible" (interview 5). If women choose to work, however, then the CNV is supportive of the formal organization of childcare.

Due to these views the $\mathrm{CNV}$ was rather reactive with regard to childcare (contrary to FNV which were proactively advocating childcare since the late 1970s). For the CNV childcare only became an issue in the late 1980s and early 1990s. The trade union federation was never a very active participant in the debate. "If the $\mathrm{CNV}$ is asked to issue an opinion on a proposal or on a governmental initiative then the $\mathrm{CNV}$ will formulate one, but proactive drafting of positions is rather rare" (interview $5)$.

The reason to support the formalization of childcare is the combination between work and family life i.e. F2 (Paas, 2008). Hence, there is full alignment between the EU and the CNV discourse. Nevertheless, the support of this policy frame comes from the proximity between the $\mathrm{CDA}$ and the $\mathrm{CNV}$ discourses rather than from EU-level influence.

\subsubsection{Vakcentrale voor middengroepen en hoger personeel (MHP)}

The smallest Dutch trade union federation, the one for middle and higher level employees, was founded in 1974. The main reason for the emergence of this union was that the interests of professional and managerial staff became clearly distinct from the interests of the other employees and in need of separate representation at the national level during the 1970s. Similarly to the other Dutch trade unions the "MHP represents its members at national and international level regarding terms of employment, industrial relations, working conditions, equal opportunities, participation, social security, pensions and education"1. Unfortunately, despite numerous attempts, no interview with a representative of MHP could take place during the data collection period of this research. Hence, this study does not reflect the MHP position on childcare.

\footnotetext{
${ }^{1}$ Retrieved from www.vakcentralemhp.nl on 24 May 2010.
} 


\section{Employer's organizations}

There are three major employer's representatives in the Netherlands: the VNO-NCW, the MKB-Nederland, and LTO-Nederland. The VNO-NCW is the largest organization, and represents $90 \%$ of the employment positions in the market sector of the country ${ }^{1}$. The MKB-Nederland represents the interests of more than 186,000 small and medium-sized enterprises, and LTO-Nederland represents the agricultural and horticultural sectors. The sections below briefly present VNO-NCW and $\mathrm{MKB}$, and review their standpoints regarding childcare.

\subsubsection{Vereniging $V N O-N C W$}

VNO-NCW (the Confederation of Netherlands Industry and Employers) is the biggest Dutch employers' confederation. VNO-NCW was founded in 1996 by a merger of the Christian-democratic Nederlands Christelijk Werkgeversverbond (NCW - Dutch Christian Employers' Union), and the liberal Verbond van Nederlandse Ondernemingen (VNO - Union of the Dutch Enterprises). Both organizations had strong ties with the Protestant and the Liberal pillar respectively. The VNO-NCW represents Dutch business in numerous governmental advisory and consultative committees.

The issue of provision of formal childcare became important for the employers in the 1970s and the 1980s when women entered massively the labour market and the employers wished to support this new development (interview 12). The childcare service had an important role in this process - more women could start working or return to their jobs after giving birth if the number of childcare places in the country grew. Initially, the employers reacted on these developments by providing vouchers to their employees to cover the costs or by organizing day-care centres within their enterprises (bedrijfscreches).

During the mid-1980s, however, it became visible that the scale of the process was enormous and that state support was needed. The VNO was instrumental in putting the childcare issue firmly on the governmental agenda (interview 12). Upon insistence by the Employers that childcare is an important reconciliation measure that will boost the female participation on the labour market and consequently the Dutch

1 The data about the membership numbers were taken from the respective websites: www.vno-ncw.nl and www.mkb.nl (accessed on: 24 May 2010). 
economic reforms, the government undertook decisive policy actions to stimulate the childcare service.

The main actors (the government, the employers and the trade unions) realised that the growth of formal childcare was inevitable if women were to work (interview 12). Thus, the main issue for the $\mathrm{VNO}$ was who will finance the process of expansion that was gaining speed at the beginning of the 1990s. It was decided at the time that there would be a tripartite financing of the service - the state, the employer and the employee/parent. It was underlined that this was a voluntary agreement and not something that had to be regulated by law. The state contribution got materialised in a tax relief measure, and the employer's contribution was regulated at the level of the company or at sectoral level (in the collective labour agreements - the CLAs).

The developments in the 2000s, namely the ever-increasing regulation of the sector by laws (in 2005 the Law Basic Provision of Childcare came into force), and especially the end of the voluntary contributions and the introduction of the obligation to pay $1 / 3$ of the childcare costs (as of 2007) were not welcomed by the Employers, and they tried to resist them (interview 12).

With regard to the EU's influence on the field, the EES did not make any difference in the VNO-NCW position. When the EES was endorsed the country had already taken a firm decision to enlarge its childcare facilities. So, the EES simply confirmed and supported the adopted policy line, and in particular the VNO-NCW position (interview 12). In more general terms, the EES is considered useful for the Netherlands by the VNO-NCW as it serves as a reminder that reform in the labour market is an ongoing process. Furthermore, the Netherlands owe the whole paradigm of development of human capital and life-long learning to the EES (interview 12). In the VNO-NCW it is believed that every EU member state should have its own choices and policies, but that an overall process at the EU level is important as a supportive measure. Furthermore, the Lisbon Strategy is useful because the Netherlands receives an assessment from an 'external' evaluator - the Commission. "For example, we always get a recommendation on R\&D spending... this creates a pressure on the country to perform, and this makes a difference." (interview 12)

Finally, the Dutch employers from the VNO are in favour of setting EU targets for overall employment level and for employment rates for women and the elderly. Such global objectives are acceptable. But fixing specific targets for childcare at the EU level is not welcomed by the VNO. "These are much too concrete policy issues to let the EU decide on them" (interview 12). Moreover they are much too contingent upon culture and prior policy choices, "one cannot specify this for all member states". 


\subsubsection{MKB-Nederland}

The MKB-Nederland was established in $1995^{1}$ from a merger of Koninklijk Nederlands Ondernemers Verbond (KNOV - the Royal Dutch Entrepreneurs' Union) and the Nederlands Christelijk Ondernemers Verbond (NCOV - the Dutch Christian Entrepreneurs' Union). The organization represents the interests of the small and medium-sized enterprises (midden- en kleinbedrijf: MKB) at national and international fora. It cooperates closely with the VNO-NCW and since recently they occupy the same building in the Hague (de Malietoren) and representatives of the two organisations may speak for both unions.

It is therefore hardly surprising that the $\mathrm{MKB}$ has a very similar vision toward childcare as the VNO-NCW. The childcare service is seen as an opportunity that allows parents (especially women) to engage in paid employment (interview 3). For the MKB childcare is first and foremost a reconciliation measure. Moreover, it is the preferred reconciliation measure (i.e. receives priority among other measures such as part-time work or leave schemes) because it allows people to stay or return quickly to their jobs. This is important for the entrepreneurs form the MKB and they are prepared to pay for it i.e. to contribute to the childcare costs of their employees (interview 3).

Unlike the FNV trade union, which pleads for childcare to acquire the status of a service of universal character (basisvoorziening), the MKB only regards it as a reconciliation measure that ideally fulfils the " 7 to 7 " concept i.e. an employer to being able to leave his/her child in a day-care centre at $7 \mathrm{am}$ and to pick him/her up at $7 \mathrm{pm}$, and not to worry in between (interview 3).

The other issue of great importance for this employers' organisation is the financing of the childcare provision. The MKB is ready to pay for childcare for the working population, and not as a universal service for the general population. Furthermore, the quality of the service should be constantly improving.

The MKB (similarly to all other Dutch policy actors) cannot identify any influence of the EES in the field of childcare provision: the national reforms have started long before the endorsement of the Strategy. Nevertheless, the MKB regards the Lisbon Strategy as a positive development. It has as a central concept the issue of activation which is also very important for the Dutch employers. 


\section{Belangenvereniging van ouders in de kinderopvang en peuterspeelqalen (BOINK)}

The BOINK is the organization that represents the interests of parents of children who visit day-care centers and playgroups. It exists since 1995 and aims to influence policy- and law-making at the national level. By own estimates, the BOINK currently represents about $80 \%$ of the parents whose children make use of daycare ${ }^{1}$. The organization stands for good quality and affordable childcare services, and for a clear and simple regulatory framework for the sector. BOINK representatives are frequently invited to national discussions and conferences that debate the issue of childcare, where the aim is to share the information and experiences of parental committees from all over the country (interview 4).

If one childcare policy frame has to be singled out which BOINK supports then this will be the early education and socialization one - F5 (interview 4). According to the Chair of the Board of the organization the attention at the national level has shifted from emphasis on the quantitative growth to an emphasis on the quality of the service provision (interview 4). This is quite natural given that the period of rapid growth has already taken place. Once the sector has matured it is to be expected that the quality of the service will move higher up on the agenda. The present representation of childcare as an educational issue (e.g. the move in 2007 of the childcare dossier to the portfolio of the Education ministry) should be interpreted precisely in these terms - the maturity of the sector and the shift from quantitative to qualitative considerations (interview 4).

The use of childcare facilities as an instrument to boost female labour market participation is dubious. According to interviewee \#4 such a tool is successful only up to a certain level of participation. Afterwards, it becomes more and more difficult to 'swing' housewives into working. Moreover, convincing mothers to work could only be successful if the quality of the service is very high and guaranteed, which is not the case in the Netherlands yet (see the studies of IJzendoorn et al., 2004 and the Nederlands Consortium Kinderopvang Onderzoek). But even when the quality is high the inflow of women onto the Dutch labour force is dubious because women in the Netherlands do not work because they are economically forced to work (i.e. if the salary of the husband would not be enough) but out of social needs. "We in the Netherlands have a luxury problem" (interview 4). Hence, culture plays a significant

\footnotetext{
${ }^{1}$ Data retrieved from the organization's website: http://www.boink.info/wie is boink (accessed on 14.06.2010)
} 
role for such decisions and in the case of childcare it is not supportive (see section 5.1.).

The EU is not present in the work of BOINK. Naturally, the Lisbon strategy and the Employment policy coordination process are known, but there are allegedly no direct implications thereof on the daily workings of the BOINK. According to the Board's Chair the Employment Strategy does not have much impact in the field of childcare policy. When the EU requested the member states to enlarge their childcare facilities in 1997 with the endorsement of the EES and in 2002 with the approval of the Barcelona quantitative targets, the Netherlands had already realised the need for a bigger childcare sector and was already implementing measures in that context (interview 4). Hence, the EU guidelines came as a confirmation and encouragement of an already ongoing domestic process to which all influential actors had agreed.

\subsection{ANALYSIS OF THE EVOLUTION IN THE ACTORS' POSITIONS AND OF THE COALITION BUILDING DYNAMICS}

From the policy actors' analysis presented in this section it became visible that the EU developments embedded in the framework of the EES did not have much, if any, influence on the discourses of the individual actors in the policy community, and hence almost no impact on the domestic discourse as a whole. On the one hand, the governmental bureaucracy reacted to the new EU process by 'encapsulating' its dayto-day practice within the administrative structures that are responsible for EU and global governance but whose civil servants rarely interact with their 'domestic' counterparts. Within this small, rather closed and functionally oriented to the EU community the civil servants enjoy substantial level of discretion, and report to be quite socialised in the EU discourse. Nevertheless, they do not see their job to involve the active transmission of the EU cognitive and policy lessons to the national level of policy-making. They do report about them in a memo to their colleagues in the Ministry, and most of the time this outlines the boundary of policy learning from the EU to the Dutch governmental structures. On the other hand, most of the domestic political parties and the Social Partners have adopted F2 as the leading policy frame in their discourses already in the 1980s. In this way they formed a clear coalition around F2 long before the EES was endorsed (in 1997). 
Therefore, the analysis of the Dutch policy developments (see Chapter 5) and the ensuing analysis of the evolution in the actors' positions (Chapter 6) clearly indicate that a link between the spectacular growth of Dutch childcare facilities in the last 15 years and the EU level policy developments cannot be established. Instead, the observed policy changes seem to be entirely domestically driven.

This section aims to substantiate this thesis by bringing together the domestic actors and the ideas (policy frames) they stood for in the last 50 years. The aim of this analysis is to reveal the dynamics of coalition building regarding the different childcare policy frames, and thus to account for the various policy shifts that took place in the Netherlands in the past decades. The objective is to suggest an explanation as to why the policy process and the respective policy outcomes in the Netherlands looked the way they did (see for details chapter 5). To that end the following questions will be addressed: who (which actors and coalitions) stood for what (which policy frame)? When? To what success?

To begin with, Table 6.3-1 maps out the six policy frames examined in this study and the domestic political parties that supported them (based on the policy frame analysis of the party manifestos of the major Dutch political parties - see section 6.2.) 
Table 6.3-1 Dynamics of the actors' standpoints on childcare according to the policy frame analysis of the party manifestos

\begin{tabular}{|c|c|c|c|c|c|c|}
\hline $\begin{array}{c}\text { Year of the } \\
\text { coalition } \\
\text { agreement }\end{array}$ & $\mathrm{F} 1$ & $\mathrm{~F} 2$ & F3 & $\mathrm{F} 4$ & F5 & F6 \\
\hline 1963 & & & & & & \\
\hline 1967 & & & & & & \\
\hline 1971 & PvdA, VVD & & & & & \\
\hline 1977 & D66 & & & & $\operatorname{Pvd} A$ & \\
\hline 1982 & $\operatorname{Pvd} A$ & $\operatorname{Pvd} A$ & & $\mathrm{CDA}$ & & \\
\hline 1986 & $\begin{array}{c}\text { D66, VVD, } \\
\text { CDA }\end{array}$ & $\begin{array}{l}\text { PvdA, } \\
\text { VVD }\end{array}$ & & VVD & $\begin{array}{l}\text { PvdA, } \\
\text { VVD }\end{array}$ & \\
\hline 1989 & $\begin{array}{c}\text { D66, GL, } \\
\text { PvdA, } \\
\text { VVD, CDA }\end{array}$ & $\begin{array}{c}\text { D66, GL, } \\
\text { PvdA, } \\
\text { VVD, CDA }\end{array}$ & & $\mathrm{CDA}$ & & \\
\hline 1994 & D66, GL & D66, PvdA & & $\begin{array}{l}\text { D66, } \\
\operatorname{PvdA}\end{array}$ & & \\
\hline 1998 & VVD & $\begin{array}{c}\text { D66, GL, } \\
\text { PvdA, } \\
\text { VVD, CDA }\end{array}$ & & $\begin{array}{l}\text { D66, } \\
\operatorname{PvdA}\end{array}$ & $\operatorname{Pvd} A$ & $\mathrm{CDA}$ \\
\hline 2002 & $\operatorname{PvdA}$ & $\begin{array}{c}\text { D66, PvdA, } \\
\text { VVD, SP, } \\
\text { CDA }\end{array}$ & & GL & $\begin{array}{l}\text { GL, } \\
\operatorname{PvdA}\end{array}$ & $\begin{array}{l}\text { D66, } \\
\text { PvdA, } \\
\text { CDA }\end{array}$ \\
\hline 2003 & GL & $\begin{array}{c}\text { D66, PvdA, } \\
\text { VVD, SP }\end{array}$ & & & $\operatorname{Pvd} A$ & \\
\hline 2006 & GL, SP & $\begin{array}{l}\text { D66, GL, } \\
\text { PvdA, } \\
\text { VVD, SP, } \\
\text { CDA }\end{array}$ & & GL, SP & $\operatorname{Pvd} A$ & $\operatorname{PvdA}$ \\
\hline
\end{tabular}


The table demonstrates the 'career' of the childcare solution in the Netherlands. In the 1970 and 80s it has been coupled mostly to the problem of gender inequality F1). Backed up initially by feminist groups and progressive political parties, throughout the 1980s this policy frame gained popularity amongst most political actors, and reached a peak in 1989 when all major political parties mentioned it in their party manifestos.

The support then shifted to a new policy frame. With the emergence of the debate about the reform of the welfare state in the 1980s the childcare solution received a new interpretation. It started to be regarded as an adequate tool to boost the levels of female labour market participation (F2). This interpretation received popularity among all political parties in the 1980s and the 1990s (revealed by the densely populated column of Table 6.3-1 above), and crucially, was supported by all main policy actors outside Parliament (e.g. the Social Partners - see below).

The demography policy frame (F3) does not appear in any of the manifestos, and generally is not present in the Dutch discourse on childcare (unlike in Germany, where it is one of the leading policy justifications).

The social exclusion frame (F4) is supported by all political parties as all of them mention this interpretation in various manifestos. Nevertheless, this is definitely not the engine or the leading interpretation of childcare in the Dutch policy discourse because in none of the election years there was a majority (i.e. a winning coalition) which stood behind this frame.

The interpretations of childcare provision as an early educational tool (F5) and as a means to integrate migrants (F6) receive only limited support in the Dutch policy debate. This is hardly surprising given these are relatively new interpretations. Moreover, the analysis clearly demonstrates that so far they have been the 'hobby horses' of particular political formations: $\mathrm{PvdA}$ is a long-term proponent of F5, while F6 receives support from CDA and PvdA. All in all, similarly to the social exclusion frame (F4), these two frames are definitely not the driving interpretations of the Dutch childcare policy discourse.

The above analysis confirms the observation that the gender inequality and the competitiveness frames are the most prominent legitimations of public childcare provision in the Netherlands. It comes as no surprise therefore that these two dominate also the actual policy discourses (as reflected in coalition agreements - see section 5.3). The rest of the section will zoom into each of these two policy frames and will analyse the coalition that supported it. It will then embark on an analysis as to why the competitiveness frame (F2) became core of the governmental policy (as does to the present day) while the gender equality frame (F1) was not able to mobilize public policy support. 


\section{The "Gender Equality" Coalition}

The gender equality policy frame (F1) dominated the emerging discourse on the provision of out-of-home childcare during the 1970 and 1980s. Arguably, the whole debate about the public support of childcare began due to the link between the emancipation (that peaked in these decades) and the childcare service. Prior to that childcare policy did not exist: the government only supported the few childcare facilities in the country as a welfare measure aimed at 'failing' families.

When the problem of 'gender inequality' became a pressing societal issue in the 1970s, the 'solution' of childcare was articulated firstly by feminist groups (e.g. ManVrouwMaatschappij and Dolle Mina) and then was quickly picked up also by the PvdA and the FNV trade union. Also the VVD mentions this policy frame in its party manifesto of 1971. In the mid-1970s the D66 joins the coalition around F1 as well. During the 1980s the CDA also articulates the gender equality policy frame in its party manifestos. Basically, by the mid-1980s all major policy actors express support for this policy frame. Nevertheless, it never managed to result in concrete policy actions and initiatives, and after the peak of support in 1989 (see Table 6.3-1) it comes back in the discourses of only a few political parties. Instead, the competitiveness policy frame takes over the dominant place in the Dutch childcare policy discourse.

\section{The "Competitiveness" Coalition}

The emergence of this policy frame has to be understood against the neoliberal economic paradigm shift of the 1980s that took place in the Dutch 'master discourse' on the reform of the welfare state and on the enhancement of the competitive profile of the Dutch economy. According to this discourse the housewives were 'wasted human capital', an untapped potential to which the economy could and should resort in order to accomplish the needed reforms.

The PvdA, in its party manifesto of 1982, was the first political party to articulate that investing in childcare facilities will increase the female labour market participation. In 1986 it was joined by the VVD. By 1989 all the five major political parties in the Netherlands maintained that increased provision of childcare facilities would boost the participation of women, and therefore also the economic reform of the country and its competitiveness. Moreover, the same view was shared by the 
Social Partners, and crucially this time (unlike the gender equality frame) also the Employers insisted on enlarging the capacity of childcare facilities. Thus, backed by all actors in the policy community, in 1989 the first Measure on the Stimulation of Childcare (1990-1993) was approved by the Parliament. The coalition around the competitiveness frame is maintained to the present day and has the dominant position vis-a-vis the other five 'problems' that call for the childcare solution.

\section{Why did competitiveness win over gender equality?}

It is clear from the above that the policy actors were not prepared to invest in enlarging the Dutch childcare capacities due to emancipation concerns alone. In contrast to the gender equality frame (F1) that remained a rather 'empty' rhetorical effort, the competitiveness frame (F2) mobilised all major political parties and eventually resulted in policy measures that within a decade gave birth to a full-fledged new policy field on childcare facilities stimulation. How can this finding be accounted for? Why did the ideas behind F2 managed to materialise in policy actions, while those behind F1 did not?

To begin with, the size of the coalition that backed the competitiveness frame was bigger. Basically all political parties (see Table 6.3-1) and the Social Partners supported it. Crucially, the pro-F2 coalition contained the Employers who were prepared to finance the enlargement of the childcare facilities as long as this would result in greater labour supply. The Dutch businesses did not mind paying for keeping (or for attracting) women on the labour market (interview 3 and 12). They would not (and have not done so) for the abstract ideal of gender equality alone.

Furthermore, gender equality was not a mobilising enough frame even for the women's organizations. The reason for that is that the majority of the Dutch women were prepared to give up their employment and career ambitions for the right upbringing of their children. Undoubtedly, in this 'sacrifice' cultural believes played a substantial role. As revealed in Section 5.1., emancipation may have dismantled the housewife ideal and the breadwinner model in the country, but has only moderately affected the mothering ideal transforming it in a 'parental sharing' ideal for children's upbringing. Given this background, it is not surprising that the 'gender equality' frame never led to concrete policy actions.

Conversely, the competitiveness frame (F2) was a strong motivator. When female labour market participation became a reform objective during the 1980s it was evident that this goal could only be attained if a viable solution was found to the 
reconciliation dilemma. Among all conceivable solutions to this problem, childcare provided the best "fit" to the discourse of full labour market participation. Alternative solutions to the work/care dilemma (e.g. leave schemes, part-time work, fiscal measures/ transfers, welfare allowances) either burden the fiscal pot or leave labour force capacities untapped. It is only childcare that at the same time allows women (parents) to work, and moreover creates new jobs (in the care sector). This unique 'fit' between the demands of the normative environment (activation, participation, fiscal discipline) and the capacity of childcare as a policy solution to match them accounts for the materialisation of this policy frame into actual policy actions. Next to these ideational reasons, the political process i.e. the Dutch electoral alternations clearly indicate why childcare facility growth stimulation in the Netherlands only began in 1989 (and not earlier or later).

Due to the domination of the CDA in all cabinets until the end of the 1980s, childcare was never high on the public policy agenda. Given the views on childcare of this political party (see section 6.2.1.6.) it is not surprising that few policy actions took place during the mandates of the CDA. The Christian-Democrats seem to have acted as a 'gatekeeper' (interview 14) in the field of childcare policy. Real boost and steps forward this policy achieved only when the CDA was in opposition or in coalition with a strong supporter of childcare facilities development. This is precisely the case as of 1989 onwards. After the 30 year 'reign of the CDA' - the period between 1958 and 1989 when with the exception of the 1973 cabinet the CDA was the leading political force of the country (see Table 5.5-1) in 1989 the CDA formed a governing coalition with the PvdA. Given that for the PvdA the issue of childcare was very important since the 1970s this cabinet was bound to undertake serious commitment toward childcare. Throughout the rest of the 1990s PvdA kept its top decision-making position, and led two consecutive cabinets (the Kok I and II coalition governments also known as "Purple I and II"). Naturally, they continued supporting the growth of childcare facilities in the country. By the time the PvdA handed in the steering wheel back to the CDA in 1998 the Netherlands had already an irreversible policy commitment to boosting the childcare infrastructure. Moreover, important cultural changes have taken place - the Dutch women have joined in high number the labour market and out-of-home caring has become acceptable (see section 5.1.) Furthermore, there was a huge societal need and demand for continuation of the taken course of action exemplified by the long waiting lists at the existing crèches. Hence, the new government could not do anything but continue the adopted line. And it did. 


\subsection{CONCLUSION: WHAT INFLUENCE OF THE EU?}

In this chapter the process of Dutch childcare policy-making was investigated and the main actors were identified. It was discovered that the EU developments embedded in the framework of the EES did not have any influence on the discourses of the individual actors from the policy community, and hence not on the domestic discourse as a whole. On the one hand, this was due to the fact that the governmental bureaucracy and the main actors reacted to the new EU process by 'encapsulating' it within the 'international' structures (responsible for EU and global governance) of their respective organizations. Within this small, rather closed community, functionally oriented to the EU, the civil servants enjoy substantial level of discretion. They report to be quite socialised in the EU discourse (interviews 1, 5, 10, 15). Nevertheless, they do not see it as their job to be involved in the active transmission of the EU cognitive and policy lessons to the national level of policy-making. They do report about them in a memo to their colleagues in the Ministry, but most of the time this is all that is done.

On the other hand, most of the domestic political parties and the Social Partners have adopted F2 as the leading policy frame in their discourses already in the 1980s. In this way they formed a clear coalition around F2 long before the EES was endorsed (in 1997). After 1998 the discourse of all major policy actors indeed converges to F2 and this becomes the basis for collective actions. Arguably, due to the unity this policy frame installs, such enormous progress with regard to the stimulation of formal childcare is observed in the country. The coincidence in the last 10 years between the spectacular growth in childcare places and the introduction of the EES, however, is circumstantial. All policy actors and the micro-policy frame analysis confirmed this finding. 
- 203 - 


\section{CONCLUSIONS OF THE STUDY}

This study set out to develop and test a method for the study of the domestic impact of a new policy mode in the EU - the Open Method of Coordination (OMC). Chapter 1 outlined the theoretical and methodical framework. After critical examination of the state of the art in theorising Europeanization processes, the chapter proposed a novel analytical strategy for the study of the OMC's influence on member states' policy-making, based on the theory of discursive institutionalism and the method of policy frame analysis. Chapter 2 outlined the emergence and the main characteristics of the new mode of EU governance in the field of Employment policy coordination (according to the stages of the policy cycle). Chapter 3 presented the specificities of the public provision of childcare and six different policy frames, i.e. interpretations that relate six public problems to the policy 'solution' of formal childcare. The following Chapter 4 traced the development of these six frames in EU secondary legislation by employing the method of policy frame analysis for the first time in this study. This analysis unveiled the ideational underpinnings of the EU policy on childcare. It was discovered that when the issue of childcare became subject of discussion at the EU level of governance it was interpreted in light of the problem of gender equality. Once the European Employment Strategy was endorsed, however, childcare changed its meaning as a policy solution that served the emancipation agenda and became viewed as a policy response to the decreasing Union's competitiveness. On the basis of these findings, the case study of the implementation of the childcare guideline in the Netherlands embarked.

The case study, presented in chapters 5 and 6 , began by reviewing the Dutch cultural attitudes toward formal childcare and the policy developments undertaken by various Dutch governments up to the endorsement in 1998 of the first Employment policy guidelines as part of the new process of Employment coordination. Furthermore, Chapter 5 reviewed the policy process (in terms of policy outputs and policy discourses) and the main achievements in terms of policy outcomes. At the end of the chapter it became visible that both - the policy outputs and the policy outcomes - were in full alignment with the EU policy prescriptions. The examination of the policy discourses, however, revealed that the commitment to enlarging the existing childcare capacities existed already in 1989. This indicates that it could not have been the EES (endorsed a decade later - in 1997) that instigated the policy changes in the Netherlands. Given that the domestic discourse preceded the EU one it is impossible to claim the presence of a causal relationship and hence 
Europeanization. The refutation of the Europeanization hypothesis at the end of Chapter 5, however, did not provide a full account of the policy developments. As indicated by Haverland (2007: 61-62) it does not suffice to refute an expectation, the research still needs to outline the mechanism that led to the observed policy change. To that end chapter 6 embarked on a micro-analytical frame analysis by mapping out again the six childcare policy frames but this time linking them to the domestic policy actors that articulated these frames (political parties, trade unions, employers' organizations, interest groups). Furthermore, it traced the coalition-building dynamics, and thus demonstrated the process by which childcare policy policy frames became dominant in the Netherlands and consequently got materialised in public policies. In this way the beginning of public stimulation of childcare facilities in 1989 was accounted of.

The study applied the 'bottom-up-down' research design (see section 1.1.) as argued for by Graziano and Vink (2007: 9-10) and Haverland (2005, 2007). This approach to the study of Europeanization could be regarded as completing a 'fullcircle' in the systematic examination of the domestic influence of the process of European level coordination in the field of employment policy. Concretely, in order to accomplish such an encompassing exploration the researcher should adhere to the following sequence of research steps (Graziano and Vink, 2007: 9-10):

1. Identify the domestic ex-ante policy situation - in this study this is the analysis of the Dutch cultural and policy developments prior to the introduction of the European Employment Strategy (EES) in 1998 (see sections 5.1. and 5.2.)

2. Account for the emergence of European cooperation in the field (why did 'Europe' become involved here?) - in this study this is the analysis of the emergence of the European Employment Strategy (EES) in the mid 1990s (see section 2.1.)

3. Establish what the institutionalization of the cooperation is at the European level and to what extent the member state where the domestic impact is examined has been aiming at and been successful in 'uploading' its policy model to the European level of governance (i.e. study the EU-level negotiations as in section 2.2. of this study).

4. Discuss the direct and indirect ways in which 'Europe' may affect domestic politics (in this study this is done in sections 2.4. and 2.5.)

5. Finally examine which 'Europeanization' effects are discernable in the domestic policy sphere and how can they be explained: are they attributable to the endorsed EU cooperation or not? (in this study this is done in Sections 5.3. to 5.6. and in Chapter 6).

The overall conclusion derived following this research approach is that in the Netherlands childcare policy is a domestically driven policy field, where the level of 
Europeanization is low both in terms of change in the established policy-making procedures and in terms of substantive policy influence ${ }^{1}$. In procedural terms, the study found out that the OMC process is dealt with primarily in specialized national committees with international orientation (in the national Social Economic Council or in the governmental ministries). The main actors involved in the formulation of the domestic policy, however, are disconnected from these committees and in practice do not synchronize each other's activities (see section 6.1.) In substantive terms, the analysis demonstrated that it was not the coordination process of the EU (the Employment $\mathrm{OMC}$ ) that led to the spectacular growth of childcare facilities in the Netherlands (in the 1990s and the 2000s). Despite the convergence with the EU policy frame (F2) and the Barcelona quantitative target (see section 5.4), and despite the numerous relevant policy outputs (see section 5.3), the actors' analysis (chapter 6) led to the conclusion that these policy outcomes were initiated and accomplished by domestic actors. In particular, the PvdA, D66, FNV, and VNO (the pro-childcare coalition) were pushing the issue higher on the governmental agenda, and at the times when the PvdA and D66 were in a position to directly influence policies (the periods when they were in the cabinet) the policy field experienced a boost of public support (see sections 6.2. and 6.3.) Hence, the simultaneous introduction of the EES and the Dutch policy achievements (the spectacular growth of the number of available childcare places and in the number of children who visit them) were circumstantial rather than causally linked. As revealed at the end of Chapter 5, in the Netherlands the main policy discourse was already aligned to the EU discourse at the time of the introduction of the EES. Hence, it was a matter of time for this discourse to get materialised in (increased) growth of childcare facilities. In order to realise this in practice, it was important that the policy discourse did not take a different direction. It did not indeed, and this is perhaps where certain influence of the OMC could be claimed: the EES installed an employment policy paradigm which precluded alternative policy frames (besides the competiveness frame) to become dominant.

\footnotetext{
1 The potential OMC impact is tracked in terms of substantive and procedural change as proposed by Zeitlin: "substantive policy change on the one hand, and to procedural shifts in governance and policy making on the other" (Zeitlin, 2009: 217).
} 


\section{Contributions to policy analysis and to the Europeanization}

\section{research agenda}

While the recent literature in the field of comparative political economy emphasizes the resilience of coordinated market economies, few detailed empirical studies have examined (but see Menz, 2010) exactly how different EU member states cope with and respond to the global political-economic push for liberalization. This thesis enlarged the existing academic literature with an original study of the public policy childcare service provision in the Netherlands in the context of an ever greater Europeanization of employment and social policies. Not only did this thesis present a chronological account of all major developments in the discursive structures in this policy field, but it furthermore linked the frames to the main actors - thus reconstructing the political play in this sector of Dutch policy-making for the last fifty years.

Next to providing a comprehensive account of the way in which the Dutch system of socio-economic governance copes with a European initiative for more policy convergence in the field of childcare policy (the EES), this study contributed to the emerging Administrative Governance agenda mapping out the administrative arrangement that the Netherlands developed in order to participate in the new mode of EU policy steering i.e. in the Open Method of Coordination. This administrative arrangement is characterized by a high level of functional separation of the administrative units and civil servants that "deal" with the EU. For future studies, it will be interesting to discover to what extent the observed case of 'encapsulation' of the EU affairs in the case of childcare policy is an exception or is the rule in the Dutch way of adapting to the processes of EU policy steering.

Along with the substantive findings discussed above, the major contributions of this study to the existing academic literature (on Europeanization) are of a methodological nature. This thesis presented and applied a novel analytical strategy for studying the domestic policy impact of the Open Method of Coordination. This strategy is based on three components. The first component (a theoretical framework founded on the premises of discursive institutionalism) allows for modelling a mechanism for diffusion of normative policy prescriptions and ideas. The second component (the method of policy frame analysis) allows for a practical application and testing of the discursive institutionalist model. Finally, the third component (the operationalization design) identified observables in the empirical world which can be measured and analysed for the purpose of academic inference. The following pages 
reflect on the application of each of the three components in the study, and on the contributions it has yielded.

First of all, DI proved to be a useful tool for the modelling of Europeanization processes. It provided a clear guideline for the identification of the mechanisms at stake: the dynamics of coalition-building and restructuring in the domestic framing of policies. In the case of the OMC, due to the design of the annual procedure the domestic actors have frequently the opportunity to engage in coalition restructuring. Each year there are at least two formal opportunities: during the annual preparation of the Spring Summit and during the discussions preceding the issuing of the National Progress Report. What needs to be stressed therefore is the repetitive (annual) opportunity to change the domestically pursued policy line as indicated in the following scheme:

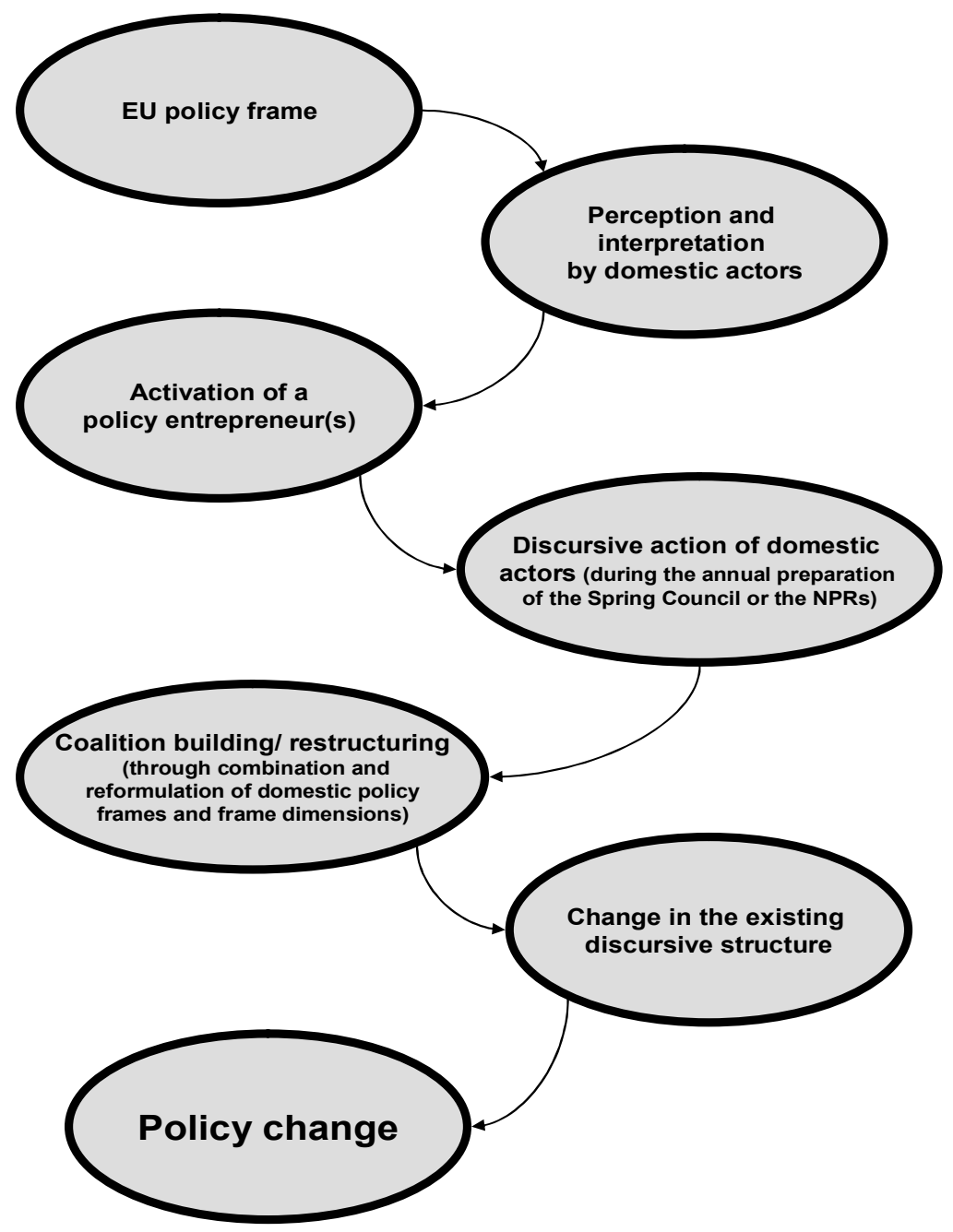


In the case studied in this thesis - the childcare policy - there was no EU influence at the national level because the annual OMC iterations were already confirming the governmental actions in the field. It was just a question of time and continuation of the same policy line for the desired policy outcomes to be achieved (i.e. the Barcelona target).

This research also pointed to two intervening variables (or mediating factors) that may speed up the process of EU influence: the access of the policy coalition to the centre of policy-making (e.g. the leading position of the PvdA in government), and the match between the normative dimension of the EU policy frame and the dominating domestic paradigm of socio-economic governance (e.g. neoliberalism). Indeed, the existing discursive superstructure conditions the possibility of certain perceptions of cause-effect, and hence certain policy solutions to be endorsed. This ideational and cognitive fit could be a useful addition (as an intervening variable) to the DI model presented above.

The second component of the analytical strategy presented in this study policy frame analysis (PFA) - proved to be a rigorous method for the study of rather intangible processes of social construction. Concretely, it allows for the systematic observation of policy discourses, and their development through time. Next to an analysis of the discursive dynamics of the policy field, PFA provides also an insight in the discursive activities of the individual policy actors. The main limitation of the method is that it depends on the existence of datasets of documents from which the discourses can be derived. Particularly important is that the dataset is comprehensive and, moreover, that the documents in it have the same weight. For example, a dataset containing all coalition agreements in the Netherlands provides an unique opportunity to study thoroughly the general governmental discourse i.e. the official public policy discourse on childcare in the country. If one coalition agreement is missing, however, the results of the study will be compromised. Moreover, this one missing document cannot be replaced by a speech of the Prime Minister when taking office: clearly the themes will be the same, however the equality between the documents in the dataset will not be upheld. For this reason, as explained above, the construction of the dataset is of highest importance. Fortunately, social scientists nowadays have an increasingly better access to comprehensive databases (e.g. EurLex) and datasets (e.g. the Party manifesto project). These will allow for more methodically sound studies in the future. Provided that good and comprehensive datasets are available, the application of the PFA method could yield a thorough account of the dynamics of a domestic policy field and the influences of EU processes upon it. A further methodological remark derived from this study is that the PFA method should whenever possible be combined with the method of expert interviewing in order to confirm and contextualize the findings of the policy frame analysis. This allows for further testing and refutation of alternative hypotheses and 
furnishes greater details and case-specific data about the discursive activities of the policy entrepreneurs and the process of coalition formation.

The applied analytical strategy - composed of the theory of discursive institutionalism (DI) coupled with the method of policy frame analysis (PFA) provided a thorough account of the evolution of the Dutch childcare policy and of the timing of the changes it underwent. It was therefore a successful analytical approach to the study of the domestic influence of international public policy-making processes. Moreover, this analytical strategy enabled the study of the dynamics at the actor level as well as at the institutional level. In this way the suggested approach remedies the methodological dilemma between examining only structure or only agency.

Furthermore, the proposed framework is particularly useful for the study of Europeanization processes based on soft law. The main difficulty in the examination of 'soft' steering mechanisms is that they do not require transposition in the domestic legal system (Zeitlin 2009: 215). So, the member states are not under the obligation to specify the implementation measures they took (Graziano and Vink, 2007: 10). The norms are often vague and imprecise and for the researcher it is not always clear what should be the unit of analysis: policy programmes, administrative restructurings, normative debates, or actors, activities and rhetoric. The third component - the operationalization - makes the analysis of implementation much more concrete as it points to operational measures that could easily be identified in any empirical case.

Particularly missing in Europeanization literature is the methodical approach to the rather complex processes of norm diffusion and socialization (Haverland, 2007: 60). Framing is considered, alongside coercion, mimetism and negative integration, as one of the main Europeanization mechanisms (Radaelli, 2003: 41), yet a concrete toolbox for the study of this mechanism and its effects was missing. Moreover, constructivist studies in general are often criticised for being quite a-methodological (Adler, 2002; Checkel, 2004; Haverland, 2007: 60) and about their lack of applied systematic tools for the examination of processes of social construction. Clearly, such a methodological tool has to be able to reconstruct the social processes of discursive exchanges and rhetorical (re)combinations. Policy frame analysis represents such an instrument.

Our analytical strategy provided a possible operationalization and a research methodology to be employed for the testing of rather intangible social phenomena. In particular, the proposed operationalization of policy discourses (i.e. policy frames) could be employed for the rigorous analysis of processes of social construction and norm diffusion. 'Discourse' is often used in constructivist theoretical frameworks and models, but due to its allegedly non-tangible properties, it is never studied in a methodical way, and as a consequence has not gained much popularity as an explanatory variable in concrete research projects. The strategy proposed here 
therefore also enlarges the methodical toolbox of the constructivist school of European Studies and International Relations. Its application is a definite improvement compared to the usual methods of qualitative studies, namely the method of interviewing and of process tracing. These methods are a reliable source of social scientific data only when they are triangulated. Due to the possibility to omit certain important respondent and/or event, and due to the possibility of 'selective memory' on the part of the interviewees, these methods cannot guarantee the rigorous and accountable result the method of PFA can yield. Most importantly the systematic analysis of long-term processes (e.g. 50 years or more) of social construction are virtually impossible with documentary analysis and interviews for the simple reason that it will require a large amounts of time and resources. Provided a comprehensive dataset could be compiled - the same reconstruction of the policy process could be accomplished in a much more systematic way via desk-research in a (relatively) shorter timespan. Naturally, whenever possible the methods of discourse analysis and interviewing should be combined in order to achieve a more thorough reconstruction of the casual mechanisms at stake. This type of triangulation was applied in this study and allowed for a thorough account of the observed policy dynamics. It will be highly relevant for EU and IR studies of implementation to compare the outcomes of these methodological approaches in future studies. Furthermore, it will be interesting to explore the boundaries of the presented analytical strategy by applying it to different cases of international policy-making i.e. to other soft law processes in and beyond the EU. 


\section{BIBLIOGRAPHY}

Abbott, Kenneth, and Duncan Snidal. 2000. Hard and Soft Law in International Governance. International Organization 54 (3): 421-456.

Abbott, Kenneth, Robert Keohane, Andrew Moravcsik, Anne-Marie Slaughter, and Duncan Snidal. 2000. The Concept of Legalization. International Organization 54 (3): 401-419.

Adler, Emanuel. 1997. Seizing the Middle Ground: Constructivism in World Politics. European Journal of International Relations 3 (3): 319-363.

Adler, Emanuel. 2002. Constructivism and International Relations, in W. Carlsnaes, T. Risse and B. Simmons (eds), Handbook of international relations, London: SAGE.

Ahonen, Perti. 2001. Soft Governance, Agile Union? Analysis of the Extensions of Open Coordination in 2000, EIPASCOPE Paper, 18(4).

Andersen, J. 2002. Change without challenge? Welfare States, Social Construction of Challenge and Dynamics of Path Dependency. In What Future for Social Security? Debates in National and Crossnational Perspective, edited by J. Clasen. Bristol: The Policy Press.

Andersen, Niels. 2003. Discursive analytical strategies: Understanding Foucault, Koselleck, Laclau, Lubmann. Bristol: The Policy Press.

Andersen, Niels. 1995. Selvskabt forvaltning: Forvaltningspolitikkens og central forvaltningens udvikling i Danmark 1900-1994. København: Nyt fraSamfundsvidenskaberne.

Andeweg, Rudy, and Galen Irwin. 2005. Governance and Politics of the Netherlands. 2nd ed. Basingstoke: Palgrave.

Arnold, Christine, and David Cameron. 2001. Why the EU Developed the European Employment Strategy: Unemployment, Public Opinion, and Member State Preferences. Paper presented at the American Political Science Association (APSA), San Francisco, California, August 30-September 2, 2001.

Arnold, Christine. 2002. How two-level Entrepreneurship works: The Influence of the Commission on the Europe-Wide Employment Strategy. Paper presented at the American Political Science Association Boston, Massachusetts, August 29-September 1, 2002.

Arrowsmith, J., Sisson, K. and Marginson, P. 2004. What can benchmarking offer the open method of coordination? Journal of European Public Policy, 11(2): 311-328.

Aspinwall, M. D. and Schneider, G. 2000. 'Same menu, separate tables: the institutionalist turn in political science and the study of European integration, European Journal of Political Research, 38: 136.

Auer, Manfred. 2002. The relationship between paid work and parenthood - a comparison of structures, concepts and developments in the UK and Austria. Community, Work and Family. 5 (2): 203-218. 
Bacchi, Carol Lee. 1999. Women, Policy and Politcs. London: SAGE.

Bauer, M., and B. Aarts. 2000. Corpus Construction: a Principle for Qualitative Data Collection. In Qualitative Researching with Text, Image and Sound, edited by M. Bauer and G. Gaskell. London: Sage.

Baumgartner, Frank, and Christine Mahoney. 2008. Forum Section: The Two Faces of Framing: Individual-Level Framing and Collective Issue Definition in the European Union. European Union Politics 9 (3): 435-449.

Behning, Ute. 2004. Die neue Methode der offenen Koordination, ÖsterreichischenZeitschrift für Politikwischenschaften, 2: 127-136.

Bergqvist, C., Borchorst, A., Christiansen, A.-D., Raanen, N., Ramstedt-Silen, V., and Styrkarsdottir, A. 1999. Equal Democracies: Gender and Politics in the Nordic Countries. Oslo: Scandinavian University Press.

Bjoernberg, Ulla. 2002. Ideology and choice between work and care: Swedish family policy for working parents. Critical Social Policy 22 (1): 33-52.

Blaikie, N. 2000. Designing Social Research: The Logic of Anticipation, Cambridge: Polity Press.

Bock, G., and Thane, P. (Eds.). 1991. Maternity and Gender Policies: Women and the Rise of the European Welfare States, 1880s-1950s. New York: Routledge.

Boerzel, T. A. and Risse, T. 2000. When Europe hits home: Europeanization and domestic change, EUI Working Papers, 00(56).

Boerzel, T. A. and Risse, T. 2003. Conceptualizing the Domestic Impact of Europe. In The Politics of Europeanisation, edited by K. Featherstone and C. Radaelli. Oxford: Oxford University Press.

Bonoli, Giuliano. 2007. Time Matters: Postindustrialization, New Social Risks, and Welfare State Adaptation in Advanced Industrial Democracies. Comparative Political Studies 40 (5): 495-520.

Borras, S. and Jacobsson, K. 2004. The Open Method of Co-ordination and the New Governance Patterns in the EU. Journal of European Public Policy 11 (2): 185-208.

Borras, S. and Greve, B. 2004. Concluding remarks: new method or just cheap talk, Journal of European Public Policy, 11(2): 329-336.

Bovens, M., and Hart, P. t. (1998). Understanding Policy Fiascos. New Brunswick: Transaction Publishers.

Brouns, Margo, and Marei Zwinkels. 1995. Arbeid, Zorg en Autonomie. In V roumenstudies in de jaren negentig: een kennismaking vanuit verschillende disciplines, edited by M. Brouns, M. Verloo and M. Gruenell. Bussum: Dick Coutinho.

Bruno, I., Jacquot, S. and Mandin, L. 2006. Europeanization through its instrumentation: benchmarking, mainstreaming and the open method of coordination... toolbox or Pandora's box? Journal of European Public Policy, 13(4): 519-536.

Bulmer, S. J. 1998. New institutionalism and the governance of the single European market, Journal of European Public Policy, 5(3): 365-386.

Bulmer, S. J. and Radaelli, C. M. 2004. The Europeanisation of national policy, Queen's Papers on Europeanisation, 04(1). 
Burnham, P., Gilland, K., Grant, W. and Layton-Henry, Z. 2004. Research Methods in Politics, Hampshire: Palgrave MacMillan.

Bursens, Peter, and Sarah Helsen. 2005. The OMC, a Legitimate Mode of Governance? Paper presented at EUS A 9th Biannual Conference in Austin, Texas March 31 - April 2005.

Bussemaker, Jet. 1998. Rationales of Care in Contemporary Welfare States: The Case of Childcare in the Netherlands, Social Politics, 5(1): 70-96.

Bussemaker, Jet, and Kees van Kersbergen. 1999. Contemporary Social-Capitalist Welfare States and Gender Inequality. In Gender and Welfare State Regimes, edited by D. Sainsbury. New York: Oxford University Press.

Butler, Judith. 1990. Gender Trouble: Feminism and the Subversion of Identity. New York: Routledge.

Campbell, John, and Ove Pedersen. 2001. Introduction: The Rise of Neoliberalism and Institutional Analysis. In The Rise of Neoliberalism and Institutional Analysis, edited by J. Campbell and O. Pedersen. Princeton: Princeton University Press.

Caporaso, James A., Jeffrey T. Checkel, and Joseph Jupille. 2002. Integrating institutions : theory, method, and the study of the European Union. ARENA Working Papers, WP 02/27 (accessed at: http://www.arena.uio.no/publications/working-papers2002/papers/wp02_27.htm).

Chalmers, D. and Lodge, M. 2003. The open method of coordination and the European welfare state, ESCR Centre for Analysis of Risk and Regulation Paper (11).

Checkel, J. T. 1999. Social construction and integration, Journal of European Public Policy, 6(4): 545-560.

Checkel, J. T. 2001. Why Comply? Social Learning and European Identity Change. International Organization, 55 (3): 553-588.

Checkel, J. T. 2001a. Forum section: a constructivist research program in EU studies? From meta to substantive theory? Social constructivism and the study of Europe, European Union Politics, 2(2): 219-226.

Checkel, J. T. 2005. International institutions and socialization in Europe: introduction and framework, International Organizations, 59(3): 801-826.

Christiansen, Thomas, Knud Erik Jorgensen, and Antje Wiener. 1999. The Social Construction of Europe. Journal of European Public Policy 6 (4): 528-544.

Citi, M. and Rhodes, M. 2007. New Modes of Governance in the EU: Common Objectives versus National Preferences, European Governance Papers, 07(01).

Citi, M. and Rhodes, M. 2009. New Modes of Governance in the European Union: A critical survey and Analysis, in K. E. Jørgensen, M. A. Pollack and B. Rosamond (eds), Handbook of European Union Politics, London: Sage Publications.

Cohen, J. 1996. Procedure and Substance in Deliberative Democracy. In S. Benhabib (Ed.), Democracy and Difference: Contesting the Boundaries of the Political. Princeton: Princeton University Press.

Cohen, Joshua, and Charles F. Sabel. 2003. Sovereignty and Solidarity: EU and US. In In Governing Work and Welfare in a New Economy: European and American Experiments, edited by J. Zeitlin and D. M. Trubek. Oxford: Oxford University Press.

Connelly, Rachel. 1992. The Effects of Child Care Costs on Women's Decision-Making. In The Economics of Child Care, edited by D. Blau. New York: Russell Sage Foundation. 
Daly, M. 2006. EU Social Policy after Lisbon, Journal of Common Market Studies, 44(3): 461-81.

Dehousse, Renaud. 2002. The Open Method of Coordination: a New Policy Paradigm? Paperpresented at the First Pan-European Conference on European Union Politics "The Politics of European Integration: Academic Acquis and Future Challenges" (Bordeaux, 26-28 September 2002).

Dehousse, Renaud. 2005. The Lisbon Strategy: Coordination as a Surrogate for Authority. Paper presented for EUSA 9 th biannual conference, Austin, Texas.

Dehousse, Renaud. 2011. The Community Method at Sixty. In R. Dehousse (Ed.), The 'Community Method': Obstinate or Obsolete?. Houndmills: Palgrave Macmillan

de la Porte, C. 2010. State of the Art. Overview of Concepts, Indicators and Methodologies used for Analyzing the Social OMC. Working Papers on the Reconciliation of Work and Welfare in Europe. RECWP 15/2010.

de la Porte, C. 2002. Is the open method of coordination appropriate for organising activities at European level in sensitive policy areas, European Law Journal, 8(1): 38-58.

de la Porte, C. and Nanz, P. 2004. The OMC a deliberative democratic mode of governance? The cases of employment and pensions, Journal of European Public Policy, 11(2): 267-288.

de la Porte, C. and Pochet, P. 2003. The OMC intertwined with the debates on Governance, Democracy and Social Europe, Research paper prepared for Minister Frank V andenbroucke, Minister for Social Affairs and Pensions, Brussels, March.

de la Rosa, S. 2005. The open method of coordination in the new member states - the perspectives for its use as a tool of soft law, European Law Journal, 11(5): 618-640.

de Ruiter, Rik. 2008. Developing Multilateral Surveillance Tools in the EU. West European Politics, 31(5), 896-914.

Diez, T. 2001. Speaking 'Europe': the politics of integration discourse', in T. Christiansen, K. E. Jørgensen and A. Wiener (eds), The Social Construction of Europe, London: Sage.

Diez, Thomas. 2001. Europe as a Discursive Battleground: Discourse Analysis and European Integration. Cooperation and Conflict, 36 (1): 5-38.

Dinan, D. 2004. Europe Recast: A History of European Union. Boulder: Lynne Rienner Publishers.

Dinan, D. 2010. Ever Closer Union: An Introduction to European Integration (4th ed.). Houndmills: Palgrave Macmillan.

Dostal, J. M. 2004. Campaigning on Expertise: how the OECD framed EU Welfare and Labour Market Policies - and why Success could trigger Failure. Journal of European Public Policy, 11(3), 440 - 460.

Dryzek, John. 1993. Policy Analysis and Planning: form Science to Argument. In The Argumentative Turn in Policy Analysis and Planning, edited by F. Fischer and J. Forester. London: Duke University Press.

Duina, F. and Raunio, T. 2007. The open method of coordination national parliaments: further marginalization or new opportunities? Journal of European Public Policy, 14(4): 489-506.

Eberlein, B. and Kerwer, D. 2002. Theorising the new modes of European Union governance, European Integration Online Papers, 6(5): 1-21. 
Eising, R. 2007. Interest Groups and Social Movements. In P. Graziano and M. Vink (Eds.), Europeanization: New Research Agendas (pp. 167-181). Houndmills: Palgrave Macmillan.

Esping-Andersen, Gosta. 1990. The Three Worlds of Welfare Capitalism. New Jersey: Princeton University Press.

Esping-Andersen, Gosta. 1996. After the Golden Age? Welfare State Dilemmas in a Global Economy. In Welfare States in Transition: National Adaptations in Global Economies, edited by G. EspingAndersen. London: Sage Publications.

Fagan, C., Rubery, J., Grimshaw, D., Smith, M., Hebson, G., and Figueiredo, H. 2005. Gender mainstreaming in the enlarged European Union: recent developments in the European employment strategy and Social Inclusion Process. Industrial Relations Journal, 36(6), 568-591.

Falkner, Gerda. 2003. The EU's social dimension, in M. Cini (eds), European Union Politics, New York: Oxford University Press.

Falkner, Gerda, Oliver Treib, Miriam Hartlapp, and Simone Leiber. 2005. Complying with Europe. EU Harmonisation and Soft Law in the Member States. New York: Cambridge University Press.

Featherstone, K. and Radaelli, C. M. (eds) 2003. The Politics of Europeanization, Oxford: Oxford University Press.

Feindt, P H., and A Oels. 2005. Does Discourse Matter? Discourse Analysis in Environmental Policy Making. Journal of Environmental Policy and Planning 7 (3): 161-173.

Fischer, Frank. 2003. Reframing Public Policy: Discursive Politics and Deliberative Practices. Oxford: Oxford University Press.

Fitzpatrick, Tony. 2005. New Theories of Welfare. Houndmills: Palgrave.

Foucault, Michel. 1984. The Order of Discourse. In Language and Politics, edited by M. J. Shapiro. Oxford: Blackwell.

Fraser, Nancy. 1994. After the Family Wage: Gender Equity and the Welfare State. Political Theory 22 (4): 591-618.

Gerhard, Ute, Trudie Knijn, and Anja Weckwert. 2005. Introduction: Social Practices and Social Policies. In Working Mothers in Europe: A Comparison of Policies and Practices, edited by U. Gerhard, T. Knijn and A. Weckwert. Cheltenham: Edward Elgar.

Goetschy, Janine. 1999. The European Employment Strategy: Genesis and Development. European journal of industrial relations, 5 (2): 117-138.

Gornitzka, Ase. 2005. Coordinating Policies for a "Europe of Knowledge": Emerging Practices of the Open Method of Coordination in Education and Research. ARENA Working Paper No. 16 (http://www.arena.uio.no).

Graziano, Paolo, and Maarten Vink. 2007. Challenges of a New Research Agenda. In Europeanization: New Research Agendas, edited by P. Graziano and M. Vink. Houndmills: Palgrave Macmillan.

Hague, Rod, and Martin Harrop. 2001. Comparative Government and Politics: An Introduction. 5th ed. Houndmills, Basingstoke: Palgarve.

Hakim, Catherine. 2000. Work-Lifestyle Choices in the 21st Century: Preference Theory. New York: Oxford University Press. 
Hall, P. 1993. Policy Paradigms, Social Learning, and the State. The Case of Economic Policymaking in Britain. Comparative Politics, 25(3), 275-296.

Hantrais, Linda. 2000. From Equal Pay to Reconciliation of Employment and Family Life. In Gendered Policies in Europe: Reconciling Employment and Family Life, edited by L. Hantrais. Houndmills: Macmillan Press.

Hantrais, Linda. 2007. The Gender Dimension of Social Policy. In Social Policy in the European Union, edited by L. Hantrais. Basingstoke: Palgrave.

Hartlapp, Miriam, and Gerda Falkner. 2009. Problems of Operationalization and Data in EU Compliance Research. European Union Politics 10 (2): 281-304.

Hartlapp, Miriam. 2009. Learning about policy learning. Reflections on the European Employment Strategy In What we have learnt: Advances, piffalls and remaining questions in $\mathrm{OMC}$ research, edited by $\mathrm{S}$. Kroeger. European Integration online Papers (EIoP), Special Issue 1, vol. 13.

Haverland, Marcus. 2000. National adaptation to European integration: the importance of institutional veto points. Journal of Public Policy 20 (1): 83-103.

Haverland, Markus. 2005. Does the EU cause Domestic Developments? The Problem of Case Selection in Europeanization Research. European Integration online Papers (EIoP) 9 (2): http://eiop.or.at/eiop/texte/2005-002a.htm.

Haverland, M. 2006. Does the EU cause Domestic Developments? Improving Case Selection in Europeanization Research. West European Politics, 29(1), 134-146.

Haverland, M. 2007. Methodology. In P. Graziano and M. Vink (Eds.), Europeanization: New Research Agendas (pp. 59-70). Houndmills: Palgrave Macmillan.

Heritier, Adrienne. 2002. New Modes of Governance in Europe: Policy-Making without Legislating? In Common Goods: Reinventing European and International Governance, edited by A. Heritier. Lanham: Rowman \& Littlefield: 185-206.

Hermans, Stefaan. 2005. The Social Agenda of the European Union and the Modernisation of the European Social model. Collegium No. 33 (Winter 2005): accessed at on 29-10-2008: www.coleurop.be/file/content/publications/pdf/Collegium\%2033.pdf

Hill, M., and Hupe, P. 2009. Implementing Public Policy (2nd ed.). London: SAGE Publications.

Hill, M. 2005. The Public Policy Process. Harlow: Pearson/ Longman.

Hix, Simon. 1994. The study of the European Community: the challenge to comparative politics, West European Politics, 17(1): 1-30.

Hix, Simon. 2005. The Political System of the European Union. 2nd ed. Houndmills: Palgrave.

Hochschild, Arlie, and Anne Machung. 1989. The second shift: working parents and the revolution at home. New York: Viking Penguin.

Hodson, Dermot, and Imelda Maher. 2001. The Open Method as a New Mode of Governance: The Case of Soft Economic Policy Co-ordination. Journal of Common Market Studies 39 (4): 719-746.

Holzhacker, Ronald. 2007. Democratic Legitimacy and the European Union. Journal of European Integration 29 (3): 257-269. 
Hooghe, L. and Marks, G. 2001. Types of multi-level governance, European Integration Online Papers, $5(11)$.

Hoskyns, C. 1996. Integrating Gender: Women, Law and Politics in the European Union. London: Verso.

Idema, T., and Kelemen, D. 2006. New modes of governance, the open method of coordination and other fashionable red herring. Perspectives on European Politics and Society, 7(1), 108-123.

IJzendoorn, Rien van, Louis Tavecchio, and Marianne Riksen-Walraven. 2004. De Kwaliteit van de Nederlandse Kinderopvang. Amsterdam: Boom.

Ioannou, D., and A. Niemann. 2003. Taking Stock of the Open Method of Co-ordination: Nature, Modus Operendi and Theoretical Perspectives. Dresdener Arbeitspapiere Internationale Beziehungen (DAP) No.8 (Dresden: Technische Universitaet Dresden).

Jachtenfuchs, Marcus. 2001. The Governance Approach to European Integration. Journal of Common Market Studies 39 (2): 245-264.

Jacobsson, Kerstin, and Asa Vifell. 2003. Integration by Deliberation? On the Role of Committees in the Open Method of Coordination. Paper prepared for the workshop on "The Forging of Deliberative Supranationalism in the EU" (Florence, 7-8 February 2003).

Jacobsson, Kerstin. 2004. Between deliberation and discipline: soft governance in EU employment policy, in U. Mörth (eds), Soft Law in Governance and Regulation: An Interdisciplinary Analysis, Cheltenham: Edward Elgar.

Jenson, Jane, and Philippe Pochet. 2002. Employment and Social Policy since Maastricht: Standing up to the European Monetary Union. Paper prepared for "The Year of the Euro", Nanovic Institute for European Studies, University of Notre Dame December 5-8, 2002.

Joachim, J., Reinalda, B., and Verbeek, B. 2008. International Organizations and Implementation: Pieces of the Puzzle. In J. Joachim, B. Reinalda and B. Verbeek (Eds.), International Organizations and Implementation: Enforcers, Managers, Authorities? (pp. 3-18). London: Routledge

Johansson, Karl. 1999. Tracing the Employment Title in the Amsterdam Treaty: Uncovering Transnational Coalitions. Journal of European Public Policy 6 (1): 85-101.

Jorgensen, K. E., Pollack, M. A. and Rosamond, B. (eds) 2009. Handbook of European Union Politics, London: Sage Publications.

Juncker, Jean-Claude. 2002. Preface. In From Luxembourg to Lisbon and Beyond: Making the Employment Strategy Work, edited by E. Best and D. Bossaert. Maastricht: European Institute of Public Administration.

Jupille, J., Caporaso, J. A. and Checkel, J. T. 2003. Integrating institutions: rationalism, constructivism, and the study of the European Union, Comparative Political Studies, 36(1/2): 7-40.

Kaiser, R. and Prange, H. 2002. A new concept of deepening European integration? the European research area and the emerging role of policy coordination in a multi-level governance system, European Integration Online Papers (EIoP), 6(18): 1-22.

Kallestrup, Morten. 2002. Europeanisation as a Discourse: Domestic Policy Legitimisation through articulation of a need for adaptation. Public Policy and Administration 17(2): 110-124.

Kersbergen, Kees van. 1995. Social Capitalism: A Study of Christian Democracy and the Welfare State. London: Routledge. 
Kersbergen, Kees van, and Monique Kremer. 2008. Conservatism and the Welfare State: Intervening to Preserve In Culture And Welfare State: V alues and Social Policy in Comparative Perspective edited by W. v. Oorschot, M. Opielka and B. Pfau-Effinger. Cheltenham: Edward Elgar.

Kingdon, J. 2003. Agendas, Alternatives, and Public Policies (2nd ed.). New York: Longman.

Kjaer, Peter, and Ove Pedersen. 2001. Translating Liberalization: Neoliberalism in the Danish Negotiated Economy. In The Rise of Neoliberalism and Institutional Analysis, edited by J. Campbell and O. Pedersen. Princeton: Princeton University Press.

Knijn, Trudie. 1994. Social Dilemmas in Images of Motherhood in the Netherlands. European Journal of Women's Studies 1 (2): 183-205.

Knill, C. and Lehmkuhl, D. 1999. How Europe matters. Different mechanisms of Europeanization, European Integration Online Papers, 3(7).

Knill, C., and Lenschow, A. 1998. Coping with Europe: the impact of British and German administrations on the implementation of EU environmental policy. Journal of European Public Policy 5 (4): 595-614.

Knill, C., and Lenschow, A. 2003. Modes of Regulation in the Governance of the European Union: Towards a Comprehensive Evaluation. European Union online Papers (EIoP) 7 (1).

Kohler-Koch, B. 2002. European networks and ideas: changing national politics? European Integration Online Papers, 6.

Kohler-Koch, B. and Eising, R. (eds) 1999. The Transformation of Governance in the European Union, London: Routledge.

Korpi, W. 2000. Faces of inequality: Gender, class, and patterns of inequalities in different types of welfare states. Social Politics 7 (2): 127-191.

Kremer, Monique. 2005. How Welfare States Care: Culture, Gender and Citizenship in Europe. Utrecht: PhD Thesis (defended on 16 November 2005).

Kroeger, S. 2006. When learning hits politics or: social policy coordination left to the administrations and the NGOs? European Integration Online Papers, 10(3).

Kroeger, Sandra. 2009. The Open Method of Coordination: Underconceptualisation, overdetermination, depoliticisation and beyond. In What we have learnt: Advances, pitfalls and remaining questions in OMC research, edited by S. Kroeger. European Integration online Papers (EIoP), Special Issue 1, vol. 13.

Ladrech, R. (2010). Europeanization and National Politics. Houndmills: Palgrave Macmillan

Laffan, B. 2002. 'Lisbon Europe': Experimental arrangements and new modes of governance. Paper presented at the Conference on 'Policies, institutions and citizens in the knowledge society', Barcelona 6-7 May, 2002.

Laffan, B. and Shaw, C. (2006) 'Classifying and mapping OMC in different policy areas', Report for NEWGOV NewModes of Governance (Integrated Project Priority 7: Citizens and Governance in the Knowledge based society).

Laffan, B. 2007. Core Executives. In P. Graziano and M. Vink (Eds.), Europeanization: New Research Agendas (pp. 128-140). Houndmills: Palgrave Macmillan. 
Larsson, A. 2001. A Turning Point of Employment Policy. Europa - Novas Fronteiras, N. 9/10, December 2001, 49-54

Laver, M., and Mair, P. 1999. Party Policy and Cabinet Portfolios in the Netherlands, 1998: Results from an Expert Survey. Acta Politica, 34, 49-66.

Leibfried, S. and Pierson, P. 2000. 'Social Policy', in H. Wallace and W. Wallace (eds), Policy-Making in the European Union, Oxford: Oxford University Press.

Leira, Arnlaug. 1989. Models of Motherhood. Welfare State Policies and Everyday Practices: The Scandinavian Experience. Oslo: Institute for Social Research.

Leira, Arnlaug. 1992. Welfare States and Working Mothers: The Scandinavian Experience. Cambridge.

Lewis, Jane. 1992. Gender and the Development of Welfare Regimes. Journal of European Social Policy 2 (3): 159-173.

Lewis, Jane. 2001. The Decline of the Male Breadwinner Model: Implications for Work and Care. Social Politics 8 (2): 152-169.

Lewis, Jane, Penny Bernstock, Virginia Bovell, and Fiona Wookey. 1997. Implementing care management: issues in relation to the new community care. The British journal of social work, (1): 524.

Lewis, Jane. 2006. Work-Family Reconciliation, Equal Opportunities and Social Policies: the Interpretation of Policy Trajectories at the EU Level and the Meaning of Gender Equality. Journal of European Public Policy 13 (3): 420-437.

Lodge, M. 2007. Comparing non-hierarchical governance in action: the open method of coordination in pensions and information society, Journal of Common Market Studies, 45(2): 343-365.

Lombardo, Emanuela, and Petra Meier. 2006. Gender Mainstreaming in the EU: Incorporating a Feminist Reading. European Journal of Women's Studies 13 (2): 151-166.

Lopez-Santana, M. 2006. The domestic implications of European soft law: framing and transmitting change in employment policy, Journal of European Public Policy, 13(4): 481-499.

Lutz, Helma. 2007. Editorial: Domestic Work. European Journal of Women's Studies 14 (3): 187-192.

Lynggaard, Kennet. 2007. The institutional construction of a policy field: a discursive institutional perspective on change within the common agricultural policy. Journal of European Public Policy 14 (2): 293-312.

Mahon, Rianne. 2002. Gender and Welfare State Restructuring: Through the Lens of Child Care. In Child Care Policy at the Crossroads: Gender and Welfare State Restructuring, edited by S. Michel and R. Mahon. New York: Routledge.

Maher, I. 2004. Law and the open Method of coordination: towards a new flexibility in European policy making? Zeitschrift für Staats und Europawissenschaften, 2(2).

Mair, Peter. 2004. The Europeanization Dimension. Journal of European Public Policy 11 (2): 337-348.

Mair, Peter. 2007. Political Parties and Party Systems. In P. Graziano and M. Vink (Eds.), Europeanization: New Research Agendas (pp. 154-166). Houndmills: Palgrave Macmillan.

Majone, G. 1994. The rise of the regulatory state in Europe, West European Politics, 17(3): 77-101. 
Manow, Philip, Armin Schaefer, and Hendrik Zorn. 2004. European Social Policy and Europe's PartyPolitical Center of Gravity, 1957-2003. MPIfG Discussion Paper No. 04/6.

Marchbank, Jennifer. 1996. The Political Mobilisation of Women's Interest Issues: The Failure of Childcare. Politics 16 (1): 9-15.

Marsh, D. and Stoker, G. (Eds.) 2002. Theory and Methods in Political Science, Basinstoke: Palgrave MacMillan.

Mastenbroek, Ellen, and Michael Kaeding. 2006. Europeanization Beyond the Goodness of Fit: Domestic Politics in the Forefront. Comparative European Politics 4 (331-354).

Mastenbroek, Ellen. 2005. EU Compliance: Still a 'Black Hole'? Journal of European Public Policy 12 (6): 1103-1120.

Mazey, Sonia. 1998. The European Union and women's rights: from the Europeanization of national agendas to the nationalization of a European agenda? Journal of European Public Policy 5 (1): 131152.

Mosher, J. S. and Trubek, D. M. 2003. Alternative approaches to governance in the EU: EU social policy and the European employment strategy, Journal of Common Market Studies, 41(1): 63-88.

Natali, D., and Caroline de la Porte. 2004. OMC Pensions: What role for Europe in Co-ordinating the Reform of Different Pension Systems? The Cases of France and the Netherlands. Paper presented at ESPAnet Conference 'European Social Policy: Meeting the Needs of a New Europe' Oxford, United Kingdom (September 9-11 2004).

Nugent, Neil. 2003. The government and politics of the European Union. 5th ed, The European Union series. Basingstoke: Palgrave Macmillan.

Olsen, J. P. 2003. Europeanization, in M. Cini (eds), European Union Politics, Oxford: Oxford University Press.

Olsen, J. P. 2002. The many faces of Europeanization, Journal of Common Market Studies, 40(5): 921-52.

Orloff, A. S. 2002. Equality, Employment, and State Social Policies: a Gendered Perspective. In What Future for Social Security? Debates and Reforms in National and Cross-national Perspective, edited by J. Clasen. Bristol: Policy Press.

Orloff, A. S. 1996. Gender in the welfare state. Annual Review of Sociology, 22, 51-78.

Ostner, I. 1993. Slow motion: Women, work and the family in Germany. In J. Lewis (Ed.), Women and Social Policies in Europe (pp. 92-115). Aldershot: Edward Elgar.

Overdevest, C. 2002. The Open Method Coordination, New Governance, and Learning: Towards a Research Agenda. New Governance Project Working Paper University of Wisconsin-Madison, USA.

Parsons, Wayne. 1995. Public Policy: An Introduction to the Theory and Practice of Policy Analysis. Cheltenham: Edward Elgar.

Paul Pennings and Hans Keman, Vrije Universiteit Amsterdam, in cooperation with the Social Science Reserach Centre Berlin (Andrea Volkens, Hans-Dieter Klingemann) the Zentralarchiv für empirische Sozialforschung, GESIS, Universität zu Köln, and the Manifesto Research Group (chairman: Ian Budge). Financed by the Netherlands Organization for Scientific Research (NWO project 480-42-005). 
Peters, Klaartje. 1999. Verdeelde Macht: een Onderzoek naar Invloed op Rijksbeshitvorming in Nederland. Amsterdam: Boom.

Peterson, J. 2004. Policy networks, in A. Wiener and T. Diez (eds), European Integration Theory, New York: Oxford University Press.

Pfau-Effinger, Birgit. 2004. Development of Culture, Welfare States and Women's Employment in Europe. Aldershot: Ashgate.

Plantenga, Janneke. 1999. Welfare-State Reform and Equal Opportunities: the Case of the Netherlands. In Women and Public Policy: the Shifting Boundaries between Public and Private Spheres, edited by S. Baker and A. v. Doorne-Huiskes. Aldershot: Ashgate.

Plantenga, Janneke, and Chantal Remery. (Eds.) 2009. The Provision of Childcare Services: A Comparative Review of 30 European Countries. Luxembourg: Office for Official Publications of the European Communities.

Pochet, Philippe. 2004. Some Reflections around European Employment Strategy (EES). Observatoire Social Europeen at: http://www.ose.be/SEE/files/ESSreflectOSE2004.pdf (9.08.2005).

Pochet, P. 2005. The Open Method of Co-ordination and the Construction of Social Europe: A Historical Perspective. In J. Zeitlin, P. Pochet and L. Magnusson (Eds.), The Open Method of Coordination in Action: The European Employment and Social Inclusion Strategies. Brussels: P.I.E. - Peter Lang.

Pollack, M. A. 1997. Delegation, agency, and agenda setting in the European Community, International Organizations, 51(1): 99-134.

Pollack, M. A. 2000. The End of Creeping Competence? EU Policy-Making Since Maastricht, Journal of Common Market Studies, 38(3): 519-38.

Portegijs, W., Cloin, M., Keuzenkamp, S., Merens, A., and Steenvoorden, E. 2008. Verdeelde Tijd: Waarom vrouwen in deeltijd werken. Den Haag: Sociaal en Cultureel Planbureau.

Radaelli, Claudio M. 2000. Whither Europeanization? Concept Stretching and Substantive Change. European Integration online Papers (EIoP) 4 (8).

Radaelli, Claudio M. 2003. The open method of coordination: a new governance architecture for the European Union? Swedish Institute for European Policy Studies (SIEPS), Stockholm, 20 February 2003

Radaelli, Claudio M. 2003. The Europeanization of Public Policy. In The Politics of Europeanization (pp. 26-53). K. Featherstone and C. Radaelli (Eds.), Oxford: Oxford University Press.

Radaelli, Claudio M. 2004. Europeanisation: Solution or problem? European Integration online Papers (EIoP) 8 (16).

Radaelli, C., and Pasquier, R. 2007. Conceptual Issues. In P. Graziano and M. Vink (Eds.), Europeanization: New Research Agendas (pp. 35-45). Houndmills: Palgrave Macmillan.

Radulova, E. 2007. Variations on Soft EU governance: the Open Method(s) of Coordination. In De Bievre, Dirk and Neuhold, Christine (Ed.), Dynamics and Obstacles of European Governance (pp. 327). Edward Elgar: Cheltenham.

Radulova, E. 2007a. The OMC: An opaque Method of Consideration or Deliberative Governance in Action? Journal of European Integration, 29(3): 363-380. 
Radulova, E. 2009. The construction of EU's childcare policy through the Open Method of Coordination. In What we have learnt: Advances, pitfalls and remaining questions in OMC research, edited by S. Kroeger. European Integration online Papers (EIoP), Special Issue 1, vol. 13.

Regent, S. 2003. The open method of coordination: a new supranational form of governance? European Law Journal, 9(2): 190-214.

Rein, Martin, and Donald Schoen. 1993. Reframing Policy Discourse. In The Argumentative Turn in Policy Analysis and Planning, edited by F. Fischer and J. Forester. London: Duke University Press.

Rhodes, M. 2005. Employment Policy: Between Efficacy and Experimentation. In H. Wallace, W. Wallace and M. Pollack (Eds.), Policy-Making in the European Union (5th ed., pp. 279-304). Oxford: Oxford University Press.

Ribar, David. 1995. A Structural Model of Child Care and the Labor Supply of Married Women. Journal of Labor Economics 13 (3): 558-597.

Richardson, J. (eds) 2001. European Union: Power and Policy Making, London: Routledge. 368

Risse, T. 2004. Social constructionism and European integration', in A. Wiener and T. Diez (eds), European Integration Theory, New York: Oxford University Press.

Risse, T., Caporaso, J., and Cowels, M. 2001. Europeaisation and Domestic Change: Introduction. In T. Risse, J. Caporaso and M. Cowels (Eds.), Transforming Europe: Europeanisation and Domestic Change. New York: Cornell University Press.

Rittberger, V., and Zangl, B. 2006. International Organization: Polity, Politics and Policies. Houndmills: Palgrave Macmillan.

Rodrigues, M. J. 2001. The open method of coordination as a new governance tool. Europa Europe, Special issue, No. 2-3(Fondazione Instituto Gramisci, Rome), 96-107.

Rodrigues, M. J. 2002. Introduction: for a European Strategy at the Turn of the Century. In M. J. Rodrigues (Ed.), The New Knowledge Economy in Europe. Cheltenham, UK: Edward Elgar.

Rooden, Peter von. 1996. Religieuze Regimes. Over godsdienst en maatschappij in Nederland, 1570-1990. Amsterdam: Bert Bakker.

Rosamond, B. 2000. Theories of European Integration, Basingstoke: Macmillan.

Rosamond, B. 2007. New theories of European integration, in M. Cini (Ed.), European Union Politics, New York: Oxford University Press.

Rose, R. 1991. What is Lesson-Drawing? Journal of Public Policy, 11, 3-30

Rubery, Jill. 2002. Gender Mainstreaming and Gender Equality in the EU: the Impact of the EU Employment Strategy. Industrial Relations Journal 33 (5): 500-522.

Rubery, Jill, Damian Grimshaw, and Hugo Figueiredo. 2005. How to close the gender pay gap in Europe: towards the gender mainstreaming of pay policy. Industrial Relations Journal 36 (3): 184213.

Rubio, Eulalia. 2007. A Policy in its Infancy: The case for strengthening and rethinking EU action on childhood. Notre Europe Policy Paper No. 30 (available at: http://www.notreeurope.eu/uploads/tx_publication/Policypaper30-Erubio-PolicyEnfancy-en.pdf (19 August 2008)). 
Sabel, C. F., and Zeitlin, J. 2003. Active Welfare, Experimental Governance, Pragmatic Constitutionalism: The New Transformation of Europe. Draft prepared for the International Conference of the Hellenic Presidency of the European Union, "The modernisation of the European Social Model \& EU Policies and Instruments", Ioannina, Greece, 21-22 May 2003, http://eucenter.wisc.edu/OMC/Papers/EUC/zeitlinSabel3.pdf (07-06-2007)

Sainsbury, D. 1999. Gender and Social-Democratic Welfare States. In Gender and Welfare State Regimes, D. Sainsbury (Ed.), (pp. 75-114). New York: Oxford University Press.

Sapir, Andre. 2006. Globalization and the Reform of the European Social Model. Journal of Common Market Studies 44 (2): 369-390.

Schaefer, A. 2004. Beyond the Community method: Why the open method of coordination was introduced to EU policy-making', European Integration Online Papers, 8(13): 1-19.

Schaefer, A. 2006. Resolving Deadlock: Why International Organisations Introduce Soft Law. European Law Journal, 12(2), 194-208.

Schaefer, A. 2006a. A new form of governance? Comparing the open method of co-ordination to multilateral surveillance by the IMF and the OECD. Journal of European Public Policy, 13(1), 70 88 .

Scharpf, F. 1999. Governing in Europe: Effective and Democratic, Oxford: Oxford University Press.

Scharpf, F. 2001. European Governance: Common Concerns vs. the Challenge of Diversity. Jean Monnet Working Paper No.6/01 (http://www.jeanmonnetprogram.org/papers/01/010701.html).

Scharpf, F. 2002. The European social model: coping with the challenges of diversity, Journal of Common Market Studies, 40(4): 645-670.

Schmidt, V. A. 2001. Europeanization and the mechanics of economic policy adjustment, European Integration Online Papers (EIoP), 5(6).

Schmidt, V. A. 2005. The Role of Public Discourse in European Social Democratic Reform Projects. European Integration online Papers (EIoP), 9(8).

Schmidt, V. A. 2006. Procedural democracy in the EU: the Europeanization of national and sectoral policy-making processes, Journal of European Public Policy, 13(5): 670-691.

Schmidt, V. A. 2010. Taking ideas and discourse seriously: explaining change through discursive institutionalism as the fourth 'new institutionalism'. European Political Science Review, 2(1): 1-25

Schmidt, V. A., and Radaelli, C. M. 2004. Policy Change and Discourse in Europe: Conceptual and Methodological Issues. West European Politics 27 (2): 183-210.

Scott, J. and Trubek, D. M. 2002. Mind the gap: law and new approaches to governance in the European Union, European Law Journal, 8(1): 1-18.

SER (Sociaal-Economische Raad) 1989. Advies kinderopvang: advies inzake kinderopvang door de Commissie Vrouw en Arbeid. Publikatie Sociaal-Economische Raad 89/9 Nr. 8(20 april 1989), den Haag.

Sevenhuijsen, S. 2003. The Place of Care. The Relevance of the Ethics of Care for Social Policy. In Labyrinths of Care: The Relevance of the Ethics of Care Perspective for Social Policy (pp. 13-41). S. Sevenhuijsen and A. Švab (Eds.), Ljubljana: Peace Institute. 
Smismans, S. 2006. New modes of governance and the participatory myth, European Governance Papers (EUROGOV), 06(01).

Stevens, Anne, and Handley Stevens. 2001. Brussels Bureaucrats? Basingstoke: Palgrave.

Stratigaki, Maria. 2004. The Cooptation of Gender Concepts in EU Policies: The Case of "Reconciliation of Work and Family". Social Politics 11 (1): 30-56.

Stratigaki, Maria. 2000. The European Union and the Equal Opportunities Process. In L. Hantrais (Ed.), Gendered Policies in Europe: Reconciling Employment and Family Life (pp. 27-48). Houndmills: Macmillan Press.

Stubb, Alexander, Helen Wallace, and John Peterson. 2003. The Policy-Making Process. In The European Union: How does it Work?, by E. Bomberg and A. Stubb (Eds.). New York: Oxford University Press.

Sverdrup, Ulf. 2007. Implementation. In Europeanization: New Research Agendas (pp.197-211), edited by P. Graziano and M. Vink. Houndmills: Palgrave Macmillan.

Szysczak, E. 2006. Experimental governance: the open method of coordination. European Law Journal, 12(4), 486-502.

Teague, P. 2001. Deliberative governance and EU social policy, European Joumal of Industrial Relations, 7(1): 7-26.

Telo, M. 2002. Governance and Government in the European Union: The Open Method of Coordination. In The New Knowledge Economy in Europe (pp. 242-272). M. J. Rodrigues (Ed.), Cheltenham, UK: Edward Elgar.

Timmermans, Arco. 2003. High politics in the Low Countries: an empirical study of coalition agreements in Belgium and the Netherlands. Aldershot: Ashgate

Torfing, J. 2005. Discourse Theory: Achievements, Arguments, and Challenges. In Discourse Theory in European Politics: Identity, Policy and Governance (pp. 1-32). D. R. Howarth and J. Torfing (Eds.), Houndmills: Palgrave.

Treib, O. 2008. Implementing and complying with EU governance outputs. Living Reviews in European Governance, Vol. 3, (2008), No. 5: http://www.livingreviews.org/lreg-2008-5 (accessed on 12-0320011)

Trubek, D. M. and Trubek, L. G. 2004. The open method of coordination and the debate over hard and soft law, In The Open Method of Coordination in Action: The European Employment and Social Inclusion Strategies. By J. Zeitlin, P. Pochet and L. with Magnusson (Eds.), Brussels: Peter Lang

Trubek, D. M. and Trubek, L. G. 2005. Hard and Soft Law in the Construction of Social Europe: the Role of the Open Method of Co-ordination. European Law Journal 11 (3) 343-364.

Vandenbroucke, F. 2001. European social policy: is cooperation a better route than regulation? New Economy: 30-33.

Van der Lippe, Tanja. 2001. The Effect of Individual and Institutional Constraints on Hours of Paid Work of Women: An International Comparison. In Women's Employment in a Comparative Perspective, By T. V. d. Lippe and L. V. Dijk (Eds.) New York: Aldine de Gruyter.

Verloo, Mieke, and Emanuela Lombardo. 2007. Contested Gender Equality and Policy Variety in Europe: Introducing a Critical Frame Analysis Approach. In Multiple Meanings of Gender Equality: 
A Critical Frame Analysis of Gender Policies in Europe, By M. Verloo (Ed.) Budapest: Central European University Press (CEU Press).

Versluis, E. 2007. Even Rules, Uneven Practices: Opening the "Black Box" of EU Law in Action. West European Politics, 30(1), 50-67.

Versluis, E., Keulen, M. v., and Stephenson, P. 2011. Analyzing the European Union Policy Process. Houndmills: Palgrave Macmillan.

Visser, Jelle. 2005. The OMC as selective amplifier for national strategies of reform. In The Open Method of Coordination in Action, By J. Zeitlin and P. Pochet (Eds.) Brussels: Peter Lang.

Visser, Jelle. 2009. The Open Method of Coordination and National Social and Employment Policy Reforms: Influences, Mechanisms, Effects. In Changing European Welfare and Employment Regimes: The Influence of the Open Method of Coordination on National Reforms, By Heidenreich, M., and Zeitlin, J. (Eds.) London: Routledge.

Visser, Jelle., and Hemerijck, Anton. 1997. 'A Dutch Miracle': Job Growth, Welfare Reform and Corporatism in the Netherlands. Amsterdam: Amsterdam University Press.

Wallace, Helen. 2010. An Institutional Anatomy and Five Policy Modes. Chapter 4 in Policy-making in the European Union, edited by H. Wallace, M. Pollack and A. Young. 6th edition. Oxford: Oxford University Press.

Warleigh-Lack, Alex, and Ralf Drachenberg. 2009. Policy Making in the European Union. (Ch. 13) in European Union Politics, By M. Cini and N. Perez-Solorzano Borragan (Eds.) 3rd edition. Oxford: Oxford University Press.

Weaver, O. 2004. Discursive Approaches. In European Integration Theory (pp. 197-215). By A. Wiener and T. Diez (Eds.) New York: Oxford University Press.

Weedon, Chris. 1997. Feminist Practice and Poststructuralist Theory. Oxford: Blackwell.

Weishaupt, Timo. 2009. Money, Votes or Good Ideas? How Partisan Politics Shape the Impact of the European Employment Strategy. In What we have learnt: Advances, pitfalls and remaining questions of OMC research, edited by S. Kröger. European Integration online Papers (EIoP): Special Issue 1 (13).

Wendt, A. 1998. On constitution and causation in international relations, Review of International Studies, $4(101-118)$.

Wiener, A. and Diez, T. (Eds.) 2004. European Integration Theory, New York: Oxford University Press.

Williams, J. 2000. Unbending gender: why family and work conflict and what to do about it. Oxford: Oxford University Press

Wincott, D. 2003. Beyond social regulation? New instruments and/or a new agenda for social policy at Lisbon? Public Administration, 81(3): 533-553.

Yanow, Dvora. 2000. Conducting Interpretative Policy Analysis. Thousand Oaks: Sage Publications.

Zeitlin, J. 2005. Introduction: The Open Method of Co-ordination in Question. In The Open Method of Co-ordination in Action: The European Employment and Social Inclusion Strategies, By J. Zeitlin, P. Pochet and L. Magnusson (Eds.). Brussels: Peter Lang.

Zeitlin, J. 2005a. Conclusion: the open method of coordination in action: theoretical promise, empirical realities, reform strategies. In The Open Method of Co-ordination in Action: The European Employment 
and Social Inclusion Strategies, By J. Zeitlin, P. Pochet and L. Magnusson (Eds.). Brussels: Peter Lang.

Zeitlin, J. 2009. The Open Method of Coordination and National Social and Employment Policy Reforms: Influences, Mechanisms, Effects. In Changing European Welfare and Employment Regimes: The Influence of the Open Method of Coordination on National Reforms, By Heidenreich, Martin, and Zeitlin, Jonathan (Eds.), London: Routledge.

Zeitlin, J. 2009a. Is the Open Method of Coordination an Alternative to the Community Method. In The Community Method: Obstinate or Obsolete? By R. Dehousse (Ed.), Basingstoke: Palgrave Macmillan.

Zürn, M. and Checkel, J. T. 2005. Getting socialized to build bridges: constructvism and rationalism, Europe and the nation-state, International Organizations, 59(3): 1045- 1079. 


\section{APPENDIX A. THE CHILDCARE GUIDELINE IN THE VARIOUS STAGES OF THE EUROPEAN EMPLOYMENT STRATEGY}

\begin{tabular}{|c|c|c|c|}
\hline $\begin{array}{l}1999 \text { Employment } \\
\text { Guidelines }\end{array}$ & 2001 Employment Guidelines & 2003 Employment Guidelines & $\begin{array}{l}2005 \text { Integrated Guidelines for } \\
\text { Growth and Jobs }\end{array}$ \\
\hline Four pillars: & Four pillars: & Three objectives: & Three main areas: \\
\hline 1. Employability & 1. Employability & 1. Full employment & $\begin{array}{l}\text { 1. Knowledge and innovation for } \\
\text { growth }\end{array}$ \\
\hline 2. Entrepreneurship & 2. Entrepreneurship & 2. Improving quality and & 2. Making Europe a more attractive \\
\hline 3. Adaptability & 3. Adaptability & productivity at work & place to invest and work \\
\hline 4. Equal opportunities: & 4. Equal opportunities: & $\begin{array}{l}\text { 3. Strengthening social cohesion } \\
\text { and inclusion }\end{array}$ & 3. Creating more and better jobs \\
\hline $\begin{array}{l}\text { GL 21. Reconciling work and } \\
\text { family life }\end{array}$ & $\begin{array}{l}\text { GL 18. Reconciling work and } \\
\text { family life (merged GL } 20 \text { and } \\
\text { 21) }\end{array}$ & $\begin{array}{l}\text { Ten priorities for action: } \\
\text { No. } 6 \text { Gender equality }\end{array}$ & $\begin{array}{l}\text { GL 18. Promote a lifecycle } \\
\text { approach to work }\end{array}$ \\
\hline
\end{tabular}




\section{APPENDIX B. QUANTITATIVE TARGETS ENDORSED BY THE EUROPEAN \\ COUNCIL IN THE CONTEXT OF THE LISBON STRATEGY}

$\checkmark$ By 2010 3\% of GDP to be devoted to investment in research and innovation( $2 / 3$ of wich to come from the ptrivate sector).

$\checkmark$ By $201070 \%$ of overall employment rate(60\% for women, 50\% for elderly)

$\checkmark$ By $201033 \%$ coverage rate for children between 0 and 3 years of age and $90 \%$ for children between 4 and 12 years of age

$\checkmark$ By 2010 12,5\% of the adult labour population should take part in life-longlearning programmes

$\checkmark$ By 2007 every unemployed person is offered a new start before reaching six months of unemployment in the case of young people and 12 months in the case of adults in the form of training, retraining, work practice, a job or other employability measure, combined where appropriate with on-going job search assistance

$\checkmark$ By 2012 25\% reduction of the EU related administrative red tape

$\checkmark$ By 2010 every school leaver should acquire a job, an internship or a follow up education within 4 months

$\checkmark$ By 2010 the number of young people with a diploma from a higher secondary education should reach 85\% (from 20 -24 year-olds)

$\checkmark$ By the end of 2007 it should be possible in EU to establish a company within 1 week 


\section{APPENDIX C. CONDUCTED INTERVIEWS*}

\section{Conducted interviews in the Netherlands}

1. Advisor for International Social Affairs in the FNV Central offices (FNV vakcentarle), (24.06.2009, Amsterdam)

2. Advisor for Childcare at the Ministry for Education, Culture and Science of the Netherlands, (25.09.2009, telephone interview)

3. Advisor Labour market, Social Insurance and Pensions of the MKB Nederland Employers' Union, (12.10.2009, telephone interview)

4. Chair of the Dutch Parental organization of Children who go to Childcare facilities (BoinK), (1.07.2009, telephone interview)

5. Advisor for International Social Affairs in the CNV Central offices (CNV vakcentrale), (22.07.2009, Utrecht)

6. Independent member of the ISEA committee of the Social Economic Council (SER) of the Netherlands and Professor at the College of Brugge, Brussels, (09.09.2009, Maastricht)

7. Dutch Coordination Officer of the European Women's Lobby, (15.05.2009, Utrecht)

8. Executive Director of Daycare centre "De TUimelaar" and Freelance consultant in the field of Childcare Management (17.06.2008, Eindhoven)

9. Advisor for Childcare of the FNV Central offices (FNV vakcentarle), (24.06.2009, Amsterdam)

\footnotetext{
* The interviewees' names are available upon request.
} 
10. Dutch (alternate) Representative in the Employment Committee (EMCO) of the European Union, (15.03.2006, the Hague)

11. Former D66 politician, advisor in e-Quality - the Knowledge centre for Gender and Diversity, (24.06.2009, Utrecht)

12. Advisor for International Social Affairs in the VNO-NCW Central offices, (22.07.2009, the Hague)

13. Housewife, (26.09.2008, Eindhoven)

14. Member of the Board of the FNV Vrouwenbond trade union, and former employee of the Vrouwen Alliantie, (3.06.2009, Maastricht)

15. Secretary of the committee for social-economic policy (Social-Economisch Beleid) of the Dutch Social Economic Council (SER), (11.09.2009, telephone interview)

\section{Conducted interviews at the EU level}

16. Social Attachee in the Belgian Permanent Representation to the EU and Belgian Representative in the Employment Committee (EMCO) of the European Union, (11 March 2006, Brussels)

17. Director of Directorate G "Resources, Communication", DirectorateGeneral 'Employment, Social Affairs and Equal Opportunities', Commission of the European Communities (07.10.2009, telephone interview)

18. Alternate member of the Portuguese representative in the Employment Committee (EMCO) of the EU, (7 April 2006, Brussels)

19. Secretary of the Employment Committee (EMCO) of the EU, DirectorateGeneral 'Employment, Social Affairs and Equal Opportunities', Commission of the European Communities (31.03.2005, Brussels)

20. Secretary of the 'Social Protection Committee', Directorate-General 'Employment, Social Affairs and Equal Opportunities', Direction , Commission of the European Communities (30.03.2005, Brussels)

21. Alternate member of the Spanish representative in the Employment Committee (EMCO) of the EU, (30 March 2006, Brussels)

22. Danish Representative in the Employment Committee (EMCO) of the European Union, (9 March 2006, Brussels) 
23. Official from the Commission of the European Communities, DirectorateGeneral for Research, Direction M, Unit 2 'Open Coordination of Research Policies', (08.04.2005, Brussels)

24. Austrian Representative in the Employment Committee (EMCO) of the European Union, (15.03.2006, telephone interview)

25. Head of the Permanent Representation of Finland and alternate member of the Employment Committee (EMCO) of the European Union, (28.03.2006, Brussels)

26. Director of Unit 2 'Employment Strategy', Directorate-General 'Employment, Social Affairs and Equal Opportunities', Direction A, Commission of the European Communities (30.03.2005, Brussels)

27. Swedish Representative in the Employment Committee (EMCO) of the European Union, (31 March 2006, Brussels)

28. German Representative in the Employment Committee (EMCO) of the European Union, (14 April 2006, Bonn, Germany)

29. Official from the CREST Secretariat, General Secretariat of the Council of the European Union, Directorate-General C 'Internal Market Competitiveness - Industry - Research - Energy - Transport - Information Society', Directorate 2 (25.03.2005, Brussels) 


\title{
APPENDIX D. TREATY PROVISIONS \\ WITH REGARD TO EMPLOYMENT \\ POLICY COORDINATION(THE \\ EUROPEAN EMPLOYMENT STRATEGY)
}

\author{
TITLE VIII \\ EMPLOYMENT
}

Article 125

Member States and the Community shall, in accordance with this title, work towards developing a coordinated strategy for employment and particularly for promoting a skilled, trained and adaptable workforce and labour markets responsive to economic change with a view to achieving the objectives defined in Article 2 of the Treaty on European Union and in Article 2 of this Treaty.

\section{Article 126}

1. Member States, through their employment policies, shall contribute to the achievement of the objectives referred to in Article 125 in a way consistent with the broad guidelines of the economic policies of the Member States and of the Community adopted pursuant to Article 99(2).

2. Member States, having regard to national practices related to the responsibilities of management and labour, shall regard promoting employment as a matter of common concern and shall coordinate their action in this respect within the Council, in accordance with the provisions of Article 128.

\section{Article 127}

1. The Community shall contribute to a high level of employment by encouraging cooperation between Member States and by supporting and, if necessary, complementing their action. In doing so, the competences of the Member States shall be respected. 
2. The objective of a high level of employment shall be taken into consideration in the formulation and implementation of Community policies and activities.

\section{Article 128}

1. The European Council shall each year consider the employment situation in the Community and adopt conclusions thereon, on the basis of a joint annual report by the Council and the Commission.

2. On the basis of the conclusions of the European Council, the Council, acting by a qualified majority on a proposal from the Commission and after consulting the European Parliament, the Economic and Social Committee, the Committee of the Regions and the Employment Committee referred to in Article 130, shall each year draw up guidelines which the Member States shall take into account in their employment policies. These guidelines shall be consistent with the broad guidelines adopted pursuant to Article 99(2).

3. Each Member State shall provide the Council and the Commission with an annual report on the principal measures taken to implement its employment policy in the light of the guidelines for employment as referred to in paragraph 2.

4. The Council, on the basis of the reports referred to in paragraph 3 and having received the views of the Employment Committee, shall each year carry out an examination of the implementation of the employment policies of the Member States in the light of the guidelines for employment. The Council, acting by a qualified majority on a recommendation from the Commission, may, if it considers it appropriate in the light of that examination, make recommendations to Member States.

5. On the basis of the results of that examination, the Council and the Commission shall make a joint annual report to the European Council on the employment situation in the Community and on the implementation of the guidelines for employment.

\section{Article 129}

The Council, acting in accordance with the procedure referred to in Article 251 and after consulting the Economic and Social Committee and the Committee of the Regions, may adopt incentive measures designed to encourage cooperation between Member States and to support their action in the field of employment through initiatives aimed at developing exchanges of information and best practices, providing 
comparative analysis and advice as well as promoting innovative approaches and evaluating experiences, in particular by recourse to pilot projects.

Those measures shall not include harmonisation of the laws and regulations of the Member States.

\section{Article 130}

The Council, after consulting the European Parliament, shall establish an Employment Committee with advisory status to promote coordination between Member States on employment and labour market policies. The tasks of the Committee shall be:

- to monitor the employment situation and employment policies in the Member States and the Community,

- without prejudice to Article 207, to formulate opinions at the request of either the Council or the Commission or on its own initiative, and to contribute to the preparation of the Council proceedings referred to in Article 128.

In fulfilling its mandate, the Committee shall consult management and labour.

Each Member State and the Commission shall appoint two members of the Committee. 


\section{SAMENVATTING}

Dit proefschrift heeft als doel het ontwikkelen en testen van een analytische methode voor de studie van de invloed van een nieuw regeermethode binnen de Europese Unie (EU) - de open coördinatiemethode (Open Method of Coordination) - OMC op de beleidsprocessen in de lidstaten van de Unie. Hoofdstuk 1 geeft de theoretische en methodische kader van het onderzoek aan. $\mathrm{Na}$ een kritisch overzicht van de theoretische state of the art van de literatuur over Europeanisering, steelt het hoofdstuk voor een nieuwe analytische strategie voor de studie van de invloed van de OMC, gebaseerd op de theorie van discursieve institutionalisme en de methode van het policy frame analyse (PFA). Hoofdstuk 2 schetst de opkomst en de belangrijkste kenmerken van de OMC op het gebied van werkgelegenheid (volgens de beleidscyclus). Hoofdstuk 3 presenteert de specifieke kenmerken van kinderopvang als een publieke dienstverrichting, en zes verschillende beleidskaders (de z.g. frames), die de kinderopvangvoorzieningen als de 'oplossing' aangeven voor zes openbare problemen. Het volgende hoofdstuk 4 volgt de ontwikkeling van deze zes frames in de EU-wetgeving door gebruik van de methode van de PFA. Deze analyse onthult de cognitieve onderbouw van het EU-beleid inzake kinderopvang. Het werd ontdekt dat in het begin de kwestie van de kinderopvang op EU-niveau werd geïnterpreteerd in het licht van de problematiek van gendegelijkheid. Zodra de Europese Werkgelegenheidsstrategie (EWS) werd goedgekeurd (1997-1998), echter, kinderopvang veranderde zijn betekenis en werd gezien als een beleidsstrategie om het afnemende concurrentievermogen van de Unie te verhogen. Op basis van deze bevindingen begint de case study over de uitvoering van de EU-kinderopvang richtlijn in Nederland.

Hoofdstuk 5 begint met een overzicht van de beleidsontwikkelingen die door verschillende Nederlandse overheden tot 1998 waren ondernomen. Bovendien, hoofdstuk 5 beoordeelt het beleidsproces na de uitvoering van de Europese Werkgelegenheidsstrategie (in termen van beleidsactiviteiten en de resultaten daarvan). Aan het eind van het hoofdstuk werd zichtbaar dat beide - het beleidsactiviteiten en de beleidsresultaten - waren in volledige aanpassing aan de EUvoorschriften. Uit het onderzoek van de discoursen, echter, blijkt dat de inzet voor uitbreiding van de bestaande kinderopvang capaciteiten bestond al in 1989. Dit geeft aan dat het niet kon de EWS (een decennium later onderschreven overeenkomst) zijn dat het beleid veranderingen in Nederland aanzette. Gezien het feit dat het nationale discours voorafging aan de EU-discours, het is onmogelijk om aanspraak te maken op de aanwezigheid van een causaal verband en dus van Europeanisering. 
De weerlegging van de Europeanisering hypothese aan het einde van hoofdstuk 5 , heeft niet een volledig verslag van de beleidsontwikkelingen. Te dien einde hoofdstuk 6 voert een micro policy farme analyse uit. Er zijn nogmaals de zes kinderopvang policy frames onderzocht, maar deze keer zijn ze gekoppeld aan de binnenlandse actoren (politieke partijen, vakbonden, werkgeversorganisaties, belangengroepen) die deze frames gebruikten. Verder is de coalitievorming dynamiek getraceerd, en daarmee aangetoond het proces waarbij kinderopvang policy frames werden dominant in Nederland en dus werden gematerialiseerd in het openbaar beleid. De algemene conclusie van dit onderzoek is dat in Nederland kinderopvang een binnenlands gedreven beleidsveld is, waar het niveau van Europeanisering laag is, zowel in termen van verandering in de gevestigde beleidsvorming procedures en in termen van inhoudelijke beleid. Inhoudelijk, de analyse toonde aan dat het niet de coördinatie proces van de EU (de OMC and de EWS) is, die leidde tot de spectaculaire groei van de kinderopvang in Nederland (in de jaren 1990 en de jaren 2000). Ondanks de convergentie met het EU-beleid frame (F2) en het Barcelonakwantitatieve doelstelling, en ondanks de vele relevante beleidsactiviteiten, de actoren analyse (hoofdstuk 6) heeft geleid tot de conclusie dat deze beleidsuitkomsten werden geïnitieerd en uitgevoerd door binnenlandse actoren. In het bijzonder wisten de PvdA, D66, FNV, en de VNO (de pro-kinderopvang coalitie) de bestuurlijke agenda in de jaren 1980 te veranderen, en op de momenten dat de PvdA en D66 waren in staat om directe invloed op het beleid uit te voren (de perioden waarin zij waren in het kabinet) het kinderopvangsector kende een boost van publieke steun.

Dit proefschrift vergroot de bestaande wetenschappelijke literatuur met een originele studie van de openbare kinderopvangdienstverlening in Nederland in het kader van een steeds grotere Europeanisering van werkgelegenheid en sociaal beleid. Niet alleen bied dit proefschrift een chronologisch verslag van alle belangrijke ontwikkelingen in de discursieve structuren op dit beleidsterrein aan, maar het bovendien verbind de policy frames met de belangrijkste actoren. Dus, het stelt een volledige reconstructie van het politieke spelen in deze sector voor de laatste vijftig jaar.

Naast het verstrekken van een volledig overzicht van de manier waarop het Nederlandse systeem van sociaal-economische governance omgaat met een Europees initiatief voor meer beleidsmatige convergentie op het gebied van kinderopvang beleid (de EWS), deze studie heeft ook bijgedragen aan de opkomende Administrative Governance agenda. Het heeft namelijk in kaart gebracht van de administratieve regeling die Nederland ontwikkeld om deel te nemen aan de nieuwe manier van het EU-beleid sturen - de open methode van coördinatie. Deze administratieve regeling wordt gekenmerkt door een hoge mate van functionele scheiding van de administratieve eenheden en ambtenaren die "handelen" met de EU. Voor toekomstige studies, is het interessant om te ontdekken in hoeverre het 
geval van 'inkapseling' van de EU-zaken in het geval van kinderopvang beleid is een uitzondering of is de regel in de Nederlandse manier van aanpassen aan de processen van EU governance.

Samen met de inhoudelijke bevindingen hierboven besproken, de belangrijkste bijdragen van deze studie om de bestaande wetenschappelijke literatuur zijn van methodologische aard. Dit proefschrift presenteert en toepast een nieuwe analytische strategie voor het bestuderen van het binnenlands invloed van de open coördinatiemethode (de OMC). In de eerste plaats, discursieve institutionalisme bleek een nuttig instrument voor het modelleren van Europeanisering processen. Het leverde een duidelijke richtlijn voor de identificatie van de mechanismen die op spel waren. De tweede component van de analytische strategie van deze studie - de policy frame analyse (PFA) - bleek een rigoureuze methode voor de studie van tamelijk ongrijpbare processen van sociale constructie. Concreet, het zorgt voor de systematische observatie van de beleidsdiscoursen, en hun ontwikkeling door de tijd. Er ontbreekt in de Europeanization literatuur met name een methodische aanpak van de complexe processen van norm diffusie en socialisatie. Bovendien zijn constructivistische studies vaak bekritiseerd over hun gebrek aan systematische tools voor het onderzoek van processen van sociale constructie. Het is duidelijk dat zulk een methodologisch instrument moet de sociale processen van discursieve uitwisselingen en retorische (re) combinaties kunnen reconstrueren. De PFA is een dergelijk instrument. In het kort, de toegepaste analytische strategie - samengesteld uit de theorie van de discursieve institutionalisme (DI) in combinatie met de PFA leverde een grondige verklaring van de evolutie van de Nederlandse kinderopvang beleid en van de timing van de veranderingen die het onderging. Het is dus een succesvolle analytische benadering van de studie van de invloed van de internationale beleidsprocessen, die de dynamiek op de acteur niveau als op institutioneel niveau kan ophelderen. 


\section{CURRICULUM VITAE}

Elissaveta Radulova (1978) was born in Sofia, Bulgaria, where she graduated from the National Gymnasium for Finance and Business Administration in 1996, and completed her bachelor degree in Business Administration (major) and Economics (minor) at the University of Sofia "St. Kliment Ohridski" in 2001. Subsequently, she was granted a scholarship to study International Relations and European Studies in the International Institute of Advanced International and European Studies in Nice, France. Upon completion of her MA degree in 2002, Radulova did a two-month research internship at the EIM research institute for small and medium-sized enterprises in Zoetermeer (the Netherlands), where she examined the key characteristics of European entrepreneurship. In September 2002, Radulova embarked on her second Master study - the MA in European Public Affairs at Maastricht University, the Netherlands. In 2003, she graduated (Cum Laude) and followed a two- month research internship in the European Institute of Public Administration (EIPA), where she examined several soft-law mechanisms in EU governance.

In September 2003, Radulova started working as a junior lecturer in the newly established bachelor programme in European studies of the Faculty of Arts and Culture (at present Faculty of Arts and Social Sciences). In the autumn of 2004, she embarked on her PhD study. The first two years of her dissertation research were funded by the Research and Training Network "Dynamics and Obstacles of European Governance". Within the framework of this network were organized several seminars on research methods and theories of European integration. Radulova also took part in the European Research Colloquium "Democracy in the EU", organized by the Netherlands Institute of Government and the CONNEX (Connecting Excellence on European Governance) network. Since September 2009, Radulova is the director of studies of the research-oriented Master program "Analyzing Europe" of the Faculty of Arts and Social Sciences of Maastricht University. 